University of Rhode Island

DigitalCommons@URI

Open Access Dissertations

2012

\title{
Age-Structured Multispecies Model of the Georges Bank Fish Community
}

Kiersten Lynn Curti

University of Rhode Island, kiersten.curti@gmail.com

Follow this and additional works at: https://digitalcommons.uri.edu/oa_diss

\section{Recommended Citation}

Curti, Kiersten Lynn, "Age-Structured Multispecies Model of the Georges Bank Fish Community" (2012). Open Access Dissertations. Paper 90.

https://digitalcommons.uri.edu/oa_diss/90

This Dissertation is brought to you for free and open access by DigitalCommons@URI. It has been accepted for inclusion in Open Access Dissertations by an authorized administrator of DigitalCommons@URI. For more information, please contact digitalcommons-group@uri.edu. 


\section{AGE-STRUCTURED MULTISPECIES MODEL OF THE GEORGES BANK FISH COMMUNITY}

BY

KIERSTEN LYNN CURTI

A DISSERTATION SUBMITTED IN PARTIAL FULFILLMENT OF THE

REQUIREMENTS FOR THE DEGREE OF

DOCTOR OF PHILOSOPHY

IN

OCEANOGRAPHY

UNIVERSITY OF RHODE ISLAND

2012 


\section{DOCTOR OF PHILOSOPHY DISSERTATION}

OF

KIERSTEN LYNN CURTI

APPROVED:

Dissertation Committee:

Major Professor Jeremy S. Collie

Lawrence J. Buckley

Christopher M. Legault

Joseph T. DeAlteris

Nasser H. Zawia 


\begin{abstract}
Georges Bank has exhibited marked changes in ecosystem structure over the last half century. The community once dominated by groundfish and other finfish is now primarily composed of pelagic and elasmobranch species. Community dynamics are profoundly influenced by species interactions such as predation. The focus of this dissertation is to estimate the trophic interactions among fish species on Georges Bank. These species interactions are estimated by developing a multispecies, statistical catch-atage model of the Georges Bank fish community that explicitly quantifies the mortality due to predation.
\end{abstract}

Manuscript I: A submodel was developed for three important fish species on Georges Bank: Atlantic cod, silver hake, and Atlantic herring. The model was fit to time series of commercial catch, fishery-independent survey catch, and predator diet composition data from 1978-2007. Estimated predation rates were high, compared with fishing mortality, and variable with time. Monte Carlo simulations were used to evaluate the ability of the model to statistically estimate parameters with known error introduced into each of the three input datasets. The model parameters and derived indices could be estimated with confidence from input data with error levels similar to those obtained from the model fit to the observed data. This manuscript helps to elevate multispecies statistical catch-at-age models to the level of statistical rigor expected of fishery dynamics models.

Manuscript II: The submodel developed in the first chapter was expanded by applying the model to nine fish species within the Georges Bank community. While sensitivity to dataset weights and initial parameter estimates was apparent, both the 
magnitude and temporal trends in the predation mortality rates experienced by prey species were statistically estimated. Predation mortality rates again varied both temporally and ontogenetically. Mackerel, herring and silver hake experienced the greatest mortalities due to predation, with maximum predation mortality rates of 0.62 for mackerel, 1.01 for herring and 1.58 for silver hake. For these species, losses due to predation generally exceeded annual landings. Goosefish was the most dominant predator, followed by cod and silver hake, and consumption of modeled fish was related to prey abundance. These results demonstrate the strong impact of predation on Georges Bank fish community dynamics.

Manuscript III: The multispecies statistical catch-at-age model developed in the first two manuscripts was used to develop stochastic forward projections. These projections were used to explore the consequences of different fishing scenarios while accounting for predation. Stochastic projections indicated strong interactions between modeled species, though the interactions were not always direct. Examples of indirect interactions included the effect of goosefish on herring and similarly, the impact of goosefish on white hake. Consequently, population responses to fishing were a function of not only the rates of fishing, but also of these direct and indirect interactions among species.

Collectively, this dissertation demonstrates the strong impact of predation on Georges Bank fish community dynamics and provides a tool for statistically estimating the mortality due to predation. Through the development of a multispecies statistical catch-at-age model, we have expanded the multispecies modeling approaches implemented for Georges Bank and the Northeast U.S. Continental Shelf. 


\section{ACKNOWLEDGMENTS}

I thank my advisor, Jeremy Collie, for his patience, guidance and helpful feedback throughout my time at GSO, as well as providing me with the opportunity to work on this project. I thank Jason Link for his mentorship in the population dynamics fellowship, checking in regularly to ensure I wasn't stuck in the middle of a do-loop, and his regular, much-needed reminders, to see the forest through the trees or at times, through the weeds. I thank Chris Legault for sharing his invaluable knowledge of AD Model Builder and the data that went into this modeling effort. His patience and generosity of time were critical in helping me solve my modeling challenges. I thank Jon Hare, Larry Buckley, and Joe DeAlteris for their participation on my dissertation committee and their thoughtful, constructive feedback on my research. I thank the many scientists who have contributed to the Northeast Fisheries Science Center's (NEFSC) bottom trawl survey and food web dynamics programs. If it wasn't for these data and the dedicated work of many individuals, I wouldn't have a dissertation. I thank Kray VanKirk for endless modeling conversations and maintaining humor during our ADMB endeavors. I thank my supervisors at the NEFSC, Paul Rago and Gary Shepherd, for their support of my research and completion of my dissertation since I have joined the population dynamics team. I thank Tom Miller for introducing me to quantitative fisheries ecology and for his wisdom in telling a young, naïve graduate student, that if she had any inclination for statistics, she should take as many quantitative courses as possible.

To my friends and peers, you have made my experience at GSO what it is. In particular, I thank Georges Dossot for "balancing me out" and being both my rock and partner in crime during the last few years of this endeavor. I thank Janet Nye for her 
scientific insight over the years, her friendship, and for giving me my own room at the Nye-Kirkpatrick abode for my regular adventures to Woods Hole. I thank Rich Bell for always being a great sounding board for ideas, constantly challenging me, and regularly reminding me that the view at the end would be worth the climb. I thank Sarah Corman, Julie Fliegler Kalansky and Alyson Venti for their endless support and friendship. I thank Brita Jessen for being my "wife" in all it entails, for putting up with me, never judging, keeping me in constant supply of wonderful food, and of course introducing me to Ovaltine.

To my family, I cannot thank you enough for your support and encouragement over the years. Your faith in me at times when I questioned myself was what kept me going. 
For my Pap, Joseph Bayuk 


\section{PREFACE}

This dissertation is written in the manuscript format specified by the University of Rhode Island Graduate School.

Manuscript I is written for the Canadian Journal of Fisheries and Aquatic Sciences and recently passed an internal review with NOAA's Northeast Fisheries Science Center. It will be submitted to the journal soon.

Manuscript II is written for the ICES Journal of Marine Science and will be submitted for review upon completion of this dissertation.

Manuscript III is written for Fisheries Research and will also be submitted for review upon completion of this dissertation. 


\section{TABLE OF CONTENTS}

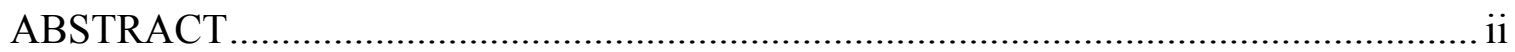

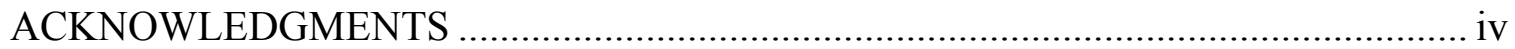

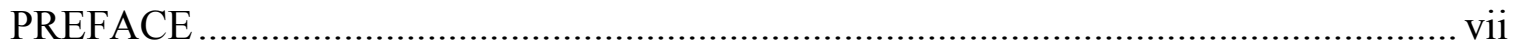

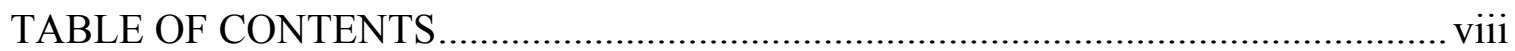

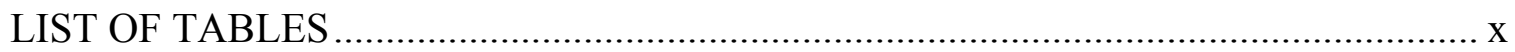

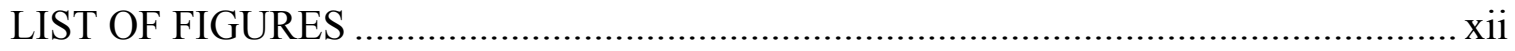

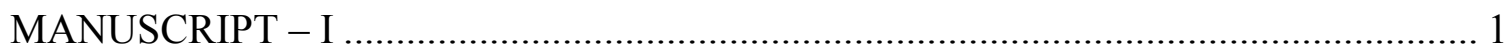

How well do multispecies, statistical catch-at-age models stand up to measurement error? .

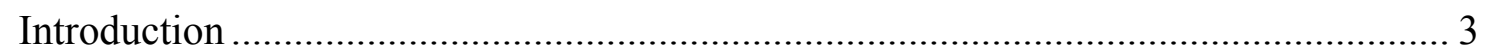

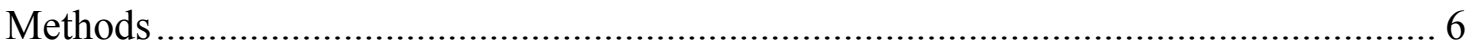

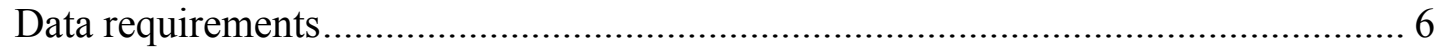

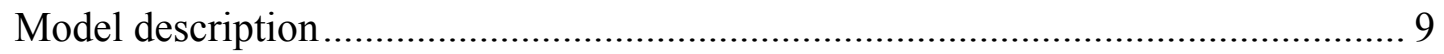

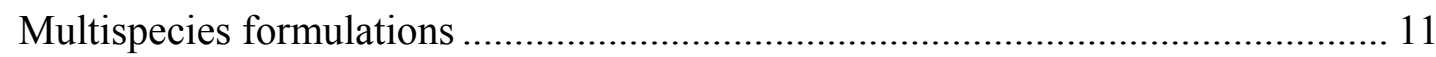

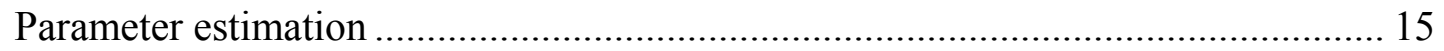

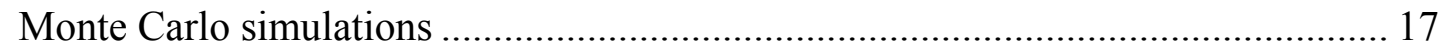

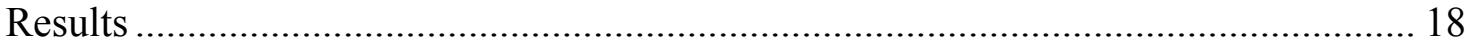

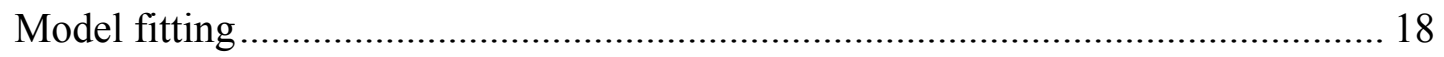

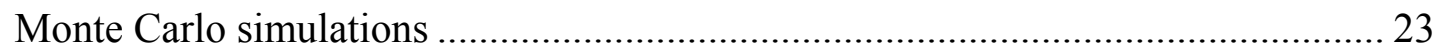

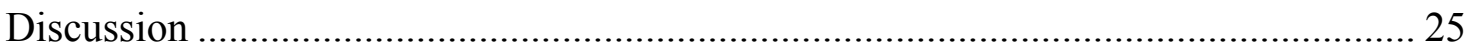




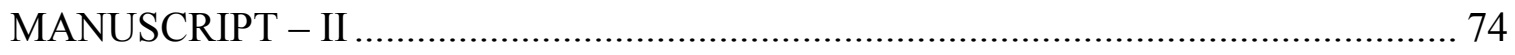

Estimating species interactions among the fish species on Georges Bank ..................... 74

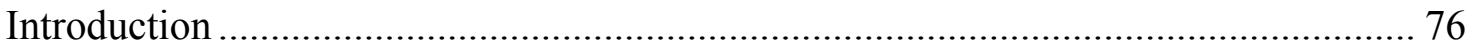

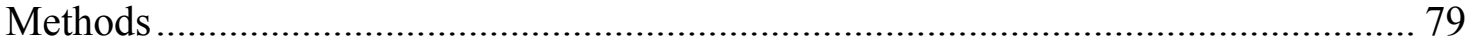

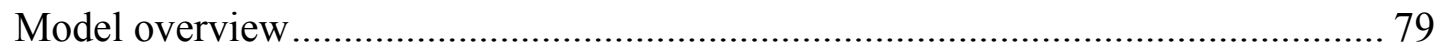

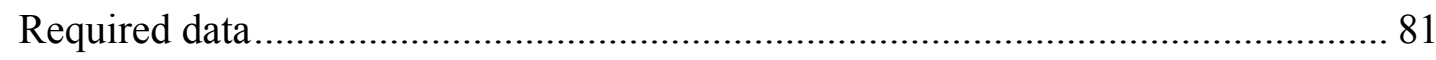

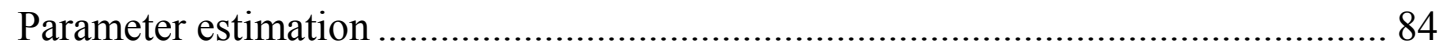

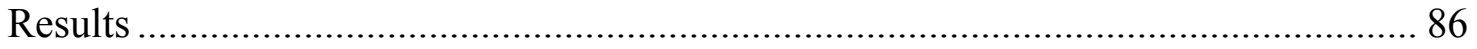

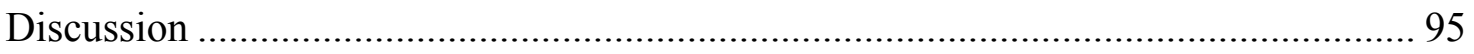

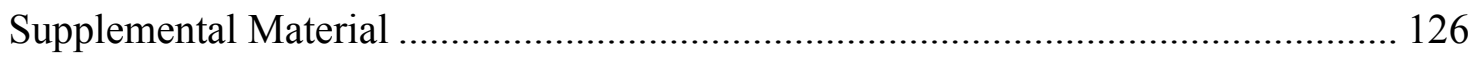

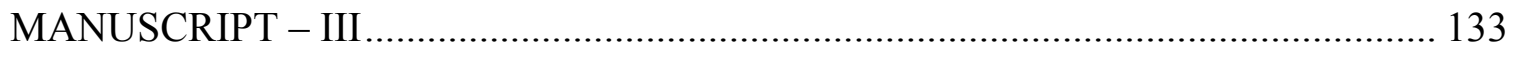

Multispecies management of the Georges Bank fish community .............................. 133

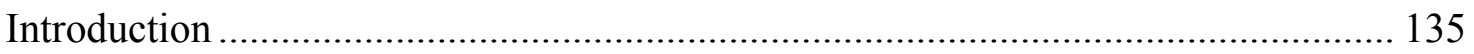

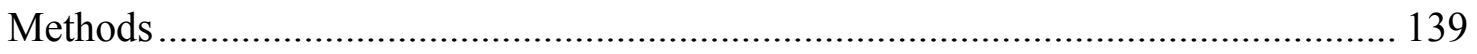

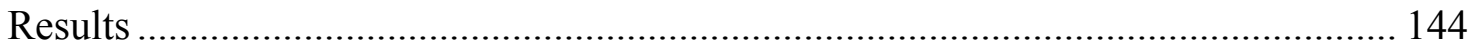

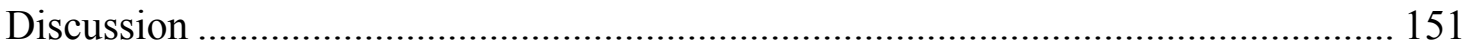

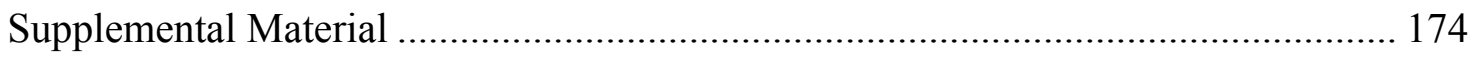

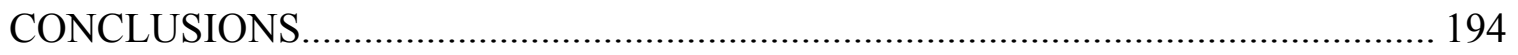




\section{LIST OF TABLES}

\section{Manuscript I}

Table 1: Symbols used in model formulations. 41

Table 2: Single-species equations from Quinn and Deriso (1999). Symbols are defined in

Table 1 . 43

Table 3: Components of the likelihood function where $I$ represents a dataset index, DI the corresponding objective function weighting, $L L I$ the log likelihood for dataset $I$, Peni the total likelihood penalty for each species, and Pwtp the objective function weighting for penalty $p$. All additional symbols are defined Table 1 ....

Table 4: The contributions of each objective function component in both the singlespecies and multispecies models. The abundance penalty constrains the age distribution in the initial year; the recruitment penalty constrains the $\mathrm{CV}$ of estimated recruitment each year (Table 3 )

Table 5: Average predator-prey weight ratios $(\eta)$, the variance in each ratio $(\sigma)$, estimated species preference coefficients $(\ln \rho)$ and their associated standard deviations for each species interaction. Parameters $\eta$ and $\sigma$ were calculated from observed predator and prey lengths. Parameter $\rho$ was estimated as a model parameter in log space. 46

Table 6: The range of scaled mean error (SME) and coefficient of variation (CV) values across years for predicted annual fishing mortality (F), recruitment, and age-1 predation mortality (M2) from the simulation in which measurement error was incorporated into all three datasets. 
Table S1: The weightings for each dataset included in both the single species (ssp) and multispecies (msp) models. Weightings of zero indicate that the dataset was not used in parameter estimation. 55

Table S2: The standard deviation of the residuals for each dataset included in both the single species (ssp) and multispecies (msp) models. NA's represent datasets that were not used in the objective function for a particular species. 56

\section{Manuscript II}

Table 1. Input data sources for each species. 114

Table 2. Biological assumptions made for each modeled species. M1 represents the residual natural mortality rate assumed in the multispecies model. 116

Table 3: Size-preference coefficients estimated for each predator species from the observed distribution of logged (base $e$ ) predator-prey weight ratios.

\section{Manuscript III}

Table 1: Species-specific fishing mortality rates assumed in each projection scenario. 162 


\section{LIST OF FIGURES}

\section{Manuscript I}

Fig. 1: Observed (open circles) and predicted total annual a) commercial catch and b) survey catch from the single-species (dashed line) and multispecies (solid line)

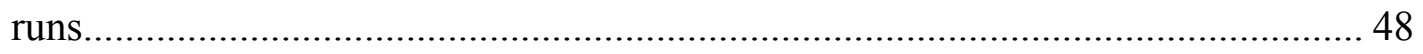

Fig. 2: Comparison of predicted annual a) total abundance, b) recruitment and c) fishing mortality from the single-species run (dashed line), multispecies run (solid line) and the most recent stock assessment (points). For silver hake total abundance and recruitment, absolute estimates were not available; therefore the points represent minimum swept area estimates that do not incorporate catchability.

Fig. 3: For each prey species, the a) age-specific predation mortality, $M 2$, b) proportion of total mortality, $Z$, due to predation, and c) the predator species responsible for the observed predation. 50

Fig. 4: 95th percentiles for estimated annual fishing mortality rate when low measurement error levels were introduced into a) commercial catches, b) survey catches, and c) predator diets. For commercial and survey catches, error levels represent the standard deviations of the multiplicative errors incorporated into total annual catches. For food habits data, error levels represent the number of draws from a multinomial distribution where measurement error increases as effective sample size decreases. In all plots, the solid line represents the true parameter values. 51

Fig. 5: 95th percentiles for estimated annual recruitment when low measurement error levels were introduced into a) commercial catches, b) survey catches, and c) 
predator diets. For commercial and survey catches, error levels represent the standard deviations of the multiplicative errors incorporated into total annual catches. For food habits data, error levels represent the number of draws from a multinomial distribution where measurement error increases as effective sample size decreases. In all plots, the solid line represents the true parameter values....... 52

Fig. 6: 95th percentiles for estimated age-1 predation mortality when all measurement error levels were introduced into a) commercial catches, b) survey catches, and c) predator diets. For commercial and survey catches, error levels represent the standard deviations of the multiplicative errors incorporated into total annual catches. For food habits data, error levels represent the number of draws from a multinomial distribution where measurement error increases as effective sample size decreases. In all plots, the solid line represents the true parameter values....... 53

Fig. 7: 95th percentiles (dashed lines), median (dotted line) and true (solid line) annual recruitment (a), annual fully recruited fishing mortality (b), and age-1 predation mortality rates (c) for the simulation where measurement error was incorporated into all three datasets. 54

Fig. S1: Trends in the $95^{\text {th }}$ percentiles (dashed blue lines) and medians (dotted green lines) of a) total abundance, b) fully recruited fishing mortality, and c) recruitment of each species in the $17^{\text {th }}$ simulation year with increasing number of simulations. In all plots, the solid orange line represents the true parameter value. Similar trends were apparent for other simulation years 57 
Fig. S2: Atlantic cod observed (open circles) and predicted proportions-at-age of the commercial catch from the single-species (blue dashed line) and multispecies

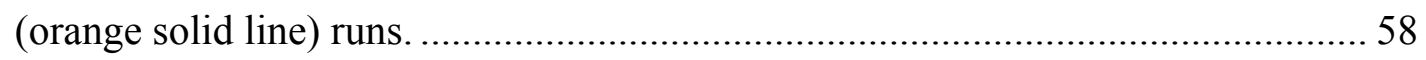

Fig. S3: Silver hake observed (open circles) and predicted proportions-at-age of the commercial catch from the single-species (blue dashed line) and multispecies (orange solid line) runs. 59

Fig. S4: Atlantic herring observed (open circles) and predicted proportions-at-age of the commercial catch from the single-species (blue dashed line) and multispecies (orange solid line) runs. 60

Fig. S5: Atlantic cod observed (open circles) and predicted proportions-at-age of the autumn trawl survey from the single-species (blue dashed line) and multispecies (orange solid line) runs.

Fig. S6: Silver hake observed (open circles) and predicted proportions-at-age of the autumn trawl survey from the single-species (blue dashed line) and multispecies (orange solid line) runs. 62

Fig. S7: Atlantic herring observed (open circles) and predicted proportions-at-age of the spring trawl survey from the single-species (blue dashed line) and multispecies (orange solid line) runs. 63

Fig. S8: Annual calculated effective sample size (open circles) for the proportions-at-age of the commercial catch in the a) single-species and b) multispecies formulations. The solid lines represent the dataset weightings used in the objective function. .... 64 
Fig. S9: Annual calculated effective sample size (open circles) for the proportions-at-age of the survey catch in the a) single-species and b) multispecies formulations. The solid lines represent the dataset weightings used in the objective function. 65

Fig. S10: Annual calculated effective sample size (open circles) for the food habits data (proportion by weight) for each predator species. The solid lines represent the dataset weightings used in the objective function. 66

Fig. S11: Observed age-specific diet of Atlantic cod averaged over 5-year intervals, represented as the proportion by weight of a particular prey item to the total stomach content weight. Year-bins represent 1) 1978-1982, 2) 1983-1987, 3) 1988$1992,4)$ 1993-1997, 5) 1998-2002, and 6) 2003-2007.

Fig. S12: Predicted age-specific diet of Atlantic cod averaged over 5-year intervals, represented as the proportion by weight of a particular prey item to the total stomach content weight. Year-bins represent 1) 1978-1982,2) 1983-1987, 3) 1988$1992,4)$ 1993-1997, 5) 1998-2002, and 6) 2003-2007. 68

Fig. S13: Observed age-specific diet of silver hake averaged over 5-year intervals, represented as the proportion by weight of a particular prey item to the total stomach content weight. Year-bins represent 1) 1978-1982,2) 1983-1987, 3) 1988$1992,4)$ 1993-1997, 5) 1998-2002, and 6) 2003-2007. 69

Fig. S14: Predicted age-specific diet of silver hake averaged over 5-year intervals, represented as the proportion by weight of a particular prey item to the total stomach content weight. Year-bins represent 1) 1978-1982,2) 1983-1987, 3) 1988$1992,4)$ 1993-1997, 5) 1998-2002, and 6) 2003-2007. 70 
Fig. S15: 95th percentiles for estimated annual instantaneous fishing mortality when all measurement error levels were introduced into a) commercial catches, b) survey catches, and c) predator diets. For commercial and survey catches, error levels represent the standard deviations of the multiplicative errors incorporated into total annual catches. For food habits data, error levels represent the number of draws from a multinomial distribution where measurement error increases as effective

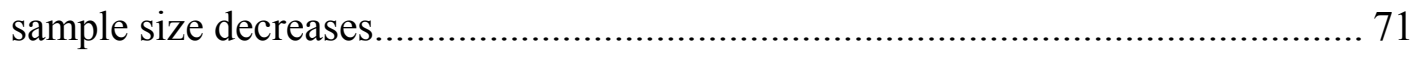

Fig. S16: 95th percentiles for estimated annual recruitment when all measurement error levels were introduced into a) commercial catches, b) survey catches, and c) predator diets. For commercial and survey catches, error levels represent the standard deviations of the multiplicative errors incorporated into total annual catches. For food habits data, error levels represent the number of draws from a multinomial distribution where measurement error increases as effective sample size decreases. 72

Fig. S17: 95th percentiles for estimated species preference coefficients ( $\rho$ ) for a) cod-cod, b) cod-silver hake, c) cod-herring, d) silver hake-silver hake, and e) silver hakeherring when all measurement error levels were introduced into commercial catches, survey catches, and predator diets. For commercial and survey catches, error levels represent the standard deviations of the multiplicative errors incorporated into total annual catches. For food habits data, error levels represent the number of draws from a multinomial distribution where measurement error increases as effective sample size decreases.............................................. 73 


\section{Manuscript II}

Figure 1. Predation interactions between the nine modeled Georges Bank fish species. The arrows point from prey to predator species. 118

Figure 2: Observed (open circles) and predicted (lines) distribution of the logged ratio of predator-to-prey weight for each predator species.

Figure 3: Age-specific predation mortality rates for each prey species. Each line represents an age class.

Figure 4: Total annual catch (solid line) and biomass consumed (dashed line) of each

prey species.

Figure 5: Total annual species-specific biomass (solid line) and consumption (dotted line) of all prey species, including other food. Consumption by herring or mackerel was not calculated. 122

Figure 6: Total annual consumption (thousands of metric tons) of modeled prey species by each predator species.

Figure 7: Annual predator-specific consumption (thousands of metric tons) of each prey species.

Figure 8: Prey species-preference coefficients for each species interaction. 125

Figure S1: Total annual fisheries catch (thousands of metric tons) for each modeled species. In the multispecies formulation, spiny dogfish and winter skate catches do not exhibit any deviations because their dynamics were assumed to be known inputs. 126

Figure S2: Total fishery-independent survey catch from the spring (a) and fall (b) NEFSC bottom trawl surveys. For the spring survey, silver hake and cod survey catches 
were not included in the objective function; herring and mackerel catches were not included for the fall survey. 127

Figure S3: Observed average predator diet composition by age, represented as the proportion by weight of a particular prey item to the total stomach-content weight.

Figure S4: Predicted average predator diet composition by age, represented as the proportion by weight of a particular prey item to the total stomach-content weight

Figure S5: Predicted average predator diet composition of modeled fish species in each year, represented as the proportion by weight of a particular prey item to the total weight of modeled fish prey consumed.

Figure S6: Silver hake observed (circles) and predicted (line) proportions-at-age of the spring trawl survey.

Figure S7: Goosefish observed (circles) and predicted (line) proportions-at-age of the spring trawl survey.

\section{Manuscript III}

Figure 1: Predation interactions between the nine modeled Georges Bank fish species. Each species is grouped into one of three functional groups: 1) top predators, 2) intermediate predators, 3) principle prey species. The arrows point from prey to predator species 163

Figure 2: Predicted spawning stock biomass and recruitment estimates from the 9-species model (circles) and the fitted hockey-stick stock-recruitment models used in the 
forward projections (lines). The horizontal line represents the median recruitment.

Figure 3: $95^{\text {th }}$ percentiles (dashed lines) and median (solid line) total annual spawning stock biomass $\left(10^{3} \mathrm{mt}\right)$ in the unfished base projection. 165

Figure 4: Average annual predator-specific consumption (thousands of metric tons) of each prey species in the unfished base projection. 166

Figure 5: Comparison of the average median and $95^{\text {th }}$ percentiles (vertical dashed lines) of total spawning stock biomass in the unfished base projection $(U n F)$, status quo (SQ) and base fishing projection (BaseF). For each species, the horizontal dotted line represents $\mathrm{SSB}_{\mathrm{MSY}}$, the dashed line represents $\mathrm{SSB}_{25}$ and the dot-dash line represents $\mathrm{SSB}_{10}$ 167

Figure 6: Comparison of the average median and $95^{\text {th }}$ percentiles (vertical dashed lines) of total commercial catch in the unfished base projection (UnF), status quo (SQ) and base fishing projection (BaseF). For each species, the horizontal dotted line represents MSY 168

Figure 7: Comparison of the average median and $95^{\text {th }}$ percentiles (vertical dashed lines) of total spawning stock biomass as fishing mortality on the top predators is increased two (T2) and three (T3) times the fishing mortality rates in the base fishing projection (BF) while the remaining species were fished at the base fishing rates. Fishing mortality on the top predators was then maintained at three-times the BF, while fishing mortality on the intermediate predators was increased two (IT2) and three (IT3) times the base fishing mortality rates. Projection scenarios are further detailed in Table 1. The benchmarks are as detailed in Figure 5. 169 
Figure 8: Comparison of the average median and $95^{\text {th }}$ percentiles (vertical dashed lines) of total commercial catch as fishing mortality was varied among top and intermediate predator species. For each species, the horizontal dotted line represents MSY. Projection scenarios are as described in Figure 7 and Table 1. 170

Figure 9: Average annual predator-specific consumption (thousands of metric tons) of each prey species in when both top and intermediate predators were fished at threetimes their base rates of fishing. 171

Figure 10: Comparison of the average median and $95^{\text {th }}$ percentiles (vertical dashed lines) of total spawning stock biomass as the fishing mortality on the prey species was increased from the base rate $(\mathrm{P} 1)$ to ten $(\mathrm{P} 10)$, fifteen $(\mathrm{P} 15)$ and thirty $(\mathrm{P} 30)$ times the base rate of fishing, while the top predators were heavily fished but intermediate predators were not fished. In the last projection (G3P), prey species were still fished at 30-times their base fishing rates, but goosefish was heavily fished as well. Projection scenarios are further detailed in Table 1. The benchmarks are as detailed in Figure 5 172

Figure 11: Comparison of the average median and $95^{\text {th }}$ percentiles (vertical dashed lines) of total spawning stock biomass as fishing was sequentially increased on goosefish (G3), cod (C2-C4), silver hake (S3) and finally the principal prey species (P5). Projection scenarios are detailed in Table 1. The benchmarks are as detailed in Figure 5 . 173

Figure S1: Estimated posterior distributions of predicted spiny dogfish abundance-at-age (millions of fish) in the last year of the 9-species model. 174 
Figure S1, contd.: Estimated posterior distributions of predicted spiny dogfish abundance-at-age (millions of fish) in the last year of the 9-species model.......... 175

Figure S1, contd.: Estimated posterior distributions of predicted spiny dogfish abundance-at-age (millions of fish) in the last year of the 9-species model.......... 176

Figure S2: Estimated posterior distributions of predicted winter skate abundance-at-age (millions of fish) in the last year of the 9-species model. 177

Figure S2 contd.: Estimated posterior distributions of predicted winter skate abundanceat-age (millions of fish) in the last year of the 9-species model. 178

Figure S3: Estimated posterior distributions of predicted goosefish abundance-at-age (millions of fish) in the last year of the 9-species model. 179

Figure S4: Estimated posterior distributions of predicted cod abundance-at-age (millions of fish) in the last year of the 9-species model. 180

Figure S5: Estimated posterior distributions of predicted mackerel abundance-at-age (millions of fish) in the last year of the 9-species model. 181

Figure S6: Estimated posterior distributions of predicted pollock abundance-at-age (millions of fish) in the last year of the 9-species model. 182

Figure S7: Estimated posterior distributions of predicted white hake abundance-at-age (millions of fish) in the last year of the 9-species model. 183

Figure S8: Estimated posterior distributions of predicted silver hake abundance-at-age (millions of fish) in the last year of the 9-species model. 184

Figure S9: Estimated posterior distributions of predicted herring abundance-at-age (millions of fish) in the last year of the 9-species model. 185 
Figure S10: Estimated posterior distributions of predicted species-preference coefficients (log preference) from the 9-species model. Species abbreviations are as follows: spiny dogfish (SDog), winter skate (WSk), goosefish (Goose), mackerel (Mack), pollock (Pol), white hake (WH), silver hake (SH) and herring (Her). 186

Figure S10, contd.: Estimated posterior distributions of predicted species-preference coefficients (log preference) from the 9-species model. Species abbreviations are as follows: spiny dogfish (SDog), winter skate (WSk), goosefish (Goose), mackerel (Mack), pollock (Pol), white hake (WH), silver hake (SH) and herring (Her)...... 187

Figure S10, contd.: Estimated posterior distributions of predicted species-preference coefficients (log preference) from the 9-species model. Species abbreviations are as follows: spiny dogfish (SDog), winter skate (WSk), goosefish (Goose), mackerel (Mack), pollock (Pol), white hake (WH), silver hake (SH) and herring (Her)...... 188

Figure S11: $95^{\text {th }}$ percentiles (dashed lines) and median (solid line) total annual spawning stock biomass $\left(10^{3} \mathrm{mt}\right)$ in the base fishing projection. 189

Figure S12: Average annual predator-specific consumption (thousands of metric tons) of each prey species in the status quo fishing projection. 190

Figure S13: Average annual predator-specific consumption (thousands of metric tons) of each prey species in the base fishing projection. 191

Figure S14: Average annual predator-specific consumption (thousands of metric tons) of each prey species when the top predators are fished at three-times their base fishing rates, with the remaining species fished at their base rates. 192

Figure S15: Average annual predator-specific consumption (thousands of metric tons) of each prey species when the top predators and goosefish are fished at three-times 
their base fishing rates, remaining intermediate predator species were unfished, and prey species were fished at 30-times their base fishing rates. 


\section{MANUSCRIPT - I}

Intended for submission to the Canadian Journal of Fisheries and Aquatic Sciences

\section{How well do multispecies, statistical catch-at-age models stand up to measurement error?}

Kiersten L. Curti and Jeremy S. Collie

Graduate School of Oceanography; University of Rhode Island; 215 South Ferry

Road; Narragansett, RI 02882 USA

Christopher M. Legault and Jason S. Link

National Marine Fisheries Service, Northeast Fisheries Science Center; 166 Water

Street; Woods Hole, MA 02543 USA 


\begin{abstract}
Accounting for the trophic interactions among harvested species is an important component of the ecosystem approach to fisheries management. This need creates a challenge of incorporating species interactions in statistical, catch-at-age models in a way that accounts for the uncertainty in input data, parameters, and results. We developed a statistical, age-structured, multispecies model for three important species in the Georges Bank fish community: Atlantic cod, silver hake, and Atlantic herring. The model was fit to commercial catch, survey, and diet data from 1978-2007. The estimated predation rates were high, compared with fishing mortality, and variable with time. The dynamics of the three species can be explained by the interplay between fishing and predation mortality. Monte Carlo simulations were used to evaluate the ability of the model to estimate parameters with known error introduced into each of the data types. The model parameters and derived indices could be estimated with confidence from input data with error levels similar to those obtained from the model fit to the observed data. These results and evaluations of model performance should help to move multispecies, statistical, catch-at-age models from proof of concept to functional tools for ecosystem based fisheries management.
\end{abstract}

\title{
KEYWORDS
}

multispecies statistical catch-at-age model, Monte Carlo, measurement error, predation mortality, Georges Bank 


\section{INTRODUCTION}

Accounting for trophic interactions among species is an important component of an ecosystem approach to fisheries (Link 2010). Approaches for incorporating species interactions have expanded substantially over the last few decades and range from expanded versions of single-species models to full ecosystem models that incorporate all trophic levels (Plagányi 2007). This spectrum of available models varies in data requirements and model assumptions, exhibiting trade-offs between the ability to incorporate particular species-specific population dynamic processes and the ability to depict the full system (Link 2002). The full array of modeling approaches available to support an ecosystem approach to fisheries has been catalogued elsewhere (Hollowed et al. 2000, Plagányi 2007, Townsend et al. 2008). Here we address those models generally classified as dynamic multispecies models, which are most similar to the age-structured model developed in this study.

Virtual population analysis (VPA), a retrospective method that uses catch-at-age data to estimate population numbers and fishing mortality rates, was extended to multispecies virtual population analysis (MSVPA) through incorporation of Andersen and Ursin's (1977) seminal work on predator food-selection (Helgason and Gislason 1979, Pope 1979, Sparre 1980). MSVPA explicitly models predation mortality among interacting species and therefore more fully describes the age dependence and interannual variability in natural mortality (Sparre 1991, Magnússon 1995). Since its creation, MSVPA and expanded MSVPA-X have been used to estimate the interactions among commercially important fish stocks in several ecosystems, including the North Sea (Gislason and Helgason 1985), Baltic Sea (Sparholt 1994, Gislason 1999), Bering Sea 
(Livingston and Jurado-Molina 2000), Georges Bank (Tsou and Collie 2001a), northwest Atlantic (Tyrrell et al. 2008) and the western mid-Atlantic (Garrison et al. 2010). MSVPA is a deterministic model that assumes input time series are measured without error (Lewy and Vinther 2004); accordingly, it does not incorporate stochastic variability or uncertainty in the parameter estimates.

In contrast to VPA, statistical catch-at-age models account for error in observed catches and other input data through the statistical estimation of model parameters and quantification of uncertainty (Fournier and Archibald 1982, Deriso et al. 1985, Quinn and Deriso 1999). Statistical catch-at-age models are one of the preferred methods for singlespecies stock assessments because the model uncertainty can inform management decisions. These models have been combined with the predation equations from MSVPA to produce multispecies, statistical catch-at-age models (Jurado-Molina et al. 2005, Van Kirk et al. 2010).

Several multispecies statistical catch-at-age models have been developed with varying assumptions and applied to several different ecosystems. Some formulations include the estimation of food-selection parameters (Lewy and Vinther 2004, Kinzey and Punt 2009, Van Kirk et al. 2010). Lewy and Vinther's (2004) Stochastic Multi-Species Model for the North Sea is semi age-length structured; species abundance, fishing mortality rates and catch data are age-structured, but both the stomach-content data and the food-selection model are structured by length because predator preference depends on size. Furthermore, the statistical multispecies age-structured model of the Aleutian Shelf (Kinzey and Punt 2009) considered uncertainty regarding the predator functional response. Other variants such as Gadget are also spatially explicit and incorporate 
additional biological processes such as migration and reproduction (Begley and Howell 2004). To the best of our knowledge, none of these modeling efforts have evaluated model performance with simulated data containing known levels of error.

Here we use Monte Carlo analysis to evaluate the uncertainty in parameter estimation to varying levels of measurement error. Evaluating model performance with simulated data incorporating measurement error will help to elevate these models to the level of statistical rigor expected of fishery population dynamic models.

In the northeast US, a variety of approaches has been applied to incorporate ecological considerations into fisheries models (Townsend et al. 2008). Over the last half century, Georges Bank has exhibited substantial changes in community dynamics. The community once dominated by groundfish and other finfish is now primarily composed of pelagic and elasmobranch species (Fogarty and Murawski 1998, Link and Garrison 2002). Furthermore, several studies have indicated a shift in the dominant piscivores from cod and silver hake to spiny dogfish and winter skate (Tsou and Collie 2001a, Link and Garrison 2002). Predation mortality on the youngest ages is high, variable (Overholtz et al. 2008, Moustahfid et al. 2009), and may affect the year-class strength of commercially important species (Tsou and Collie 2001b, Tyrrell et al. 2008, Tyrrell et al. 2011). The overall objective of this study is to develop a multispecies statistical catch-atage model of the Georges Bank fish community that explicitly quantifies the mortality due to predation, and once fully developed, can be used as a tool for incorporating ecological considerations into fisheries management.

To test the performance of the multispecies statistical catch-at-age model, we first constructed a sub-model of the Georges Bank fish community, including Atlantic cod 
(Gadus morhua), silver hake (Merluccius bilinearis) and Atlantic herring (Clupea harengus). These three species were chosen because previous work has demonstrated their importance as predators or prey in the ecosystem (Tsou and Collie 2001a, Tyrrell et al. 2008), they are known to exhibit strong interactions via predation (Tsou and Collie 2001b, Overholtz and Link 2007), and the required input data are readily available. Accordingly, the specific goals of this manuscript are to 1) fit single-species versions of the model to each species to obtain baseline results for the multispecies model, 2) enable species interactions through predation and compare these results to the single-species runs, and 3) measure uncertainty in parameter estimation with Monte Carlo analysis. This three-species model contains important species interactions but is still small enough to permit extensive Monte Carlo simulation.

\section{METHODS}

The catch-at-age model comprises Atlantic cod, silver hake, and Atlantic herring. In this submodel, cod is a top predator of both silver hake and herring, silver hake is an intermediate predator only of herring, and herring is a forage species. Cod and silver hake can also exhibit cannibalism.

\section{Data requirements}

Six input data series are required for each species: total commercial catch in weight, total survey catch in number/tow, age proportions for both commercial and survey catches, average individual weight-at-age, and for the multispecies runs, age-specific predator diet. 
Total annual commercial catch was obtained from the most recent published stock assessments (cod: NEFSC 2008, herring: Shepherd et al. 2009) or directly from Northeast Fisheries Science Center (NEFSC) databases (silver hake). For cod and herring, total commercial catches represented landings plus discards; discard estimates were not available for silver hake. Both silver hake and herring stocks are assessed over a wider geographic area than just Georges Bank. Following Collie and Delong (1999), the NEFSC trawl survey was used to calculate the proportion of the species' biomass found on Georges Bank each year from 1978-2007. For both species, these proportions did not exhibit a systematic temporal trend. Accordingly, average proportions (silver hake $=$ 0.165 , herring $=0.119)$ were used to determine the commercial catches attributable to Georges Bank in each year.

Time series of annual catch-at-age (millions of fish) were used to calculate age proportions from the commercial catch. For cod, this time series was obtained from the most recent assessment. However, for silver hake and herring older assessments were used (silver hake: Brodziak et al. 2001, herring: Overholtz et al. 2004) due to limitations in data availability. Herring age-proportions in years since the last assessment (20032007) were treated as missing data; however, the use of average age proportions was necessary for silver hake (1999-2007) to avoid parameter confounding.

Age-structured seasonal (spring and fall) trawl-survey catches (number-per-tow) were obtained from the most recent assessments for cod and herring. Since herring survey catches represented the Georges Bank-Gulf of Maine stock complex, we assumed that these relative abundances were representitive of just Georges Bank as well. For silver hake, average seasonal estimates of catch-per-tow for Georges Bank strata were 
calculated directly from the NEFSC trawl-survey database. Age-structured survey catches were not available in all years. Consequently, trawl-survey catches were split into two time series: total seasonal survey catch (summed over age classes), and the age proportions of the survey catch.

Average individual weight-at-age is needed in both the single- and multi-species versions of the model to convert from numbers to biomass units. Weight-at-age time series were taken from the recent age-structured assessments (cod: NEFSC 2008, herring: Shepherd et al. 2009, silver hake: Brodziak et al. 2001). The silver hake weight-at-age time series extended only through 1999, therefore, average weight-at-age from 19951999 was used for 2000-2007.

For multispecies runs, additional data requirements include consumption:biomass (C/B) estimates, the biomass of "other food" in the ecosystem, and average predator diet. Age-specific C/B ratios were obtained from Grosslein et al. (1980). Following Sparre (1980) as well as the MSVPA application to Geoges Bank (Tsou and Collie 2001a), we assumed a constant, time-invariant total ecosystem biomass, permitting the biomass of available other food to vary annually. Prior studies have confirmed that the total biomass on Georges Bank has remained relatively stationary (Link et al. 2008, Auster and Link 2009). During the development of the Georges Bank MSVPA, the total ecosystem biomass of fish and their prey on Georges Bank was estimated to be 15 million metric tons (Tsou and Collie 2001a). More recent work estimated the total Georges Bank ecosystem biomass as 7.34 million metric tons (Rochet et al. 2011). While Tsou and Collie's (2001a) estimate was used in this study, the impact of assuming Rochet's (2011) estimate on estimated predation rates was explored in a sensitivity run. 
Georges Bank stomach-content data were obtained from the NEFSC Food Web Dynamics Program, which has systematically sampled predator food habits since 1973 (Link and Almeida 2000). These food-habits data are structured by predator species and length, but primarily only by prey species because prey lengths and ages are not routinely measured. A subset of the database is structured by both predator and prey lengths; it contains over 1900 predator and prey length measurements for the species interactions modeled here and collected though the time series. Average length-at-age estimates (Penttila et al. 1989) were used to convert predator and prey lengths to ages. Age-specific predator diet, represented as proportion by weight, was averaged over 5-year periods to reduce the inherent variability in the dataset as well as the amount of missing data (Van Kirk et al. 2010), while still capturing the temporal trends.

\section{Model description}

Equations for the progression of year class abundance, commercial catch-at-age and fishing mortality-at-age (assuming separable fishing mortality) follow those equations traditionally used in age-structured, single-species stock assessments (Quinn and Deriso 1999). All symbols are defined in Table 1 and single-species equations are listed in Table 2.

In single-species runs, total mortality in year $t$ comprised an age- and time-invariant instantaneous natural mortality $(M)$ rate and an age- and year-specific instantaneous fishing mortality rate:

$$
Z_{i, a, t}=F_{i, a, t}+M_{i} .
$$


Total natural mortality $(M)$ was set to 0.2 for all three species based on values used in recent stock assessments or species' life histories (Hoenig 1983, NEFSC 2008, Shepherd et al. 2009).

Fishery independent survey catch $\left(F I C_{i, a, t}\right)$ was related to age-specific abundances, assuming age-invariant catchability $q_{i}$, and age-specific selectivity $r_{i, a}$ coefficients, as

$$
F I C_{i, a, t}=q_{i} r_{i, a} N_{i, a, t} e^{-\frac{m}{12} Z_{i, a, t}}
$$

where $m$ represents the month in which the trawl survey was conducted. Relative abundance estimates from both the spring and fall surveys were initially used for each species; the season providing the most consistent abundance estimates and the best diagnostics, was included in the final model. Fall time series were used for cod and silver hake; the spring time series was used for herring. Species-specific catchabilities $\left(q_{i}\right)$ were calculated from deviations between predicted absolute abundance, $N_{i, a, t}$ and predicted relative abundance, $F I C_{i, a, t}$, as in Walters and Ludwig (1994). Age-specific fishery and survey selectivity coefficients were estimated for each species from age-1 to the assumed age of full recruitment. The ages of full recruitment to the fishery and survey were both selected iteratively. Ages corresponding to selectivities whose estimates were approximately 1.0 in initial runs were assumed to be fully recruited in subsequent iterations. Furthermore, dome-shaped selectivity ogives were not permitted; once full selectivity was reached, all selectivity parameters for older age classes were fixed at one. For the fishery, the age of full recruitment in the final run was set to age- 4 for cod, and age-3 for both silver hake and herring. Likewise, the age of full recruitment to the survey was set to age-3 for cod, and age-2 for silver hake and herring. 


\section{Multispecies formulations}

The formulation of the multispecies model generally follows that of MSVPA and the multispecies age-structured assessment of Van Kirk et al. (2010). In multispecies runs, natural mortality was partitioned into two components: the mortality due to predation (M2) and the residual natural mortality (M1) (Helgason and Gislason 1979), such that

$$
M_{i, a, t}=M 1_{i}+M 2_{i, a, t}
$$

In these runs, the species-specific residual natural mortality was chosen such that the total natural mortality rate $\left(M_{i, a, t}\right)$ for the oldest age classes was as similar as possible to the 0.2 value assumed in the single-species runs. Accordingly, residual natural mortality was set to 0.2 for cod and 0.1 for silver hake and herring.

Calculation of predation mortality follows that of MSVPA and is calculated from suitability coefficients, incorporating the preference for a particular prey species by a predator (Sparre 1991). Predator $j, b$ size-preference for prey $i, a$ is modeled as a lognormal function of the ratio of predator-to-prey weight (Andersen and Ursin 1977, Helgason and Gislason 1979)

$$
g_{i, a, j, b, t}=\exp -\left[\frac{1}{2 \sigma_{i, j}^{2}}\left(\ln \frac{W_{j, b, t}}{W_{i, a, t}}-\eta_{i, j}\right)^{2}\right]
$$

where $\eta_{i, j}$ represents the preferred lognormal predator-to-prey weight ratio and $\sigma_{i, j}^{2}$ reflects the variance in this ratio (i.e. how selective the predator species is with regards to the size of its prey). A distinct set of size-preference coefficients $(\eta, \sigma)$ is estimated for each species interaction. Preliminary analyses with simulated data indicated that predator 
size-preference coefficients were not estimable within the model framework because the full dataset was not structured by prey length. Consequently, the subset of data for which both predator and prey lengths were available was used to empirically calculate observed predator size-preference coefficients.

The calculated average predator-to-prey weight ratio was used to approximate the preferred ratio, $\eta$, and the observed variance in that ratio was assumed to be equivalent to $\sigma$. To calculate these coefficients, season-specific length-weight relationships (Wigley et al. 2003) were used to convert observed predator and prey lengths to weights. These empirical size-preference parameters were then inputted into the model framework as known constants. In preliminary runs, we also explored whether these size-preference parameters could be estimated using priors. However, this analysis again indicated a high sensitvity to parameter confounding and only minimal movement from starting parameter estimates when confounding was not apparent; therefore, the base run with empirical size-preference parameters treated as known constants was used.

From age-specific, size-preference coefficients, the suitability of each prey $i, a$ to predator $j, b$ is calculated as

$$
v_{i, a, j, b, t}=\rho_{i, j} \cdot g_{i, a, j, b, t}
$$

where $\rho_{i, j}$ represents the general vulnerability of prey species $i$ to predation by predator species $j$, or the species preference of a predator. Vulnerability, $\rho$, incorporates all differences in food selection, for example behavioral and vertical distribution differences, that are not attributable to size differences (Gislason and Helgason 1985). Species preference is relative to a reference prey species, in this case "other food", whose $\rho_{\text {other }}$ 
is set to one. The suitability of "other food" is also equal to one because it is assumed to be of the preferred size.

Suitability and underlying size-preference coefficients are permitted to vary annually as a function of annual variation in the input time series of individual weight-atage. Suitability coefficients are scaled across all prey species and ages to facilitate comparisons between estimated available (suitable) prey biomass and food-habits data such that the suitabilities for a predator age class sum to one (Sparre 1980)

$$
\tilde{v}_{i, a, j, b, t}=\frac{v_{i, a, j, b, t}}{\sum_{i} \sum_{a} v_{i, a, j, b, t}+v_{o t h e r}} .
$$

These scaled suitability coefficients are then used to calculate the biomass of prey $i, a$ available to each predator $j, b$ :

$$
\phi_{i, a, j, b, t}=\tilde{v}_{i, a, j, b, t} \cdot B_{i, a, t}
$$

and the available biomass of other food

$$
\phi_{\text {other }}=\tilde{v}_{\text {other }} \cdot B_{\text {other, },}
$$

where $B_{\text {other }, t}$ represents the total biomass of other food in the system. Following Sparre (1980), the total biomass of other food is calcuated as

$$
B_{\text {other }, t}=E c o B-\sum_{i} \sum_{a} B_{i, a, t}
$$

where $E \operatorname{coB} B$ represents the total biomass of the ecosystem and $\sum_{i} \sum_{a} B_{i, a, t}$ the total biomass of those species included in the model, permitting the biomass of other food to 
vary annually. The total available prey biomass then represents the sum of the available biomass of the modeled species and the available other-food biomass:

$$
\phi_{j, b, t}=\phi_{o t h e r}+\sum_{i} \sum_{a} \phi_{i, a, j, b, t}
$$

The ratio of the available biomass of prey $i, a$ to the total available prey biomass is equivalent to the proportion, by weight, of prey $i, a$ in the stomach of the predator, or

$$
\frac{S_{i, a, j, b, t}}{S_{j, b, t}}=\frac{\phi_{i, a, j, b, t}}{\phi_{j, b, t}}
$$

where $S_{i, a, j, b, t}$ is the weight of prey species $i, a$ in the stomach of predator $j, b$ and $S_{j, b, t}$ is the total stomach content weight of predator $j, b$. The scaling of the suitability coefficients creates a one-to-one direct correspondence between the stomach-contents of the predator and the relative suitable prey biomass. The predicted annual diet proportions were then averaged over 5-year bins.

Finally, following Lewy and Vinther (2004), the mortality due to predation is approximated as

$$
M 2_{i, a, t} \approx \frac{1}{N_{i, a, t} W_{i, a, t}} \sum_{j} \sum_{b} C B_{j, b} B_{j, b, t} \frac{\phi_{i, a, j, b, t}}{\phi_{j, b, t}}
$$

where $C B_{j, b}$ represents the age-specific consumption-to-biomass ratio for each predator species. Due to the time-invariance of these consumption estimates, it is assumed that predators are not food-limited (Magnússon 1995). These definitions of predation mortality and predator stomach contents correspond to a Type-II functional response (Sparre 1980). To obtain an instantaneous rate of predation mortality, estimates of 
average annual predator biomass and prey abundance should ideally be used instead of beginning year abundance, making the equation for predation mortality recursive (Lewy and Vinther 2004). As in Van Kirk et al. (2010), an approximation of predation mortality was used to avoid the extensive iterations that would be required for parameter estimation.

\section{Parameter estimation}

The set of estimated model parameters includes age-specific abundances in the first year $N_{i, a, 1}$, annual recruitment in subsequent years $N_{i, 1, t}$, annual fully recruited fishing mortality rates $F_{i, t}$, age-specific fishery $s_{i, a}$ and survey $r_{i, a}$ selectivity coefficients, and the vulnerability parameters, $\rho_{i, j}$ :

$$
\theta=\left\{N_{i, a, 1}, N_{i, 1, t}, F_{i, t}, s_{i, a}, r_{i, a}, \rho_{i, j}\right\} .
$$

Due to estimation of age- and species-specific abundances in the first year as initial parameters, the model does not depend on an assumption of equilibrium. For all subsequent years beyond the first year of the time series, annual recruitment is estimated as a mean parameter plus a vector of annual deviation parameters that must sum to zero.

Model parameters were estimated with maximum likelihood techniques, programmed in AD Model Builder (ADMB Project 2009). A Bayesian approach with priors was implemented though penalized likelihoods. The statistical estimation of model parameters allows the assumption that commercial catch, survey catch and food habits data are subject to observation error.

The total likelihood comprised five components and the penalty functions (Table 3). Total commercial catch and total survey catch were assumed to be lognormally 
distributed. Commercial catch age proportions, survey age proportions and predator food habits (average proportions by weight) were assumed to follow multinomial distributions.

The objective function weights for each dataset were determined with an iterative approach. In particular, weightings for the lognormal components were chosen to achieve approximately a $10 \%$ coefficient of variation (CV) for total commercial catch, and a $30-40 \% \mathrm{CV}$ for total survey catch. A higher CV was assumed for the trawl-survey component due to the large interannual variability apparent in the observed time series. It is presumed that this interannaul variability partly results from variation in availability to survey gear and not necessarily only true changes in abundance (Overholtz et al. 1999). Weightings for the multinomial components were chosen to best approximate the average effective sample size. Following McAllister and Ianelli (1997), the effective sample size for species $i$ in year $t$ was calculated as

$$
\operatorname{EfN}_{i, t}=\frac{\sum_{a} \hat{P}_{i, a, t}\left(1-\hat{P}_{i, a, t}\right)}{\sum_{a}\left(P_{i, a, t}-\hat{P}_{i, a, t}\right)^{2}}
$$

where $P_{i, a, t}$ is the observed proportion-at-age for species $i$ in year $t$, and $\widehat{P}_{i, a, t}$ is the predicted proportion-at-age. Annual effective sample sizes were then averaged over time. Sensitivity runs were conducted to determine the influence of the food-habits weighting on resulting predation rates.

Penalty functions were imposed on initial abundances, annual recruitment and agespecific biomasses (Table 3). The penalty imposed on initial abundances, Ypen, prevents age-specific abundances from deviating substantially from those predicted by exponential decay, Yr1, assuming a total mortality equal to the age-specific average. The penalty imposed on annual recruitment, Rpen, prevents the coefficient of variation for the log 
recruitment of any species from becoming greater than a pre-defined threshold value. The threshold values for cod, silver hake and herring were set at $1,0.7$ and 0.4 , respectively. Bpen, the penalty imposed on age-specific biomasses, prevents any age-specific biomass from falling below a pre-defined threshold of ten kilograms. The weights for each of these penalties, $P w t_{Y}, P w t_{R}$ and $P w t_{B}$, and their corresponding threshold values were selected iteratively.

\section{Monte Carlo simulations}

Parameter estimates from the three-species model best fit were used to create a known simulation dataset without error. Measurement errors of varying magnitudes were then added sequentially to each of the three datasets (commercial catches, survey catches and predator diet) to evaluate the sensitivity of predicted indices, including recruitment, predation mortality and fishing mortality, to increasing observation error. In all simulations, initial parameter values were set to the final parameter estimates from the single-species runs.

Random multiplicative errors were added to both total annual survey and commercial catches following Collie and Kruse (1998), with standard deviations of 0.2, $0.4,0.6$, and 0.8 . Multinomial errors were added to catch-age proportions and predator food habits assuming known effective sample sizes. When measurement error was added to either commercial or survey catch datasets, errors were added simultaneously to both annual total catches and age proportions. The standard deviations for lognormal multiplicative errors and sample sizes for the random multinomial draws were chosen to achieve approximately the same percent difference between observed and true catches. Accordingly, effective sample sizes of 500, 75, 40 and 20 were chosen for commercial 
catch age proportions, 1000, 200, 100 and 60 for survey age proportions, and 2500, 500, 100, 50 and 10 for predator food habits. As the multinomial effective sample size decreases, the magnitude of measurement error incorporated into the proportions increases.

Preliminary simulations tested the stability of parameter estimates and their variances in relation to the number of replicates. Analysis of trends in 95th percentiles and scaled root mean squared error over time indicated that both measures generally achieved stable values at approximately 200-300 simulations (Fig. S1). Based on these preliminary results, 400 randomizations were completed for each error level.

In an effort to more fully portray the magnitude of error present in the input data, measurement error was simultaneously incorporated into all three datasets in levels comparable to the standard deviations of the residuals of the best model fit. Total commercial and survey catch standard deviations for lognormal errors were set to 0.1 and 0.4 , respectively. Multinomial effective sample sizes for commercial catch age proportions, survey catch age proportions and predator diet were set to 1000, 200 and 10 . For this simulation, 500 randomizations were conducted. Scaled mean error and coefficient of variation were used to quantify resulting parameter bias and precision, respectively (Walther and Moore 2005).

\section{RESULTS}

\section{Model fitting}

We compare single-species and multispecies fits to examine both the consistencies and points of deviations between the two approaches. These model fits are compared to 
the observed data and predicted indices from recent stock assessments. The assessment predicted indices are not considered to be truth, but instead a starting point for the catchat-age models presented here.

In both formulations, single- and multi-species predicted total annual commercial catch closely followed observed catches with only minor differences apparent between runs (Fig. 1a). Total annual survey catch also followed temporal trends in the observed time series, but greater interannual variability was apparent (Fig. 1b). For both commercial and survey age proportions, the predicted trends captured much of the apparent interannual variability. However, both formulations predicted an accumulation of biomass in the older age classes of cod and silver hake during the end of the time series that was inconsistent with the observed age proportions (Fig. S2 - Fig. S7).

The objective-function weightings for each dataset were selected iteratively to reflect prespecified coefficient of variations for lognormal variables and calculated effective sample sizes for multinomial variables (Table S1). The resulting standard deviations of total commercial catch residuals across both model formulations ranged from $0.04-0.11$, whereas those for total survey catch ranged from $0.34-0.56$ (Table S2). Contributions of each dataset to the objective function further indicated a better fit to commercial catches than to trawl-survey catches (Table 4). Multinomial dataset weightings approximated average effective sample sizes over the time series (Fig. S8 Fig. S10). Across all runs, the maximum observed correlation between parameter pairs was 0.80 .

Agreement among models in predicted total annual abundance varied across species (Fig. 2a). For cod, both single-species and multispecies predictions closely matched the 
decline in total abundance estimated in the single-species stock assessment. For silver hake and herring, total abundance estimated from the multispecies model was generally greater than that estimated from the single-species run. For herring, both multispecies and single-species predictions were the same order of magnitude as that predicted by the assessment; predicted abundance increased and peaked between 1995 and 2003. In the case of silver hake, total abundance estimated with both model formulations consistently exceeded estimates of minimum swept biomass from the trawl surveys. Silver hake abundance varied without a clear trend, with peaks in the 1980s and 2000s. For all species, trends in predicted recruitment for both model formulations generally followed the same trends as total annual abundance (Fig. 2b).

As expected, the single-species models generally produced higher estimates of fully recruited fishing mortality rates than the multispecies models (Fig. 2c). For cod, fishing mortality estimated in both the single- and multi-species models closely followed the rates estimated in the assessment. In the beginning of the time series, both models consistently predicted higher fishing mortality rates than those of the assessment, while both models predicted consistently lower rates during the latter half of the time series. For herring, the trends in fishing mortality predicted by the assessment drastically differed from those predicted using both catch-at-age models. The VPA conducted during the herring stock assessment predicted a decline in fishing mortality over the time series, while the results of both the single- and multi-species catch-at-age models developed here predicted a strong increase in fishing mortality.

Estimated predation mortality $\left(M_{2}\right)$ varied across species, prey age, and time (Fig. 3a). Predation mortality only represented a maximum of $15 \%$ of total morality for cod 
(Fig. 3b) and declined in parallel with cod abundance (as associated with cannibalism). For silver hake and herring, however, predation accounted for as much as $91 \%$ of total mortality. As with cod, silver hake $M_{2}$ mirrored the pattern of silver hake abundance. By contrast, herring M2 was high but declined over time as herring abundance increased. For cod and silver hake, predation mortality decreased with increasing age, whereas herring $M_{2}$ increased from age-1 to age-2, beyond which it decreased with age.

For silver hake, predation mortality constituted a substantial proportion of total mortality even for the oldest age classes. In this multispecies model, predation sizeselectivity is dictated by predator size-preference coefficients, which were empirically calculated from observed predator and prey lengths. Across the time series, the dominant source of silver hake predation was cannibalism (Fig. 3c). Accordingly, the sizepreference parameters for silver hake cannibalism can provide insight as to the source of these large predation mortality rates on older age classes. In particular, the large estimated variance in the observed predator-prey weight ratio $(\sigma)$ resulted in a wide distribution of silver hake size preference (Table 5).

Sensitivity runs were conducted to investigate the influence of this variance term on silver hake size preference. Reducing this variance by either one-half or by an order of magnitude caused a substantial decline in the width of the silver hake size-preference curve and an increase in the silver hake-silver hake species-preference coefficient $(\rho)$. However, it also caused an unrealistically large increase in both silver hake recruitment and age-1 predation mortality near the end of the time series. Consequently, the original scenario was selected as the final run. 
The principle predator varied among prey species (Fig. 3c). While the dominant sources of both silver hake and Atlantic cod predation were cannibalism (cod is only prey to itself in this submodel), the dominant predator of herring was cod even though cod abundance exhibited a precipitous decline. For both silver hake and herring, the proportion consumed by cod declined in the last decade, as expected from cod's estimated abundance. Estimated species-preference coefficients indicated that relative to other food, cod had a high preference for herring, a moderate preference for silver hake, and a low preference for cannibalism (Table 5). Furthermore, the coefficient for cod cannibalism was highly uncertain, as indicated by the large corresponding standard deviation. By contrast, silver hake had a higher preference for cannibalism than for herring. Predicted diets indicated an underestimation in the proportion of modeled fish species in predator diets. In the case of cod, the model overestimated cod consumption of herring relative to silver hake (Fig. S11 - Fig. S14).

Increasing the food-habits objective-function weighting moderately impacted trends in the dominant predator for each prey species but minimally impacted other predictions including recruitment, fishing mortality and predator diet. An increase in this objectivefunction weighting minimally influenced rates of predation, resulitng in a $5.7 \%$ increase in the maximum observed $M 2$ for silver hake and a 3.9\% increase in that for herring. While predation mortality rates were robust to the food-habits dataset weighting, the weighting influenced estimated species-preference coefficients. As the weighting increased, cod's preference for cannibalism decreased, its preference for silver hake increased and its preference for herring slightly decreased. Likewise, the increased weighting resulted in a decreased preference for silver hake cannibalism and an increased 
silver hake preference for herring. These changes in species-preference coefficients resulted in enhanced roles of both cod as a predator to silver hake, and silver hake as a predator to herring. However, increasing the food-habits objective-function weighting also resulted in convergence errors and an overestimation of effective sample size; therefore, the original objective-function weighting was selected for the final run.

A sensitivity run was also conducted to examine the impact of a reduction in assumed total ecosystem biomass on estimated predation mortality rates and speciespreference coefficients. Reducing ecosystem biomass to approximately one-half its original estimate had a negligible impact on estimated recruitment, total annual abundance, predicted predator diets, and rates of predation. For any species or age class, the maximum percent difference in predicted recruitment, total abundance and $M_{2}$ beween runs was $0.53 \%, 0.59 \%$, and $3.49 \%$, respectively. In contrast, estimated speciespreference coefficients decreased by $51-53 \%$ due to the definition of these coefficients as predator preference relative to other food.

\section{Monte Carlo simulations}

In general, the parameters of the multispecies model could be estimated, even with substantial levels of simulated error. As expected, the uncertainty in predicted indices such as recruitment and fishing mortality increased with increased measurement error in commercial catches, survey catches, and food-habits data.

At low measurement error levels $(\sigma \leq 0.4)$, errors introduced into commercial catches resulted in greater uncertainty in predicted fishing mortality rates than corresponding levels of error in survey catches (Fig. 4a, Fig. 4b). However, at higher 
error levels ( $\sigma=0.6$ to 0.8$)$ the model could not fully resolve fishing mortality rates of the prey species when error was introduced into the survey dataset (Fig. S15).

Across all levels of measurement error, errors in commercial catches resulted in less uncertainty in predicted recruitment than errors in survey catches (Fig. 5a, Fig. 5b). For survey catch errors, recruitment estimation, particularly at the end of the time series, began to break down at an error level of 0.4. With error in the commercial catch, all error levels produced reasonable, yet increasingly uncertain recruitment estimates for cod and herring (Fig. 5a, Fig. S16). However for silver hake, recruitment estimation broke down at an intermediate error level of 0.6.

Similar to recruitment, estimated predation mortalities were more sensitive to measurement error in survey catches than in the commercial catch (Fig. 6a, Fig. 6b). For both data sources, parameter uncertainty increased substantially at a measurement error level of 0.6 . For the trawl-survey dataset, an error level of 0.8 resulted in age-1 predation mortalities greater than 3.0 for both silver hake and herring. Across all estimated parameters and levels of measurement error, error in predator diets had the least effect on parameter estimates (Fig. 5 -Fig. 7). Species-preference coefficients were quite sensitive to measurement errors in both survey and commerical catches (Fig. S17). Across all sources of measurement error, the species-preference coefficient for cod cannibalism was the most sensitive to errors in the input data.

With measurement error added to all three data sources in levels comparable to the standard deviations of the residuals of the best model fit (Table S2), the model produced reasonable estimates for most parameters (Fig. 7). Notable exceptions included the annual recruitment of both silver hake and herring near the end of the time series (Fig. 
7a), where some runs predicted a large increase in recruitment that was not apparent in the observed time series. Across all years, silver hake recruitment estimates were quite uncertain, where the width of the 95th percentiles was approximately twice as large as the magnitude of the true recruitment level and the annual CV ranged from 33.6 to $156.6 \%$ (Table 6). However, the medians were within approximately $20 \%$ of the true recruitment values. For herring, predicted recruitment exhibited an average $\mathrm{CV}$ of $34.3 \%$ until the final year of the time series where jumped it to $196 \%$ (Table 6, Fig. 7a). Similarly, uncertainty in predicted fishing mortality increased substantially in the last three years (Fig. 7b), further indicating that the model was unable to fully resolve herring dynamics at the end of the time series.

For all three species, this model overestimated age-1 predation mortality (Fig. 7c). This overestimation was most severe for $\operatorname{cod} M 2$, which exhibited a scaled mean error ranging from 1.47 to 1.87 and an average annual CV exceeding 120\% (Table 6). Taken together with the large standard deviation of the cod cannibalism species-preference coefficient and the high sensitivity of this coefificent to measurement error in the input datasets, this overestimation in cod M2 further demonstrates the uncertainty in the extent of cod cannibalism.

\section{DISCUSSION}

The multispecies model fit the observed data as well as the individual single-species age-structured models, but differed in the estimated levels of abundance, fishing mortality, and natural mortality. The differences among the multispecies, single-species, and stock-assessment model results can be interpreted with respect to the trophic role of 
the species. Like previous modeling efforts (Collie and Delong 1999, Tsou and Collie 2001a, Overholtz et al. 2008, Tyrrell et al. 2008), our results demonstrate temporal and ontogenetic variation in total natural mortality and the strong influence of predation on community dynamics. Abundance patterns predicted in the multispecies formulation result from the interplay between fishing and predation mortality.

In the case of Atlantic cod, the close consistency in abundance predictions across the three outputs is due to cod's primary role as a predator species in the model; the effect of predation is minimal. In this sub-model, cod is only a prey species to itself through cannibalism and the estimated species-preference coefficient indicates a low preference towards cannibalism. Furthermore, with predicted age-specific predation mortality rates less than 0.04 and constituting a maximum of $15 \%$ of total mortality, cod's total natural mortality rate was effectively constant between model formulations. Therefore the decline in cod abundance was driven by fishing mortality.

For silver hake the difference in magnitude between model and survey-based abundance estimates occurs because the latter estimate is based on the area swept by the trawl survey and therefore represents a minimum estimate that does not take into account species catchability. Furthermore, total abundance estimated from the multispecies run was considerably larger than that estimated from the single-species run. The dominant role of silver hake as prey of cod and silver hake resulted in the greater predicted abundance of the multispecies formulation, even though residual natural mortality was lower in the multispecies run. The decline in silver hake abundance during the late 1990s corresponded with a period of high fishing mortality. Predation mortality was higher during the abundance peaks in the 1980s and 2000s. 
Predicted recruitment and total annual abundance of herring from the single- and multi-species models roughly follow the trends of the single-species stock assessment. Total abundance estimated from the multispecies run was somewhat greater than that estimated from the single-species run, which again reflects the trophic role of herring as prey of cod and silver hake. In an application of MSVPA-X on the Northeast US Continental Shelf evaluating the influence of predation on forage species, both agespecific and total annual predicted abundance was greater in the multispecies VPA than in the single-species formulation (Tyrrell et al. 2008). The peak in herring abundance in the late 1990s corresponds to lower predation mortality from cod; the decline in herring abundance since 2003 can be explained by increased fishing mortality.

Similarly for fishing mortality, the consistency between cod fishing mortality rates estimated by the single- and multi-species models is due to the low levels of predation experienced by the species. With these low predation rates and therefore similar total natural mortality rates, fishing mortality is the primary factor driving cod population dynamics in both formulations. The retrospective pattern observed between the singlespecies and stock assessment predictions is likely an artifact of the varying assumptions made between this statistical catch-at-age model and the VPA conducted for the singlespecies assessment. In the VPA, the time series was split in 1994 (NEFSC 2008); however, we assumed one continuous time series with one selectivity ogive.

For herring and silver hake, the multispecies predicted fishing mortality was consistently lower than the single-species estimate, with the substantial predation mortality rates resulting in a smaller contribution of fishing to the total mortality experienced. For these species both predation and fishing drive their population 
dynamics. The added losses experienced by prey species due to predation help to explain the differences in fishing mortality and abundance estimates between the single-species and multispecies formulations. A greater species abundance, and therefore, a smaller imposed fishing mortality, was needed to account for the predation losses incurred. This result is consistent with those of other multispecies modeling efforts (Overholtz et al. 2008, Tyrrell et al. 2008, Moustahfid et al. 2009).

Furthermore, for Atlantic herring, the drastic difference in temporal trend between the fishing mortality predicted in the assessment and that predicted using both catch-atage models may be a function of assumptions regarding stock dynamics. The stock assessment assumes a stock complex spanning both Georges Bank and the Gulf of Maine (Shepherd et al. 2009), while the results from the catch-at-age models are based on commercial catches from Georges Bank alone. Our assumption that a constant proportion of the stock is found on Georges Bank could have potentially biased the results. Furthermore, the large difference in predicted fishing mortality between the assessment and both catch-at-age models could be a reflection of differences in the dynamics of the Georges Bank versus Gulf of Maine populations. Previous work has indicated that the Georges Bank component of the stock complex exhibited both a more precipitous decline in abundance than that of the Gulf of Maine, as well as a more recent recovery (Overholtz and Friedland 2002).

Regardless, trends in age-specific predation mortality indicate that the losses due to predation vary substantially over both age and time. Consequentially, models that assume a time- and/or age- invariant total natural mortality do not fully capture the dynamics of the population. Increased biological realism however, can result in 
increased uncertainty in parameter estimation, indicated here by the uncertainty in some of the species-preference coefficients, particularly that for cod cannibalism.

The magnitude of predation mortality experienced by the model's two primary prey species is substantial. Silver hake and herring both experience predation mortality rates exceeding 0.8 ; two and four times, respectively, the natural mortality rate assumed in the single-species stock assessments. The estimated predation rates constitute $70-80 \%$ of the total mortality imposed on these two species, indicating the importance of predation in controlling the population dynamics of the prey species in this model. This increased total natural mortality reduces the influence of fishing on the species' population dynamics and projections for future fisheries yield.

Other multispecies models constructed for the northeast U.S. indicate similar rates of predation. Tsou and Collie (2001a), in an MSVPA constructed for Georges Bank, estimated predation mortality rates between $0.003-0.3$ for cod, $0.13-1.6$ for silver hake and $0.06-0.75$ for herring. Likewise, in an MSVPA-X of the Northeast US Continental Shelf, Tyrell et al. (2008) estimated average age- 0 and age-1 herring predation mortality between $0.94-3.2$. Together these studies further support the importance of predation in prey population dynamics. However, age-specific rates of predation may change once the model presented here is expanded to include additional fish species on Georges Bank.

We assumed that the empirical average $(\eta)$ predator-prey weight ratio and variance $(\sigma)$ reflected the preferred ratio and variance because prey lengths were only available for a subset of the food-habits data. While our empirical weight ratios are similar to those estimated for cod and silver hake in the Georges Bank (Tsou and Collie 2001a) and North Sea (Gislason and Helgason 1985) MSVPA applications, some of our variance terms are 
greater than those either estimated or assumed in other MSVPA applications (Gislason and Helgason 1985, Van Kirk 2008). This increased variance is particularly apparent for silver hake cannibalism, resulting in a wide range of consumed prey sizes as well as a possibility, albeit small, that individuals consume prey larger than themselves. This large variance estimate did not appear to be related to sample size ( $n=743$ and represented the largest sample size of any species interaction). Regardless, these high $\sigma$ estimates resulted in wide ranges of consumed prey sizes and consequently enhanced predation mortality rates of the oldest age-classes. As in previous studies (Andersen and Ursin 1977, Helgason and Gislason 1979) we assumed a lognormal size selectivity function, which is symmetric on a log scale. Some authors have used asymmetric functions, which allow predators to eat prey much smaller but not larger than themselves (Tsou and Collie 2001a, Lewy and Vinther 2004). These asymmetric size-preference curves could be considered in future applications.

The majority of silver hake predation is due to cannibalism, indicating strong density dependence. This result is supported by previous modeling efforts, which indicated that cannibalism accounted for as much as 50 to $80 \%$ of silver hake predation (Tsou and Collie 2001a, Link et al. 2012). For herring, however, cod is the principle predator across the time series in this model, in contrast to previous MSVPA studies. Tyrell et al (2008) showed that the most important predators for herring were silver hake, white hake, summer flounder and goosefish. Likewise, while Tsou and Collie (2001a) indicated that both cod and silver hake were predators of herring, silver hake was responsible for 50 to $90 \%$ of herring consumed biomass. The dominance of cod as herring's top predator in this model is in part due to the effective sample size of the food- 
habits data and the resulting objective-function weighting assigned to the dataset. While increasing the food-habits weighting increased silver hake consumption of herring, silver hake still exhibited a higher preference for cannibalism than herring, and cod maintained its preference for herring over silver hake. Furthermore, the emergence of convergence errors and overestimation of food-habits effective sample size ultimately prohibited its use as the final run.

The food-habits data contain important information needed to quantify predation mortality. However as a result of the small effective sample size of the diet data, most of the statistical power for parameter estimation originates from the commercial and survey catch datasets. Due to the large interannual variability apparent in the trawl-survey data as a consequence of changes in availability to the survey gear (Overholtz et al. 1999), commercial catch data were assigned the greatest dataset weighting and exhibited the smallest resulting $\mathrm{CV}$. The use of annual food-habits data, in contrast to binning data over five-year intervals, may have produced a greater effective sample size; yet in doing so, the model would have tried to capture the large variability inherent of food-habits data and not necessarily true changes in predation (Van Kirk et al. 2010). On the other hand assuming time-invariant predator diets would have ignored true changes in prey availability and predation rates over the time series. Accordingly, averaging over 5-year blocks served as a compromise.

As a result of the large variability in the observed food-habits data, predicted predator diets exhibited only small changes with increases in the food-habits objectivefunction weighting. This result indicated that the model was unable to fully capture trends in diet even when it was given more power to fit the observed data. This pattern 
may change if more species, especially prey, were included in the model. While the magnitude of the species interactions was uncertain (as indicated by the underestimated proportion of modeled fish species in predator diets and the overestimated role of cod as a predator to herring) the model produced robust estimates of predation mortality rates. It is the estimation of these losses due to predation that are arguably the most critical aspect to the incorporation of ecological interactions into stock assessments.

A key benefit of the statistical multispecies model, compared with MSVPA, is the statistical estimation of model parameters and the recognition that observed datasets contain measurement error. A potential drawback of multispecies statistical models is the necessity of simultaneously estimating numerous parameters for each species as well as the predation parameters that define the interactions among species (Van Kirk et al. 2010). With Monte Carlo simulations, we evaluated robustness in parameter estimation to predetermined levels of measurement error in the three input datasets. We note that these simulations address the influence of observation error but do not consider structural uncertainty of the underlying model. The consequence of structural uncertainty, for example, through fitting single-species models to simulated multispecies data, could be examined in future simulation analyses.

As expected, uncertainty in the predicted indices increased with increasing levels of measurement error in commercial catch, survey catch and food-habits time series. Uncertainty in fishing mortality was most sensitive to increasing commercial catch measurement errors, whereas uncertainty in recruitment and predation mortality was most sensitive to increased survey catch measurement error. These results demonstrate the importance of both datasets to the estimation of population parameters. Across all 
predicted indices, estimates were most robust to increased uncertainty in predator stomach contents. This finding was presumably due to the low effective sample size and resulting small objective-function weighting for the food-habits data.

While the model began to fail at high levels of measurement error, parameters of the multispecies model were estimable from data simulated with levels of error comparable to those in the observed data. The multispecies model was able to reconstruct the true underlying trends in predation mortality. Furthermore, while uncertainty in the resulting parameter estimates was apparent, the median estimates were not substantially biased. The small positive bias in estimated silver hake and herring predation mortality rates could arise from the approximation used to calculate $M 2$. For cod, the more substantial positive bias likely results from the underlying uncertainty in the extent of cod cannibalism. The Monte Carlo simulations enhance our confidence in the performance of the statistical model, even with the increased complexity in parameter estimation inherent in the multispecies framework.

Through the development of a statistical catch-at-age model, we have expanded the multispecies modeling approaches implemented for Georges Bank and the Northeast U.S. Continental Shelf. Building upon previous efforts, we have demonstrated that multispecies models can be fit statistically to time series of catch, abundance and diet data. Monte Carlo simulations indicated that parameter estimation is robust, and successful when input data contain measurement errors similar to those levels found in the observed datasets. The ability to estimate the uncertainty associated with the results of statistical, multispecies, age-structured models should make them useful tools for furthering ecosystem-based fisheries management. 


\section{ACKNOWLEDGEMENTS}

We thank Steve Martell and Jim Ianelli for sharing their expertise in ADMB and model development. We thank Kray Van Kirk for assistance in troubleshooting model code. This project was funded by Rhode Island Sea Grant through project numbers R/F041, R/F-061 and by a NOAA/National Sea Grant Graduate Fellowship in Population Dynamics NA070AR4170482. 


\section{REFERENCES}

ADMB Project. 2009. AD Model Builder: automatic differentiation model builder. Developed by David Fournier. Available at admb-project.org.

Andersen, K.P., and Ursin, E. 1977. A multispecies extension to the Beverton and Holt theory of fishing, with accounts of phosphorus circulation and primary production. Meddr. Danm. Fisk. Havunders. (N.S.) 7: 319-435.

Auster, P.J., and Link, J.S. 2009. Compensation and recovery of feeding guilds in a northwest Atlantic shelf fish community. Mar. Ecol. Prog. Ser. 382: 163-172.

Begley, J., and Howell, D. 2004. An overview of Gadget, the Globally applicable AreaDisaggregated General Ecosystem Toolbox. ICES CM 2004/FF:13.

Brodziak, J.K.T., Holmes, E.M., Sosebee, K.A., and Mayo, R.K. 2001. Assessment of the silver hake resource in the Northwest Atlantic in 2000. Northeast Fish. Sci. Cent. Ref. Doc. 01-03, NOAA - National Marine Fisheries Service, Woods Hole, MA.

Collie, J.S., and Delong, A.K. 1999. Multispecies interactions in the Georges Bank fish community. In Ecosystem approaches for fisheries management. Alaska Sea Grant College Program, AK-SG-99-01, Fairbanks, Alaska. pp. 187-210.

Collie, J.S., and Kruse, G.H. 1998. Estimating king crab (Paralithodes camtschaticus) abundance from commercial catch and research survey data. Can. Spec. Publ. Fish. Aquat. Sci. 125: 73-83.

Deriso, R.B., Quinn, T.J., and Neal, P.R. 1985. Catch-age analysis with auxiliary information. Can. J. Fish. Aquat. Sci. 42(4): 815-824.

Fogarty, M.J., and Murawski, S.A. 1998. Large-scale disturbance and the structure of marine system: Fishery impacts on Georges Bank. Ecol. Appl. 8(1): S6-S22.

Fournier, D., and Archibald, C.P. 1982. A general theory for analyzing catch at age data. Can. J. Fish. Aquat. Sci. 39(8): 1195-1207.

Garrison, L.P., Link, J.S., Kilduff, D.P., Cieri, M.D., Maffley, B., Vaughan, D.S., Sharov, A., Mahmoudi, B., and Latour, R.J. 2010. An expansion of the MSVPA approach 
for quantifying predator-prey interactions in exploited fish communities. ICES J. Mar. Sci. 67(5): 856-870.

Gislason, H. 1999. Single and multispecies reference points for Baltic fish stocks. ICES J. Mar. Sci. 56(5): 571-583.

Gislason, H., and Helgason, T. 1985. Species interaction in assessment of fish stocks with special application to the North Sea. Dana 5: 1-44.

Grosslein, M.D., Langton, R.W., and Sissenwine, M.P. 1980. Recent fluctuations in pelagic fish stocks of the northwest Atlantic, Georges Bank region, in relation to species interactions. Rapp. P.-v. Réun. Cons. int. Explor. Mer 177: 374-404.

Helgason, T., and Gislason, H. 1979. VPA-analysis with species interaction due to predation. ICES CM 1979/G:52.

Hoenig, J.M. 1983. Empirical use of longevity data to estimate mortality rates. Fishery Bulletin 82(1): 898-903.

Hollowed, A.B., Bax, N., Beamish, R., Collie, J., Fogarty, M., Livingston, P., Pope, J., and Rice, J.C. 2000. Are multispecies models an improvement on single-species models for measuring fishing impacts on marine ecosystems? ICES J. Mar. Sci. 57(3): 707-719.

Jurado-Molina, J., Livingston, P.A., and Ianelli, J.N. 2005. Incorporating predation interactions in a statistical catch-at-age model for a predator-prey system in the eastern Bering Sea. Can. J. Fish. Aquat. Sci. 62(8): 1865-1873.

Kinzey, D., and Punt, A.E. 2009. Multispecies and single-species models of fish population dynamics: comparing parameter estimates. Nat. Resour. Model. 22(1): 67-104.

Lewy, P., and Vinther, M. 2004. A stochastic age-length-structured multispecies model applied to North Sea stocks. ICES CM 2004/FF:19.

Link, J., O'Reilly, J., Fogarty, M., Dow, D., Vitaliano, J., Legault, C., Overholtz, W., Green, J., Palka, D., Guida, V., Brodziak, J., Methratta, E., and Stockhausen, W.T. 2008. Energy flow on Georges Bank revisited: the Energy Modeling and 
Analysis eXercise (EMAX) in historical context. J. Northwest Atl. Fish. Sci. 39: 83-101.

Link, J.S. 2002. What does ecosystem-based fisheries management mean? Fisheries 27(4): 18-21.

Link, J.S. 2010. Ecosystem-Based Fisheries Management: Confronting Tradeoffs. Cambridge University Press, Cambridge.

Link, J.S., and Almeida, F.P. 2000. An overview and history of the Food Web Dynamics Program of the Northeast Fisheries Science Center, Woods Hole, Massachusetts. NOAA Tech. Memo. NMFS-NE-159.

Link, J.S., and Garrison, L.P. 2002. Changes in piscivory associated with fishing induced changes to the finfish community on Georges Bank. Fish. Res. 55(1-3): 71-86.

Link, J.S., Lucey, S.M., and Melgey, J.H. 2012. Examining cannibalism in relation to recruitment of silver hake Merluccius bilinearis in the U.S. northwest Atlantic. Fish. Res. 114: 31-41.

Livingston, P.A., and Jurado-Molina, J. 2000. A multispecies virtual population analysis of the eastern Bering Sea. ICES J. Mar. Sci. 57(2): 294-299.

Magnússon, K.G. 1995. An overview of the multispecies VPA -- theory and applications. Rev. Fish Biol. Fish. 5(2): 195-212.

Moustahfid, H., Link, J.S., Overholtz, W.J., and Tyrrell, M.C. 2009. The advantage of explicitly incorporating predation mortality into age-structured stock assessment models: an application for Atlantic mackerel. ICES J. Mar. Sci. 66(3): 445-454.

NEFSC (Northeast Fisheries Science Center). 2008. Assessment of 19 northeast groundfish stocks through 2007: Report of the 3rd Groundfish Assessment Review Meeting (GARM III), Northeast Fisheries Science Center, Woods Hole, Massachusetts, August 4-8, 2008. Northeast Fish. Sci. Cent. Ref. Doc. 08-15, NOAA - National Marine Fisheries Service, Woods Hole, MA.

Overholtz, W.J., and Friedland, K.D. 2002. Recovery of the Gulf of Maine-Georges Bank Atlantic herring (Clupea harengus) complex: perspectives based on bottom trawl survey data. Fishery Bulletin 100(3): 593-608. 
Overholtz, W.J., Jacobson, L.D., and Link, J.S. 2008. An ecosystem approach for assessment advice and biological reference points for the Gulf of Maine-Georges Bank Atlantic herring complex. N. Am. J. Fish. Manag. 28(1): 247-257.

Overholtz, W.J., Jacobson, L.D., Melvin, G.D., Cieri, M., Power, M., Libby, D., and Clark, K. 2004. Stock assessment of the Gulf of Maine - Georges Bank Atlantic herring complex, 2003. Northeast Fish. Sci. Cent. Ref. Doc. 04-06, NOAA National Marine Fisheries Service, Woods Hole, MA.

Overholtz, W.J., and Link, J.S. 2007. Consumption impacts by marine mammals, fish, and seabirds on the Gulf of Maine-Georges Bank Atlantic herring (Clupea harengus) complex during the years 1977-2002. ICES J. Mar. Sci. 64(1): 83-96.

Overholtz, W.J., Link, J.S., and Suslowicz, L.E. 1999. Consumption and harvest of pelagic fishes and squids in the Gulf of Maine-Georges Bank ecosystem. In Ecosystem approaches for fisheries management. Alaska Sea Grant College Program, AK-SG-99-01, Fairbanks, Alaska. pp. 163-186.

Penttila, J.A., Nelson, G.A., and Burnett, J.M. 1989. Guidelines for estimating lengths at age for 18 northwest Atlantic finfish and shellfish species. NOAA Tech. Memo. NMFS-F/NEC-66.

Plagányi, É.E. 2007. Models for an ecosystem approach to fisheries. FAO Fish. Tech. Pap. 477, FAO, Rome.

Pope, J.G. 1979. A modified cohort analysis in which constant natural mortality is replaced by estimates of predation levels. ICES CM 1979/H:16.

Quinn, T.J., and Deriso, R.B. 1999. Quantitative Fish Dynamics. Oxford University Press, New York.

Rochet, M.J., Collie, J.S., Jennings, S., and Hall, S.J. 2011. Does selective fishing conserve community biodiversity? Predictions from a length-based multispecies model. Can. J. Fish. Aquat. Sci. 68(3): 469-486.

Shepherd, G., Cieri, M., Power, M., and Overholtz, W. 2009. Transboundary Resources Assessment Committee Gulf of Maine/Georges Bank Atlantic Herring Stock Assessment Update. TRAC Ref. Doc. 2009/04. 
Sparholt, H. 1994. Fish species interactions in the Baltic Sea. Dana 10: 131-162.

Sparre, P. 1980. A goal function of fisheries (legion analysis). ICES CM 1980/G:40.

Sparre, P. 1991. Introduction to multispecies virtual population analysis. ICES Marine Science Symposium, Multispecies Models Relevant to Management of Living Resources 193: 12-21.

Townsend, H.M., Link, J.S., Osgood, K.E., Gedamke, T., Watters, G.M., Polovina, J.J., Levin, P.S., Cyr, N., and Aydin, K.Y. 2008. National Marine Fisheries Service Report of the National Ecosystem Modeling Workshop (NEMoW). NOAA Tech. Memo. NMFS-F/SPO-87.

Tsou, T.S., and Collie, J.S. 2001a. Estimating predation mortality in the Georges Bank fish community. Can. J. Fish. Aquat. Sci. 58(5): 908-922.

Tsou, T.S., and Collie, J.S. 2001b. Predation-mediated recruitment in the Georges Bank fish community. ICES J. Mar. Sci. 58(5): 994-1001.

Tyrrell, M.C., Link, J.S., and Moustahfid, H. 2011. The importance of including predation in fish population models: Implications for biological reference points. Fish. Res. 108(1): 1-8.

Tyrrell, M.C., Link, J.S., Moustahfid, H., and Overholtz, W.J. 2008. Evaluating the effect of predation mortality on forage species population dynamics in the Northeast US continental shelf ecosystem using multispecies virtual population analysis. ICES J. Mar. Sci. 65(9): 1689-1700.

Van Kirk, K.F. 2008. A multispecies age-structured assessment model for the Gulf of Alaska. M.Sc. thesis, School of Fisheries and Ocean Sciences, University of Alaska Fairbanks, Fairbanks, Alaska.

Van Kirk, K.F., Quinn, T.J., and Collie, J.S. 2010. A multispecies age-structured assessment model for the Gulf of Alaska. Can. J. Fish. Aquat. Sci. 67(7): 11351148 .

Walters, C., and Ludwig, D. 1994. Calculation of Bayes posterior probability distributions for key population parameters. Can. J. Fish. Aquat. Sci. 51(3): 713722 . 
Walther, B.A., and Moore, J.L. 2005. The concepts of bias, precision and accuracy, and their use in testing the performance of species richness estimators, with a literature review of estimator performance. Ecography 28(6): 815-829.

Wigley, S.E., McBride, H.M., and McHugh, N.J. 2003. Length-weight relationships for 74 fish species collected during NEFSC research vessel bottom trawl sureys, 1992-99. NOAA Tech. Memo. NMFS-NE-171. 
Table 1: Symbols used in model formulations.

Symbol Description (units)

\begin{tabular}{|c|c|}
\hline 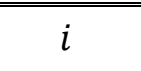 & Species or prey species \\
\hline$a$ & Age or prey age (year) \\
\hline$j$ & Predator species \\
\hline$b$ & Predator age (year) \\
\hline$t$ & Year \\
\hline$N_{i, a, t}$ & Abundance-at-age in beginning of year $\left(10^{6}\right.$ fish $)$ \\
\hline$W_{i, a, t}$ & Average individual weight-at-age (kg) \\
\hline$B_{i, a, t}$ & Biomass-at-age $\left(10^{6} \mathrm{~kg}\right)$ \\
\hline$Z_{i, a, t}$ & Instantaneous total mortality-at-age $\left(\mathrm{yr}^{-1}\right)$ \\
\hline$M_{i}$ & Instantaneous natural mortality (age and time invariant) \\
\hline$M 1_{i}$ & Instantaneous residual natural mortality (age and time invariant) \\
\hline$M 2_{i, a, t}$ & Instantaneous predation mortality-at-age $\left(\mathrm{yr}^{-1}\right)$ \\
\hline$F_{i, a, t}$ & Instantaneous fishing mortality-at-age $\left(\mathrm{yr}^{-1}\right)$ \\
\hline$s_{i, a}$ & Fishery selectivity-at-age \\
\hline$C_{i, a, t}$ & Commercial catch-at-age ( $10^{6}$ fish $)$ \\
\hline$F I C_{i, a, t}$ & Fishery independent (survey) catch (number/tow) \\
\hline$r_{i, a}$ & Survey selectivity-at-age \\
\hline$q_{i}$ & Survey catchability (age and time invariant) \\
\hline$\eta_{i, j}$ & Preferred predator-to-prey weight ratio \\
\hline$m$ & Month in which the trawl survey is conducted \\
\hline$\sigma_{i, j}$ & Variance in predator-to-prey weight ratio \\
\hline$g_{i, \mathrm{a}, j, b, t}$ & Predator size preference \\
\hline$\rho_{i, j}$ & Prey species preference \\
\hline$v_{i, \mathrm{a}, j, b, t}$ & Prey suitability \\
\hline$\tilde{v}_{i, \mathrm{a}, j, b, t}$ & Scaled prey suitability (scaled across prey species) \\
\hline$\phi_{i, \mathrm{a}, j, b, t}$ & Available prey biomass $\left(10^{6} \mathrm{~kg}\right)$ \\
\hline$E c o B$ & Total ecosystem biomass $\left(10^{6} \mathrm{~kg}\right)$ \\
\hline Other & Other food \\
\hline$B_{\text {other }, t}$ & Total biomass of other food $\left(10^{6} \mathrm{~kg}\right)$ \\
\hline$S_{i, \mathrm{a}, j, b, t}$ & Weight of prey $i, a$ in the stomach of predator $j, b\left(10^{6} \mathrm{~kg}\right)$ \\
\hline$C B_{j, b}$ & Consumption-to-biomass ratio (time invariant) \\
\hline$E f N_{i, t}$ & Effective sample size \\
\hline$P_{i, a, t}$ & Proportion-at-age \\
\hline
\end{tabular}


Table 1, contd.: Symbols used in model formulations.

Symbol Description (units)

\begin{tabular}{cl}
\hline \hline$I$ & Dataset index \\
$L L_{I}$ & Log likelihood of dataset $I$ \\
$D_{I}$ & Objective function weighting for dataset $I$ \\
$T C$ & Total commercial catch in weight $\left(10^{3} \mathrm{mt}\right)$ \\
$T S$ & Total survey catch (number/tow) \\
$C P$ & Commercial catch age proportions \\
$S P$ & Survey catch age proportions \\
$F H$ & Food habits proportions (proportion by weight) \\
Pen & Total likelihood penalty for each species \\
Pwt & Objective function weighting for penalty $p$ \\
$Y p e n$ & Initial abundance, $N_{i, a, 1}$, penalty \\
Rpen & Recruitment penalty \\
Bpen & Age-specific biomass penalty \\
Yr1 & Initial abundances predicted from exponential decay \\
Rthres & Threshold value for the CV of log recruitment \\
Bthres & Threshold value for age-specific biomass
\end{tabular}


Table 2: Single-species equations from Quinn and Deriso (1999). Symbols are defined in Table 1.

\begin{tabular}{ll}
\hline Equation & Description \\
\hline \hline$N_{i, a+1, t+1}=N_{i, a, t} \cdot e^{-Z_{i, a, t}}$ & Abundance-at-age: $2 \leq a<\max (a)$ \\
$N_{i, a, t+1}=N_{i, a-1, t} \cdot e^{-Z_{i, a-1, t}}+N_{i, a, t} \cdot e^{-Z i, a, t}$ & Abundance-at-age: $a=\max (a)$ \\
$C_{i, a, t}=\frac{F_{i, a, t}}{Z_{i, a, t}} N_{i, a, t}\left(1-e^{-Z_{i, a, t}}\right)$ & Catch-at-age \\
$F_{i, a, t}=s_{i, a} F_{i, t}$ & Fishing mortality-at-age \\
\hline
\end{tabular}


Table 3: Components of the likelihood function where $I$ represents a dataset index, $D_{I}$ the corresponding objective function weighting, $L L_{I}$ the log likelihood for dataset $I, \operatorname{Pen}_{i}$ the total likelihood penalty for each species, and $P w t_{p}$ the objective function weighting for penalty $p$. All additional symbols are defined Table 1.

Equation

Description

$$
\begin{aligned}
& \hline L L_{\text {Total }}=L L_{T C}+L L_{T S}+L L_{C P}+L L_{S P}+L L_{F H}+\sum_{i} \text { Pen }_{i} \\
& L L_{I}=D_{I} \cdot \sum_{t, i, a}\left(\ln \left(I+10^{-3}\right)-\ln \left(\hat{I}+10^{-3}\right)\right)^{2} \\
& L L_{I}=D_{I} \cdot \sum_{t, i, a}\left(I+10^{-30} \cdot \ln \left(\hat{I}+10^{-30}\right)\right) \\
& \text { Pen }_{i}=P w t_{Y i} \cdot \text { Ypen }_{i}+P w t_{R i} \cdot \text { Rpen }_{i}+P w t_{B i} \cdot \text { Bpen }_{i} \\
& \text { Ypen }_{i}=\sum_{a}\left(N_{i, a, 1}-Y r 1_{i, a, 1}\right)^{2} \\
& \text { Rpen }_{i}=0.01 \cdot\left(C V\left(N_{i, 1, t}\right)-\text { Rthres }_{i}\right)^{2} \\
& \text { Bpen }_{i}=\sum_{a, t} 0.01 \cdot\left(B_{i, t, a}-\text { Bthres }_{i}\right)^{2}
\end{aligned}
$$

Total log likelihood

Lognormal distribution

Multinomial distribution

Total penalty

Initial abundance penalty

Recruitment penalty

Biomass penalty 
Table 4: The contributions of each objective function component in both the singlespecies and multispecies models. The abundance penalty constrains the age distribution in the initial year; the recruitment penalty constrains the $\mathrm{CV}$ of estimated recruitment each year (Table 3 ).

\begin{tabular}{|c|c|c|c|c|c|c|}
\hline & \multicolumn{3}{|c|}{ Single species } & \multicolumn{3}{|c|}{ Multispecies } \\
\hline & Cod & Silver hake & Herring & Cod & Silver hake & Herning \\
\hline $\begin{array}{r}\text { Total commercial } \\
\text { catch }\end{array}$ & 27.24 & 71.08 & 6.80 & 29.45 & 28.59 & 3.16 \\
\hline Total survey catch & 464.12 & 441.05 & 896.28 & 459.03 & 328.88 & 456.82 \\
\hline $\begin{array}{l}\text { Comm. age } \\
\text { proportions }\end{array}$ & 96.66 & 130.49 & 2.89 & 100.88 & 150.20 & 3.46 \\
\hline $\begin{array}{l}\text { Survey age } \\
\text { proportions }\end{array}$ & 149.13 & 292.73 & 595.15 & 156.20 & 341.63 & 718.93 \\
\hline Food habits & NA & NA & NA & 146.22 & 66.51 & 0 \\
\hline Abundance penalty & 0 & 0 & 0 & 0 & 0 & 0.53 \\
\hline Recruitment penalty & 0 & 0 & 0.24 & 0 & 0 & 0 \\
\hline
\end{tabular}


Table 5: Average predator-prey weight ratios $(\eta)$, the variance in each ratio $(\sigma)$, estimated species preference coefficients $(\ln \rho)$ and their associated standard deviations for each species interaction. Parameters $\eta$ and $\sigma$ were calculated from observed predator and prey lengths. Parameter $\rho$ was estimated as a model parameter in log space.

Prey species

\begin{tabular}{ccrrr} 
& Predator species & Cod & SilverHake & \multicolumn{1}{c}{ Herring } \\
\hline \hline \multirow{7}{*}{$\eta$} & Cod & 4.159 & 4.833 & 3.996 \\
& SilverHake & NA & 3.946 & 2.261 \\
\hline \multirow{4}{*}{$\sigma$} & Cod & 2.259 & 1.875 & 1.433 \\
& SilverHake & NA & 2.979 & 1.093 \\
\hline \multirow{2}{*}{$\ln (\rho)$} & Cod & $0.618(0.889)$ & $1.549(0.171)$ & $3.255(0.048)$ \\
& SilverHake & NA & $5.396(0.029)$ & $3.223(0.155)$ \\
\hline
\end{tabular}


Table 6: The range of scaled mean error (SME) and coefficient of variation (CV) values across years for predicted annual fishing mortality (F), recruitment, and age-1 predation mortality (M2) from the simulation in which measurement error was incorporated into all three datasets.

\begin{tabular}{ccccc}
\hline \multirow{2}{*}{ Parameter } & Measure & Cod & Silver Hake & Herring \\
\hline \multirow{2}{*}{ F } & SME & $-0.04--0.01$ & $-0.07-0.02$ & $0.03-0.19$ \\
& & & & \\
& CV & $9.03-30.62$ & $15.49-25.58$ & $9.4-49.07$ \\
\hline \multirow{2}{*}{ Recruitment } & SME & $0.01-0.25$ & $0.26-0.74$ & $0.07-1.4$ \\
& CV & $14.74-88.87$ & $33.57-156.65$ & $22.23-196.72$ \\
\hline \multirow{2}{*}{ Age-1 M2 } & SME & $1.47-1.87$ & $0.12-0.25$ & $0.14-0.56$ \\
& CV & $122.39-136.68$ & $11.75-33.37$ & $10.84-43.67$ \\
\hline
\end{tabular}


a)

Cod

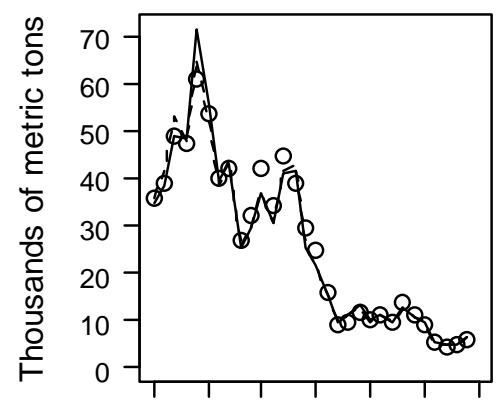

b)

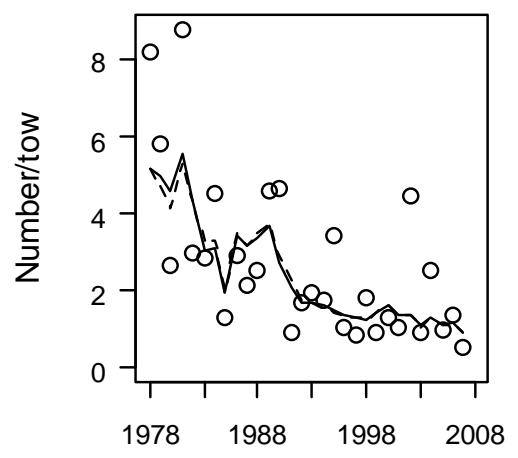

Silver hake
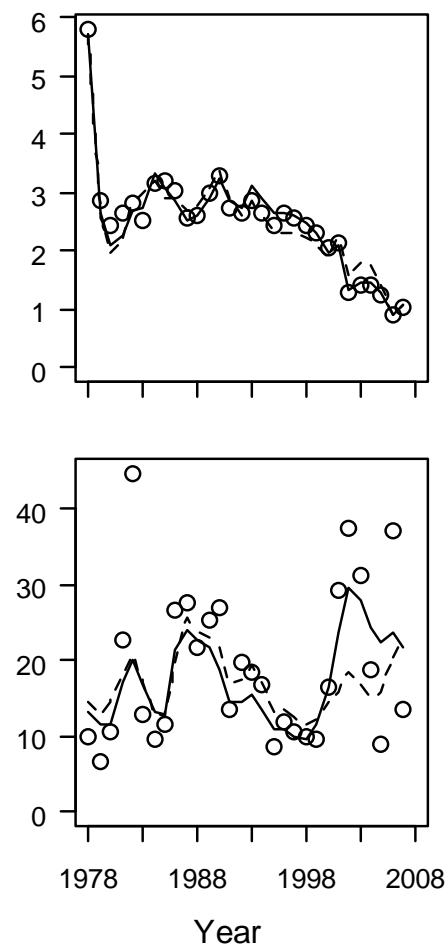

Herring
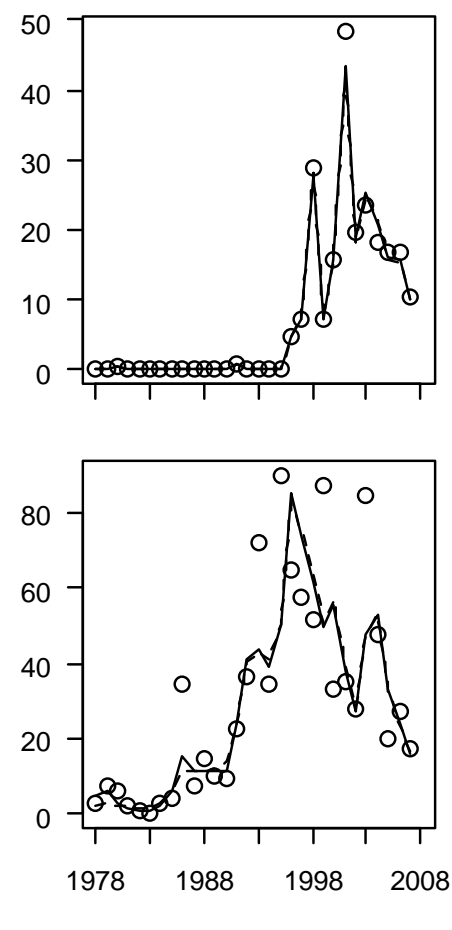

Fig. 1: Observed (open circles) and predicted total annual a) commercial catch and b) survey catch from the single-species (dashed line) and multispecies (solid line) runs. 
a)

Cod

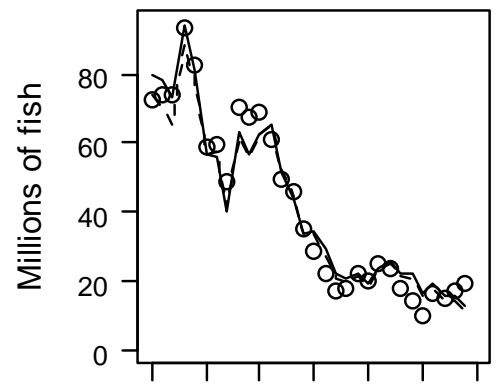

b)

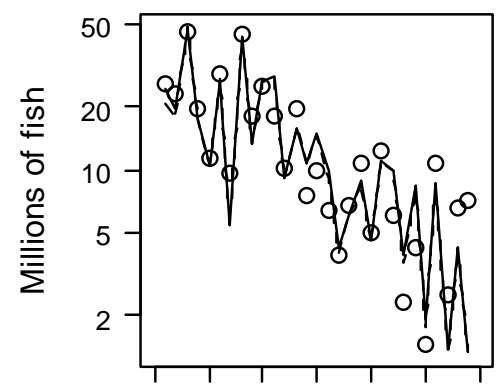

c)

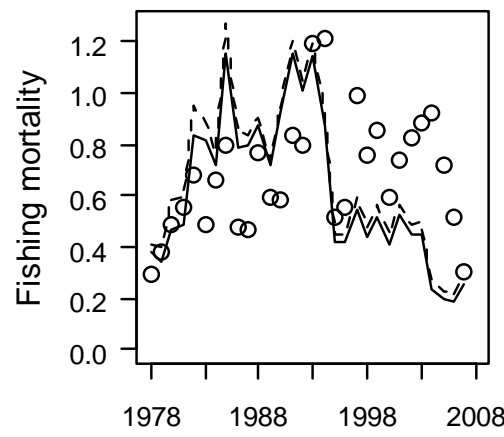

Silver hake
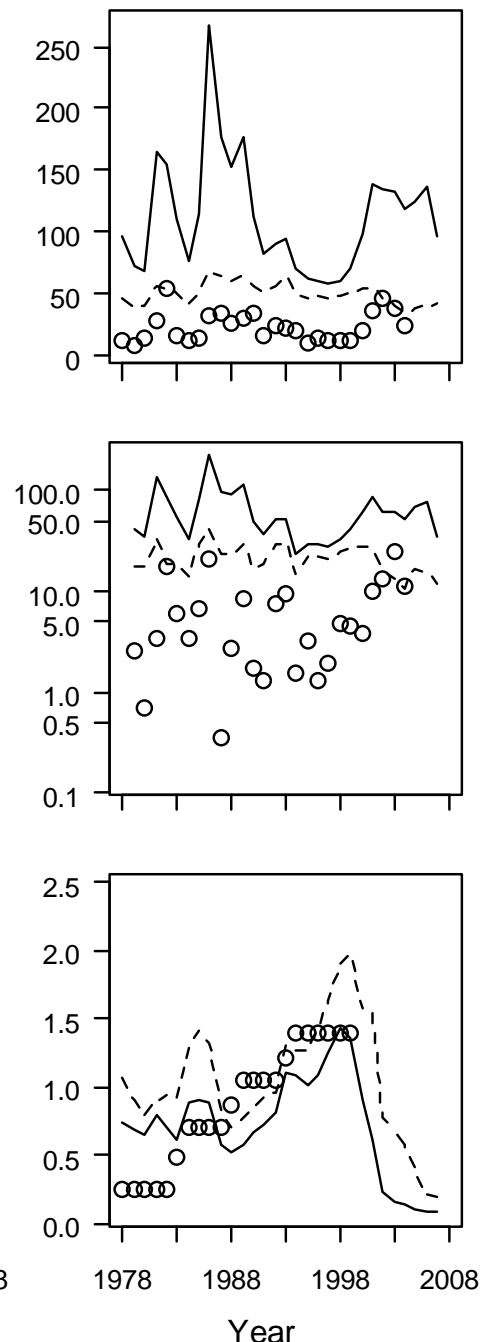

Herring
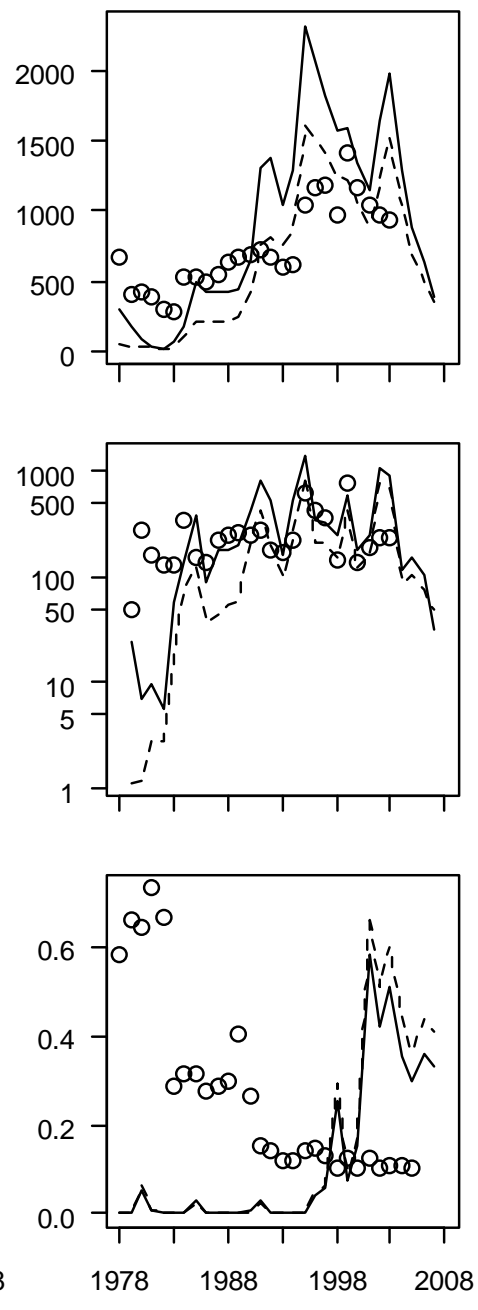

Fig. 2: Comparison of predicted annual a) total abundance, b) recruitment and c) fishing mortality from the single-species run (dashed line), multispecies run (solid line) and the most recent stock assessment (points). For silver hake total abundance and recruitment, absolute estimates were not available; therefore the points represent minimum swept area estimates that do not incorporate catchability. 
a)

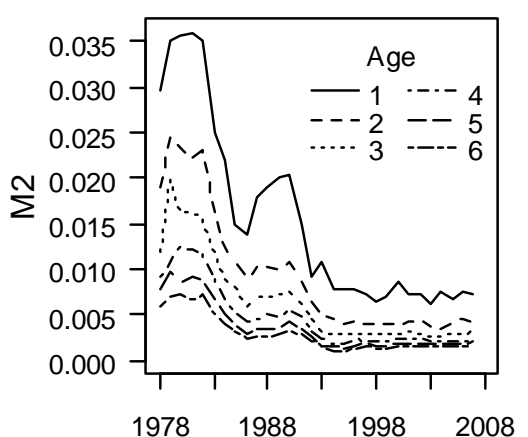

b)

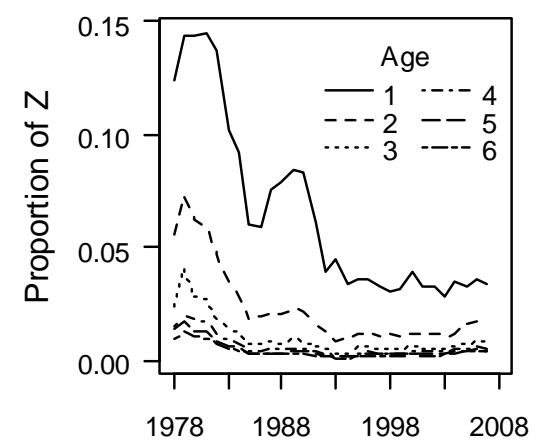

c)

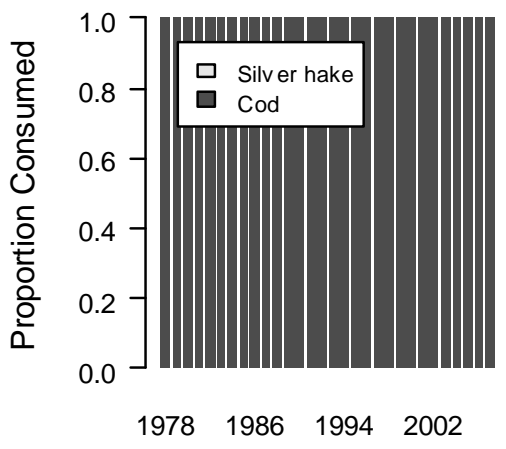

Silver hake
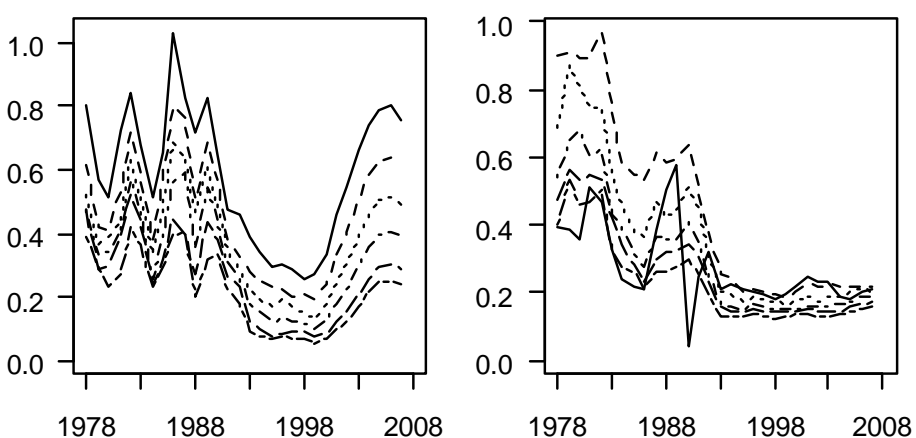
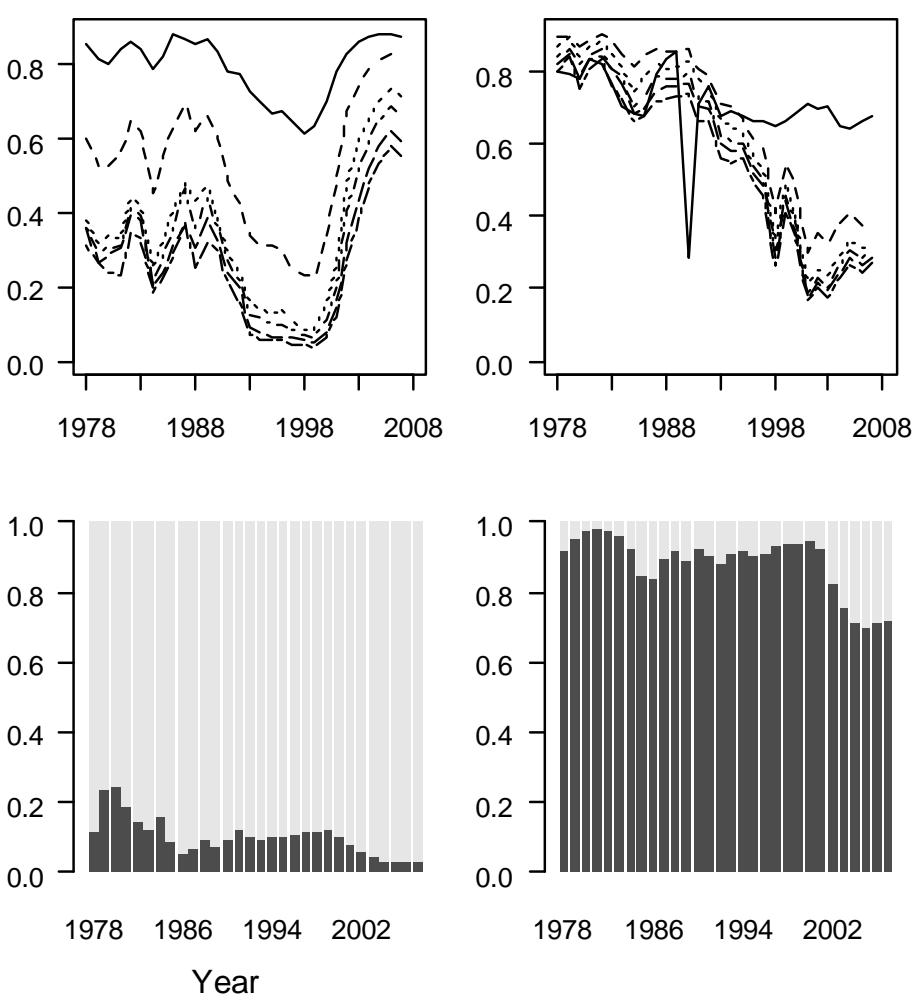

Fig. 3: For each prey species, the a) age-specific predation mortality, $M 2$, b) proportion of total mortality, $Z$, due to predation, and c) the predator species responsible for the observed predation. 


\section{Cod}

a)

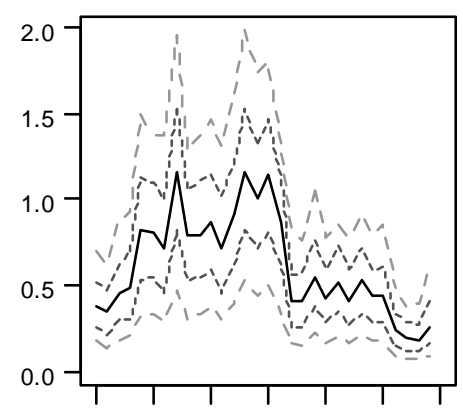

b)

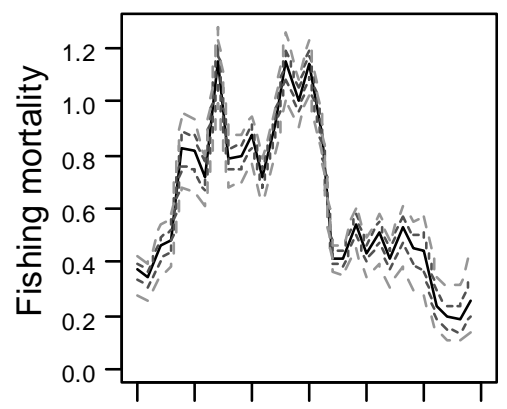

c)

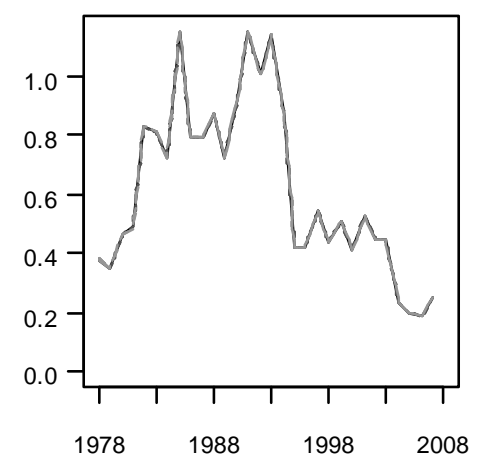

Silver hake

Error levels

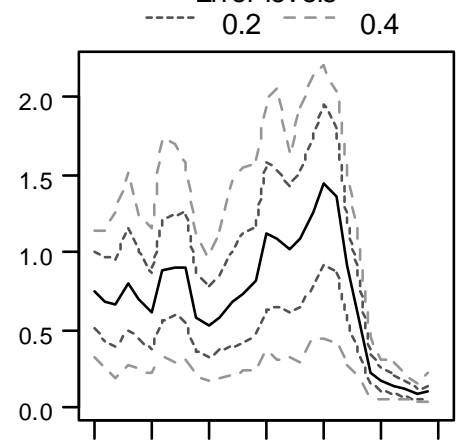

Error levels

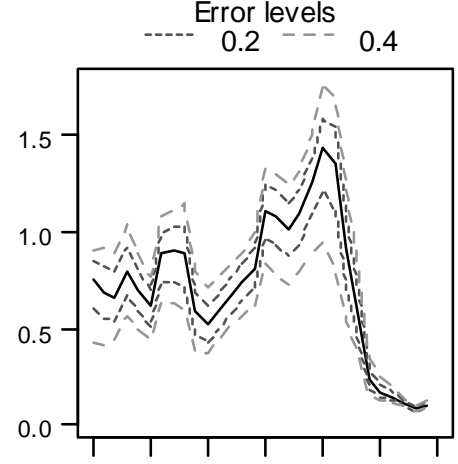

Error levels

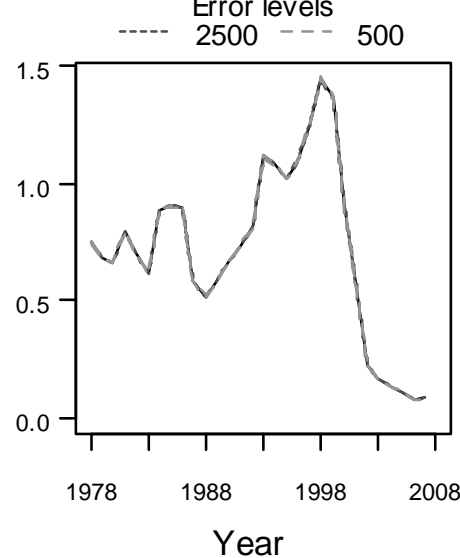

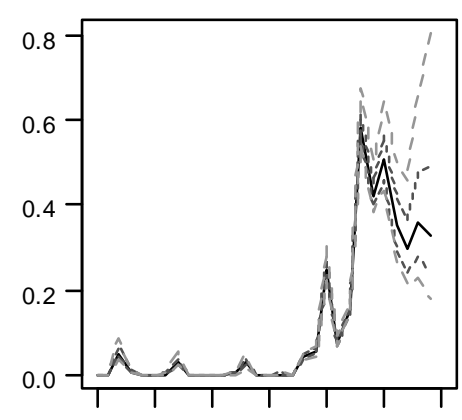

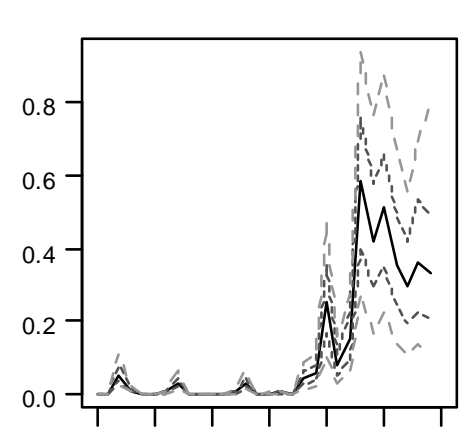

Herring

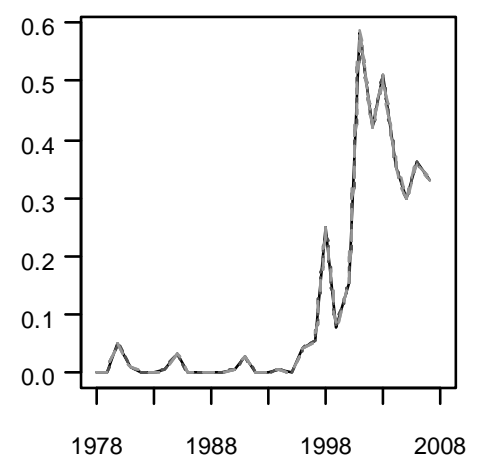

Fig. 4: 95th percentiles for estimated annual fishing mortality rate when low measurement error levels were introduced into a) commercial catches, b) survey catches, and c) predator diets. For commercial and survey catches, error levels represent the standard deviations of the multiplicative errors incorporated into total annual catches. For food habits data, error levels represent the number of draws from a multinomial distribution where measurement error increases as effective sample size decreases. In all plots, the solid line represents the true parameter values. 
Cod

a)

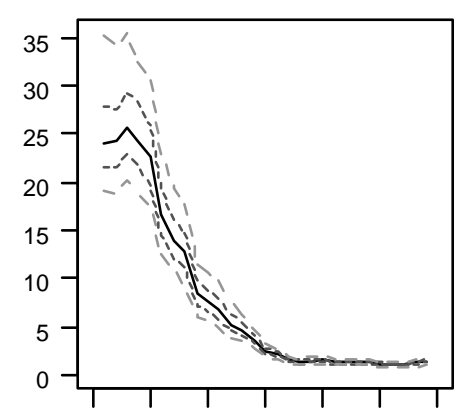

b)

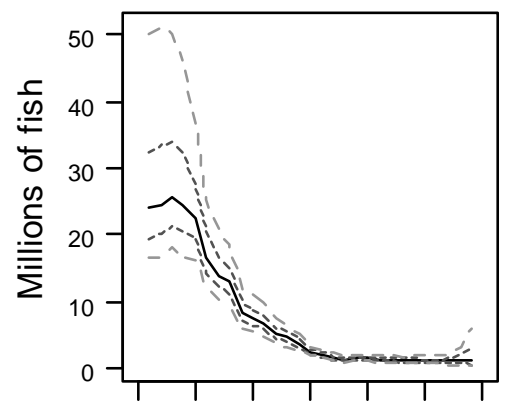

c)

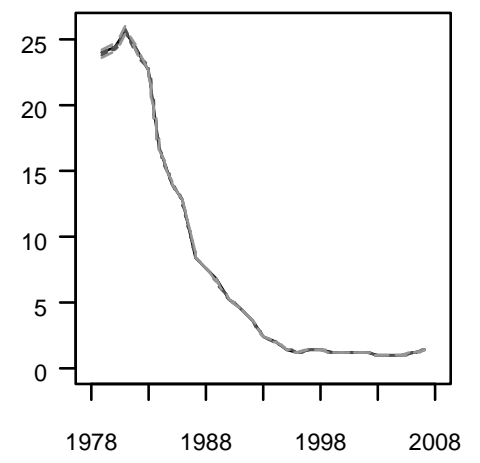

Silver hake

Error levels

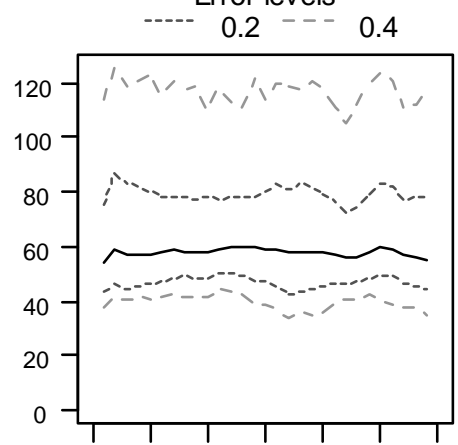

Error levels
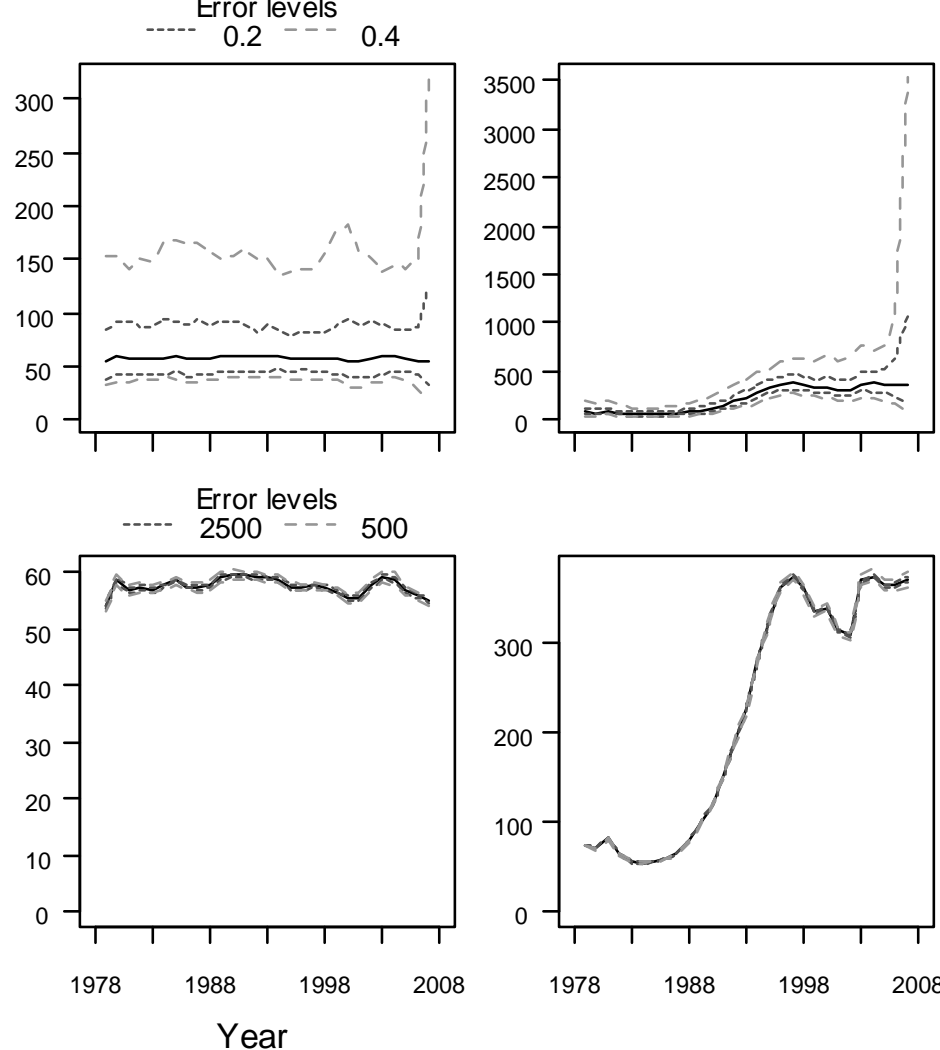

Herring
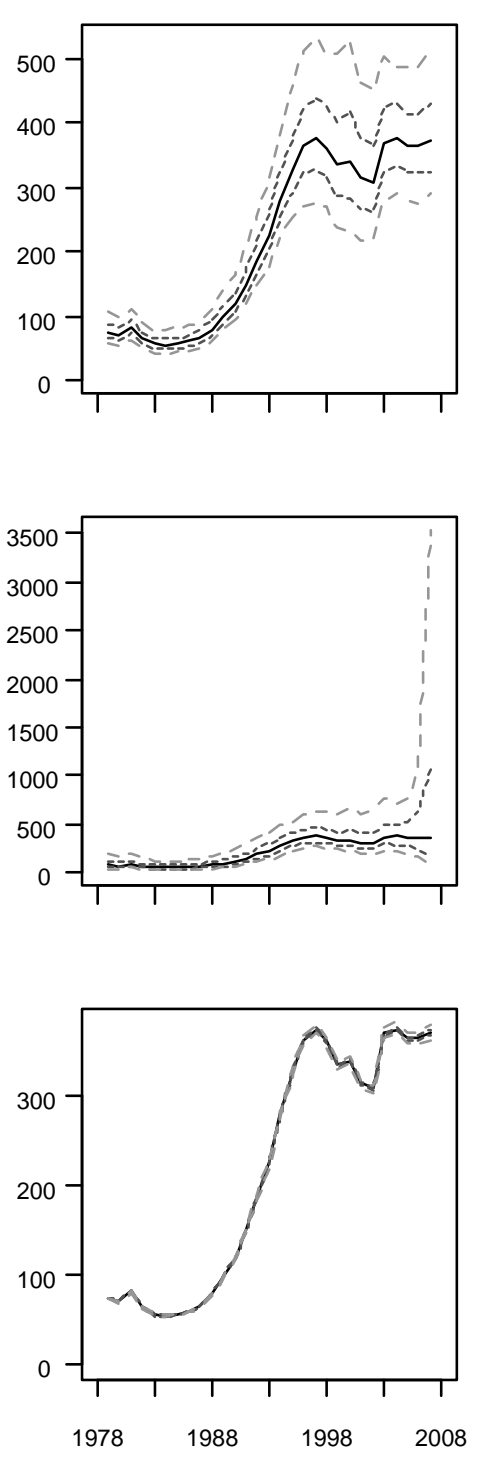

Fig. 5: 95th percentiles for estimated annual recruitment when low measurement error levels were introduced into a) commercial catches, b) survey catches, and c) predator diets. For commercial and survey catches, error levels represent the standard deviations of the multiplicative errors incorporated into total annual catches. For food habits data, error levels represent the number of draws from a multinomial distribution where measurement error increases as effective sample size decreases. In all plots, the solid line represents the true parameter values. 
Cod

a)

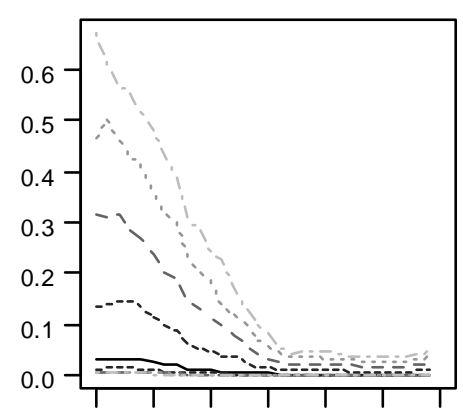

b)

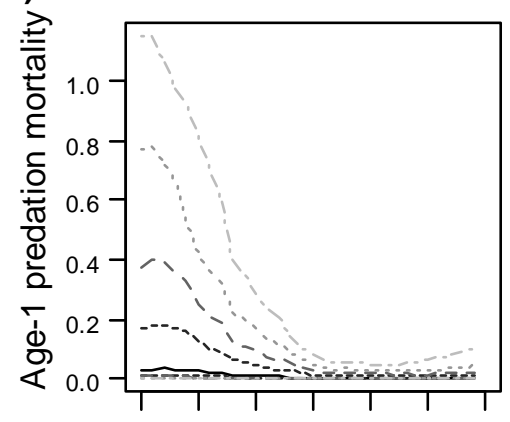

c)

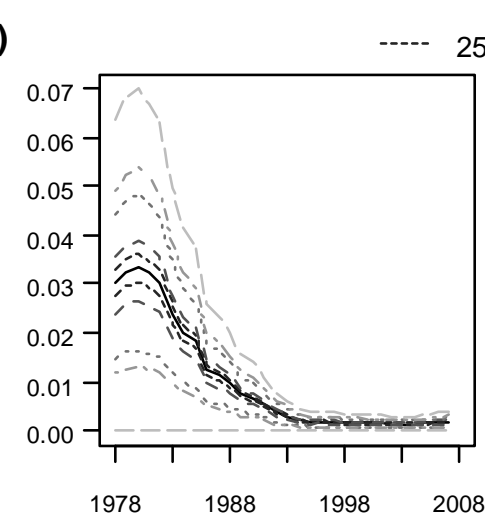

Silver hake

Error levels

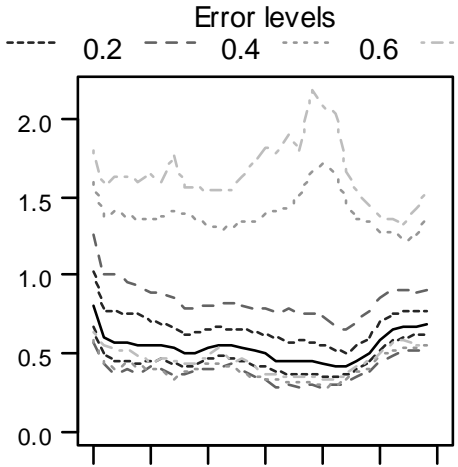

Error levels

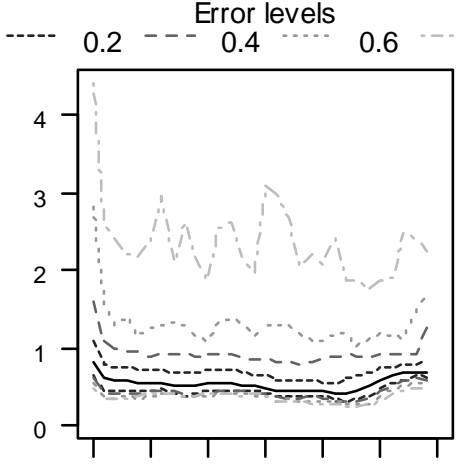

Error levels

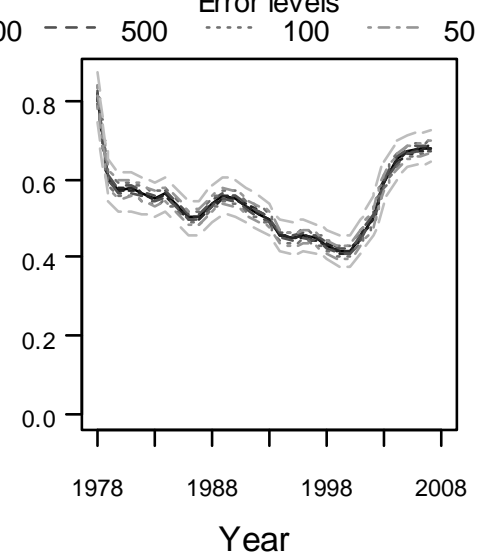

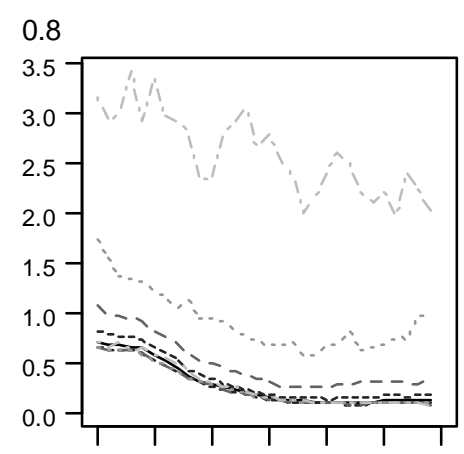

Herring

0.8
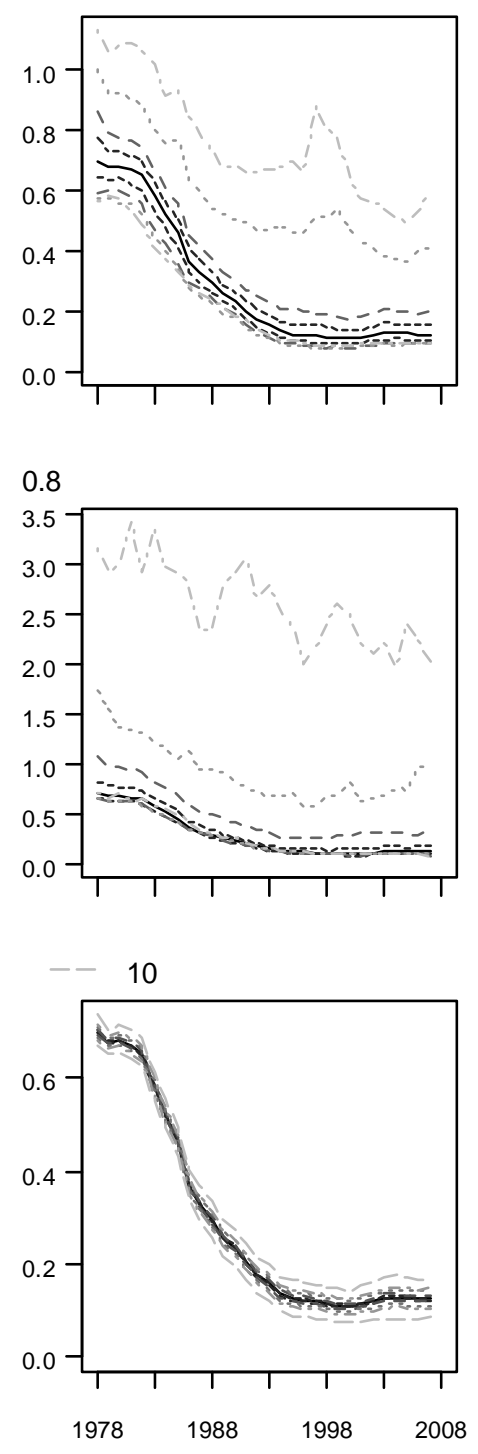

Fig. 6: 95th percentiles for estimated age-1 predation mortality when all measurement error levels were introduced into a) commercial catches, b) survey catches, and c) predator diets. For commercial and survey catches, error levels represent the standard deviations of the multiplicative errors incorporated into total annual catches. For food habits data, error levels represent the number of draws from a multinomial distribution where measurement error increases as effective sample size decreases. In all plots, the solid line represents the true parameter values. 
a)

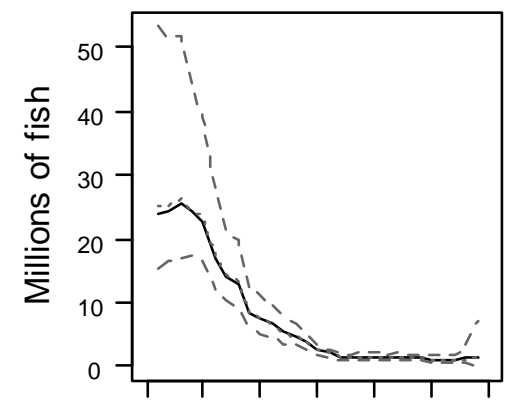

b)

c)
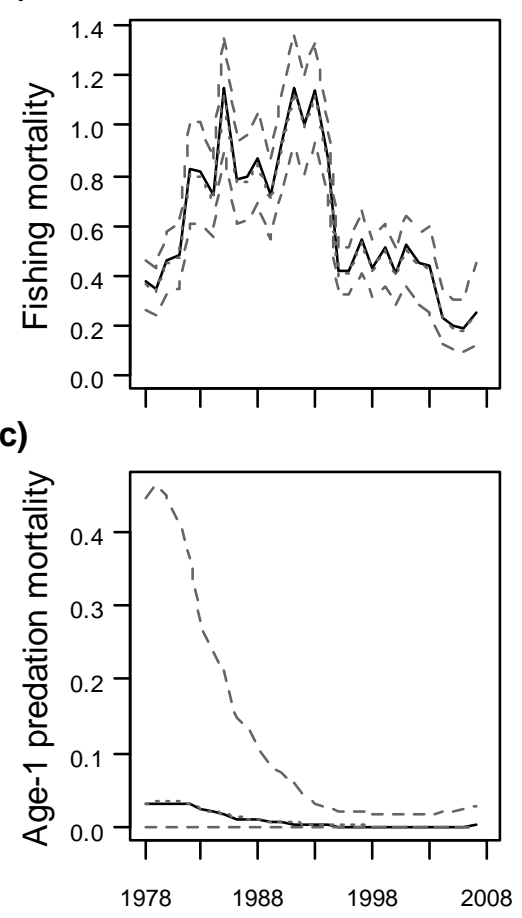

Silver hake
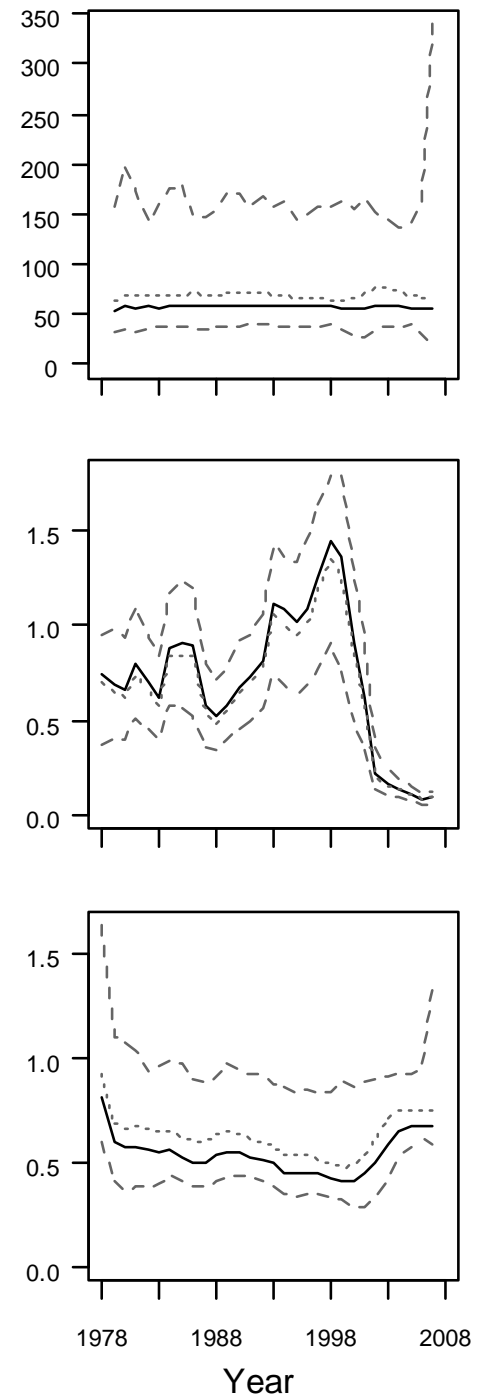

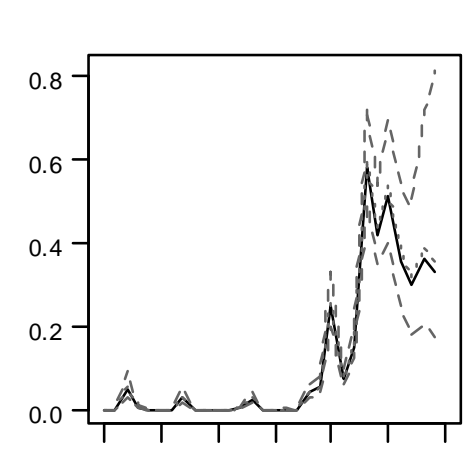

Herring
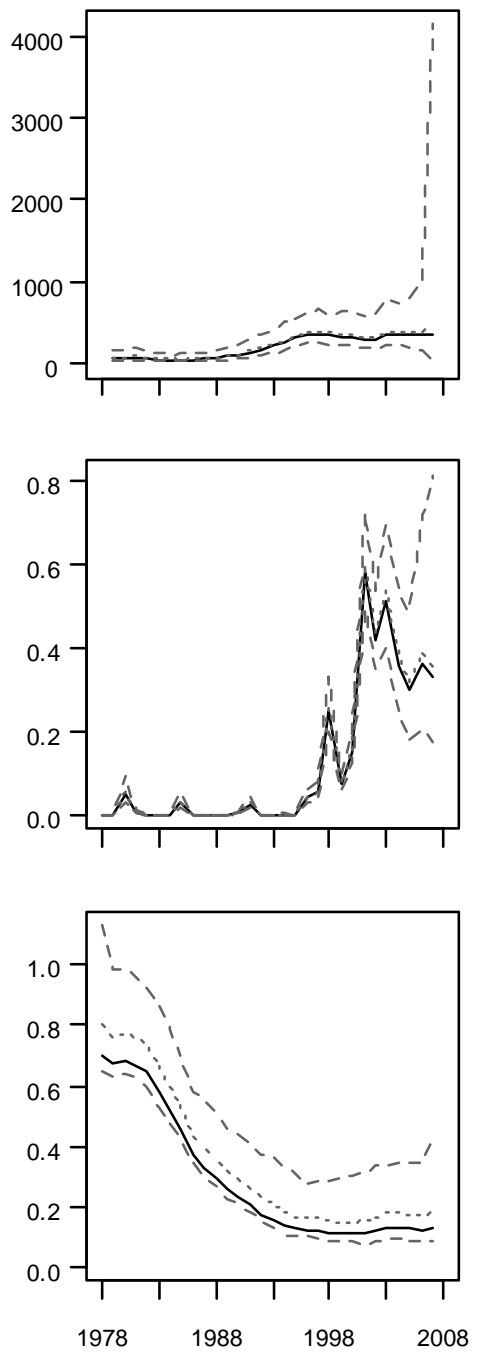

Fig. 7: 95th percentiles (dashed lines), median (dotted line) and true (solid line) annual recruitment (a), annual fully recruited fishing mortality (b), and age-1 predation mortality rates (c) for the simulation where measurement error was incorporated into all three datasets. 


\section{SUPPLEMENTAL MATERIAL}

Table S1: The weightings for each dataset included in both the single species (ssp) and multispecies (msp) models. Weightings of zero indicate that the dataset was not used in parameter estimation.

\begin{tabular}{|c|c|c|c|c|c|c|}
\hline & \multicolumn{3}{|c|}{ Single species } & \multicolumn{3}{|c|}{ Multispecies } \\
\hline & Cod & Silver hake & Herring & Cod & Silver hake & Herring \\
\hline $\begin{array}{r}\text { Total commercial } \\
\text { catch }\end{array}$ & 150 & 200 & 75 & 150 & 250 & 75 \\
\hline $\begin{array}{r}\text { Total spring survey } \\
\text { catch }\end{array}$ & 0 & 0 & 100 & 0 & 0 & 100 \\
\hline $\begin{array}{r}\text { Total fall survey } \\
\text { catch }\end{array}$ & 75 & 100 & 0 & 75 & 100 & 0 \\
\hline $\begin{array}{l}\text { Comm. age } \\
\text { proportions }\end{array}$ & 50 & 50 & 1 & 50 & 50 & 1 \\
\hline $\begin{array}{r}\text { Spring survey age } \\
\text { proportions }\end{array}$ & 0 & 0 & 50 & 0 & 0 & 50 \\
\hline $\begin{array}{r}\text { Fall survey age } \\
\text { proportions }\end{array}$ & 50 & 50 & 0 & 50 & 50 & 0 \\
\hline Food habits & NA & NA & NA & 10 & 10 & 10 \\
\hline
\end{tabular}


Table S2: The standard deviation of the residuals for each dataset included in both the single species (ssp) and multispecies (msp) models. NA's represent datasets that were not used in the objective function for a particular species.

Single species

\begin{tabular}{rcccccc} 
& Cod & Silver hake & Herring & Cod & Silver hake & Herring \\
\hline \hline $\begin{array}{r}\text { Total commercial } \\
\text { catch }\end{array}$ & 0.079 & 0.111 & 0.056 & 0.082 & 0.063 & 0.038 \\
$\begin{array}{r}\text { catch } \\
\text { Total spring survey }\end{array}$ & NA & NA & 0.556 & NA & NA & 0.397 \\
$\begin{array}{r}\text { Total fall survey } \\
\text { catch }\end{array}$ & 0.462 & 0.390 & NA & 0.459 & 0.337 & NA \\
$\begin{array}{r}\text { Comm. age } \\
\text { proportions }\end{array}$ & 0.141 & 0.161 & 0.233 & 0.144 & 0.164 & 0.262 \\
$\begin{array}{r}\text { Spring survey age } \\
\text { proportions }\end{array}$ & NA & NA & 0.291 & NA & NA & 0.347 \\
$\begin{array}{r}\text { Fall survey age } \\
\text { proportions }\end{array}$ & 0.164 & 0.217 & NA & 0.166 & 0.222 & NA \\
\hline $\begin{array}{r}\text { Food habits } \\
\text { Na }\end{array}$ & NA & NA & NA & 0.305 & 0.264 & NA \\
\hline
\end{tabular}



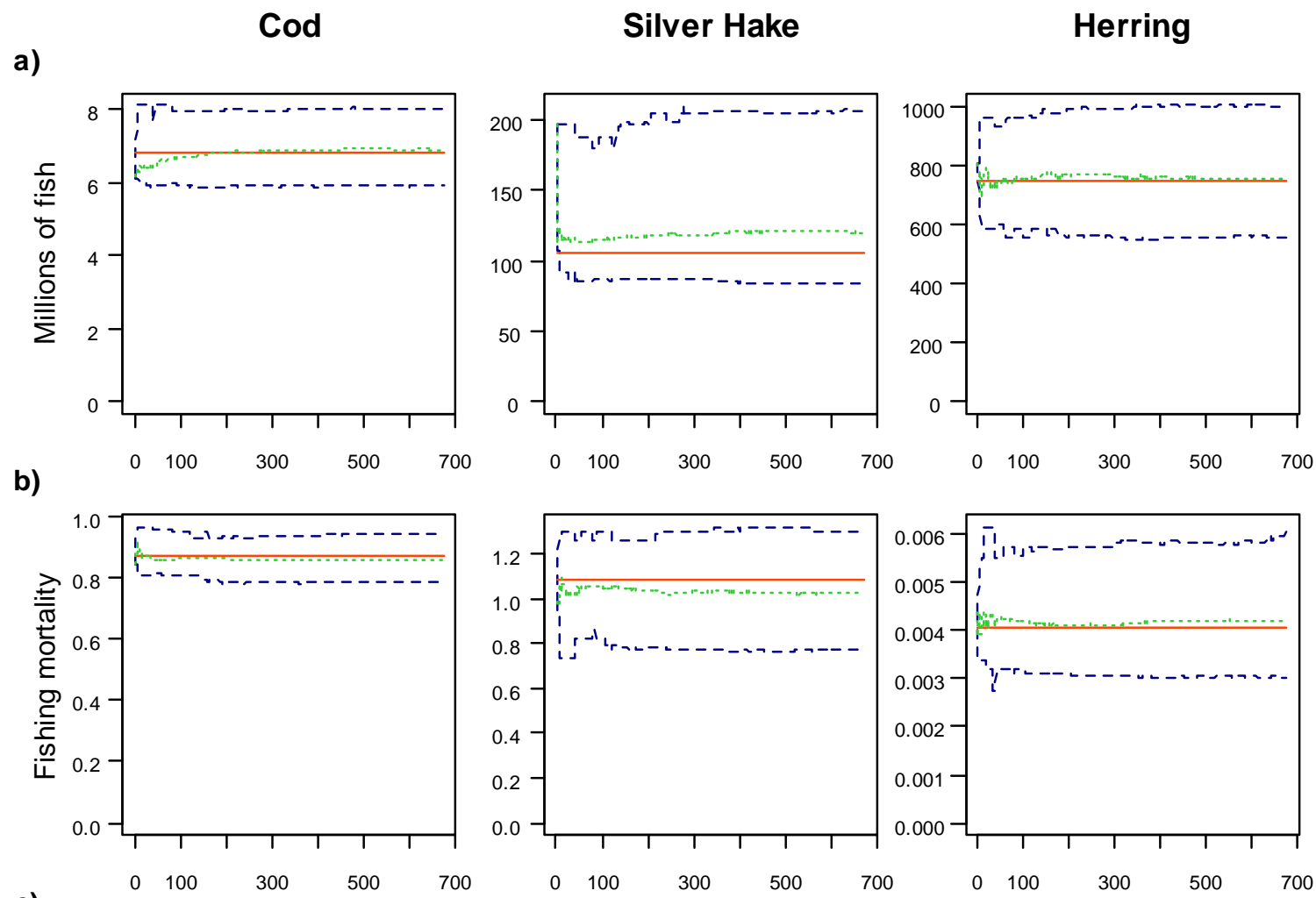

c)
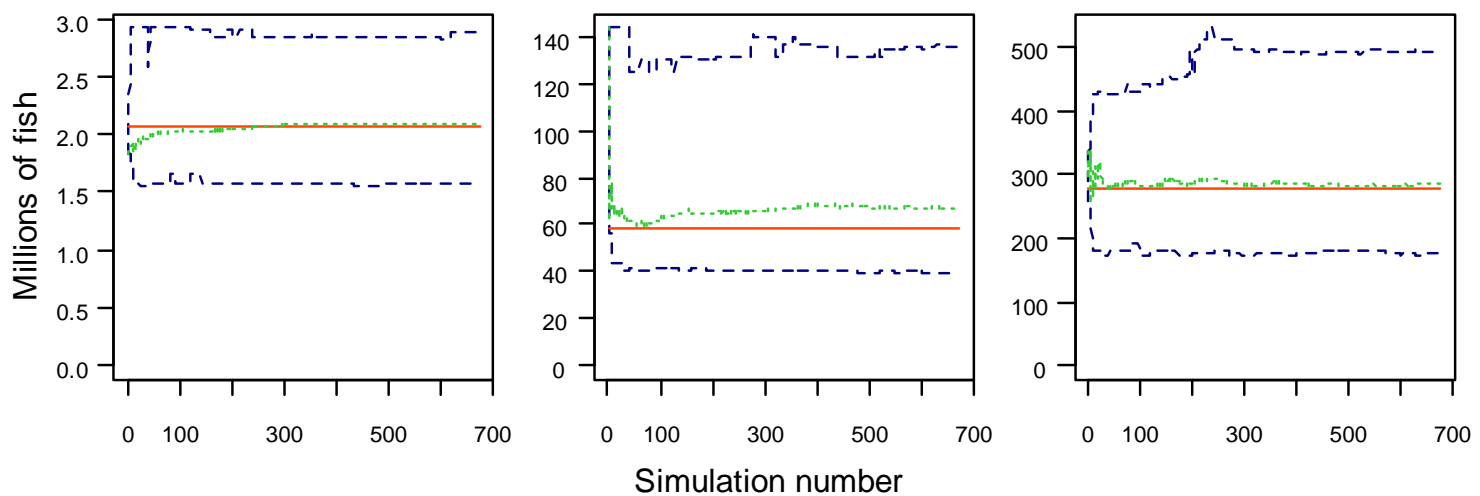

Fig. S1: Trends in the $95^{\text {th }}$ percentiles (dashed blue lines) and medians (dotted green lines) of a) total abundance, b) fully recruited fishing mortality, and c) recruitment of each species in the $17^{\text {th }}$ simulation year with increasing number of simulations. In all plots, the solid orange line represents the true parameter value. Similar trends were apparent for other simulation years. 
Age 1

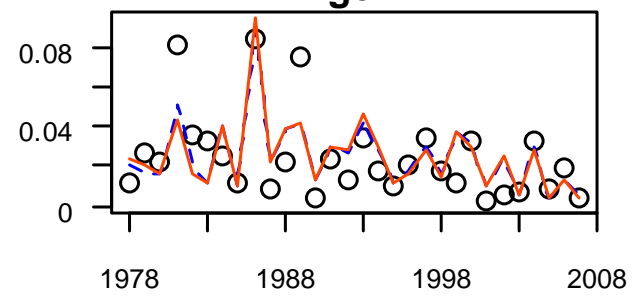

Age 2

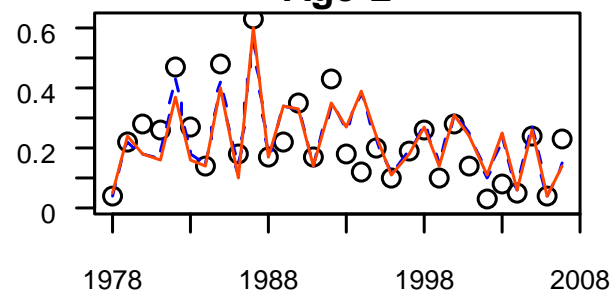

Age 3

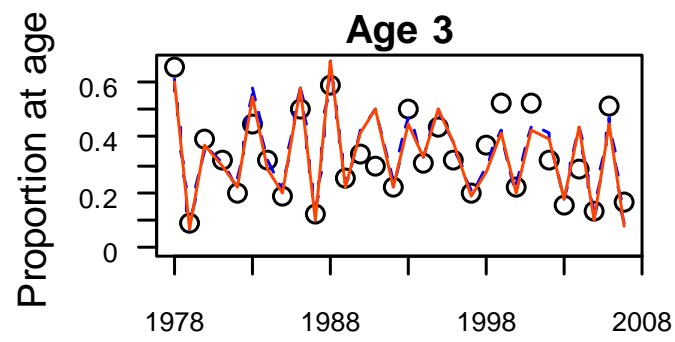

Age 4

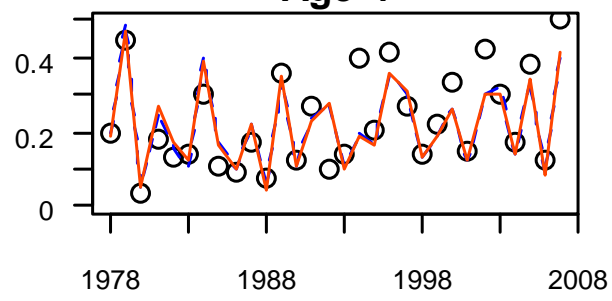

Age 5

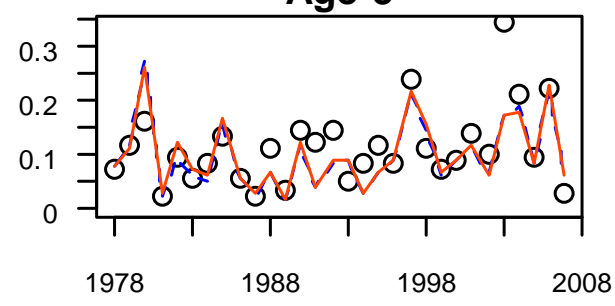

Age 6

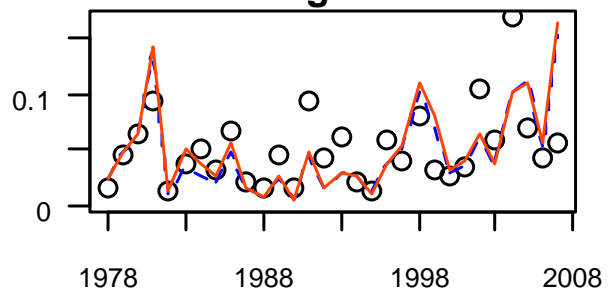

Age 7

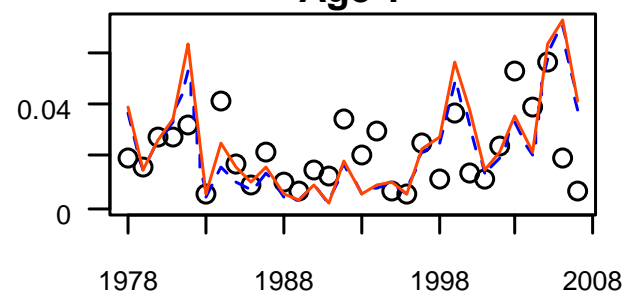

Age 8

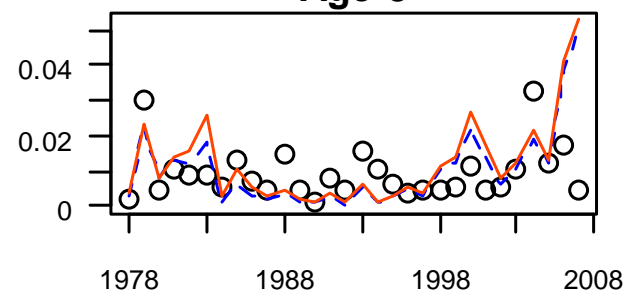

Age 9

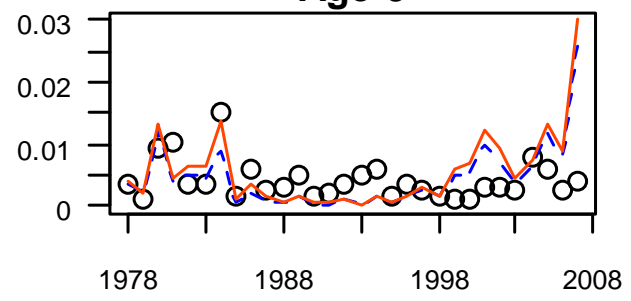

Age 10

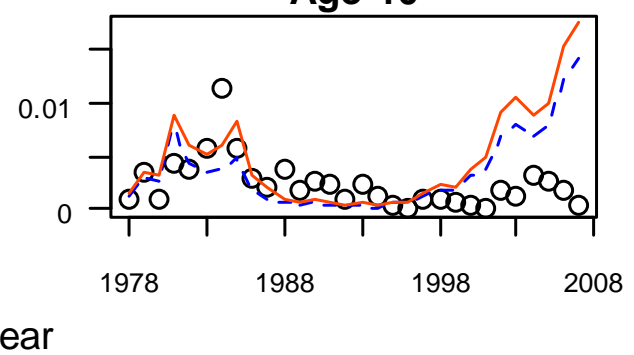

Fig. S2: Atlantic cod observed (open circles) and predicted proportions-at-age of the commercial catch from the single-species (blue dashed line) and multispecies (orange solid line) runs. 
Age 1

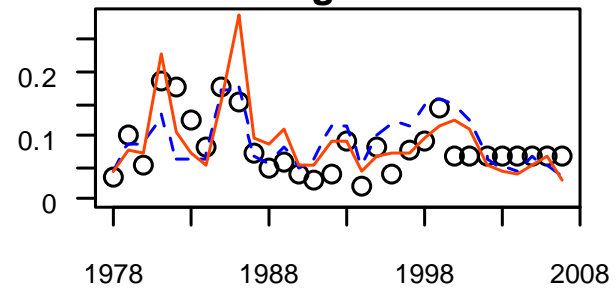

Age 2

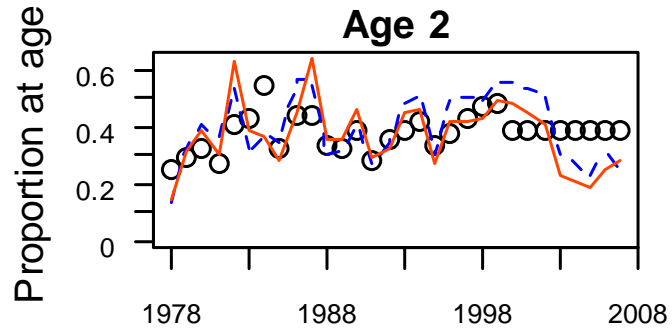

Age 3

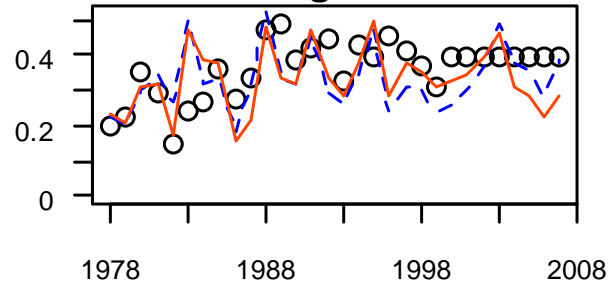

Age 4

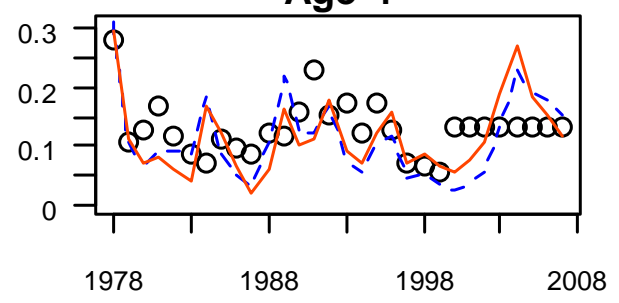

Age 5

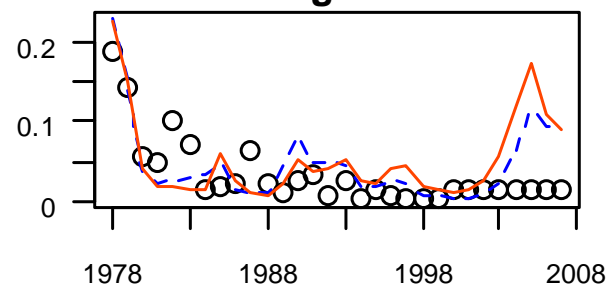

Age 6

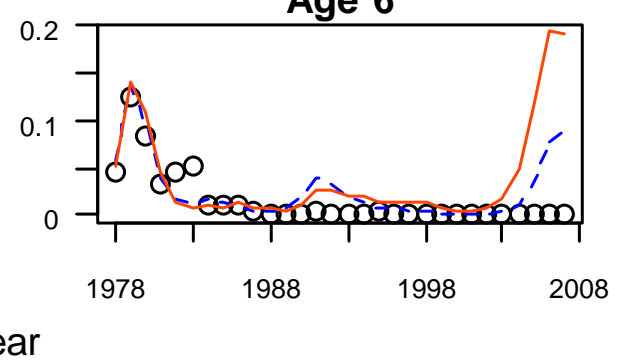

Fig. S3: Silver hake observed (open circles) and predicted proportions-at-age of the commercial catch from the single-species (blue dashed line) and multispecies (orange solid line) runs. 
Age 1

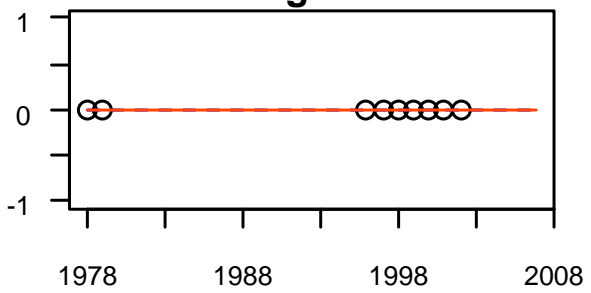

Age 2

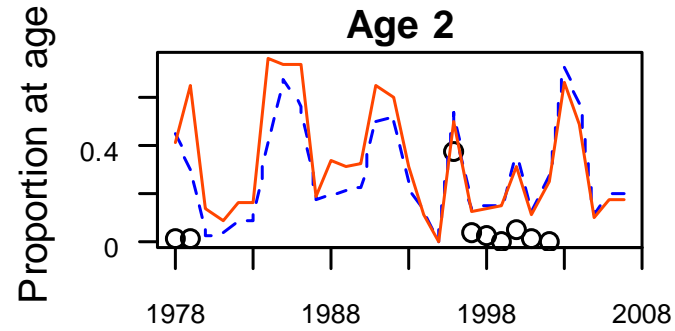

Age 3

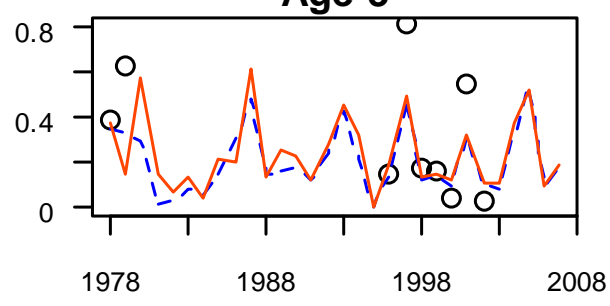

Age 4

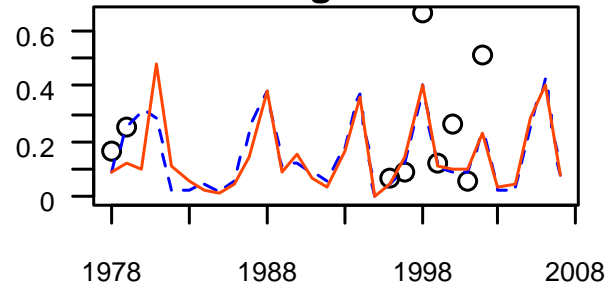

Age 5

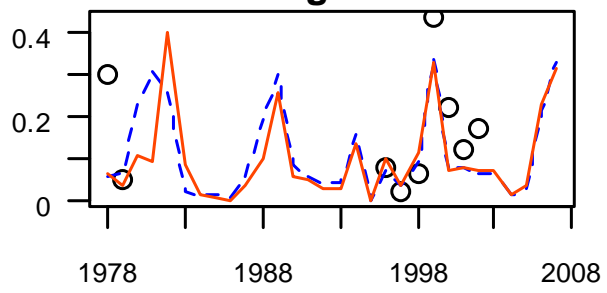

Age 6

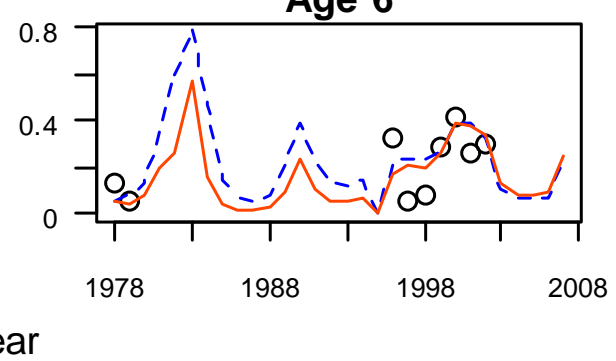

Fig. S4: Atlantic herring observed (open circles) and predicted proportions-at-age of the commercial catch from the single-species (blue dashed line) and multispecies (orange solid line) runs. 
Age 1

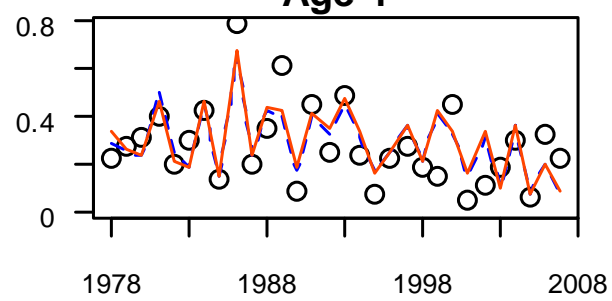

Age 2

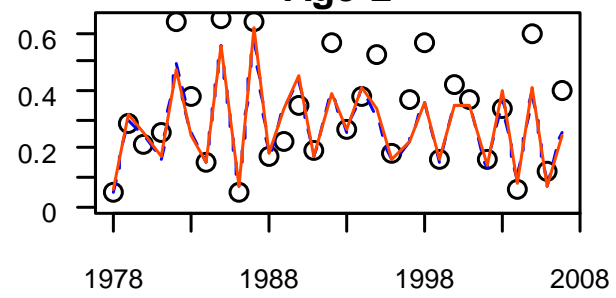

Age 3

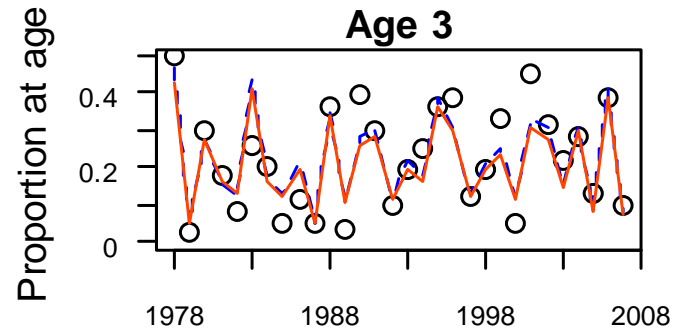

Age 4

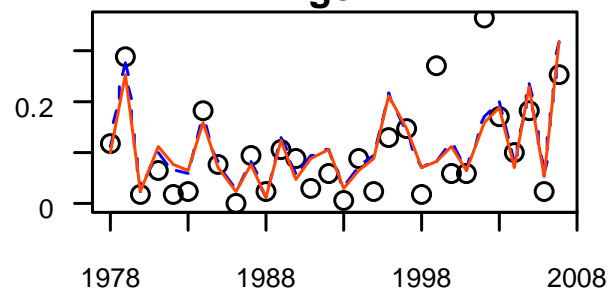

Age 5

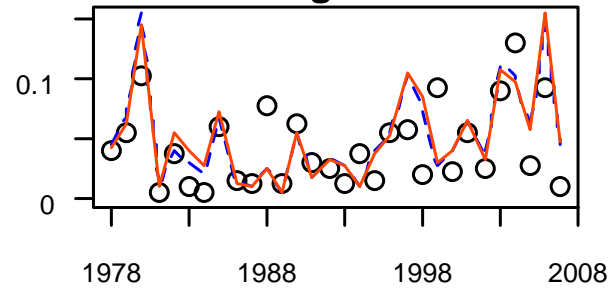

Age 6

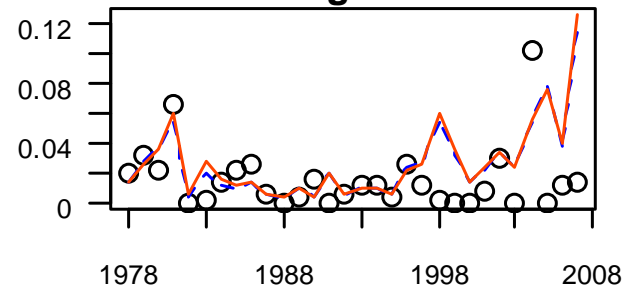

Age 7

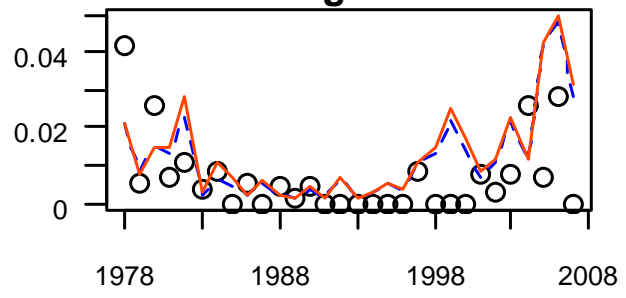

Age 8

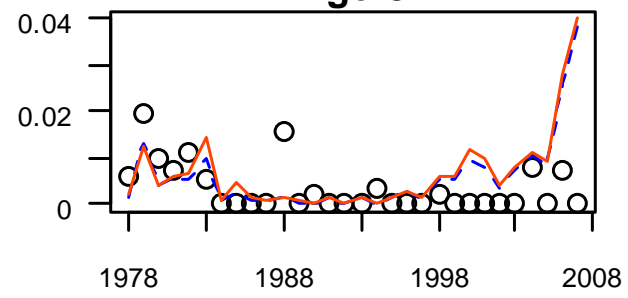

Age 9

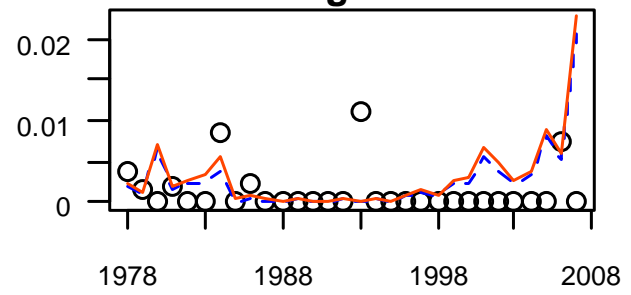

Age 10

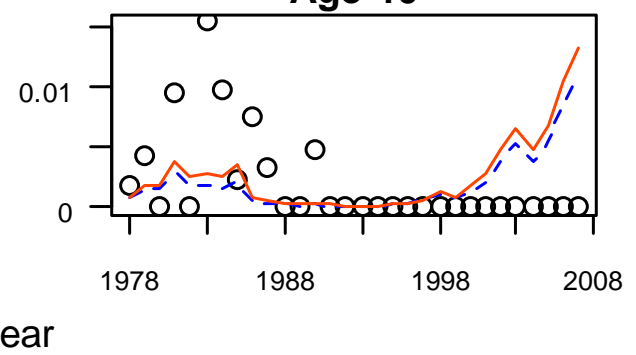

Fig. S5: Atlantic cod observed (open circles) and predicted proportions-at-age of the autumn trawl survey from the single-species (blue dashed line) and multispecies (orange solid line) runs. 
Age 1
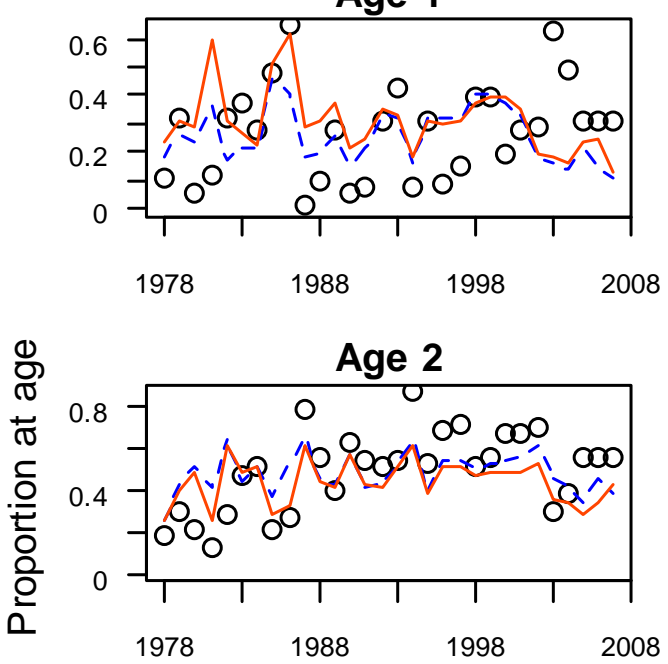

Age 3

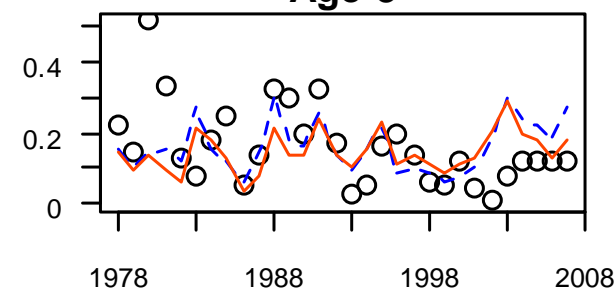

Age 4

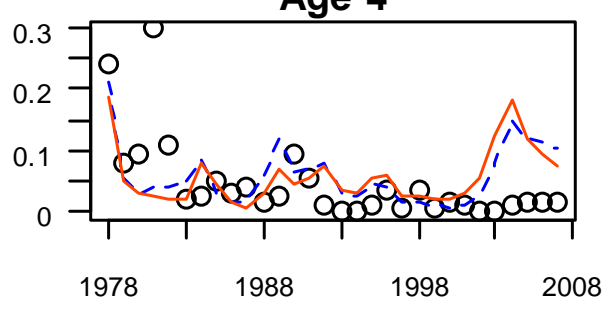

Age 5

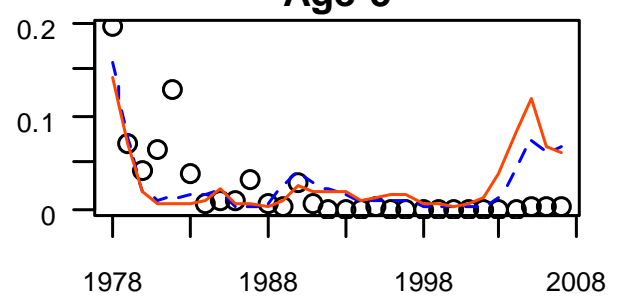

Age 6

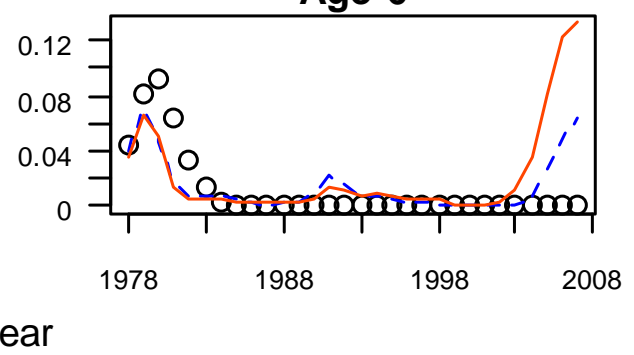

Fig. S6: Silver hake observed (open circles) and predicted proportions-at-age of the autumn trawl survey from the single-species (blue dashed line) and multispecies (orange solid line) runs. 
Age 1
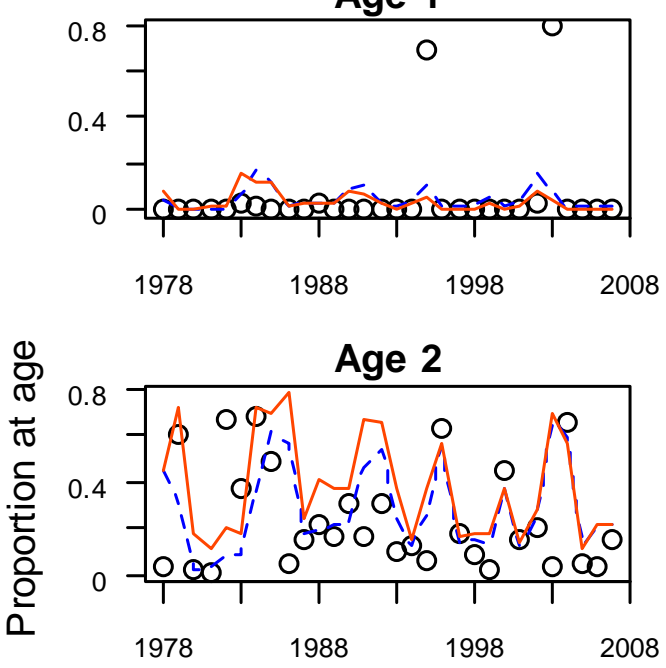

Age 3

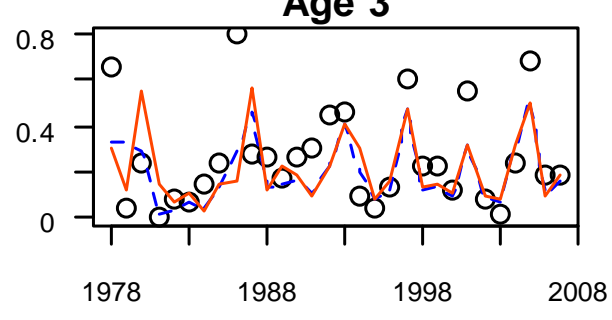

Age 4

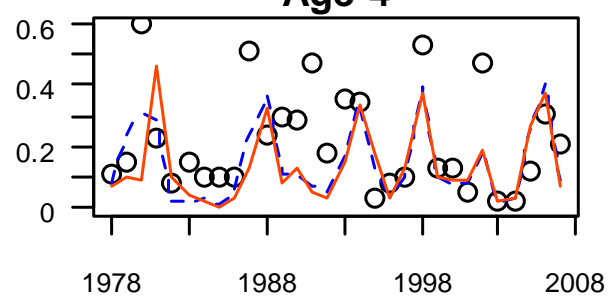

Age 5

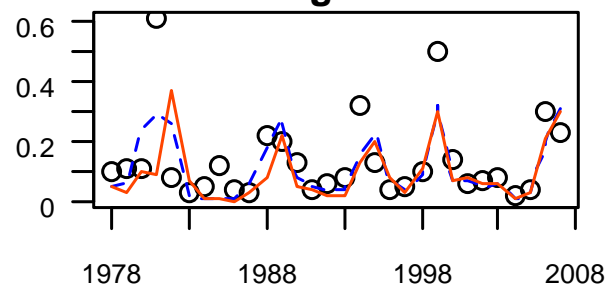

Age 6

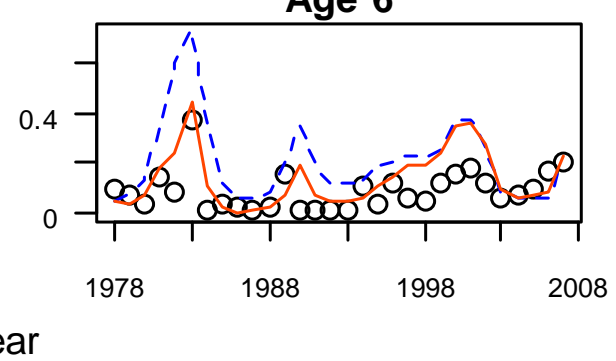

Fig. S7: Atlantic herring observed (open circles) and predicted proportions-at-age of the spring trawl survey from the single-species (blue dashed line) and multispecies (orange solid line) runs. 
a)

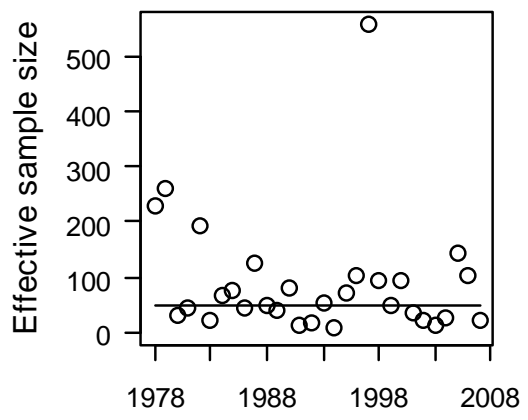

b)

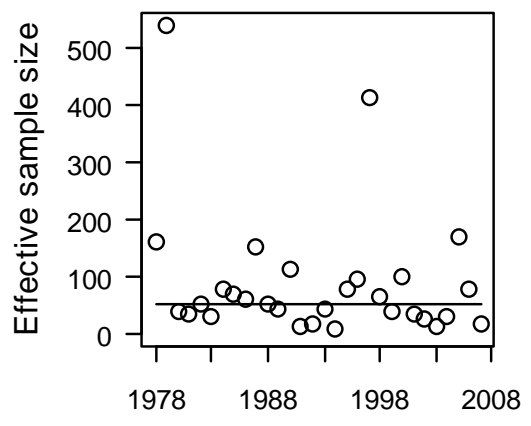

Silver hake
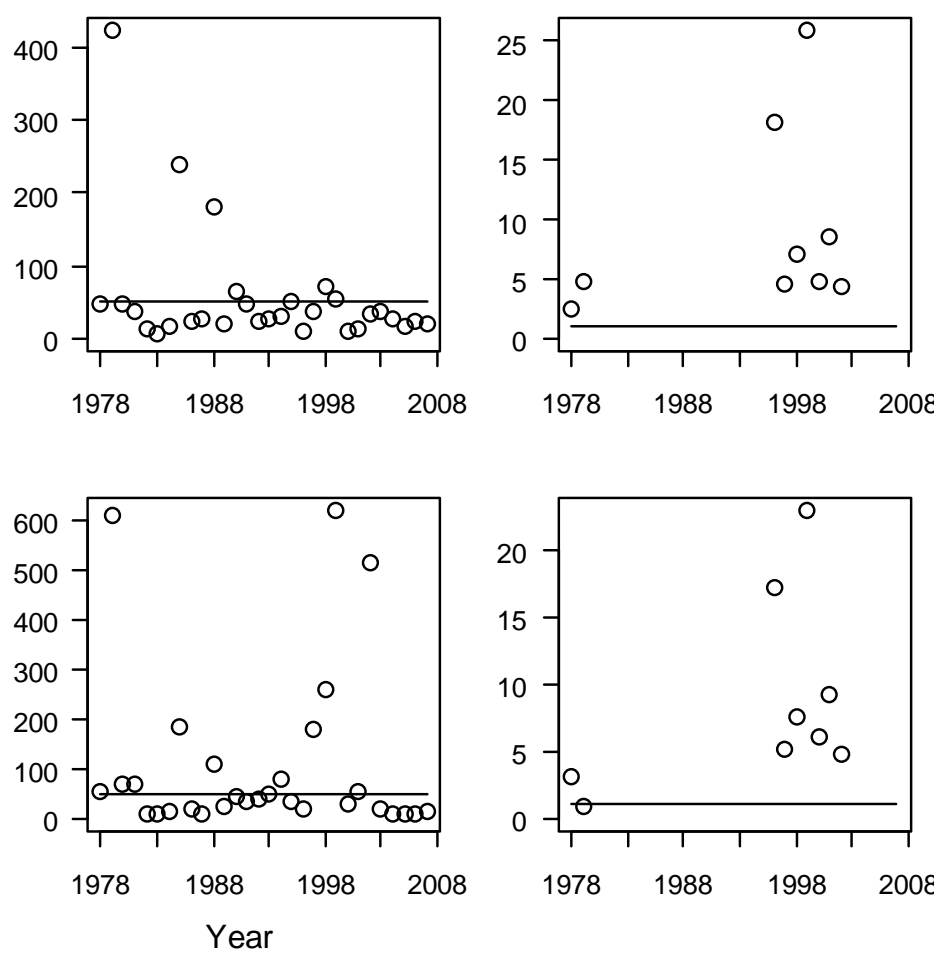

Herring

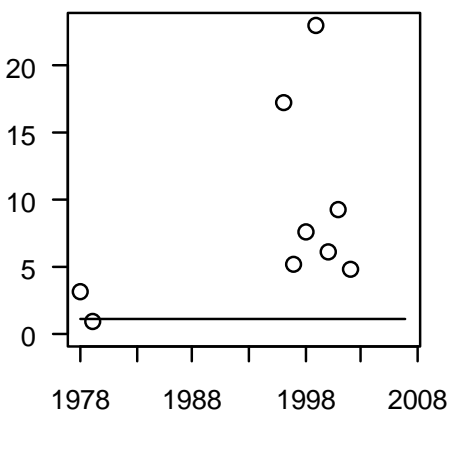

Fig. S8: Annual calculated effective sample size (open circles) for the proportions-at-age of the commercial catch in the a) single-species and b) multispecies formulations. The solid lines represent the dataset weightings used in the objective function. 
a)
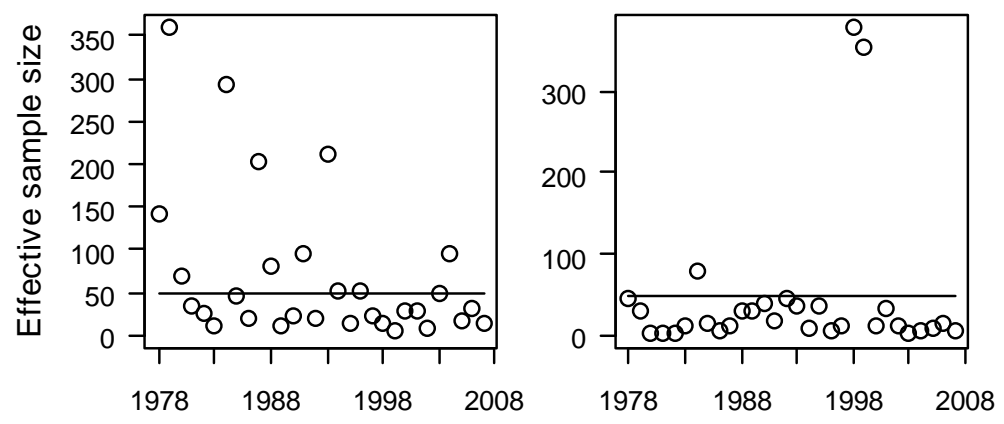

b)

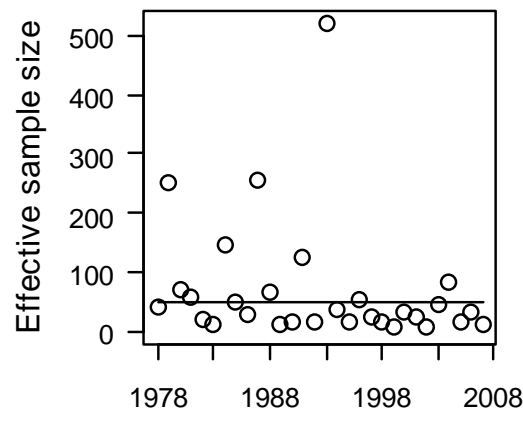

Silver hake

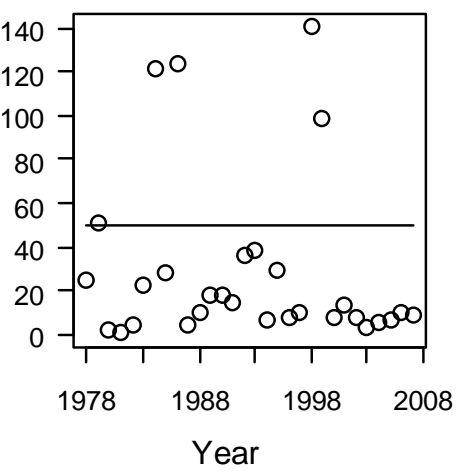

Herring
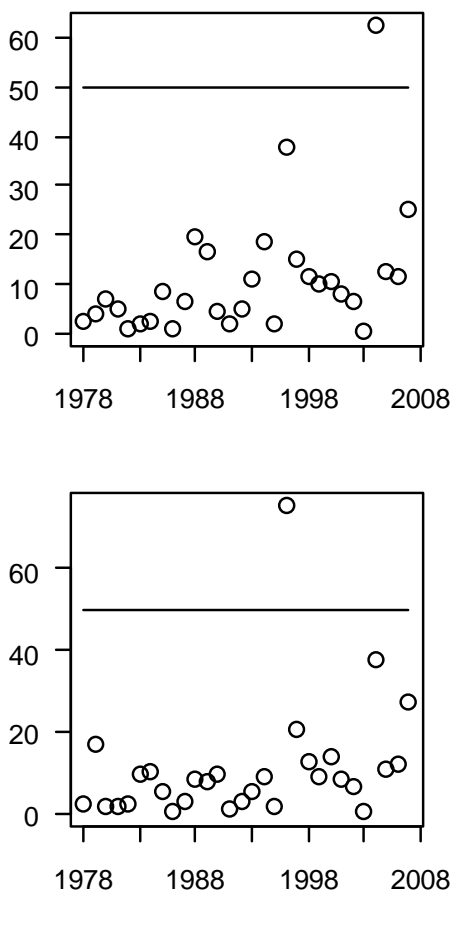

Fig. S9: Annual calculated effective sample size (open circles) for the proportions-at-age of the survey catch in the a) single-species and b) multispecies formulations. The solid lines represent the dataset weightings used in the objective function. 


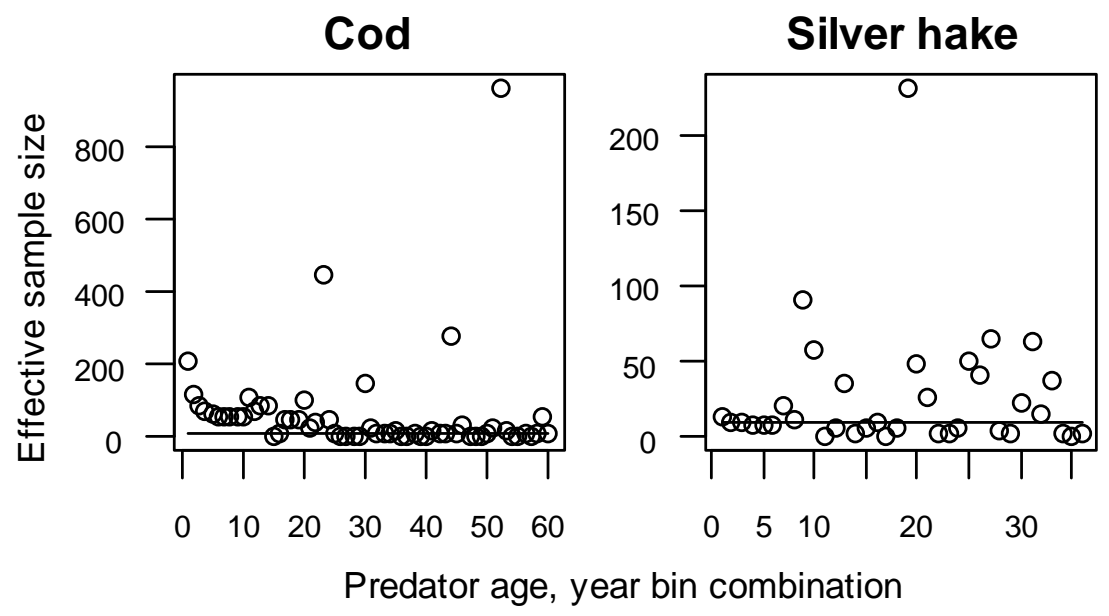

Fig. S10: Annual calculated effective sample size (open circles) for the food habits data (proportion by weight) for each predator species. The solid lines represent the dataset weightings used in the objective function. 

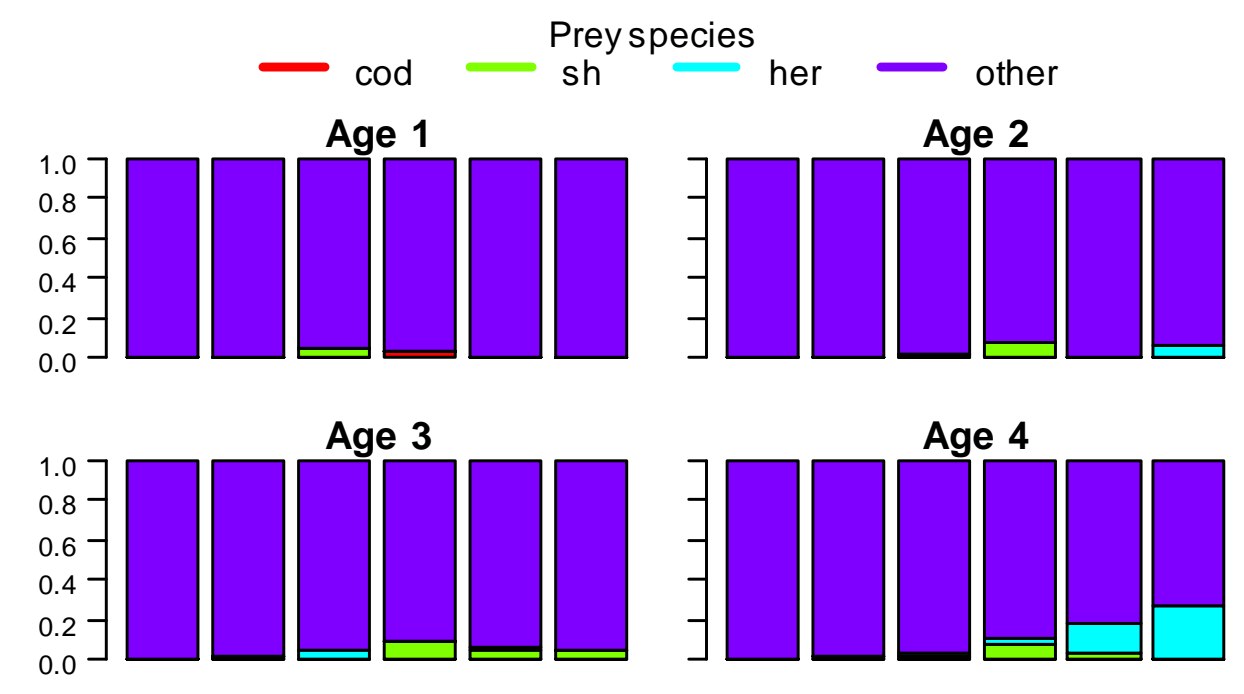

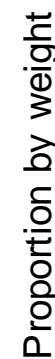

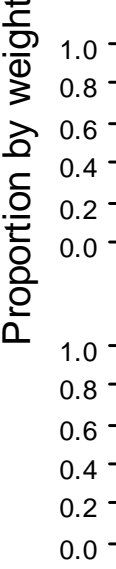

Age 5
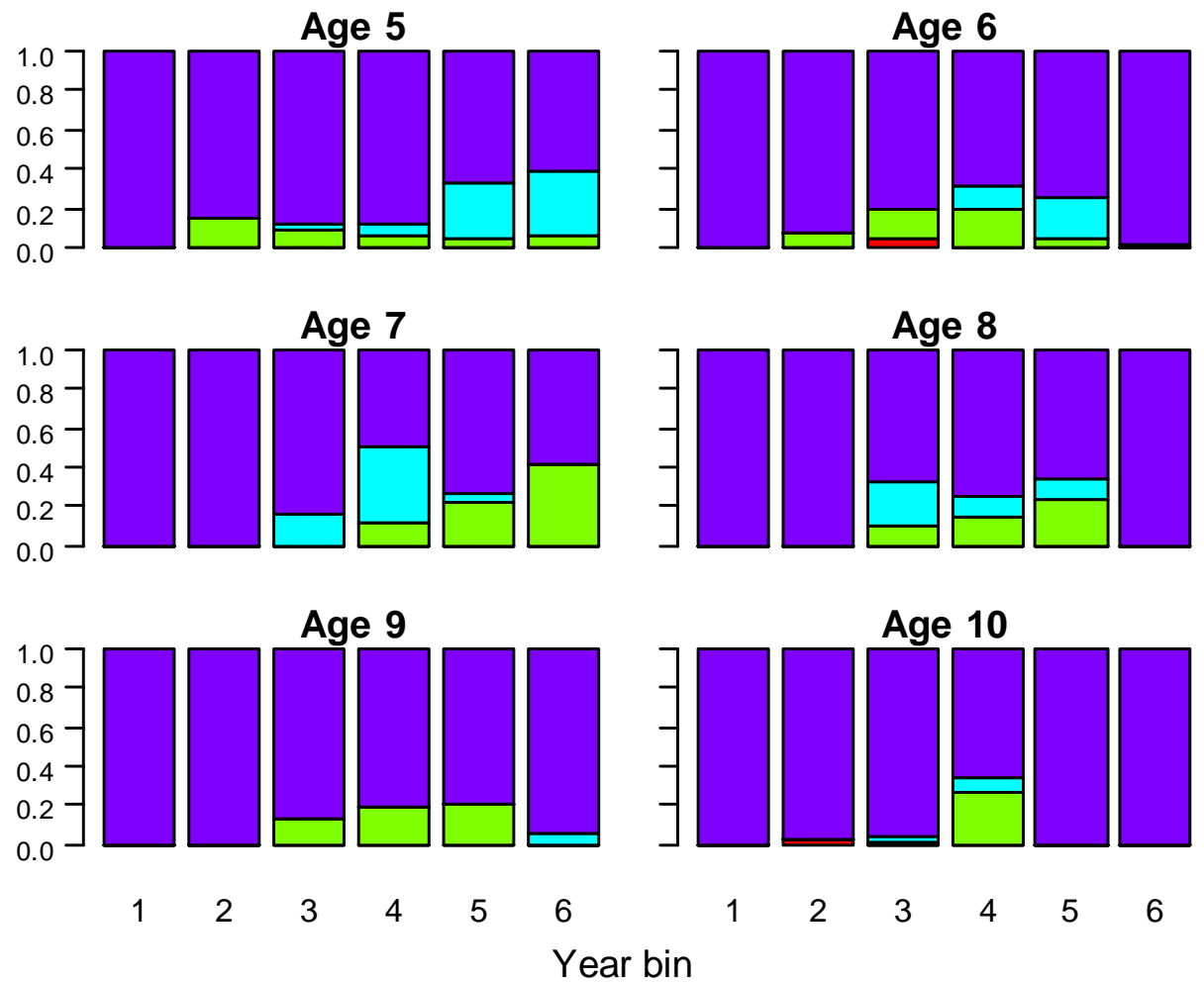

Fig. S11: Observed age-specific diet of Atlantic cod averaged over 5-year intervals, represented as the proportion by weight of a particular prey item to the total stomach content weight. Year-bins represent 1) 1978-1982, 2) 1983-1987, 3) 1988-1992, 4) 19931997, 5) 1998-2002, and 6) 2003-2007. 

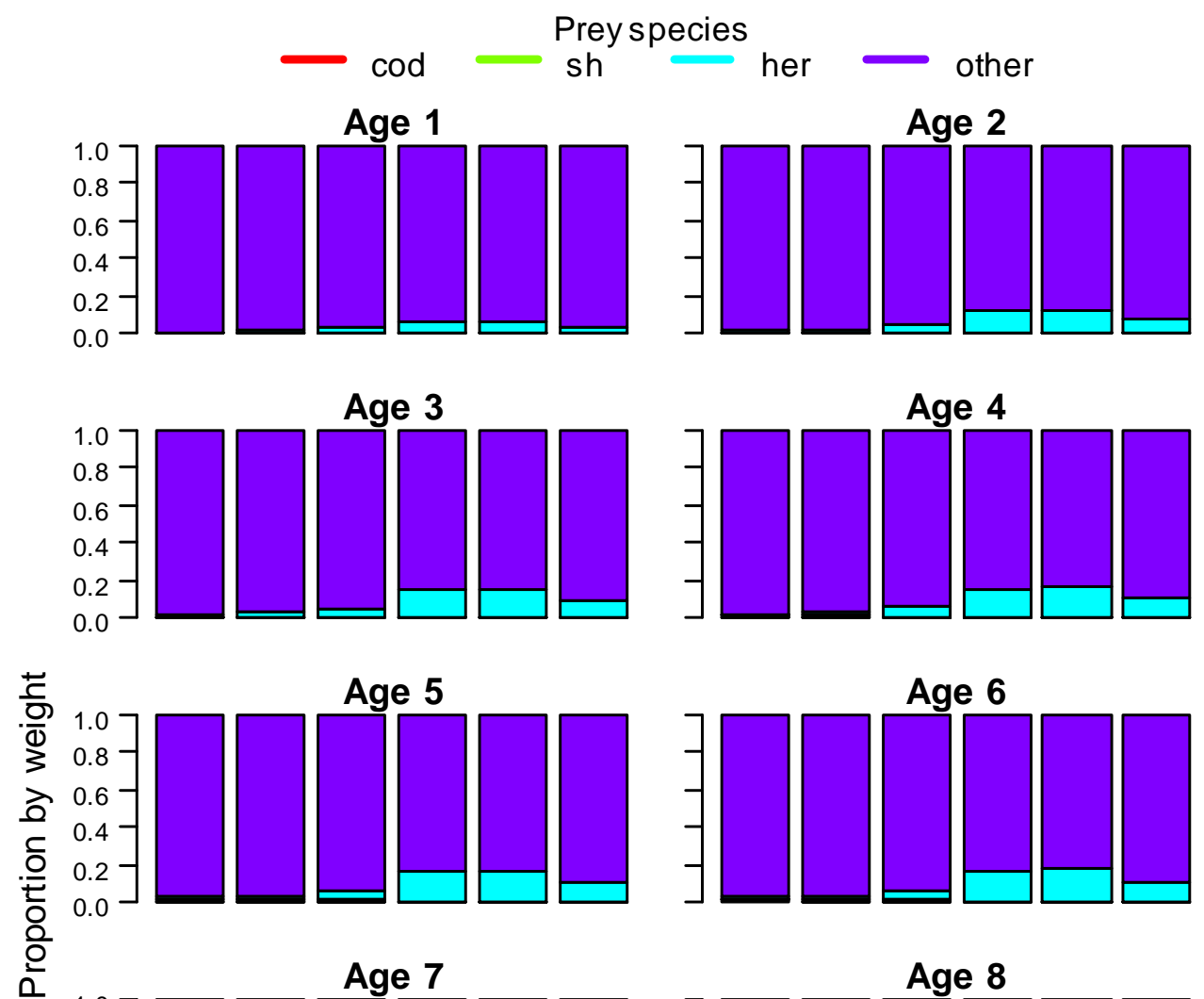

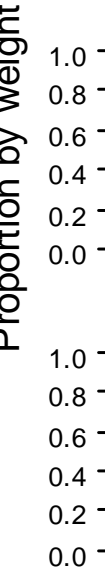

Age 5
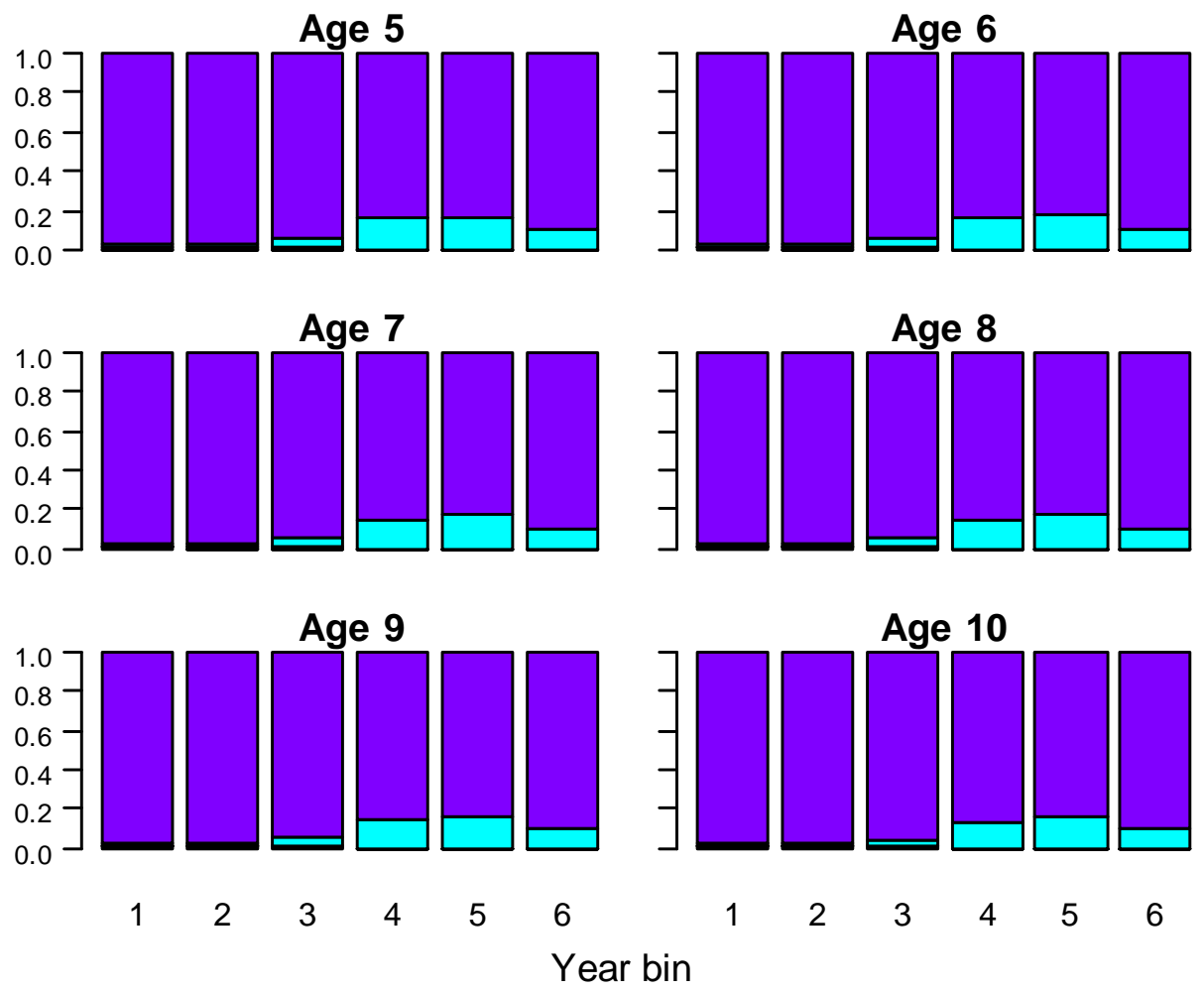

Fig. S12: Predicted age-specific diet of Atlantic cod averaged over 5-year intervals, represented as the proportion by weight of a particular prey item to the total stomach content weight. Year-bins represent 1) 1978-1982, 2) 1983-1987, 3) 1988-1992, 4) 19931997, 5) 1998-2002, and 6) 2003-2007. 


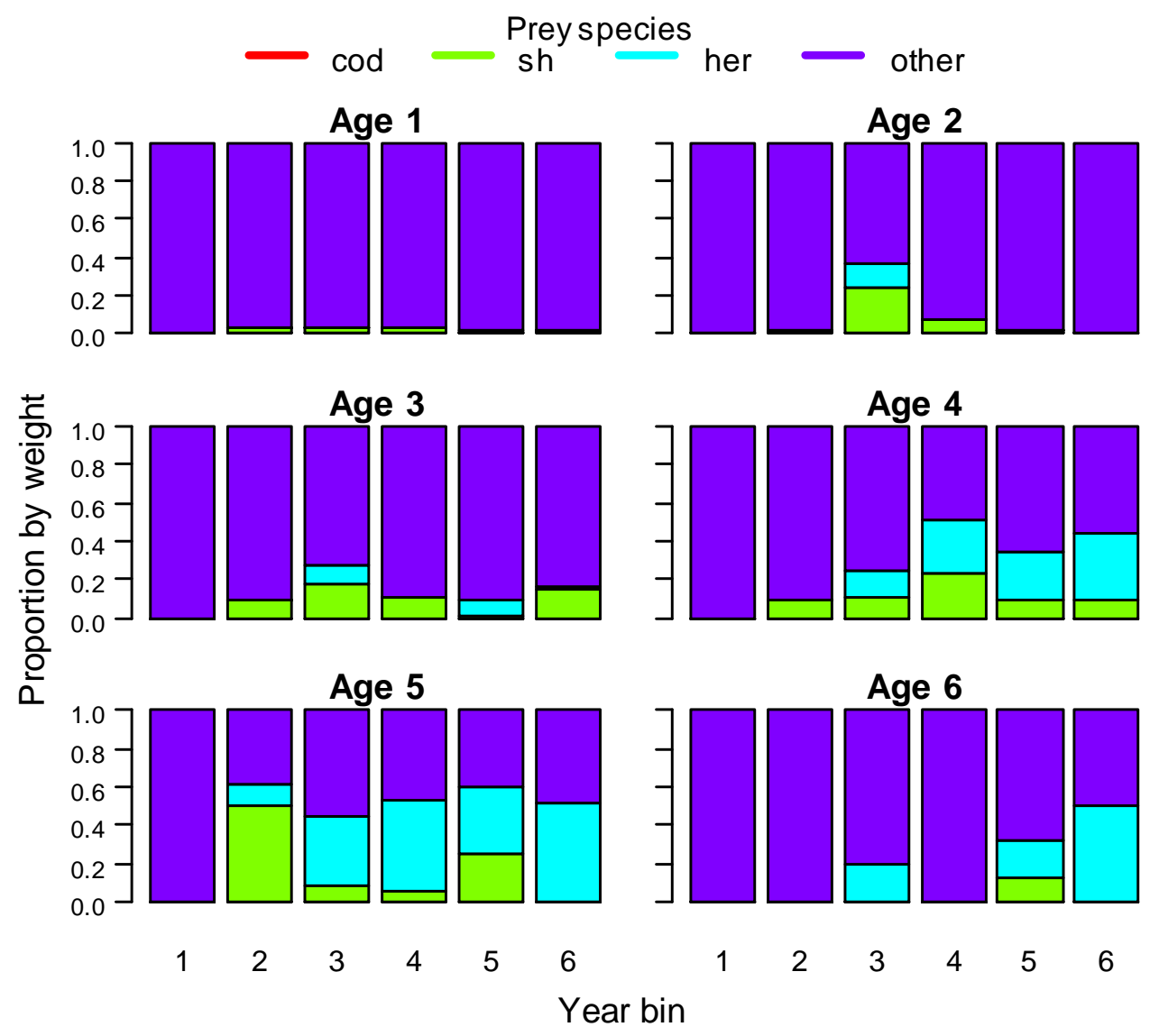

Fig. S13: Observed age-specific diet of silver hake averaged over 5-year intervals, represented as the proportion by weight of a particular prey item to the total stomach content weight. Year-bins represent 1) 1978-1982, 2) 1983-1987, 3) 1988-1992, 4) 19931997, 5) 1998-2002, and 6) 2003-2007. 


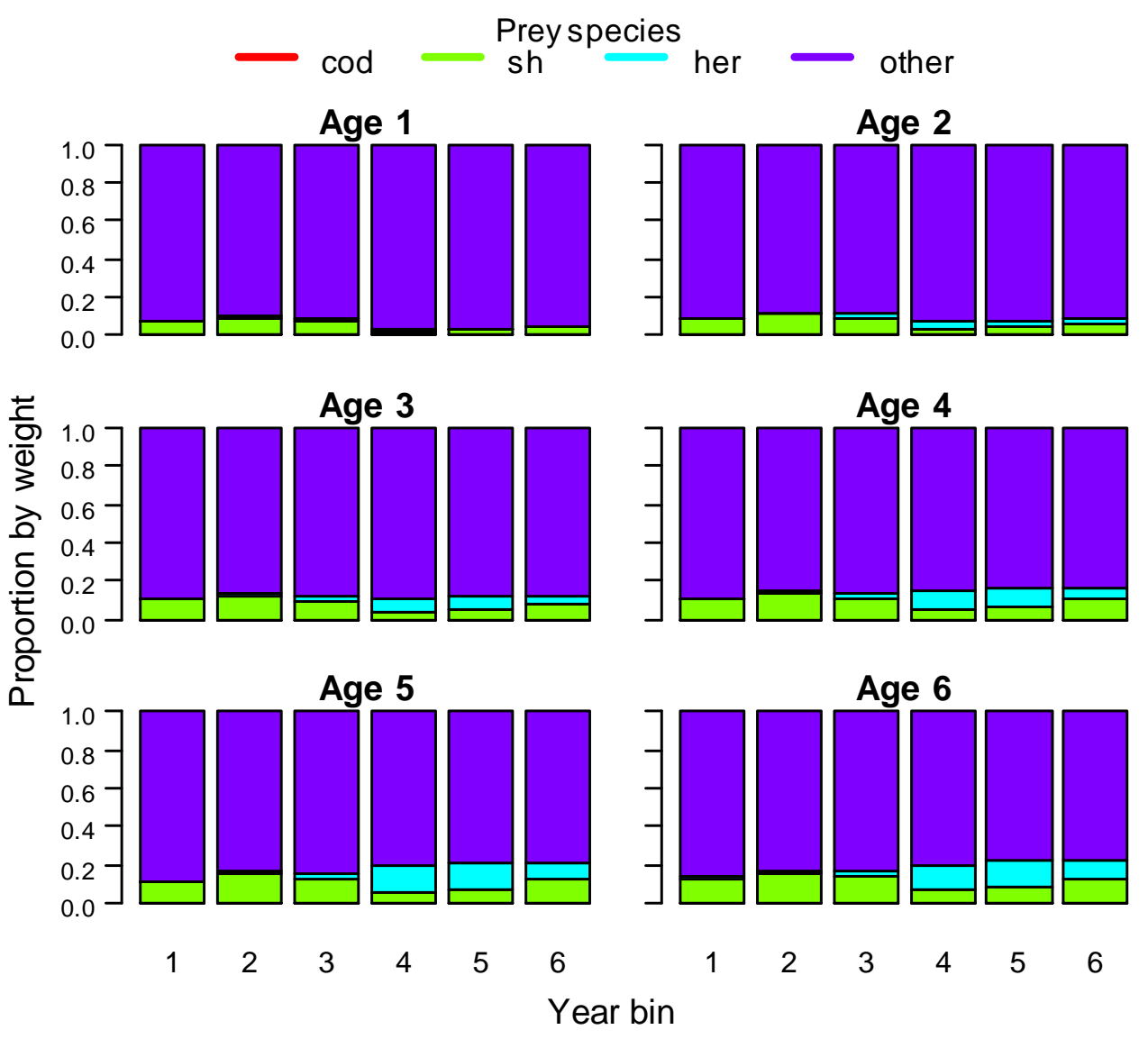

Fig. S14: Predicted age-specific diet of silver hake averaged over 5-year intervals, represented as the proportion by weight of a particular prey item to the total stomach content weight. Year-bins represent 1) 1978-1982, 2) 1983-1987, 3) 1988-1992, 4) 19931997, 5) 1998-2002, and 6) 2003-2007. 


\section{Cod}

a)

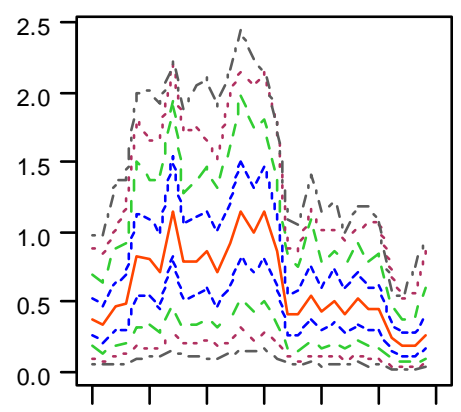

b)

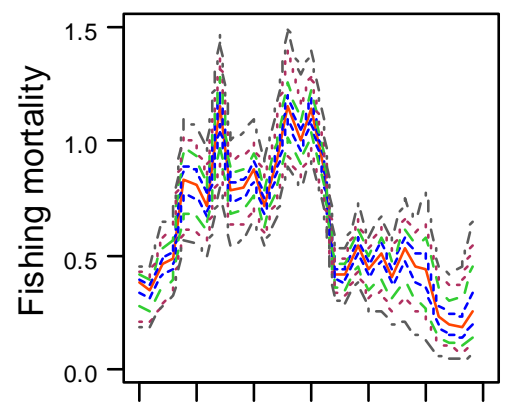

Silver hake
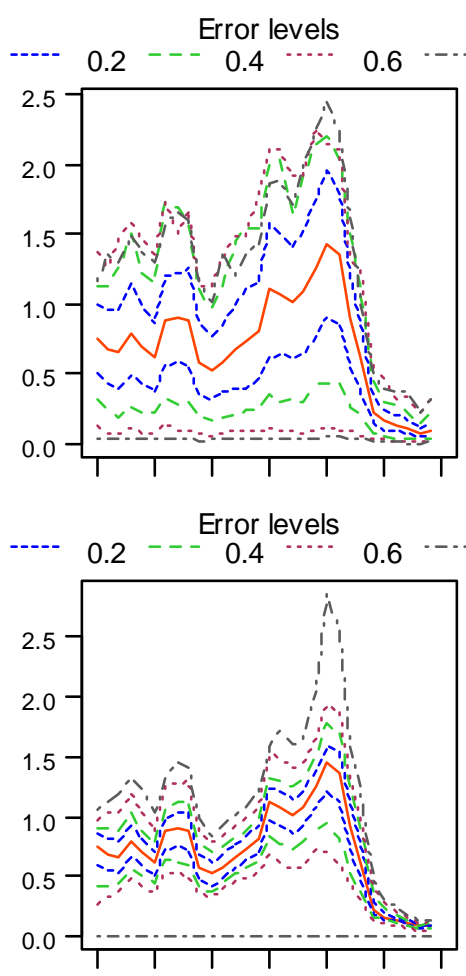

Error levels

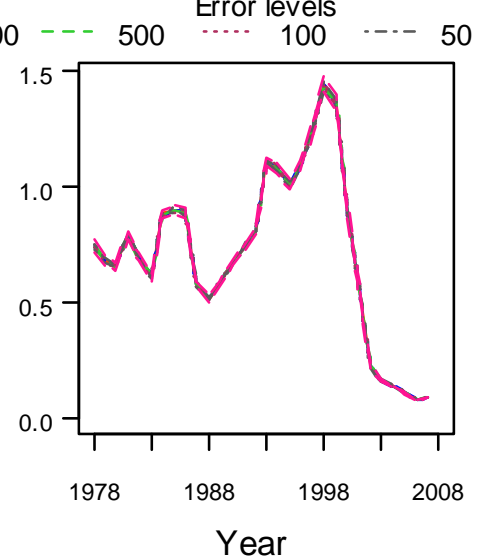

Herring
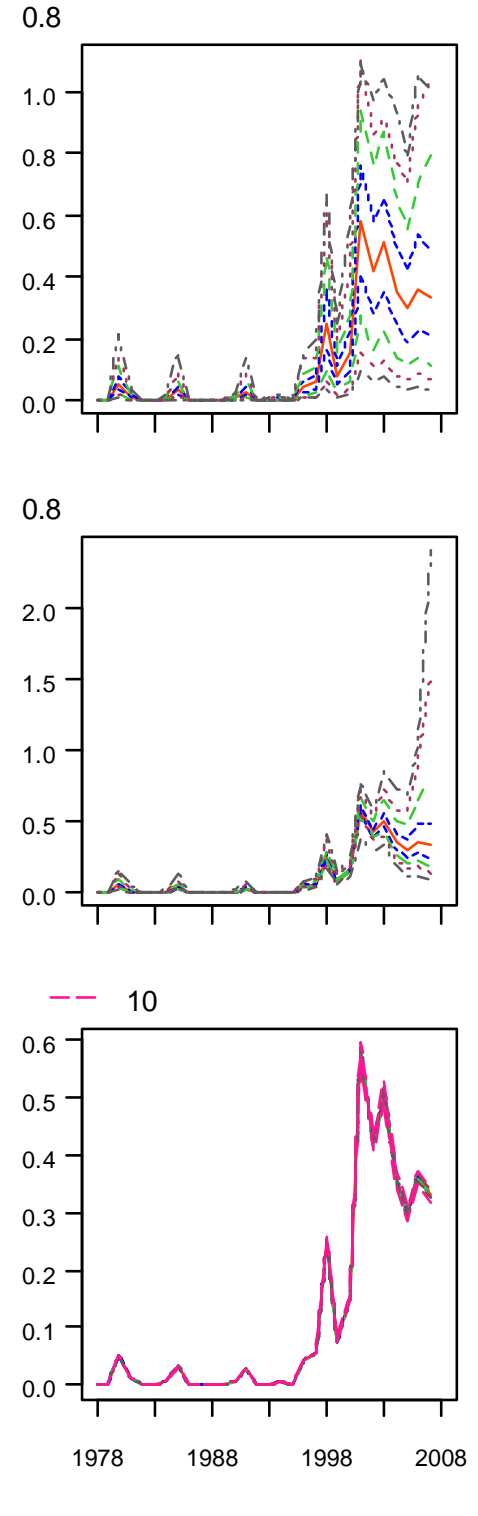

Fig. S15: 95th percentiles for estimated annual instantaneous fishing mortality when all measurement error levels were introduced into a) commercial catches, b) survey catches, and c) predator diets. For commercial and survey catches, error levels represent the standard deviations of the multiplicative errors incorporated into total annual catches. For food habits data, error levels represent the number of draws from a multinomial distribution where measurement error increases as effective sample size decreases. 
Cod

a)

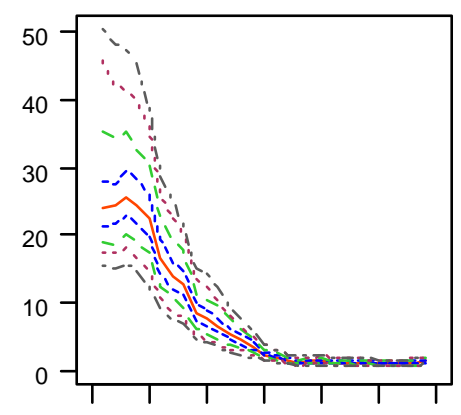

b)

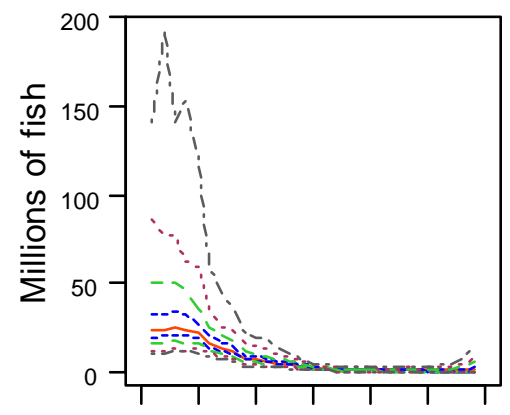

Silver hake

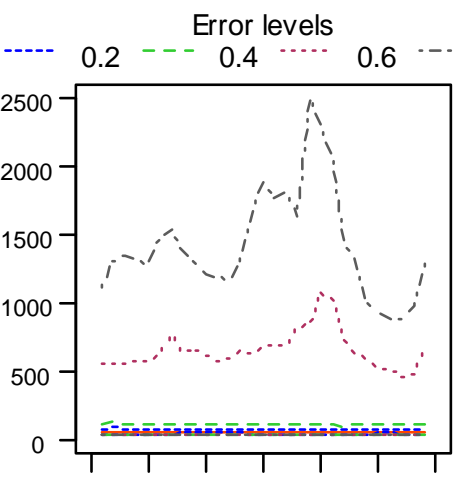

Error levels

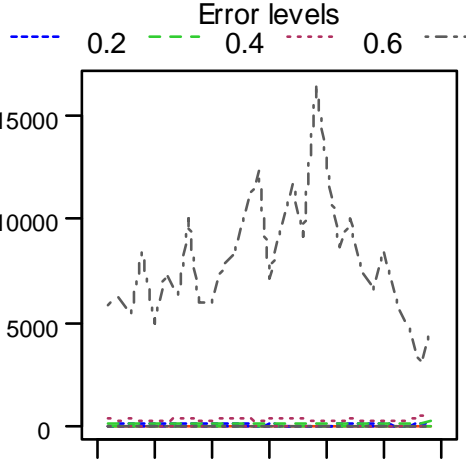

c)

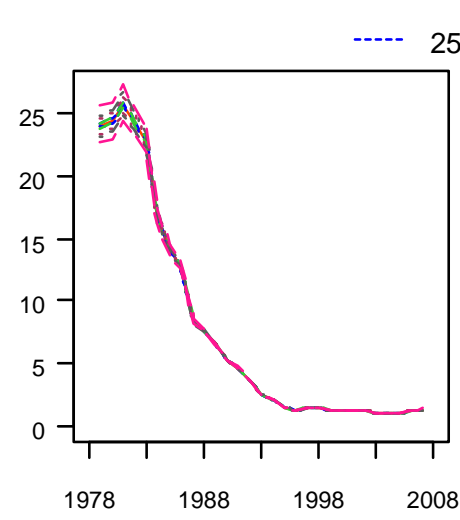

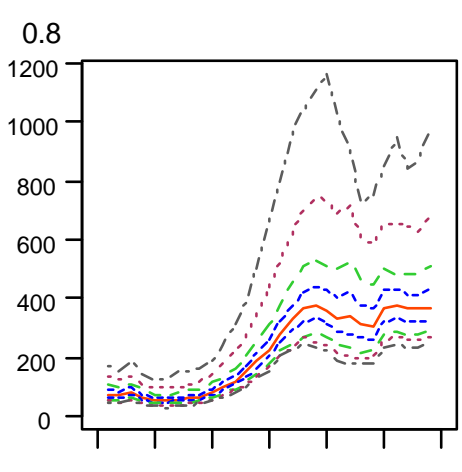

0.8

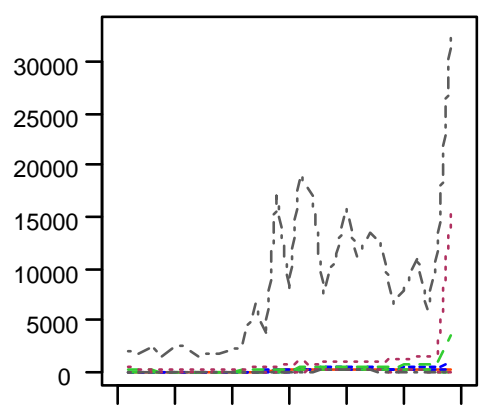

Herring

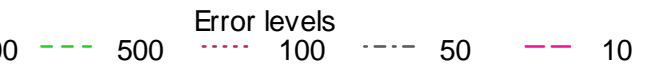
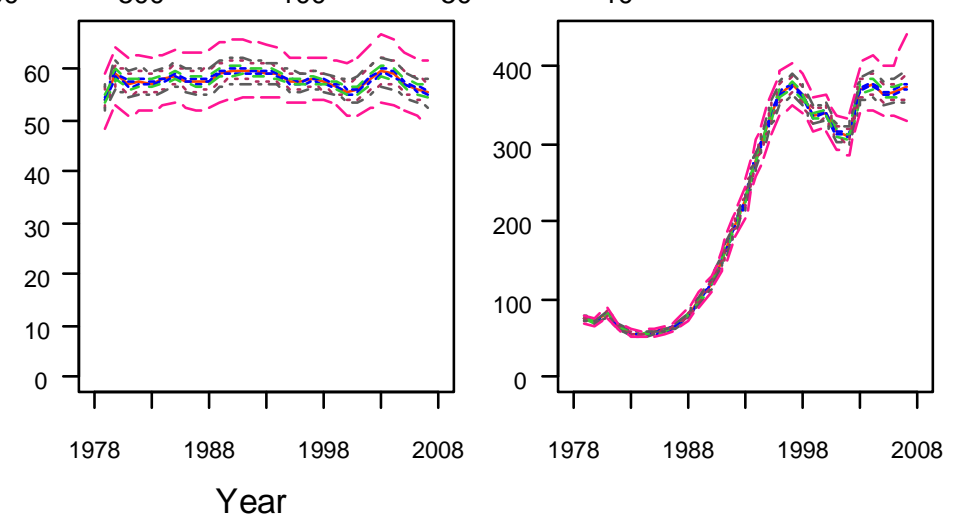

Fig. S16: 95th percentiles for estimated annual recruitment when all measurement error levels were introduced into a) commercial catches, b) survey catches, and c) predator diets. For commercial and survey catches, error levels represent the standard deviations of the multiplicative errors incorporated into total annual catches. For food habits data, error levels represent the number of draws from a multinomial distribution where measurement error increases as effective sample size decreases. 
a)

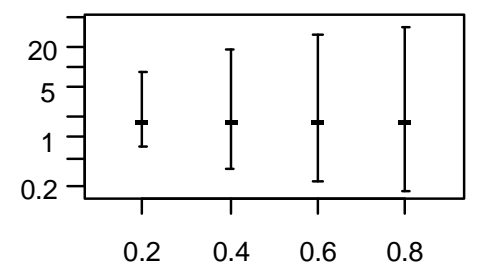

b)

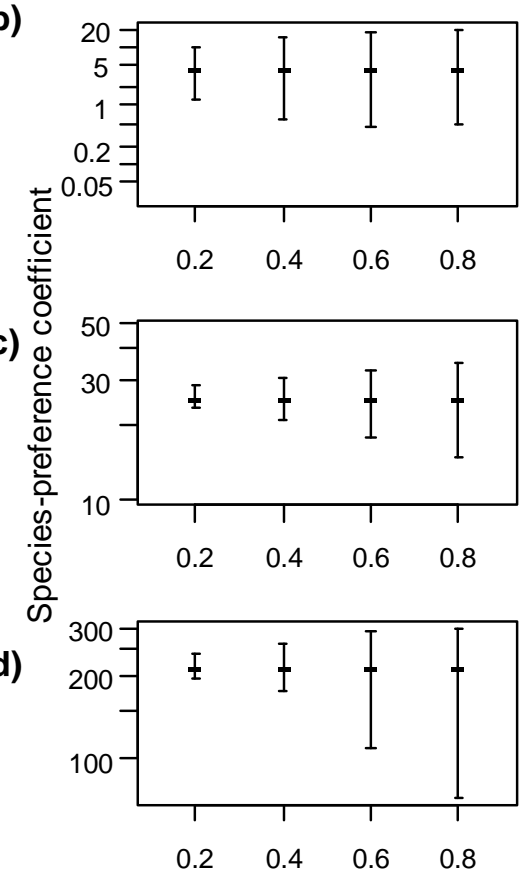

e)

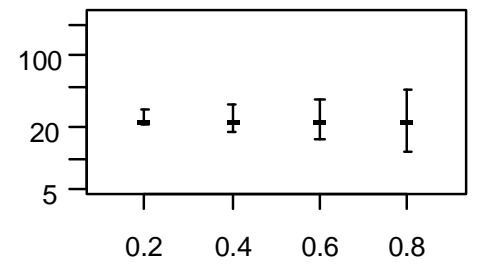

Survey catch
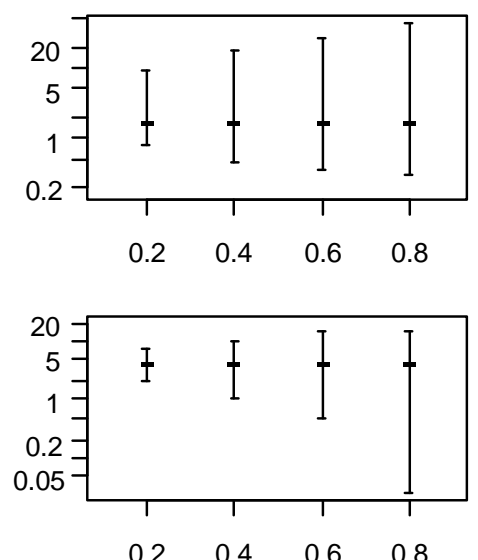

$\begin{array}{llll}0.2 & 0.4 & 0.6 & 0.8\end{array}$
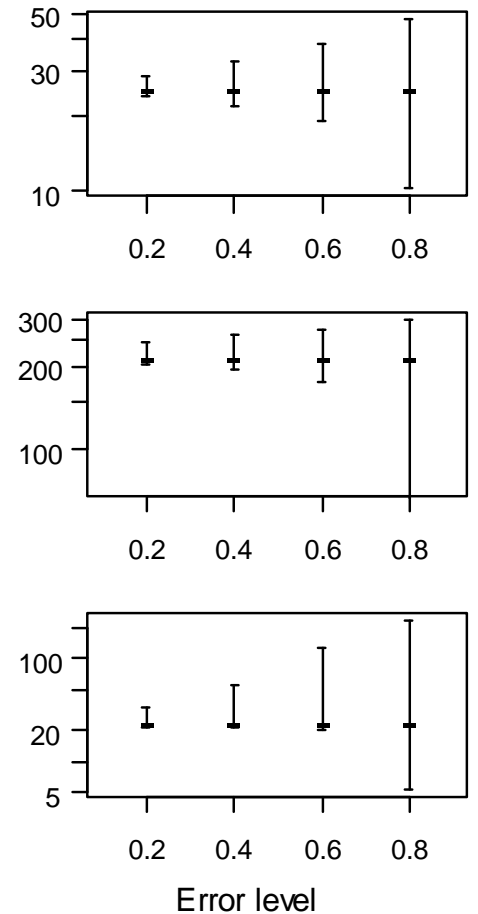

Food habits
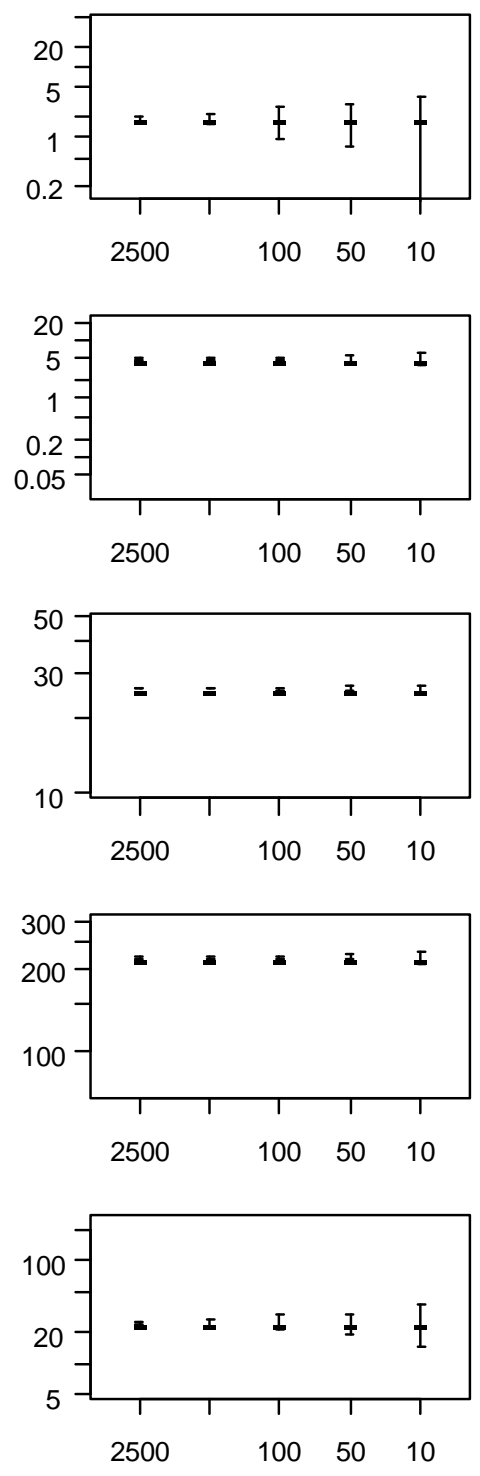

Fig. S17: 95th percentiles for estimated species preference coefficients ( $\rho$ ) for a) cod-cod, b) cod-silver hake, c) cod-herring, d) silver hake-silver hake, and e) silver hake-herring when all measurement error levels were introduced into commercial catches, survey catches, and predator diets. For commercial and survey catches, error levels represent the standard deviations of the multiplicative errors incorporated into total annual catches. For food habits data, error levels represent the number of draws from a multinomial distribution where measurement error increases as effective sample size decreases. 


\section{MANUSCRIPT - II}

Intended for submission to the ICES Journal of Marine Science

\section{Estimating species interactions among the fish species on}

\section{Georges Bank}

\section{Kiersten L. Curti and Jeremy S. Collie}

Graduate School of Oceanography; University of Rhode Island; 215 South Ferry

Road; Narragansett, RI 02882 USA

\section{Christopher M. Legault and Jason S. Link}

National Marine Fisheries Service, Northeast Fisheries Science Center; 166 Water

Street; Woods Hole, MA 02543 USA 


\begin{abstract}
Georges Bank, a productive and historically important fishing ground within the Northeast U.S. Continental Shelf (NEUS) ecosystem, has undergone extensive changes in community dynamics and ecosystem structure over the last half of a century. Due to these changes as well as evidence for ecosystem overfishing and sequential depletion of resources within the NEUS, there has been considerable movement towards an ecosystem approach to fisheries. Here we apply a multispecies, statistical catch-at-age model to nine fish species within the Georges Bank ecosystem. While sensitivity to dataset weights and initial parameter estimates was apparent, we statistically estimated both the magnitude and temporal trends in predation mortality rates experienced by prey species. Predation mortality rates varied over both time and age. Mackerel, herring and silver hake experienced the greatest mortalities due to predation, with maximum predation mortality rates of 0.62 for mackerel, 1.01 for herring and 1.58 for silver hake. For these species, losses due to predation generally exceeded annual landings. Goosefish was the most dominant predator, followed by cod and silver hake, and consumption of modeled fish generally followed patterns in prey abundance. This work further demonstrates the strong impact of predation on Georges Bank fish community dynamics and provides a tool for statistically estimating the mortality due to predation.
\end{abstract}

\title{
KEYWORDS
}

multispecies statistical catch-at-age model, predation mortality, Georges Bank 


\section{INTRODUCTION}

Over the last half of a century, Georges Bank, a historically important fishing ground off the U.S. east coast, has experienced marked changes in ecosystem structure. Perhaps most notably, the ecosystem has exhibited a shift from a community dominated by groundfish and other finish to one dominated by small pelagic and elasmobranch species (Fogarty and Murawski 1998, Link and Garrison 2002a, Methratta and Link 2006, Frisk et al. 2008). Fishing is generally recognized as the largest contributing factor to the observed changes in species composition, in particular strong pressure by the distant water fleets of the 1960's-1970's and the subsequent expansion of the domestic fleet after the establishment of the 200-mile exclusive economic zone (Fogarty and Murawski 1998, Link et al. 2002, Link et al. 2011).

Concurrent with the shift in species composition, the Northeast U.S. Continental Shelf (NEUS) has experienced profound changes in several ecosystem metrics. These changes include an increase in the pelagic-to-demersal fish ratio, an increase in the ratio of planktivores and benthivores to piscivores and shrimp/fish feeders, indicating a shift toward lower trophic levels, and declines in the average length of fish (EcoAP 2009). Since the 1970's, average trophic level of the landings from the northwest Atlantic has exhibited a steep decline (Pauly et al. 1998, EcoAP 2009), though recent work has demonstrated the trophic level of the landings is not necessarily indicative of the trophic level of the ecosystem (Branch et al. 2010). According to several ecosystem indicators and metrics, the NEUS Large Marine Ecosystem is experiencing ecosystem overfishing and likely sequential depletion of resources (Murawski 2000, Methratta and Link 2006, 
Link 2007, Coll et al. 2008, EcoAP 2009). Georges Bank is one of four subsystems comprising the NEUS ecosystem (Sherman et al. 2004).

The observed shifts in species composition and ecosystem metrics may indicate significant changes in marine food web structures (Pauly et al. 1998, Link and Garrison 2002a, Coll et al. 2008). As a result of these trends, there has been considerable movement towards an ecosystem approach to fisheries. At the national level, section 406 of the 2007 reauthorization of the Magnuson-Stevens Fishery Conservation and Management Act (Public Law 94-265) encourages the expansion of the application of ecosystem principles in fisheries management. Furthermore, through the recently passed National Ocean Policy, a national approach incorporating an ecosystem-based framework has been initiated (Lubchenco and Sutley 2010). At the regional level, the New England Fishery Management Council is planning to develop a fishery ecosystem plan to address broader ecosystem considerations (SSC NEFMC 2010). To meet these goals, additional tools are needed to examine food-web structures and species interactions with the same statistical rigor as those models currently used to inform fisheries management.

Fishing can profoundly alter the trophic structure and energy flow of an ecosystem through removal of a predator, prey or competitor species (Pauly et al. 1998, Link and Garrison 2002a, Bundy et al. 2009). Accordingly, an ecosystem approach to management requires an increased emphasis on diversity, variability and species interactions (Murawski 2000). In marine ecosystems, piscivory is often the largest removal of fish production (Bax 1998, Overholtz and Link 2007, Tyrrell et al. 2008). An investigation of the fate of fish biomass in six marine ecosystems indicated that the primary source of mortality in all systems was predation by fish (Bax 1991). On Georges 
Bank, the annual losses due to piscivory were seven times greater than those due to fishing (Bax 1991). Furthermore, recent network models of four regions within the NEUS, including Georges Bank, indicated that the proportion of mortality due to predation was greater than that due to fishing for both small pelagic and demersal fish groups (Link et al. 2008b).

Multiple studies have further demonstrated that predation is a dominant source of mortality on Georges Bank. A Multispecies Virtual Population Analysis (MSVPA) model incorporating eight Georges Bank fish species indicated the biomass of prey consumed was of the same order of magnitude or greater than commercial catch, signifying that predation is strong enough to impact prey population dynamics (Tsou and Collie 2001a). In particular, predation was significant and variable enough to modify year class size, although the age at which predation was most dominant varied across prey species (Tsou and Collie 2001b). Additional studies in the northwest Atlantic have demonstrated that the magnitude and variation in predation mortality is enough to impact the population dynamics of prey species (Overholtz et al. 2008, Moustahfid et al. 2009a, Moustahfid et al. 2009b). An expanded MSVPA of the NEUS Continental Shelf illustrated that the annual biomass consumed of two forage species (herring and mackerel) was three to five times greater than their landings (Tyrrell et al. 2008). The average predation mortality rates experienced by mackerel and herring were more than three and five times, respectively, greater than the traditionally assumed total natural mortality rate of 0.2 (Tyrrell et al. 2008). Together these studies signify that predation is strong enough to impact prey population dynamics on Georges Bank and is potentially of greater influence than commercial fisheries. Yet while these studies demonstrate the 
marked influence of predation, they do not incorporate multiple interacting species within a modeling framework that can explicitly address stochasticity and uncertainty in parameter estimates. Multispecies statistical catch-at-age models account for observation errors in input datasets through the statistical estimation of model parameters and provide a more rigorous tool for estimating trophic interactions among multiple species.

The goal of this work was to expand the multispecies statistical catch-at-age model, developed and tested in Chapter 1, to include nine species within the Georges Bank fish community. Modeled species were selected because of their documented importance within the Georges Bank ecosystem and because abundance data were available. With this model, we will quantify the predation mortality rates experienced by prey species, examine both the magnitude and temporal trends, and compare these estimates to those of past multispecies modeling efforts. The results will indicate the role of predation mortality in regulating the population dynamics of prey species. The magnitude of predation mortality rates will provide insight into the magnitude of the natural mortality rates that should be assumed in single-species models. Furthermore, if estimated predation mortality rates exhibit strong temporal variation, assuming a time-invariant natural mortality rate in single-species models may be inappropriate.

\section{METHODS}

\section{Model overview}

The multispecies catch-at-age model included nine fish species representing important predators and/or prey on Georges Bank. Species' roles as predator and prey were assessed through either their abundance and level of piscivory or their proportion in 
predator diets. Modeled predator species included Atlantic cod (Gadus morhua), silver hake (Merluccius bilinearis), goosefish (Lophius americanus), pollock (Pollachius virens), white hake (Urophycis tenuis), spiny dogfish (Squalus acanthias), and winter skate (Raja ocellata); modeled prey species included Atlantic cod, silver hake, Atlantic herring (Clupea harengus), Atlantic mackerel (Scomber scombrus) and white hake. The trophic interactions between these nine species (Figure 1) were informed by the Northeast Fisheries Science Center (NEFSC) food-habits database (Link and Almeida 2000).

The model used in this manuscript was evaluated and fully detailed in Chapter 1. In brief, total natural mortality was partitioned into the mortality due to predation and residual natural mortality, such that total mortality was quantified as the sum of fishing, predation and residual natural mortality rates. Final assumed residual natural mortality rates were determined iteratively. These species-specific residual natural mortality rates were selected to result in a total natural mortality rate for the oldest age classes as similar as possible to the natural mortality rate assumed in single-species runs.

Predation mortality was based on prey suitability coefficients, which incorporated both the size preference and species preference of a predator. Species preference (prey vulnerability) coefficients were estimated for each species interaction and incorporated all differences in food selection not attributable to size (Gislason and Helgason 1985). Species preference was relative to a reference prey species, in this case "other food", whose species-preference coefficient was set to one. Predator size-preference was a function of the 1) ratio of predator-to-prey weight, 2) preferred predator-prey weight ratio, and 3) predator selectivity with respect to the size of its prey. Finally, age-specific 
predation mortality was estimated as a function of age-specific suitable prey biomass, total predator and prey biomasses, and per-capita predator consumption.

Estimated model parameters included initial age-specific abundances, annual recruitment, age-specific fishery and survey selectivity coefficients, and speciespreference parameters.

\section{Required data}

Input time series for each species included total commercial catch $\left(10^{3} \mathrm{mt}\right.$; landings plus discards), total fishery-independent survey catch (number/tow) from the NEFSC seasonal bottom trawl surveys (Azarovitz 1981), age proportions of both commercial and survey catches, and average age-specific individual weights $(\mathrm{kg})$. These data were obtained from recent stock assessments, the primary literature or directly from the NEFSC (Table 1). For goosefish, winter skate and spiny dogfish, catch-at-age proportions and weight-at-age time series were not available. Accordingly, survey and commercial catch length-frequency data were used instead of age proportions. Timeinvariant age-specific weights were calculated with length-at-age and length-weight relationships (Table 1).

With the exception of cod, the unit stocks for all species incorporate a greater geographic area than just Georges Bank. Following Collie and Delong (1999), the average proportion of each species' biomass found on Georges Bank was estimated using the NEFSC trawl surveys (Table 2). For all species but white hake, average proportions from 1978-2007 were used because annual proportions did not exhibit systematic temporal trends. However, for white hake, the annual proportion on Georges Bank significantly decreased over the time series. Consequently, a linear relationship fit to 
annual proportions was used to estimate the average proportion on Georges Bank in each year.

For predator species, additional input data included age-specific diet composition, annual age-specific, per-capita consumption estimates and size-preference coefficients. Predator diet composition was estimated from the NEFSC food-habits database. Diet composition, represented as proportion by weight, was averaged over five-year intervals due to limited sample sizes.

Following several publications examining predator consumption, the gastric evacuation model was used to estimate total annual per-capita consumption (Tsou and Collie 2001a, Overholtz and Link 2007, Link and Sosebee 2008, Moustahfid et al. 2009a). In particular, total per-capita consumption was calculated for winter/spring and summer/fall, and subsequently summed together to obtain total annual per-capita consumption for each predator age and year bin. The food-habits database is structured by predator length; therefore predator lengths were assigned ages by using time-invariant length-at-age relationships from the literature (Table 1).

Per-capita consumption is a function of predator stomach-content weight and evacuation rate. Predator hourly evacuation rate $R$ in season $s$ year $t$ is a function of temperature

$$
R_{s, t}=\alpha e^{\beta T_{s, t}}
$$

where $\alpha$ and $\beta$ are constants and $T$ represents the average seasonal temperature in each year. The constants $\alpha$ and $\beta$ were set to 0.004 and 0.115 for teleost species and 0.002 and 0.11 for the two elasmobranch species (Durbin et al. 1983, Overholtz et al. 2000, Link et al. 2008a). NMFS trawl-survey data were used to estimate season- and year-specific 
average temperatures for Georges Bank. Average Georges Bank water temperatures from the spring survey were assumed to be representative of both winter and spring, where those from the fall survey were representative of summer and fall. Age- and season-specific predator evacuation rates were then averaged over years to estimate the average seasonal evacuation rate for each year bin.

For each predator species $i$ age $a$ in season $s$ of year bin $b$, total semi-annual percapita consumption is related to predator stomach-content weight $S$ and hourly evacuation rate $R$ as:

$$
C_{i, a, s, b}=182.5 * 24 R_{s, b} S_{i, a, s, b}^{\gamma}
$$

where $\gamma$ is assumed to equal 1 (Moustahfid et al. 2009a), and $S$ represents the average stomach-content weight of Georges Bank individuals for each predator age, season and year bin. For each year bin and predator age, total per-capita spring and fall consumption estimates were summed to obtain the average per-capita total annual consumption (grams consumed per individual predator per year). Finally, per-capita total annual consumption was divided by average individual predator weight for each predator age, year bin to obtain an age-specific consumption/biomass ratio.

Observed prey lengths for each predator age class were obtained from the foodhabits dataset and used externally to the model to estimate the size preference of each predator species. During model development, predator size-preference was modeled as a lognormal function of predator-to-prey weight (Chapter 1). However, the observed distribution of weight ratios was asymmetric, even on a log scale, such that predators rarely consumed prey of similar sizes as the predator. Following Lewy and Vinther (2004), two normal curves with the same mean but different variances were fit to 
predator-prey weight ratios to account for asymmetry in the observed distributions. For predator $j$ age $b$ and prey $i$ age $a$, predator size preference was calculated as:

$$
g_{i, a, j, b, t}=\exp \left[\frac{-1}{2 \sigma_{j, x}^{2}}\left(\ln \frac{W_{j, b, t}}{W_{i, a, t}}-\eta_{j}\right)^{2}\right]
$$

where $\eta_{j}$ represents the preferred lognormal predator-to-prey weight ratio and $\sigma_{j}^{2}$ reflects the variance in this ratio, or predator selectivity. Two different values of $\sigma$ were estimated, $\sigma_{j, 1}$ and $\sigma_{j, 2}$, for weight ratios less than or greater than $\eta_{j}$, respectively.

Prey lengths were only available for a subset of the food-habits data and had limited sample sizes for some predator species. Consequently, predator size-preference was assumed to be constant over all prey species and was estimated externally to the model to avoid parameter confounding during model fitting. If empirical wet-weights were not available, predator and prey lengths were converted to weights with species-specific length-weight relationships obtained from multiple literature sources (Gilman 1994, Newberger and Houde 1995, Wigley et al. 2003, Annis et al. 2011). A total of 14,627 predator-prey length pairs were used to calculate predator size-preference.

\section{Parameter estimation}

As in the initial model implementation (Chapter 1), the total likelihood used in parameter estimation comprised five data sources: total commercial and survey catches, age composition of survey and commercial catches, and predator diet composition. Relative abundance estimates from both the spring and fall surveys were initially used for each species. However, for some species, one trawl-survey season provided more consisent abundance estimates and better diagnostics. For these species, trawl-survey data from only one season were used in parameter estimation (Table 2). For each 
species, age-specific survey and fishery selectivity parameters were estimated from the first age of partial recruitment to the age of full recruitment, which were both selected iteratively during single-species runs (Table 2).

The initial estimates for all single-species parameters were set to the final parameter estimates from the single-species models. As in the submodel, objective function weights for each dataset were selected iteratively by using two-stage weighting (Francis 2011). Weights for the lognormal components were chosen to achieve approximately a $30-40 \%$ coefficient of variation $(\mathrm{CV})$ for aggregate survey catch and a $10 \% \mathrm{CV}$ for total commercial catch. Age compositions of the catches as well as predator diet compositions were assumed to be multinomially distributed, with objective function weights selected to best approximate the effective sample size calculated with the formulation of McAllister and Ianelli (1997). The statistical estimation of model parameters accounts for observation errors in the time series of catches and predator diets.

Goosefish, winter skate and dogfish are not routinely aged. Since goosefish exhibit linear growth up to age ten (Richards et al. 2008), observed survey and commercial catch length frequencies were converted to age proportions with a time-invariant age-length key (NEFSC 2010). In contrast, winter skate and spiny dogfish exhibit asymptotic growth. Since both species are top predators within the model, single-species runs were first conducted incorporating age-length keys to convert predicted age proportions to length proportions within the model. These single-species models were fitted to observed survey and commercial catch length frequency data. Predicted age-structured catches and estimated parameters from the single-species runs were then put into the multispecies model as known input values. 
Following Frisk et al. (2010), time-invariant age-length keys for winter skate and spiny dogfish were constructed from average length-at-age and corresponding standard deviations-at-length. Average length-at-age was calculated from published von Bertalanffy relationships (Table 1). For winter skate, the standard deviation in mean length-at-age was calculated as the product of average length-at-age and the coefficient of variation estimated in Frisk et al. (2010). The standard deviations-at-length for spiny dogfish were estimated from Nammack et al. (1985).

The observed length-frequency data were binned in 1-cm length increments. The probability that a fish of a given age fell within a particular length bin was estimated assuming a normal distribution with a mean equivalent to the average length-at-age and a standard deviation equal to the observed standard deviation-at-length. The probabilities were then scaled so that they summed to one within each age class. These scaled probabilities were used as the age-length key.

\section{RESULTS}

The observed distributions of predator-to-prey weight ratios were notably skewed, even in log space (Figure 2). A normal distribution with different assumed variances at values above and below the mode fit the observed distributions well. Average log weight ratios (base $e$ ) for each predator species ranged from 1.95-6.75, indicating that predators generally consumed prey species at least seven times smaller than them by weight (Table 3). Relative to their own weight, white hake and silver hake consumed the largest prey while winter skate and pollock consumed the smallest prey. For all predator species but winter skate, the estimated variance of the portion of the curve above the mode $\left(\sigma_{2}\right)$ was 
at least 2.5 times greater than the variance estimated for values less than the mode $\left(\sigma_{1}\right)$. This difference in estimated variances indicates a greater consumption of smaller than larger prey. However, in the case of winter skate, the estimated variances were approximately equal, suggesting relatively equal consumption of prey of a certain size greater or smaller than the mode. In applying these distributions to the age-structured model, the average observed weight ratio was assumed to be equivalent to the preferred ratio, and the observed variances equivalent to predator size selectivities.

Outputs of multispecies statistical catch-at-age models include time series of multiple predicted indices such as recruitment, total consumption, biomass and rates of predation. The primary objective of this work was to quantify both the magnitude and temporal trends in the predation mortality rates experienced by prey species. Accordingly, model fits to observed data are briefly addressed, but the results are focused on estimated predation rates and the sources of this predation.

For the teleost species, predicted total annual catch exhibited only small deviations from observed fishery catch (Figure S1). Predicted seasonal fishery-independent survey catches captured the observed trends in the species-specific time series, though greater interannual variability was evident in survey catches (Figure S2). Both fisheries and survey catches were inputted as known data for the two elasmobranch species.

With age-structured time series of commercial catches, survey catches and predator diets, the model was able to estimate initial abundances, annual recruitment, annual rates of fishing, both survey and fishery selectivity ogives, as well as species-preference coefficients that characterized the predation interactions between modeled species. An error-free model convergence was obtained, with a maximum observed parameter 
correlation of 0.8604 , indicating that parameter confounding was not evident. However, the model was sensitive to assumed dataset weights in the objective function as well as starting initial estimates for the single-species parameters. Modification of dataset weights sometimes led to model runs that contained convergence errors. Yet, there was enough power in the data to iteratively select weights for commercial age-proportions, survey age-proportions as well as predator diet compositions to best match the observed effective sample sizes.

Predation mortality rates (M2) were strongly size-dependent, whereby M2 generally decreased with increasing age (Figure 3). Goosefish, cod and white hake were both intermediate prey and predator species, exhibiting maximum predation rates between 0.18 (goosefish) and 0.43 (cod). For these intermediate prey species, the M2 rates of the oldest age classes were approximately zero, such that fishing was the dominant source of mortality for these age classes. As a consequence, the fishery landings for these three prey species were greater than the biomass consumed by modeled predator species (Figure 4).

In contrast, mackerel, herring and silver hake experienced the greatest mortalities due to predation, with maximum predation mortality rates of 0.62 for mackerel, 1.01 for herring and 1.58 for silver hake (Figure 3). For these principal prey species, the oldest age classes were still exposed to predation and experienced predation mortality rates between $0.08-0.23$ for mackerel, $0.11-0.45$ for herring and 0.32-0.95 for silver hake. For silver hake, the biomass consumed was over three times the magnitude of the landings in each year (Figure 4). For mackerel and herring, the losses due to predation generally exceeded annual landings; however, there was at least one year for each prey species in 
which landings exceeded predation losses. These years corresponded to periods when species-specific predation mortality rates were near their minima.

Predation mortality rates are a function of both predator and prey biomasses as well as predator consumption rates and diet composition. For the predator species, spiny dogfish, winter skate, white hake and cod, total biomasses were greatest near the beginning of the time series, while goosefish total biomass increased over time (Figure 5). Silver hake and pollock did not exhibit monotonic temporal trends in biomass. Differences in magnitude between biomass and total annual consumption varied among species. Calculated total annual consumptions of both elasmobranch species were lower than their annual biomass estimates, due to comparatively low consumption-to-biomass (CB) ratios averaging 0.757 for spiny dogfish and 0.328 for winter skate. In contrast, cod and pollock exhibited average $\mathrm{CB}$ ratios of 1.71 and 1.18 , respectively, resulting in annual consumption estimates slightly greater than their biomasses. Annual consumption estimates for goosefish, white hake and silver hake all substantially exceeded their annual biomass levels due to high $\mathrm{CB}$ ratios averaging 6.15 for goosefish, 3.49 for white hake and 3.96 for silver hake.

While total annual consumption of spiny dogfish and winter skate decreased over the time series, their consumption of modeled fish species increased (Figure 6). Spiny dogfish consumption comprised herring, silver hake, mackerel, and to a lesser extent, cod and goosefish. When total consumption of modeled fish was at its greatest, spiny dogfish consumed primarily herring. The increase in winter skate consumption at the end of the time series comprised both herring and silver hake. 
Predicted spiny dogfish and winter skate diets both indicated a small total consumption of modeled fish species, with consumption estimates 3-4 times less than that of cod or silver hake, and over an order of magnitude less than that of goosefish (Figure 6). The consumption of modeled prey species is a function of both relative diet composition and total consumption, which in turn is a function of predator biomass and per-capita consumption rates. The evacuation rate parameters used for the elasmobranch species were less than those of the teleosts, resulting in comparatively low consumptionto-biomass ratios for both spiny dogfish and winter skate. Furthermore, modeled prey only constituted a maximum of $6 \%$ of the average diet for winter skate and $16 \%$ for spiny dogfish (Figure S3, Figure S4). The annual predicted biomass of spiny dogfish was on the same order of magnitude as many of the predator species (Figure 5). In contrast, winter skate exhibited a greater total biomass than spiny dogfish, but consumed approximately the same quantity of modeled species due to the smaller proportion of modeled prey in winter skate diet composition. Together these trends resulted in the low consumption estimates of modeled prey species compared to many other predators, including goosefish, cod and silver hake.

Goosefish consumed the greatest quantity of modeled fish species across all years (Figure 6), indicating that it was the dominant predator species within the Georges Bank fish community. This role was presumably due to its high consumption rate and level of piscivory, because predicted total annual biomass was substantially less than that of several other predator species, including spiny dogfish, winter skate and cod (Figure 5). Both goosefish total consumption and that of modeled fish increased over time. As a consequence of these increases as well as a decrease in goosefish predation mortality, 
goosefish's role as the dominant predator within the system increased at the end of the time series.

Cod was the second most dominant predator of modeled prey species (Figure 6). Even though cod total consumption decreased proportionally with its abundance, its consumption of modeled prey and in particular herring, increased over time. Cod consumption of modeled fish was an order of magnitude greater than that of white hake even though both species were intermediate predators (Figure 6). This difference was due to the large difference in predicted biomass estimates, because the average diet of white hake generally constituted a slightly greater proportion of modeled prey. Similarly, even though white hake abundance and total consumption decreased over time, its consumption of modeled prey did not show a consistent temporal trend due to an increase in the proportion of modeled fish in the diet composition. Like several other predator species, this increase was primarily due to increased consumption of herring, though white hake diet comprised mainly silver hake, and to a smaller degree herring and conspecifics (Figure S5).

While neither silver hake nor pollock total consumption exhibited monotonic trends, their consumption of modeled fish species both increased substantially over time. For both predator species, this increase was primarily herring, though consumption of silver hake and mackerel increased as well (Figure 6, Figure S5). Across all predator species, the predicted annual consumption of modeled fish species further demonstrated the dominance of herring and silver hake as prey species.

Trends in predation were also examined from the perspective of the prey species. Goosefish was prey only to spiny dogfish; the pattern in the biomass of goosefish 
consumed resulted from the interplay of trends in spiny dogfish and goosefish abundance (Figure 7). Cod was prey to spiny dogfish, goosefish and itself (Figure 6, Figure 7). Consumption of cod by all three predator species declined over time as cod biomass decreased. Likewise, across all predator species, consumption of herring generally increased over time as herring biomass increased (Figure 7). Consistent with its biomass, consumption of silver hake did not show a pronounced temporal trend. For cod, silver hake and mackerel, goosefish was the dominant predator species. Across years, goosefish was responsible for $87.1-99.6 \%$ of total cod consumption, $45.8-87.8 \%$ of total mackerel consumption and $60.8-85.9 \%$ of total silver hake consumption.

In contrast, the dominant predator of both white hake and herring was generally cod (Figure 7). Across years, $27.6-95.5 \%$ of all white hake consumption and $41.6-90.4 \%$ of herring consumption was due to cod. For white hake, there were seven years across the 1990's and 2000's during which cannibalism was more dominant than predation by cod even though the magnitude of white hake cannibalism declined over time as white hake abundance decreased. These years corresponded to time periods where the total consumption by cod was at its lowest (Figure 5). For herring, cod was most dominant as predator during the early portion of the time series when cod abundance was at its greatest (Figure 7). Beginning in the late 1980's, herring was consumed by wider array of predators that included most notably goosefish, pollock, silver hake and spiny dogfish, in addition to cod. For most prey species, the majority of predation mortality was imposed by one or two predator species. The exception to this trend was the consumption of herring by several predator species during the latter half of the time series as herring abundance increased. 
Trends in predator biomass and diet composition as well as prey biomass can be used to interpret temporal trends in the predation mortality rates experienced by prey species (Figure 3). For ages subject to predation, goosefish and white hake predation mortality rates generally declined over the time series. For goosefish, this decrease was due to the increasing trend in goosefish biomass as well as a decline in the predicted biomass of spiny dogfish, their only predator. The decline in white hake predation mortality was primarily a consequence of decreased predation by cod and to a lesser extent, decreased cannibalism. Predation mortality rates of herring also decreased substantially over time, as a consequence of substantial increases in herring biomass as well as a decrease in the biomass of its primary predator, cod. This decrease in M2 occurred even as herring became more prevalent in the diets of several predators, with approximately a 5 -fold increase in total consumed biomass.

In contrast, cod predation mortality increased over time, with the majority of predation due to goosefish. This increase in M2 was attributed to both the increased biomass of goosefish as well as the precipitous decline in cod biomass. Age-1 mackerel experienced an average M2 of approximately 0.2 until the end of the time series when it increased, even as mackerel total biomass increased. This increase in M2 was a function of an increase in the biomass of the primary predators of mackerel: goosefish and to a lesser extent silver hake and pollock.

Silver hake predation mortality rates generally exhibited an increasing temporal trend and appeared to track the abundance of goosefish, which was by far the principal predator. Predation mortality rates at the end of the time series were up to $50 \%$ higher than rates experienced during the early part of the time series. Increased cannibalism at 
the end of the time series presumably contributed to the temporal trend in M2 and was potentially due to a pulse of recruits to the population in the late 1990's and early 2000's, as indicated by predicted survey age-proportions (Figure S6). At the beginning of the time series cod consumption of silver hake was notable, but its role as a predator to silver hake declined as its abundance decreased.

For silver hake, the distribution of M2 across ages varied with time. In the mid 1980's, silver hake predation mortality rates were very similar across ages; in 1987 age-1 individuals experienced predation rates only $10 \%$ higher than age- 6 silver hake. However, in the early 2000's, predation on silver hake was more size selective, resulting in age- 1 predation rates over three times the M2 experienced by the oldest age class. This temporal difference in the distribution of M2 across ages was attributed to changes in the age distribution of goosefish, silver hake's primary predator (Figure S7). Higher abundance of older (ages 7-10) goosefish in the late 1980's compared to the early 2000's resulted in higher predation rates on older silver hake.

All predator species exhibited considerably greater preferences for modeled prey species than "other food" (Figure 8). However, the most preferred prey species varied among predators. The most preferred prey of goosefish was silver hake, while that of cod and pollock was herring and mackerel, respectively. Examination of the standard deviations corresponding to these species preference coefficients indicated the magnitude of uncertainty surrounding each estimated species interaction. The three aforementioned predator species all exhibited significantly higher preferences for one prey than other species. Additionally, white hake had a significantly greater preference for cannibalism than other prey. However, many of the remaining predator species exhibited similar 
preferences for multiple prey species. Both silver hake and winter skate had large estimated coefficients for mackerel and silver hake; neither prey species was clearly preferred. Spiny dogfish's highest preference was for goosefish, presumably due to the combination of its low abundance and semi-regular occurrence in spiny dogfish diets, though it also exhibited a similar preference for cod. For several predator species including silver hake, pollock, white hake and winter skate, the most uncertain interaction was with mackerel. This high degree of uncertainty was presumably due to a small sample size of stomachs containing mackerel.

\section{DISCUSSION}

Multispecies statistical catch-at-age models improve upon the estimation of trophic interactions and predation mortality with MSVPA. These improvements result from the statistical estimation of model parameters, recognition that observed datasets contain measurement error, and by accounting for uncertainty in not only input data, but also resulting parameter estimates. The multispecies statistical catch-at-age model presented in this chapter builds upon the submodel developed and tested in Chapter 1 as well as previous modeling efforts for both Georges Bank and the Northeast U.S. Continental Shelf ecosystems. As such, this multispecies model provides one plausible representation of the interactions among fish species on Georges Bank and the magnitude of the predation rates experienced by prey species. The model incorporates nine fish species representing important predators and prey within the Georges Bank community.

Trends in prey abundance, resulting predation mortality rates and predator consumption are influenced by the species set included in the multispecies model. These 
differences are demonstrated through a comparison of the outputs of the 3-species submodel developed in Chapter 1 and the full 9-species model presented here. Predicted abundances of cod, silver hake and herring were greater in the full model than in the submodel. This difference in magnitude was due to the added predation losses from the five additional predator species included in the full model. Cod and herring showed the same temporal trends in abundance between models. In contrast, silver hake, though it did not exhibit a clear temporal trend in either model, exhibited a different timing of peak abundance between the two applications. In the submodel, abundance peaked during the mid-1980's, but predicted abundance in the 9-species model peaked in 2001. Yet while the timing of peak abundance varied between the models, the timing of peak biomass remained the same; silver hake biomass reached its maximum in the mid 1980's. In the full model, the difference in timing between peak abundance and biomass as well as the increase in M2 at the end of the time series was potentially due to the recruitment pulse in the late 1990's and early 2000's. The increase in silver hake cannibalism predicted in the 9-species model was also predicted in the 3-species submodel and was supported by the observed diets of age 4-6 silver hake. However, in the 3-species model, predation mortality rates did not reach unprecedented levels because the abundance of cod, silver hake's only other predator in the submodel, was at a minimum during this time.

Cod also experienced drastically different predation rates and a different temporal trend in predation between models. This pronounced difference was due to the enhanced array of predators included in the full model that prey on cod. In the 3-species submodel, cod was only prey to itself, and cannibalism declined with decreasing cod abundance. However, in the 9-species model, the decline in cannibalism was counteracted by an 
increase in cod consumption by goosefish, resulting in the predicted increase in M2 over time. Herring predation rates exhibited the same temporal trend between models, due to the marked increase in herring abundance predicted in both models.

In addition to rates of predation, the dominant predator varied between models. For both cod and silver hake, the primary source of predation in the 9-species model was no longer cannibalism but instead predation by goosefish. The dominant predator of herring was cod in both models; however, in the 9-species model herring was consumed by a wider array of predator species in the second half of the time series as cod abundance declined.

Within the 9-species model, the relative role of each species within the community can be assessed with respect to its predation rates and consumption of modeled fish species. In this model, winter skate, spiny dogfish and pollock were top predators. Yet, predicted spiny dogfish and winter skate diets both indicated a small total consumption of modeled fish species, with consumption estimates less than that of cod, silver hake, and particularly goosefish. Previous work investigating the diet composition of spiny dogfish on Georges Bank indicated that on average, clupeids only represented approximately 5\% of spiny dogfish diets, with ctenophores and unidentified fish the dominant prey categories (Smith and Link 2010). Likewise, while winter skate are piscivorous, their primary fish prey are generally sand lance, which were not included in this model (Link and Almeida 2000, Smith and Link 2010).

While the predicted total annual biomass of pollock was less than that of both spiny dogfish and winter skate, pollock generally exhibited a greater consumption of modeled fish, especially near the end of the time series, with the majority of this increase 
consisting of herring. Previous work investigating the consumptive demand of pollock also demonstrated a shift in pollock diet with increased piscivory through time (Tyrrell et al. 2007). The consumption estimates of Tyrrell et al. (2007) suggested a greater importance of herring and hake over mackerel. In the average diet of pollock predicted here, herring and silver hake constituted a greater proportion in the diet; however, estimated species preference coefficients indicated a significantly greater preference for mackerel than either silver hake or herring. This difference could be a function of differing availabilities among the prey species, resulting from differences in abundance or distribution.

In this application, goosefish appear to be the dominant predator species within the Georges Bank fish community. Previous work has indicated that goosefish exhibit rapid, linear growth (Richards et al. 2008), which would contribute to the high consumption rates estimated here. Furthermore, goosefish are important piscivores, with fish often constituting greater than $50 \%$ of their diet (Link and Garrison 2002a, NEFSC 2010, Smith and Link 2010). Though previous work investigating abundance and species composition trends of feeding guilds in the Northeast U.S. Continental Shelf indicated that goosefish constituted a small proportion of total abundance within the piscivore guild, its relative abundance appeared to increase over time (Auster and Link 2009). Together these factors contributed to goosefish's dominance in the community. Recent work on the trophic ecology and abundance of goosefish has even suggested that goosefish is functionally replacing cod as the dominant piscivore within the northwest Atlantic ecosystem (Link 2007). 
Cod and white hake serve as both intermediate predators and prey, with young age classes subject to predation but older individuals escaping predation from other species included in the model. Tsou and Collie (2001a) estimated similar predation mortality rates for cod, with age- 0 individuals experiencing an average predation mortality rate of 0.3 and predation mortality declining to 0.003 by age-3. The majority of cod predation was due to goosefish, especially as cod cannibalism decreased over time. In contrast, Link et al. (2009) suggested that goosefish were not major predators of cod both because goosefish generally did not consume a large amount of biomass and because cod did not constitute a substantial portion of their diet. While cod constituted less than $20 \%$ of the average diet of goosefish, goosefish's high estimated consumption-to-biomass ratio resulted in substantial predicted cod consumption by goosefish.

After goosefish, cod was the second most dominant predator species. Multiple studies have shown that cod are opportunistic generalists, both consuming a diverse array of prey and generally those prey species with the greatest abundance (Garrison and Link 2000a, Link and Almeida 2000, Link and Garrison 2002b, Link et al. 2009). These studies support the cod consumption trend of modeled fish species predicted in this work, in particular the increase in herring consumption in the latter half of the time series as herring abundance recovered from overfishing. The role of cod as a dominant piscivore in the northwest Atlantic is thought to have decreased as its abundance has declined (Link and Garrison 2002a, b). Previous work on the northeast U.S. shelf found a decrease in the contribution of both cod and white hake abundance to the piscivore guild (Auster and Link 2009). However, in this application, cod remained the second most dominant predator in all years but one. 
Like cod, white hake primarily consumed herring and silver hake, and experienced a decrease in cannibalism with time. This finding is supported by previous work that identified silver hake and herring as dominant fish prey items for white hake and indicated a marked decline in cannibalism from the 1970's through the 1990's (Garrison and Link 2000b, Smith and Link 2010). Though unlike cod, white hake appeared to only play a minor role in the fish community dynamics due to its low abundance compared to other predator species.

Mackerel represented an additional intermediate prey species in the ecosystem and experienced an average age-1 M2 of approximately 0.3. Previous studies have estimated similar predation rates for mackerel. Using a statistical catch-at-age model that incorporated predation losses as an additional fleet, Moustahfid et al. (2009a) estimated an average age-1 M2 of approximately 0.1 and a maximum of 0.6 . Tsou and Collie (2001a) estimated mackerel predation mortality rates less than 0.05 for all age classes on Georges Bank; however, the MSVPA only included years through 1992, which was before mackerel M2 began to increase. In contrast, an MSVPA of the entire Northeast US Continental Shelf ecosystem estimated an average M2 of 0.74 for age- 0 and age- 1 mackerel (Tyrrell et al. 2008).

Differences in estimated rates of predation among studies could be a function of the geographic range over which the models were applied in comparison to the range of the stock of a particular species. For example, mackerel in the northwest Atlantic exhibit extensive seasonal migrations. They generally overwinter in the mid-Atlantic or the warm waters of the shelf edge east of Southern New England, Georges Bank or Nova Scotia; in the summer they primarily inhabit the Gulf of Maine, Gulf of St. Lawrence and 
the Newfoundland coast (Sette 1950, Collette and Klein-MacPhee 2002, Overholtz et al. 2011). Consequently, modeling efforts that include the entire northeast US shelf may estimate different species-preference coefficients and predation rates than those that just include Georges Bank. Network models of the NEUS ecosystem also found that biomass ratios for important predatory linkages among modeled groups varied regionally due in part to migratory patterns and distributional differences (Link et al. 2008b).

Estimated mackerel predation rates indicated a decline in M2 with ontogeny, reflecting the size-selective nature of predation. However, in contrast to other intermediate prey, even the oldest age-classes still experienced an average M2 of approximately 0.1 . This result contrasts other predation studies that suggested mackerel's fast growth enabled it to grow out of the size range over which they were vulnerable to predation (Overholtz et al. 1999, Moustahfid et al. 2009a).

Although mackerel is considered to be an important forage species in the northwest Atlantic (Moustahfid et al. 2009a), the most important prey species in this application were silver hake and herring. Both silver hake and herring exhibited maximum predation rates greater than 1.0; however, temporal trends in $\mathrm{M} 2$ differed markedly among the species. Silver hake consistently experienced the highest predation mortality rates among all modeled prey species, with increasing predation mortality rates over time likely due to both goosefish and cannibalism. Recent work has indicated that cannibalism in silver hake is both prominent and an important factor influencing silver hake dynamics (Tsou and Collie 2001a, Link et al. 2012), especially on Georges Bank and in the Gulf of Maine (Garrison and Link 2000b, Smith and Link 2010). While cannibalism no longer represented the largest predation loss in the 9-species model due to the large consumption 
by goosefish, as predators silver hake still consumed primarily conspecifics and herring. Furthermore, silver hake were important predators within the community, consuming the third highest amount of modeled fish prey. Previous work examining the trophic ecology of silver hake also identified them as dominant biomass components, important as both predators and prey within the NEUS ecosystem (Garrison and Link 2000a).

The decrease in herring M2 even as herring became more prevalent in predator diets indicates that the increase in herring abundance was potentially sufficient to permit escape from predator control. Several previous studies have found similar predation mortality rates for herring, with estimates of maximum M2's ranging from 0.75 to 3.2 , as well as an increased importance of herring in predator diets over time (Tsou and Collie 2001a, Overholtz et al. 2008, Tyrrell et al. 2008). The increase of herring in predator diets as herring abundance increased demonstrates the opportunistic nature of many of the modeled predator species (Garrison and Link 2000b, Link and Garrison 2002b, Smith and Link 2010).

In this application, the dominant predator of herring was Atlantic cod, with goosefish, spiny dogfish, pollock and silver hake also notable predators. The dominance of cod is not only consistent with trends of the 3 -species submodel but also with work on cod trophic ecology that indicated herring was the dominant prey item in the 1990's (Link and Garrison 2002b). However, this trend also contrasts several previous studies. In particular, Tyrrell et al. (2008) indicated that herring's most important predators were spiny dogfish, white hake, summer flounder and goosefish, whereas Tsou and Collie (2001a) estimated that silver hake accounted for $50-90 \%$ of the predation imposed on herring. Similarly, Overholtz and Link (2007) indicated that the largest herring 
consumers were spiny dogfish and silver hake, followed by cod, white hake and goosefish. This difference is potentially due to cod's preference for herring over all other prey species, as well as a stronger preference by the other predators for many of the other modeled prey species over herring.

As with mackerel, the oldest age classes of herring and silver hake still experienced notable rates of predation. For herring, this result is supported by previous work indicating that herring are vulnerable to predation over their entire lifespan (Overholtz et al. 1999, Overholtz and Link 2007). For silver hake, this result is presumably due to predation by goosefish because cannibalism, while prominent, occurs primarily on individuals less than 20 centimeters (Link et al. 2012).

Due to the generalist nature of many of the predator species included in this model, predator diet composition generally followed patterns in prey abundance. This trend was most evident by the increased consumption of herring by several predators as herring abundance increased. Link and Garrison (2002b) demonstrated that cod exhibit prey switching. Furthermore, a study investigating the functional responses of piscivorous fish species in the northwest Atlantic found that Holling Type-II and Type-III functional responses were most common, that predator functional response varied among prey species, and there generally was insufficient statistical power to distinguish between the two functional forms (Moustahfid et al. 2010). In this application, we assumed a Holling Type-II functional response. However, due to the opportunistic nature of the predator species and the likelihood of prey switching with fluctuations in prey abundance, a TypeIII functional response would have also been appropriate. A Type-III functional response 
may have impacted the estimated predation rates experienced by prey species, especially at low prey abundances.

The multispecies statistical catch-at-age model developed here incorporates nine commercially-important fish species. However, other fish and invertebrate species, including sand lance (Link and Garrison 2002a) and squid (Moustahfid et al. 2009b), represent important prey species on the Northeast U.S. Continental Shelf. The necessity for both fishery-dependent and fishery-independent age-structured data prevented the inclusion of these species into the multispecies statistical catch-at-age model. Yet we recognize that these species represented notable portions of predator diets, especially when herring and mackerel abundances were near their minima. Similarly, age-0 individuals were not incorporated into the model due to their absence in commercial catches. Yet, we recognize that M2 rates are likely to be greatest on age-0 individuals due to the size-selective nature of predation.

The model also does not incorporate marine mammals or other large predatory species. Recent estimates of marine mammal consumption on the northeast U.S. shelf suggested that total consumption was significantly greater than commercial catches of the six prey groups investigated, which included small and large gadids, clupeids, flatfish, scrombrids and squids (Col 2012). Furthermore, in the Gulf of Maine / Georges Bank region, marine mammals are large consumers of herring, second only to demersal fish (Overholtz and Link 2007). With current management, it is possible that marine mammal populations may increase. As such, their potential impact on the dynamics of fish species would become more pronounced, enhancing the need for their inclusion in multispecies 
models. However, their incorporation into multispecies and ecosystem modeling efforts is not straightforward due to very limited time series of required abundance and diet data.

Consistent with previous multispecies modeling efforts on the Northeast U.S. Continental Shelf, the multispecies statistical catch-at-age model developed in this study demonstrates the strong impact of predation on community dynamics. For the principal forage species in this ecosystem, herring and silver hake, the losses due to predation greatly exceed commercial landings. This trend is not uncommon among ecosystems (Bax 1991, 1998) and further indicates that predation can have a marked influence on the dynamics of prey species.

While the principal finding of the strong impact of predation remains the same, some details including species-specific predation mortality rates and trends in the dominant predator differ from previous studies. These differences could arise from assumptions regarding the geographic range included in the model, the time step at which the model was implemented (e.g. annual versus quarterly) or the species set included in the model. Many of the geographic ranges of the nine modeled species encompass a greater area than just Georges Bank. Furthermore, within their geographic ranges many species also undergo extensive seasonal migrations. These factors could impact abundance estimates of both predators and prey, consequently influencing estimated rates of predation. Differences could also arise from varying model formulations. While the formulations used here generally follow those of MSVPA, prey suitability in this model varies annually due to changes in average individual weight-at-age. Furthermore, unlike many previous multispecies modeling efforts for the NEUS, here we account for measurement error in observed catches and statistically estimate model parameters. As 
with single-species approaches, a variety of multispecies approaches should be used to investigate the dynamics within a particular ecosystem or the potential impacts of management scenarios. Here we provide another possible picture of the ecosystem as well as further evidence of the strong impact of predation.

The predation mortality rates estimated for the prey species on Georges Bank are substantial and exhibit both considerable temporal and ontogenetic variation. Accordingly, the consequence of structural uncertainty and the use of single-species approaches that assume constant rates of natural mortality in systems strongly impacted by predation merits further investigation. It must also be recognized that a multispecies approach should not replace single-species management, but should instead be used to enhance and supplement single-species models (Quinn and Collie 2005). Model sensitivity to dataset weights in the likelihood function as well as initial parameter estimates demonstrates the tradeoff between increased biological realism and increased uncertainty in parameter estimation. Nonetheless, the statistical estimation of speciesspecific predation mortality rates within a complex ecosystem such as Georges Bank is feasible. Additional work should be conducted that uses the food-selection parameters quantified here to explore how these trophic interactions and various fishing scenarios could impact future community dynamics. 


\section{REFERENCES}

Annis, E.R., Houde, E.D., Harding, L.W., Jr., Mallonee, M.E., and Wilberg, M.J. 2011. Calibration of a bioenergetics model linking primary production to Atlantic menhaden Brevoortia tyrannus growth in Chesapeake Bay. Mar. Ecol. Prog. Ser. 437: 253-267.

Auster, P.J., and Link, J.S. 2009. Compensation and recovery of feeding guilds in a northwest Atlantic shelf fish community. Mar. Ecol. Prog. Ser. 382: 163-172.

Azarovitz, T.R. 1981. A brief historical review of the Woods Hole Laboratory trawl survey time series. Canadian Special Publication in Fisheries and Aquatic Sciences 58: 62-67.

Bax, N.J. 1991. A comparison of the fish biomass flow to fish, fisheries, and mammals in six marine ecosystems. ICES Marine Science Symposia 193: 217-224.

Bax, N.J. 1998. The significance and prediction of predation in marine fisheries. ICES J. Mar. Sci. 55(6): 997-1030.

Branch, T.A., Watson, R., Fulton, E.A., Jennings, S., McGilliard, C.R., Pablico, G.T., Ricard, D., and Tracey, S.R. 2010. The trophic fingerprint of marine fisheries. Nature 468(7322): 431-435.

Brodziak, J.K.T., Holmes, E.M., Sosebee, K.A., and Mayo, R.K. 2001. Assessment of the silver hake resource in the Northwest Atlantic in 2000. Northeast Fish. Sci. Cent. Ref. Doc. 01-03, NOAA - National Marine Fisheries Service, Woods Hole, MA.

Bundy, A., Heymans, J.J., Morissette, L., and Savenkoff, C. 2009. Seals, cod and forage fish: A comparative exploration of variations in the theme of stock collapse and ecosystem change in four Northwest Atlantic ecosystems. Progress in Oceanography 81(1-4): 188-206.

Col, L.A. 2012. Marine mammal consumption on the Northeast US Continental Shelf. M.Sc. thesis, School for Marine Science and Technology, University of Massachusetts Dartmouth, Dartmouth, Massachusetts.

Coll, M., Libralato, S., Tudela, S., Palomera, I., and Pranovi, F. 2008. Ecosystem overfishing in the ocean. Plos One 3(12). 
Collette, B.B., and Klein-MacPhee, G. 2002. Bigelow and Schroeder's Fishes of the Gulf of Maine. Smithsonian Institution Press, Washington and London.

Collie, J.S., and Delong, A.K. 1999. Multispecies interactions in the Georges Bank fish community. In Ecosystem approaches for fisheries management. Alaska Sea Grant College Program, AK-SG-99-01, Fairbanks, Alaska. pp. 187-210.

Durbin, E.G., Durbin, A.G., Langton, R.W., and Bowman, R.E. 1983. Stomach contents of silver hake, Merluccius bilinearis, and Atlantic cod, Gadus morua, and estimation of their daily rations. Fishery Bulletin 81(3): 437-454.

EcoAP (Northeast Fisheries Science Center Ecosystem Assessment Program). 2009. Ecosystem Status Report for the Northeast U.S. Continental Shelf Large Marine Ecosystem. Northeast Fish. Sci. Cent. Ref. Doc. 09-11, NOAA - National Marine Fisheries Service, Woods Hole, MA.

Fogarty, M.J., and Murawski, S.A. 1998. Large-scale disturbance and the structure of marine system: Fishery impacts on Georges Bank. Ecol. Appl. 8(1): S6-S22.

Francis, R.I.C.C. 2011. Data weighting in statistical fisheries stock assessment models. Can. J. Fish. Aquat. Sci. 68(6): 1124-1138.

Frisk, M.G., Martell, S.J.D., Miller, T.J., and Sosebee, K. 2010. Exploring the population dynamics of winter skate (Leucoraja ocellata) in the Georges Bank region using a statistical catch-at-age model incorporating length, migration, and recruitment process errors. Can. J. Fish. Aquat. Sci. 67(5): 774-792.

Frisk, M.G., and Miller, T.J. 2006. Age, growth, and latitudinal patterns of two Rajidae species in the northwestern Atlantic: little skate (Leucoraja erinacea) and winter skate (Leucoraja ocellata). Can. J. Fish. Aquat. Sci. 63(5): 1078-1091.

Frisk, M.G., Miller, T.J., Martell, S.J.D., and Sosebee, K. 2008. New hypothesis helps explain elasmobranch "outburst" on Georges Bank in the 1980s. Ecol. Appl. 18(1): 234-245.

Garrison, L.P., and Link, J.S. 2000a. Dietary guild structure of the fish community in the Northeast United States continental shelf ecosystem. Mar. Ecol. Prog. Ser. 202: 231-240. 
Garrison, L.P., and Link, J.S. 2000b. Diets of five hake species in the northeast United States continental shelf ecosystem. Marine Ecology-Progress Series 204: 243-255.

Gilman, S.L. 1994. An energy budget for northern sand lance, Ammodytes dubius, on Georges Bank, 1977-1986. Fishery Bulletin 92(3): 647-654.

Gislason, H., and Helgason, T. 1985. Species interaction in assessment of fish stocks with special application to the North Sea. Dana 5: 1-44.

Grégoire, F., and Maguire, J. 2010a. An assessment of the Northwest Atlantic mackerel (Scomber scombrus L.) with XSA (Extended Survivors Analysis). TRAC Ref. Doc. 2010/14.

Grégoire, F., and Maguire, J. 2010b. Separable VPA and trends in the fishing mortality, population abundance and spawning stock biomass for the Northwest Atlantic mackerel (Scomber scombrus L.) between 1968 and 2008. TRAC Ref. Doc. 2010/13.

Lewy, P., and Vinther, M. 2004. A stochastic age-length-structured multispecies model applied to North Sea stocks. ICES CM 2004/FF:19.

Link, J., O'Reilly, J., Fogarty, M., Dow, D., Vitaliano, J., Legault, C., Overholtz, W., Green, J., Palka, D., Guida, V., Brodziak, J., Methratta, E., and Stockhausen, W.T. 2008a. Energy flow on Georges Bank revisited: the Energy Modeling and Analysis eXercise (EMAX) in historical context. J. Northwest Atl. Fish. Sci. 39: 83-101.

Link, J., Overholtz, W., O'Reilly, J., Green, J., Dow, D., Palka, D., Legault, C., Vitaliano, J., Guida, V., Fogarty, M., Brodziak, J., Methratta, L., Stockhausen, W., Col, L., and Griswold, C. 2008b. The Northeast US continental shelf Energy Modeling and Analysis exercise (EMAX): Ecological network model development and basic ecosystem metrics. Journal of Marine Systems 74(1-2): 453-474.

Link, J.S. 2007. Underappreciated species in ecology: "ugly fish" in the northwest Atlantic Ocean. Ecol. Appl. 17(7): 2037-2060.

Link, J.S., and Almeida, F.P. 2000. An overview and history of the Food Web Dynamics Program of the Northeast Fisheries Science Center, Woods Hole, Massachusetts. NOAA Tech. Memo. NMFS-NE-159. 
Link, J.S., Bogstad, B., Sparholt, H., and Lilly, G.R. 2009. Trophic role of Atlantic cod in the ecosystem. Fish and Fisheries 10(1): 58-87.

Link, J.S., Brodziak, J.K.T., Edwards, S.F., Overholtz, W.J., Mountain, D., Jossi, J.W., Smith, T.D., and Fogarty, M.J. 2002. Marine ecosystem assessment in a fisheries management context. Can. J. Fish. Aquat. Sci. 59(9): 1429-1440.

Link, J.S., Bundy, A., Overholtz, W.J., Shackell, N., Manderson, J., Duplisea, D., Hare, J., Koen-Alonso, M., and Friedland, K.D. 2011. Ecosystem-based fisheries management in the Northwest Atlantic. Fish and Fisheries 12(2): 152-170.

Link, J.S., and Garrison, L.P. 2002a. Changes in piscivory associated with fishing induced changes to the finfish community on Georges Bank. Fish. Res. 55(1-3): 71-86.

Link, J.S., and Garrison, L.P. 2002b. Trophic ecology of Atlantic cod Gadus morhua on the northeast US continental shelf. Mar. Ecol. Prog. Ser. 227: 109-123.

Link, J.S., Lucey, S.M., and Melgey, J.H. 2012. Examining cannibalism in relation to recruitment of silver hake Merluccius bilinearis in the U.S. northwest Atlantic. Fish. Res. 114: 31-41.

Link, J.S., and Sosebee, K. 2008. Estimates and implications of skate consumption in the northeast US Continental Shelf ecosystem. N. Am. J. Fish. Manag. 28(3): 649662.

Lubchenco, J., and Sutley, N. 2010. Proposed US policy for ocean, coast, and Great Lakes stewardship. Science 328(5985): 1485-1486.

McAllister, M.K., and Ianelli, J.N. 1997. Bayesian stock assessment using catch-age data and the sampling - Importance resampling algorithm. Can. J. Fish. Aquat. Sci. 54(2): 284-300.

Methratta, E.T., and Link, J.S. 2006. Evaluation of quantitative indicators for marine fish communities. Ecological Indicators 6(3): 575-588.

Moustahfid, H., Link, J.S., Overholtz, W.J., and Tyrrell, M.C. 2009a. The advantage of explicitly incorporating predation mortality into age-structured stock assessment models: an application for Atlantic mackerel. ICES J. Mar. Sci. 66(3): 445-454. 
Moustahfid, H., Tyrrell, M.C., and Link, J.S. 2009b. Accounting explicitly for predation mortality in surplus production models: an application to longfin inshore squid. N. Am. J. Fish. Manag. 29(6): 1555-1566.

Moustahfid, H., Tyrrell, M.C., Link, J.S., Nye, J.A., Smith, B.E., and Gamble, R.J. 2010. Functional feeding responses of piscivorous fishes from the northeast US continental shelf. Oecologia 163(4): 1059-1067.

Murawski, S.A. 2000. Definitions of overfishing from an ecosystem perspective. ICES J. Mar. Sci. 57(3): 649-658.

Nammack, M.F., Musick, J.A., and Colvocoresses, J.A. 1985. Life history of spiny dogfish off the northeastern United States. Trans. Am. Fish. Soc. 114(3): 367-376.

NEFSC (Northeast Fisheries Science Center). 2008. Assessment of 19 northeast groundfish stocks through 2007: Report of the 3rd Groundfish Assessment Review Meeting (GARM III), Northeast Fisheries Science Center, Woods Hole, Massachusetts, August 4-8, 2008. Northeast Fish. Sci. Cent. Ref. Doc. 08-15, NOAA - National Marine Fisheries Service, Woods Hole, MA.

NEFSC (Northeast Fisheries Science Center). 2010. 50th Northeast Regional Stock Assessment Workshop (50th SAW) Assessment Report. Northeast Fish. Sci. Cent. Ref. Doc. 10-17, NOAA - National Marine Fisheries Service, Woods Hole, MA.

Newberger, T.A., and Houde, E.D. 1995. Population Biology of bay anchovy Anchoa mitchilli in the mid Chesapeake Bay. Marine Ecology-Progress Series 116(1-3): 25-37.

Overholtz, W.J., Hare, J.A., and Keith, C.M. 2011. Impacts of Interannual Environmental Forcing and Climate Change on the Distribution of Atlantic Mackerel on the U.S. Northeast Continental Shelf. Marine and Coastal Fisheries: Dynamics, Management, and Ecosystem Science 3(1): 219-232.

Overholtz, W.J., Jacobson, L.D., and Link, J.S. 2008. An ecosystem approach for assessment advice and biological reference points for the Gulf of Maine-Georges Bank Atlantic herring complex. N. Am. J. Fish. Manag. 28(1): 247-257.

Overholtz, W.J., Jacobson, L.D., Melvin, G.D., Cieri, M., Power, M., Libby, D., and Clark, K. 2004. Stock assessment of the Gulf of Maine - Georges Bank Atlantic 
herring complex, 2003. Northeast Fish. Sci. Cent. Ref. Doc. 04-06, NOAA National Marine Fisheries Service, Woods Hole, MA.

Overholtz, W.J., and Link, J.S. 2007. Consumption impacts by marine mammals, fish, and seabirds on the Gulf of Maine-Georges Bank Atlantic herring (Clupea harengus) complex during the years 1977-2002. ICES J. Mar. Sci. 64(1): 83-96.

Overholtz, W.J., Link, J.S., and Suslowicz, L.E. 1999. Consumption and harvest of pelagic fishes and squids in the Gulf of Maine-Georges Bank ecosystem. In Ecosystem approaches for fisheries management. Alaska Sea Grant College Program, AK-SG-99-01, Fairbanks, Alaska. pp. 163-186.

Overholtz, W.J., Link, J.S., and Suslowicz, L.E. 2000. Consumption of important pelagic fish and squid by predatory fish in the northeastern USA shelf ecosystem with some fishery comparisons. ICES J. Mar. Sci. 57(4): 1147-1159.

Pauly, D., Christensen, V., Dalsgaard, J., Froese, R., and Torres, F. 1998. Fishing down marine food webs. Science 279(5352): 860-863.

Penttila, J.A., Nelson, G.A., and Burnett, J.M. 1989. Guidelines for estimating lengths at age for 18 northwest Atlantic finfish and shellfish species. NOAA Tech. Memo. NMFS-F/NEC-66.

Quinn, T.J., and Collie, J.S. 2005. Sustainability in single-species population models. Philosophical Transactions of the Royal Society B-Biological Sciences 360(1453): 147-162.

Richards, R.A., Nitschke, P.C., and Sosebee, K.A. 2008. Population biology of monkfish Lophius americanus. ICES J. Mar. Sci. 65(7): 1291-1305.

Scientific and Statistical Committee NEFMC. 2010. White paper on ecosystem-based fishery management for New England Fishery Management Council. p. 25.

Sette, O.E. 1950. Biology of Atlantic mackerel (Scomber scombrus) of North America. Part II. Migrations and habits. U.S. Fish Wildl. Serv. Fish. Bull. 51: 251-358.

Shepherd, G., Cieri, M., Power, M., and Overholtz, W. 2009. Transboundary Resources Assessment Committee Gulf of Maine/Georges Bank Atlantic Herring Stock Assessment Update. TRAC Ref. Doc. 2009/04. 
Sherman, K., Celone, P., and Adams, S. 2004. NOAA Fisheries Service's Large Marine Ecosystems Program: Status Report. NOAA Tech. Memo. NMFS-NE-183.

Smith, B.E., and Link, J.S. 2010. The trophic dynamics of 50 finfish and 2 squid species on the Northeast US Continental Shelf. NOAA Tech. Memo. NMFS-NE-216.

Sosebee, K., Jacobson, L., Rago, P., and Traver, M. 2010. Spiny Dogfish - U.S. Models. TRAC Working Paper 2010/02.

Tsou, T.S., and Collie, J.S. 2001a. Estimating predation mortality in the Georges Bank fish community. Can. J. Fish. Aquat. Sci. 58(5): 908-922.

Tsou, T.S., and Collie, J.S. 2001b. Predation-mediated recruitment in the Georges Bank fish community. ICES J. Mar. Sci. 58(5): 994-1001.

Tyrrell, M.C., Link, J.S., Moustahfid, H., and Overholtz, W.J. 2008. Evaluating the effect of predation mortality on forage species population dynamics in the Northeast US continental shelf ecosystem using multispecies virtual population analysis. ICES J. Mar. Sci. 65(9): 1689-1700.

Tyrrell, M.C., Link, J.S., Moustahfid, H., and Smith, B.E. 2007. The dynamic role of pollock (Pollachius virens) as a predator in the Northeast US continental shelf ecosystem: a multi-decadal perspective. J. Northwest Atl. Fish. Sci. 38: 53-65.

Wigley, S.E., McBride, H.M., and McHugh, N.J. 2003. Length-weight relationships for 74 fish species collected during NEFSC research vessel bottom trawl sureys, 1992-99. NOAA Tech. Memo. NMFS-NE-171. 
Table 1. Input data sources for each species.

\begin{tabular}{|c|c|c|c|c|c|c|}
\hline Species & $\begin{array}{c}\text { Total commercial } \\
\text { catch }\end{array}$ & $\begin{array}{l}\text { Total survey } \\
\text { catch }\end{array}$ & $\begin{array}{l}\text { Commercial catch age } \\
\text { (length) proportions }\end{array}$ & $\begin{array}{l}\text { Survey catch age } \\
\text { (length) proportions }\end{array}$ & Weight-at-age & Length-at-age \\
\hline Atlantic cod & NEFSC 2008 & NEFSC 2008 & NEFSC $2008^{1}$ & NEFSC $2008^{1}$ & NEFSC 2008 & Penttila et al. 1989 \\
\hline Atlantic herring & $\begin{array}{l}\text { Shepherd et al. } \\
2009\end{array}$ & $\begin{array}{l}\text { Shepherd et al. } \\
2009^{3}\end{array}$ & $\begin{array}{l}\text { 1978-2007: Overholtz } \\
\text { et al. 2004 } \\
\text { 2003-2007: missing }\end{array}$ & Shepherd et al. $2009^{1,3}$ & Shepherd et al. 2009 & Penttila et al. 1989 \\
\hline $\begin{array}{l}\text { Atlantic } \\
\text { mackerel }\end{array}$ & $\begin{array}{l}\text { Grégoire and } \\
\text { Maguire 2010b }\end{array}$ & $\begin{array}{l}\text { Grégoire and } \\
\text { Maguire } 2010 \mathrm{a}^{3}\end{array}$ & $\begin{array}{l}\text { Grégoire and Maguire } \\
2010 b^{1}\end{array}$ & $\begin{array}{l}\text { Grégoire and Maguire } \\
2010 a^{1,3}\end{array}$ & $\begin{array}{l}\text { Grégoire and Maguire } \\
2010 \mathrm{~b}\end{array}$ & Penttila et al. 1989 \\
\hline Goosefish & NEFSC 2010 & NEFSC $2010^{3}$ & $\begin{array}{l}\text { 1994-2007: NEFSC } \\
\text { database }^{2} \text {, Age length } \\
\text { key(NEFSC 2010); } \\
\text { 1978-1993: missing }\end{array}$ & $\begin{array}{l}\text { NEFSC database }{ }^{2,3} \text {, } \\
\text { Age length key } \\
\text { (NEFSC 2010) }\end{array}$ & $\begin{array}{l}\text { Time-invariant: } \\
\text { Mean length-at-age, } \\
\text { Length-weight } \\
\text { parameters (Richards } \\
\text { et al. 2008) }\end{array}$ & $\begin{array}{l}\text { Richards et al. } \\
2008\end{array}$ \\
\hline Pollock & NEFSC 2010 & NEFSC $2010^{3}$ & NEFSC $2010^{1}$ & NEFSC $2010^{1,3}$ & NEFSC 2010 & Penttila et al. 1989 \\
\hline Silver hake & NEFSC database $^{4}$ & NEFSC database & $\begin{array}{l}\text { 1978-1999: Brodziak et } \\
\text { al. 2001'; } \\
\text { 2000-2007: average } \\
\text { proportions }\end{array}$ & $\begin{array}{l}\text { 1978-2004: NEFSC } \\
\text { database }^{1} ; \\
\text { 2005-2007: average } \\
\text { proportions }^{5}\end{array}$ & $\begin{array}{l}\text { 1978-1999: Brodziak } \\
\text { et al. 2001; } \\
\text { 2000-2007: average } \\
\text { weight-at-age }\end{array}$ & Penttila et al. 1989 \\
\hline Spiny dogfish & $\begin{array}{l}\text { Sosebee et al. } \\
2010\end{array}$ & NEFSC database & $\begin{array}{l}\text { 1982-2007: NEFSC } \\
\text { Database } \\
\text { 1978-1981: average } \\
\text { proportions }^{5}\end{array}$ & NEFSC database ${ }^{2}$ & $\begin{array}{l}\text { Time Invariant: } \\
\text { Von Bertalanffy } \\
\text { parameters } \\
\text { (Nammack et al. } \\
\text { 1985), Length-weight } \\
\text { parameters (Wigley et } \\
\text { al. 2003) }\end{array}$ & $\begin{array}{l}\text { Nammack et al. } \\
1985^{6}\end{array}$ \\
\hline White hake & NEFSC 2008 & NEFSC $2008^{3}$ & $\begin{array}{l}\text { 1989-2007: NEFSC } \\
\text { 2008 } \\
\text { 1978-1988: missing }\end{array}$ & $\begin{array}{l}\text { 1982-2007: NEFSC } \\
\text { 2008 } \\
\text { 1978-1981: average } \\
\text { proportions }\end{array}$ & $\begin{array}{l}\text { 1989-2007: NEFSC } \\
\text { 2008 } \\
\text { 1978-1988: average } \\
\text { proportions }\end{array}$ & $\begin{array}{l}\text { Sosebee, unpub. } \\
\text { data }\end{array}$ \\
\hline
\end{tabular}




\begin{tabular}{|c|c|c|c|c|c|c|}
\hline Species & $\begin{array}{c}\text { Total commercial } \\
\text { catch }\end{array}$ & $\begin{array}{c}\text { Total survey } \\
\text { catch }\end{array}$ & $\begin{array}{c}\text { Commercial catch age } \\
\text { (length) proportions }\end{array}$ & $\begin{array}{c}\text { Survey catch age } \\
\text { (length) proportions }\end{array}$ & Weight-at-age & Length-at-age \\
\hline Winter skate & NEFSC database $^{7}$ & NEFSC database ${ }^{8}$ & N/A & NEFSC database $\mathrm{e}^{2,8}$ & $\begin{array}{l}\text { Time invariant: } \\
\text { Length-weight } \\
\text { parameters (Frisk and } \\
\text { Miller 2006), Von } \\
\text { Bertalanffy } \\
\text { parameters (Frisk et } \\
\text { al. 2010) }\end{array}$ & Frisk et al. 2010 \\
\hline
\end{tabular}

${ }^{1}$ Age proportions

${ }^{2}$ Length proportions

${ }^{3}$ Survey catches were estimated for a wider geographic area than just Georges Bank; therefore, we assumed catches were representative of solely Georges Bank as well.

${ }^{4}$ Discards not available

${ }^{5}$ Average age-structure was used for years with missing data to minimize parameter confounding

${ }^{6}$ Averaged over sex

${ }^{7}$ Following Frisk et al. (2010), total skate recorded landings were assumed to be solely winter skate to scale landings for under-reporting. Likewise, the annual ratio of winter skate to little skate relative abundance from the NMFS trawl survey was used to estimate the proportion of total skate discards that represented winter skate in each year.

${ }^{8}$ Following Frisk et al. (2010), winter skate trawl survey indices only included individuals of $30 \mathrm{~cm}$ total length or greater due to identification difficulties of small skates. 
Table 2. Biological assumptions made for each modeled species. M1 represents the residual natural mortality rate assumed in the multispecies model.

\begin{tabular}{|c|c|c|c|c|c|c|}
\hline \multirow[b]{2}{*}{ Species } & \multirow[b]{2}{*}{ Ages } & \multirow[b]{2}{*}{ M1 } & \multirow[b]{2}{*}{ Average proportion on GB } & \multirow[b]{2}{*}{ NFMS trawl surveys } & \multicolumn{2}{|c|}{$\begin{array}{l}\text { Ages with estimated } \\
\text { selectivity parameters }\end{array}$} \\
\hline & & & & & survey & fishery \\
\hline Atlantic cod & $1-10$ & 0.2 & N/A: unit stock & Fall & $1-2$ & $1-3$ \\
\hline Atlantic herring & $1-6$ & 0.1 & 0.119 & Spring & 1 & 2 \\
\hline Atlantic mackerel & $1-10$ & 0.1 & 0.097 & Spring & 1 & $1-5$ \\
\hline Goosefish & $1-10$ & 0.3 & 0.089 & Spring/Fall & $1-5$ & $1-6$ \\
\hline Pollock & $1-9$ & 0.2 & 0.165 & Spring/Fall & $1-5$ & $1-7$ \\
\hline Silver hake & $1-6$ & 0.05 & 0.165 & Fall & 1 & $1-2$ \\
\hline Spiny dogfish & $0-30$ & 0.092 & 0.103 & Spring/Fall & $1-3$ & $13-14$ \\
\hline White hake & $1-7$ & 0.2 & Linear relationship $^{1}$ & Spring/Fall & $1-3$ & $1-2$ \\
\hline Winter skate & $1-21$ & 0.1 & 0.644 & Spring/Fall & $1-3$ & $1-3$ \\
\hline
\end{tabular}

${ }^{1}$ White hake linear relationship: Proportion $=-0.00094 *$ year +1.90 
Table 3: Size-preference coefficients estimated for each predator species from the observed distribution of logged (base $e$ ) predator-prey weight ratios.

\begin{tabular}{lccc}
\hline & $\eta$ & $\sigma_{1}$ & $\sigma_{2}$ \\
\hline \hline Spiny dogfish & 3.673 & 1.021 & 3.137 \\
Winter skate & 6.746 & 1.335 & 1.286 \\
Goosefish & 2.719 & 0.877 & 2.241 \\
Cod & 3.788 & 0.672 & 2.254 \\
Pollock & 4.400 & 0.769 & 2.052 \\
White hake & 1.950 & 0.266 & 2.845 \\
Silver hake & 2.100 & 0.520 & 2.304 \\
\hline
\end{tabular}




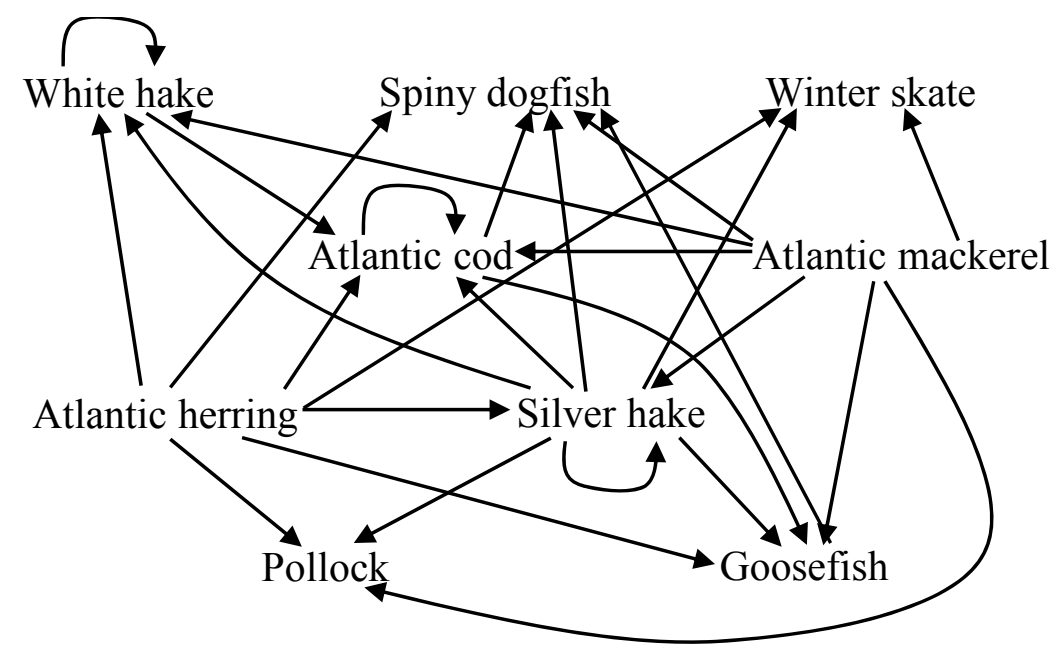

Figure 1. Predation interactions between the nine modeled Georges Bank fish species. The arrows point from prey to predator species. 

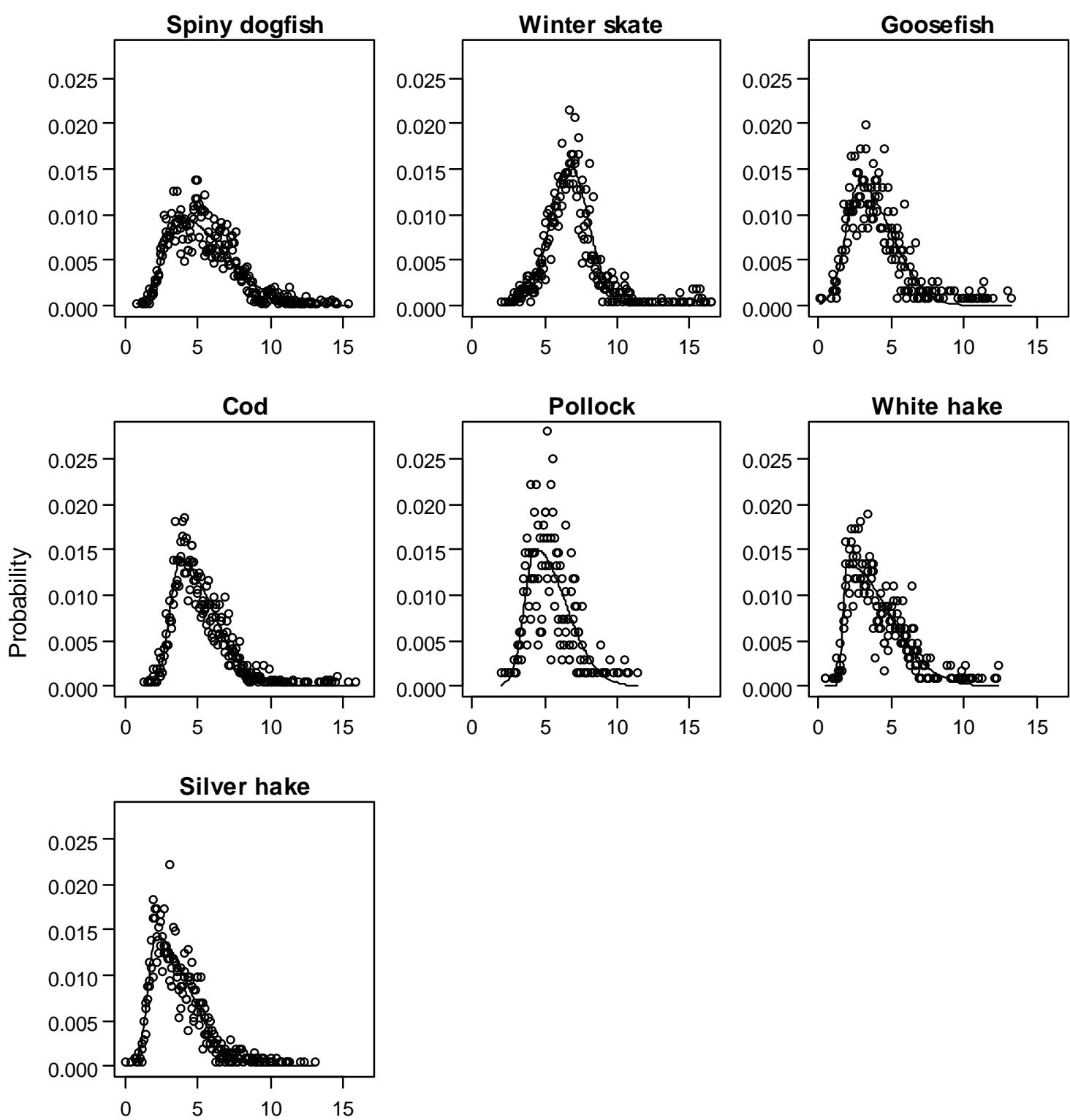

Log (Predator Wt / PreyWt)

Figure 2: Observed (open circles) and predicted (lines) distribution of the logged ratio of predator-to-prey weight for each predator species. 

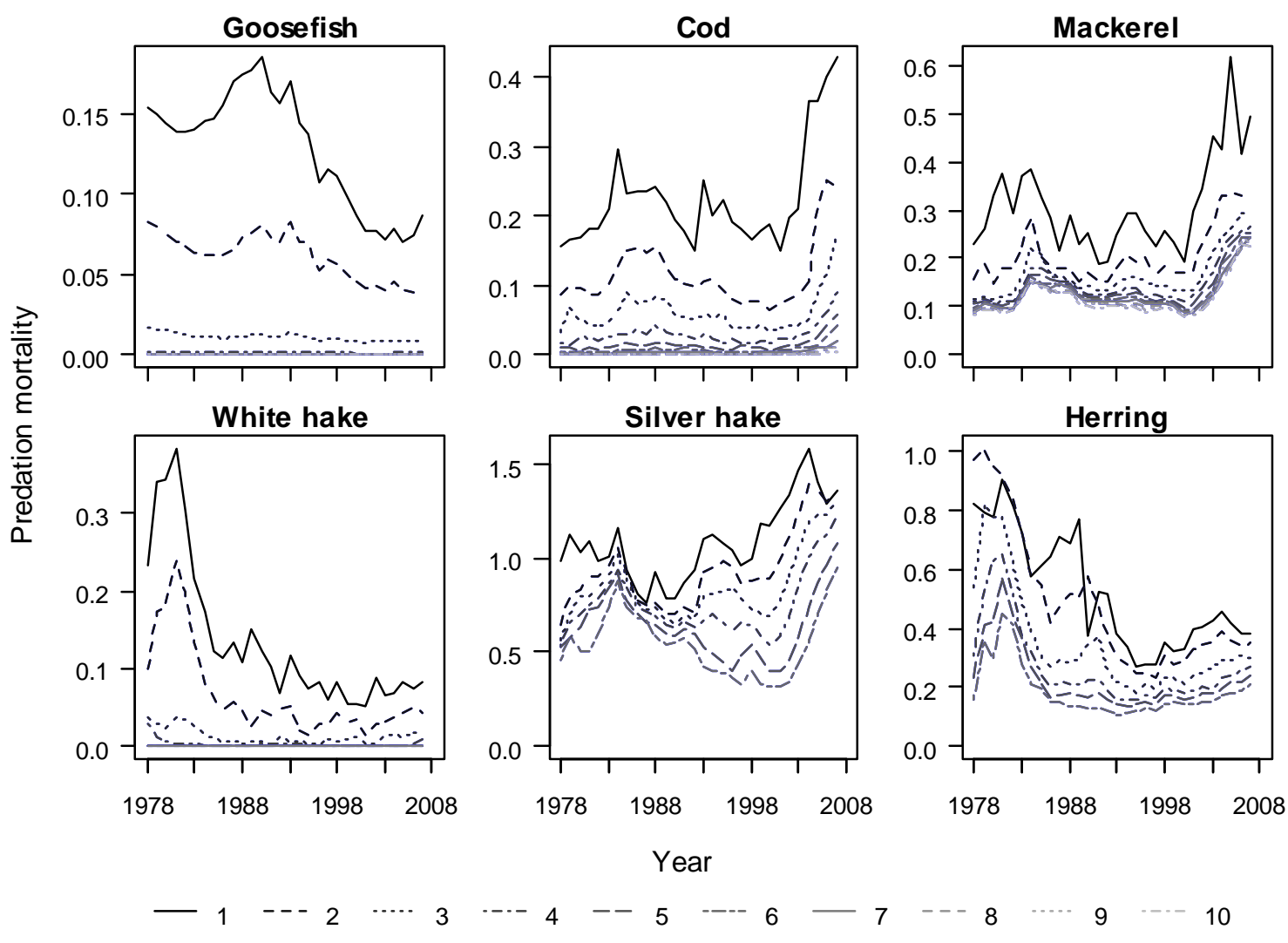

Figure 3: Age-specific predation mortality rates for each prey species. Each line represents an age class. 

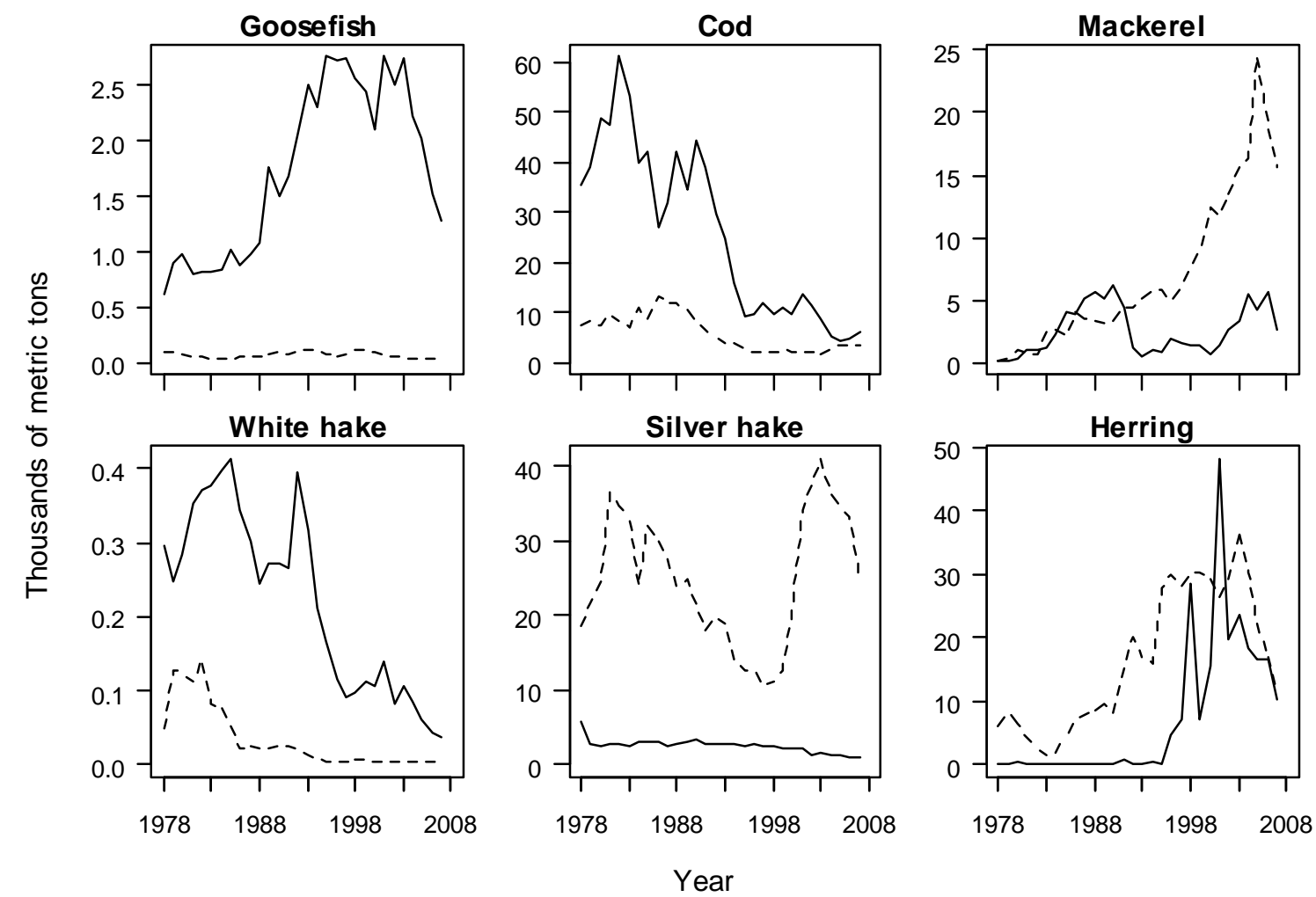

Figure 4: Total annual catch (solid line) and biomass consumed (dashed line) of each prey species. 

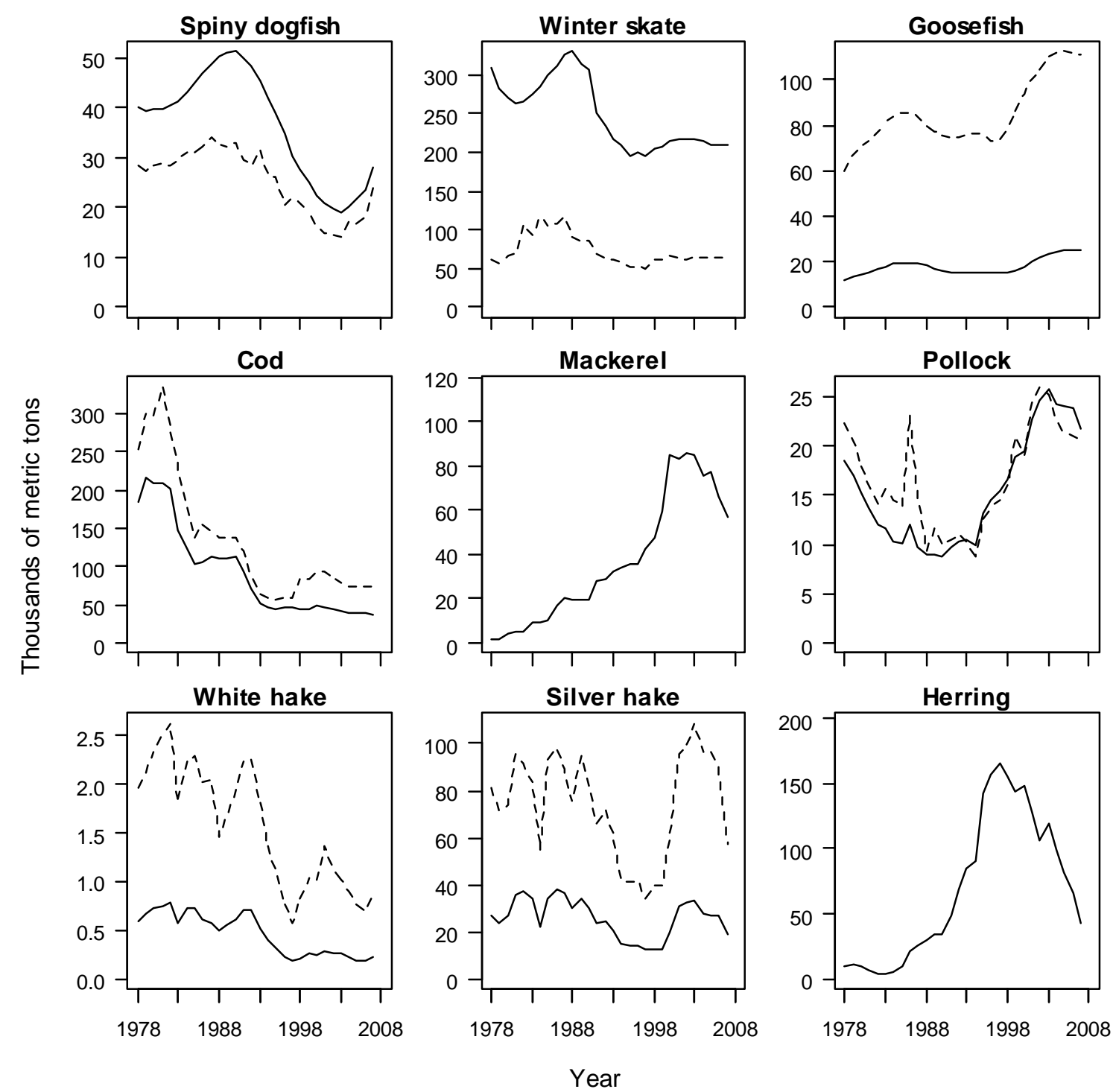

Figure 5: Total annual species-specific biomass (solid line) and consumption (dotted line) of all prey species, including other food. Consumption by herring or mackerel was not calculated. 

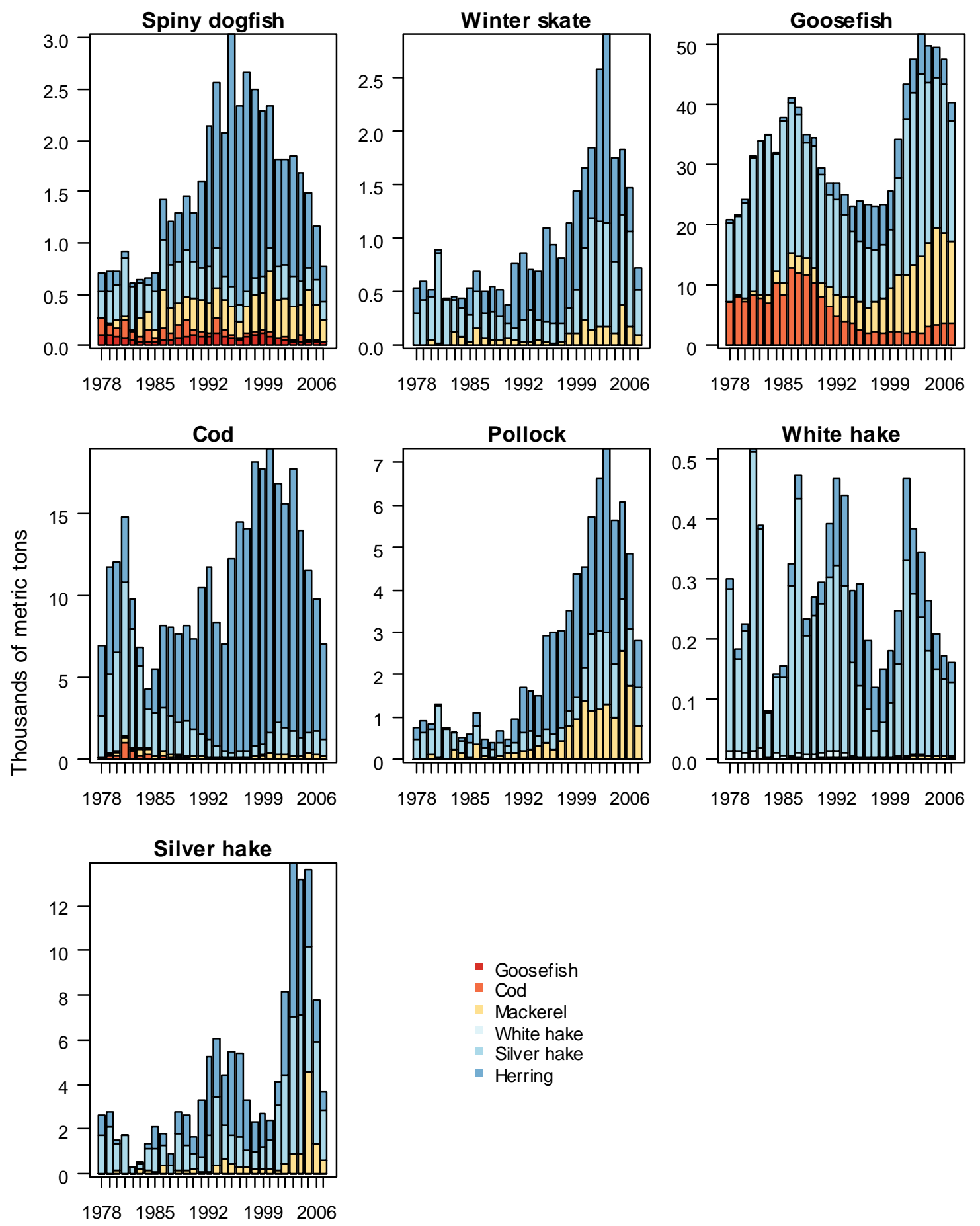

Figure 6: Total annual co
by each predator species. 

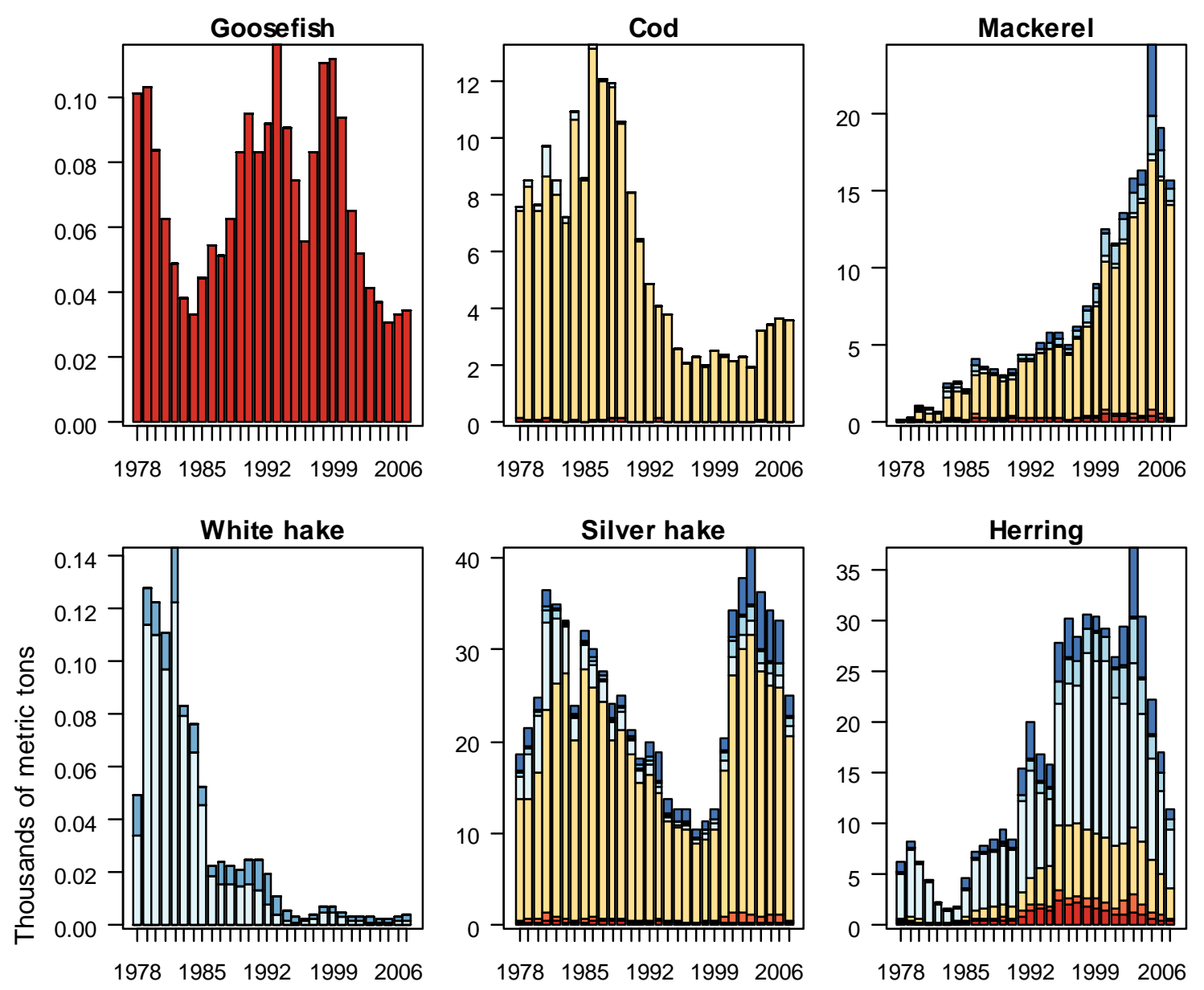

Predator species

- Spiny dogfish

- Winter skate

- Goosefish

Cod

- Pollock

- White hake

- Silver hake

Year

Figure 7: Annual predator-specific consumption (thousands of metric tons) of each prey species. 

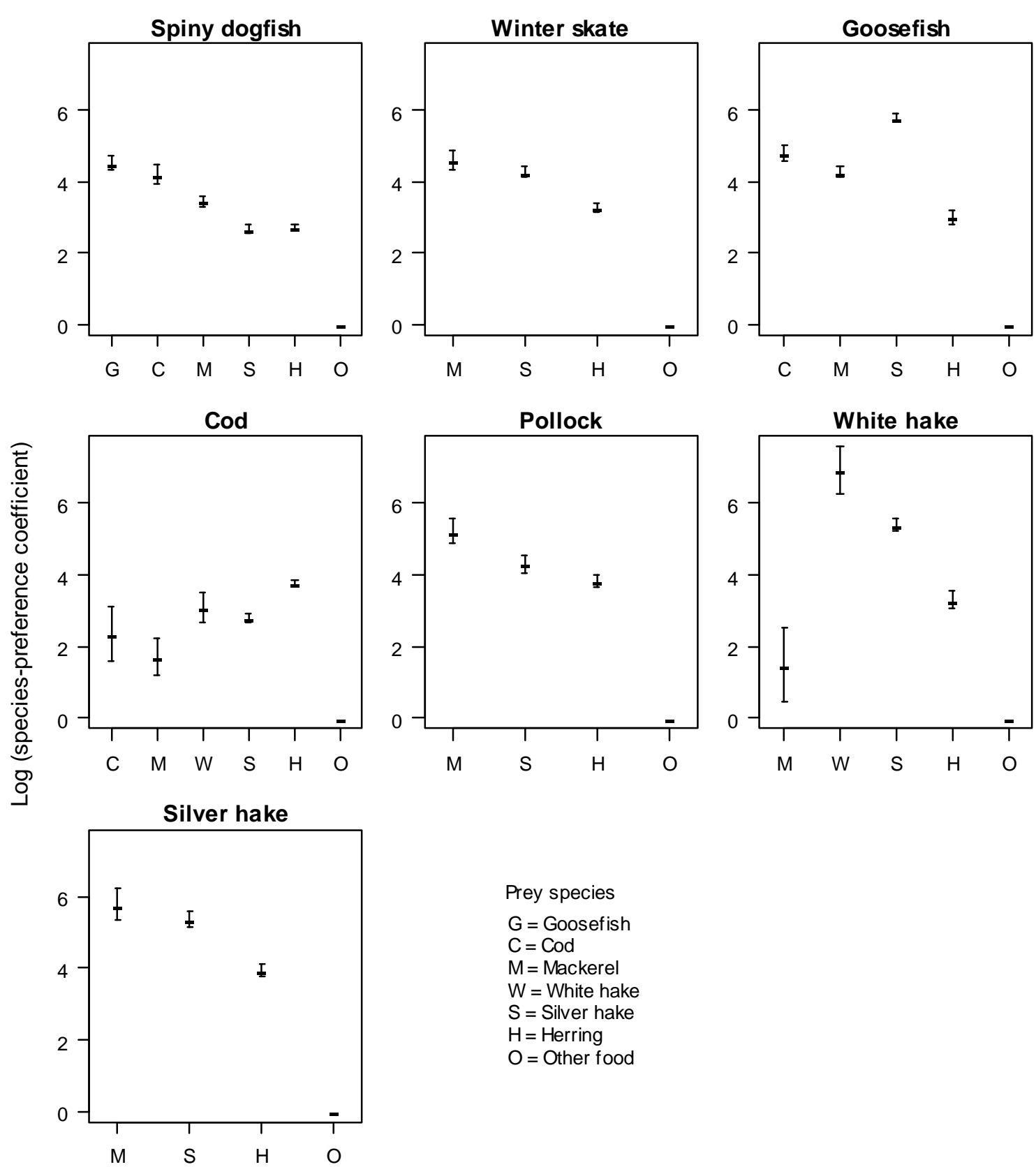

$$
\begin{aligned}
& \text { Prey species } \\
& \mathrm{G}=\text { Goosefish } \\
& \mathrm{C}=\mathrm{Cod} \\
& \mathrm{M}=\text { Mackerel } \\
& \mathrm{W}=\text { White hake } \\
& \mathrm{S}=\text { Silver hake } \\
& \mathrm{H}=\text { Herring } \\
& \mathrm{O}=\text { Other food }
\end{aligned}
$$

Prey species

Figure 8: Prey species-preference coefficients for each species interaction. 


\section{SUPPLEMENTAL MATERIAL}
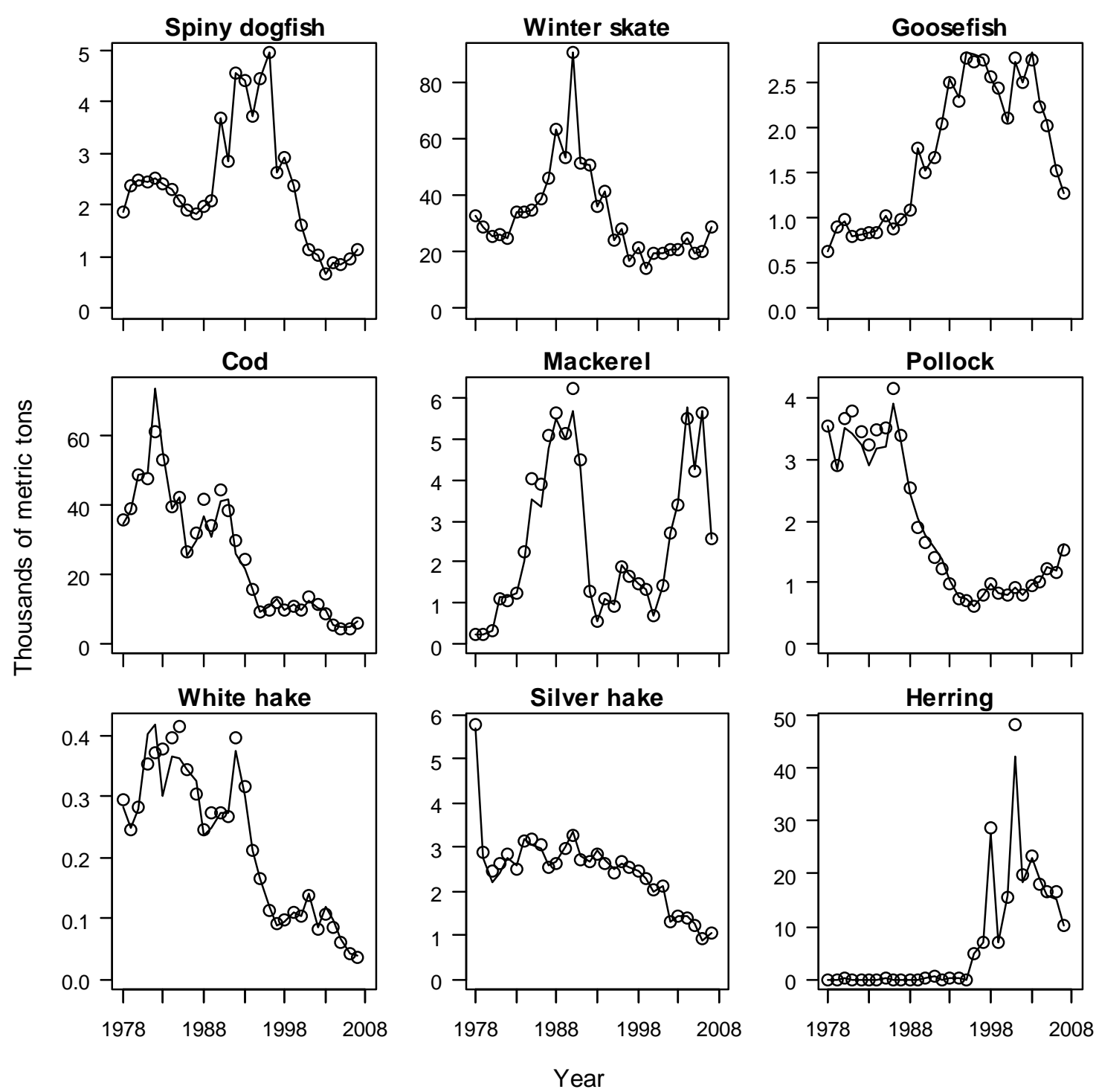

Figure S1: Total annual fisheries catch (thousands of metric tons) for each modeled species. In the multispecies formulation, spiny dogfish and winter skate catches do not exhibit any deviations because their dynamics were assumed to be known inputs. 
a)
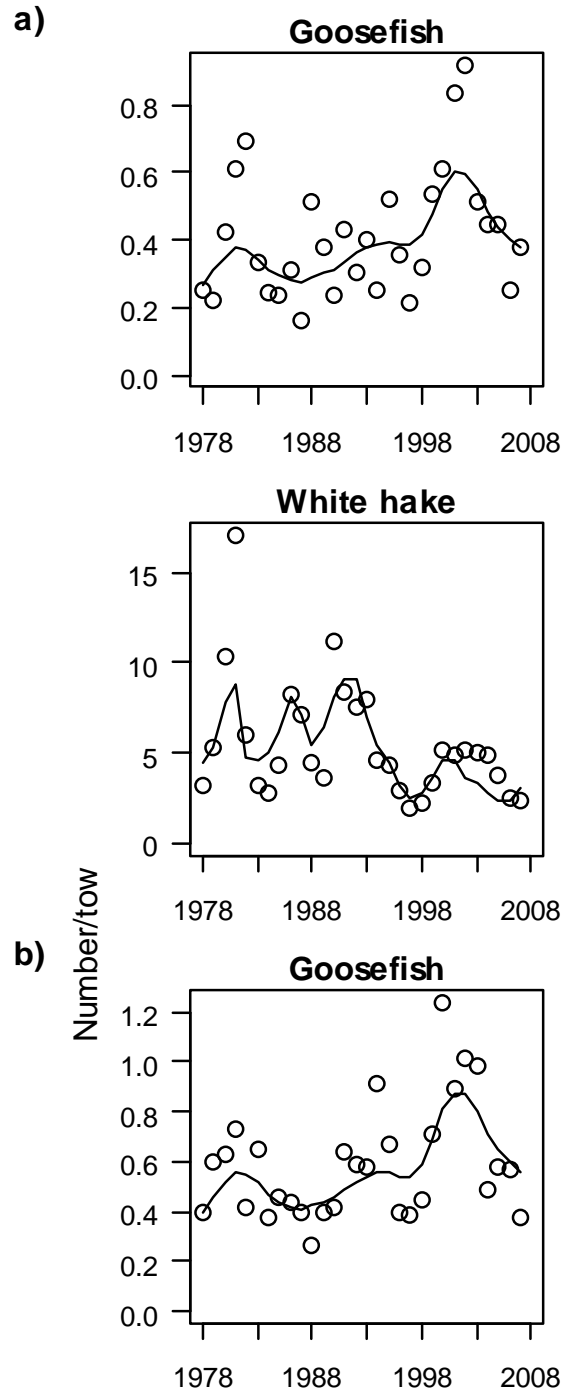

White hake

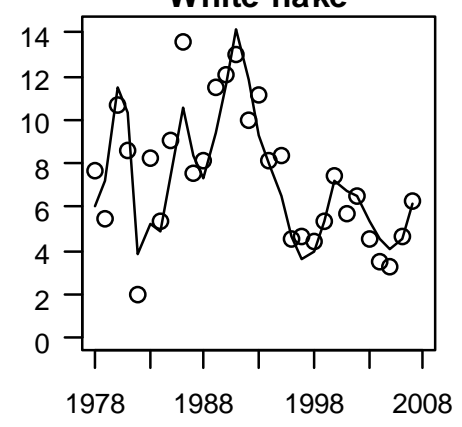

Mackerel

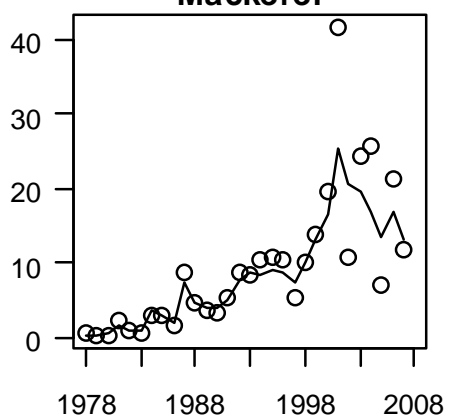

Herring
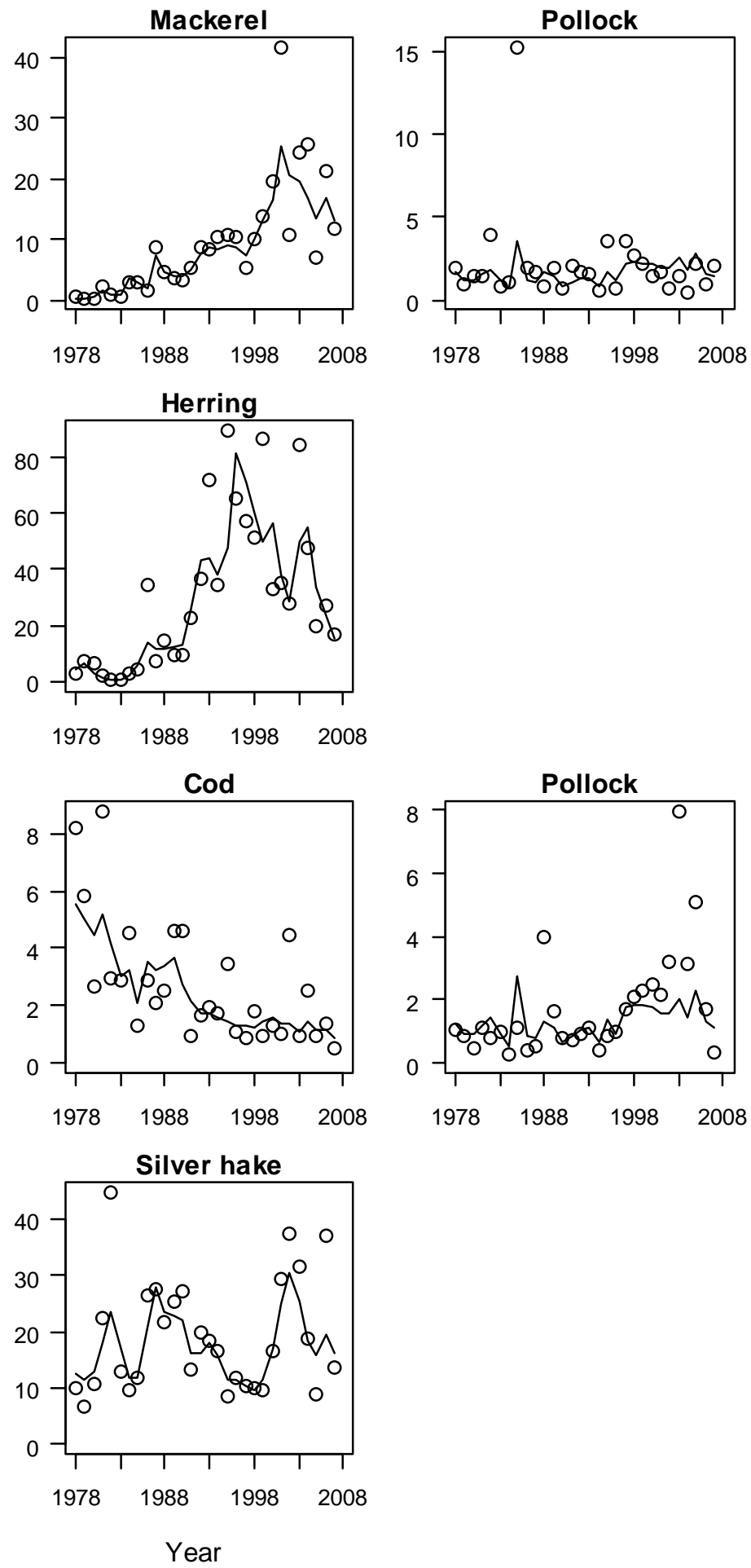

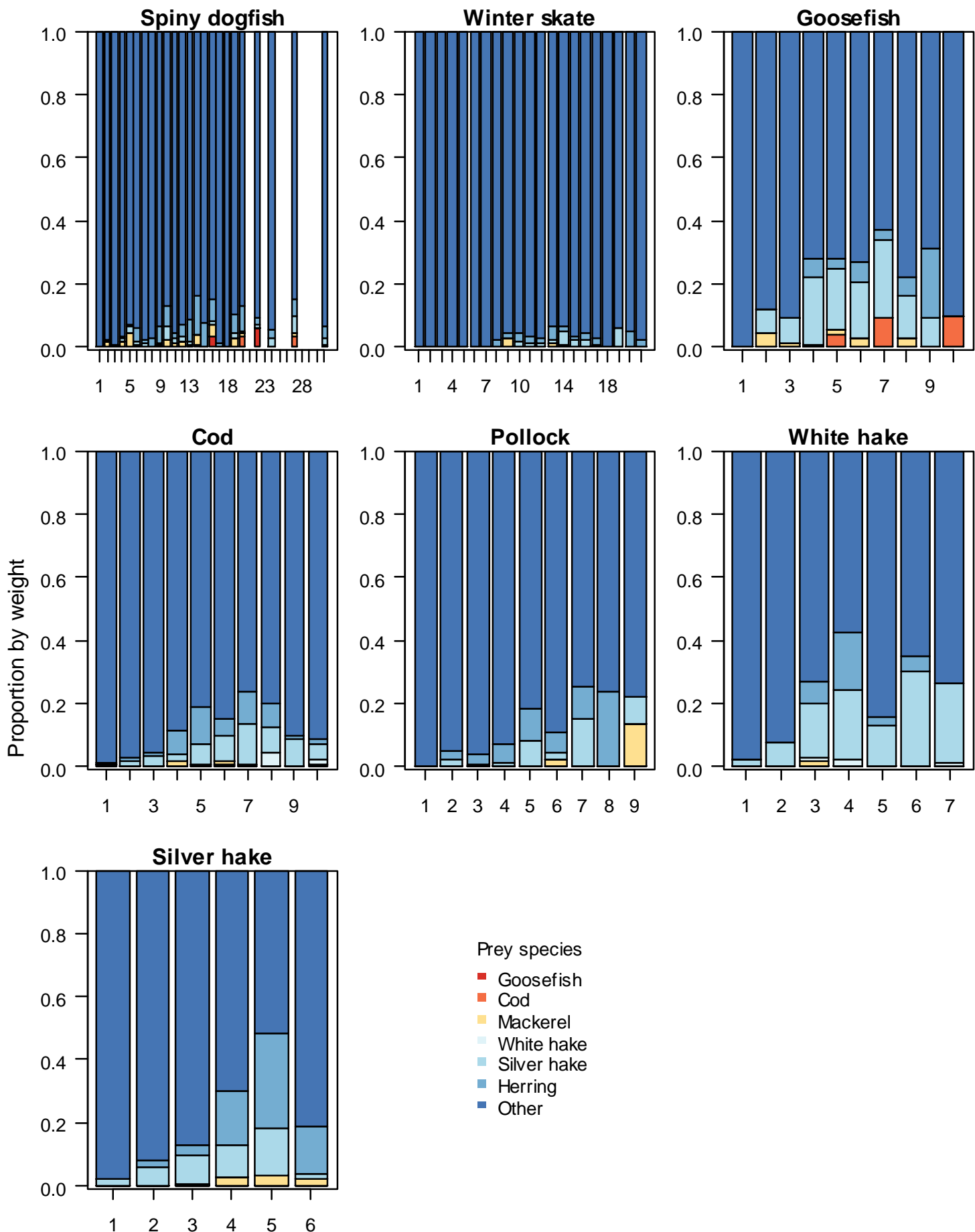

\footnotetext{
Prey species

- Goosefish

- Cod

Mackerel

White hake

- Silver hake

- Herring

- Other
}

Age

Figure S3: Observed average predator diet composition by age, represented as the proportion by weight of a particular prey item to the total stomach-content weight. 

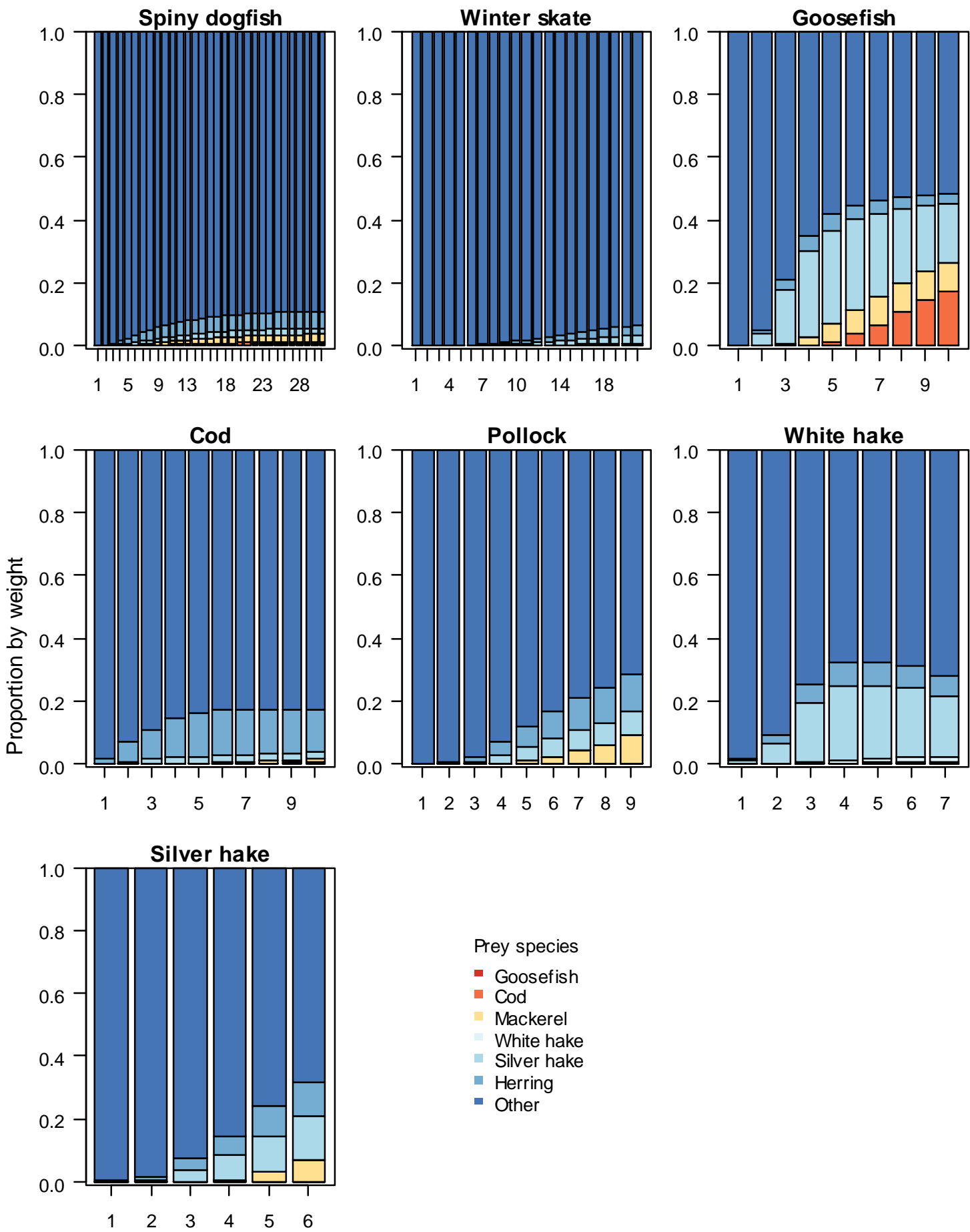

\footnotetext{
Prey species

- Goosefish

- Cod

Mackerel

White hake

- Silver hake

- Herring

- Other
}

Age

Figure S4: Predicted average predator diet composition by age, represented as the proportion by weight of a particular prey item to the total stomach-content weight 

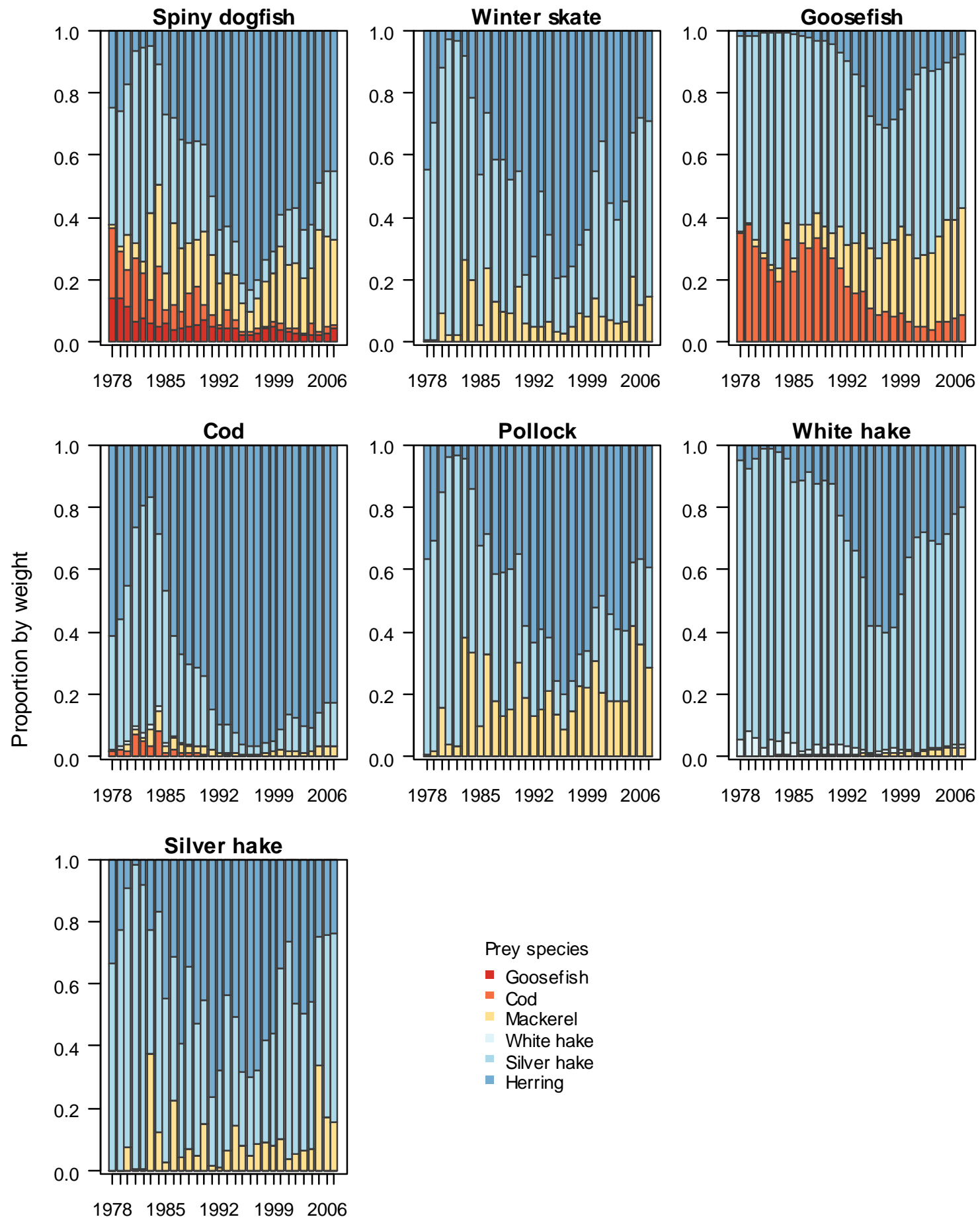

$$
\begin{aligned}
& \text { Prey species } \\
& \text { - Goosefish } \\
& \text { - Cod } \\
& \text { - Mackerel } \\
& \text { White hake } \\
& \text { - Silver hake } \\
& \text { - Herring }
\end{aligned}
$$

Figure S5: Predicted average predator diet composition of modeled fish species in each year, represented as the proportion by weight of a particular prey item to the total weight of modeled fish prey consumed. 
Age 1

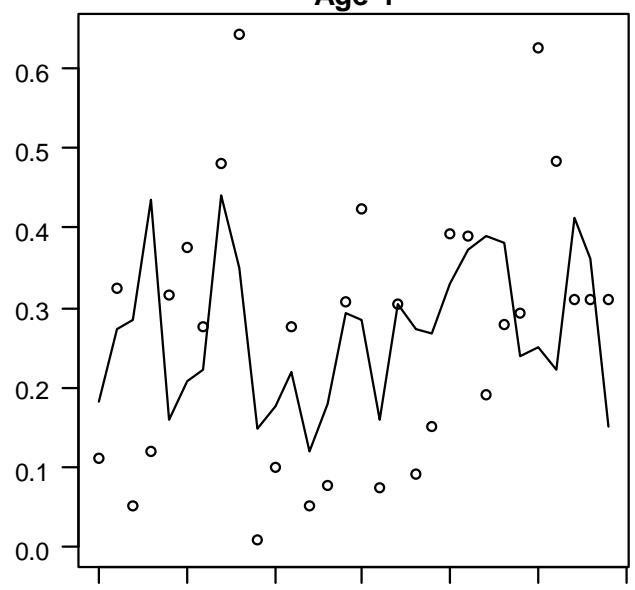

Age 2
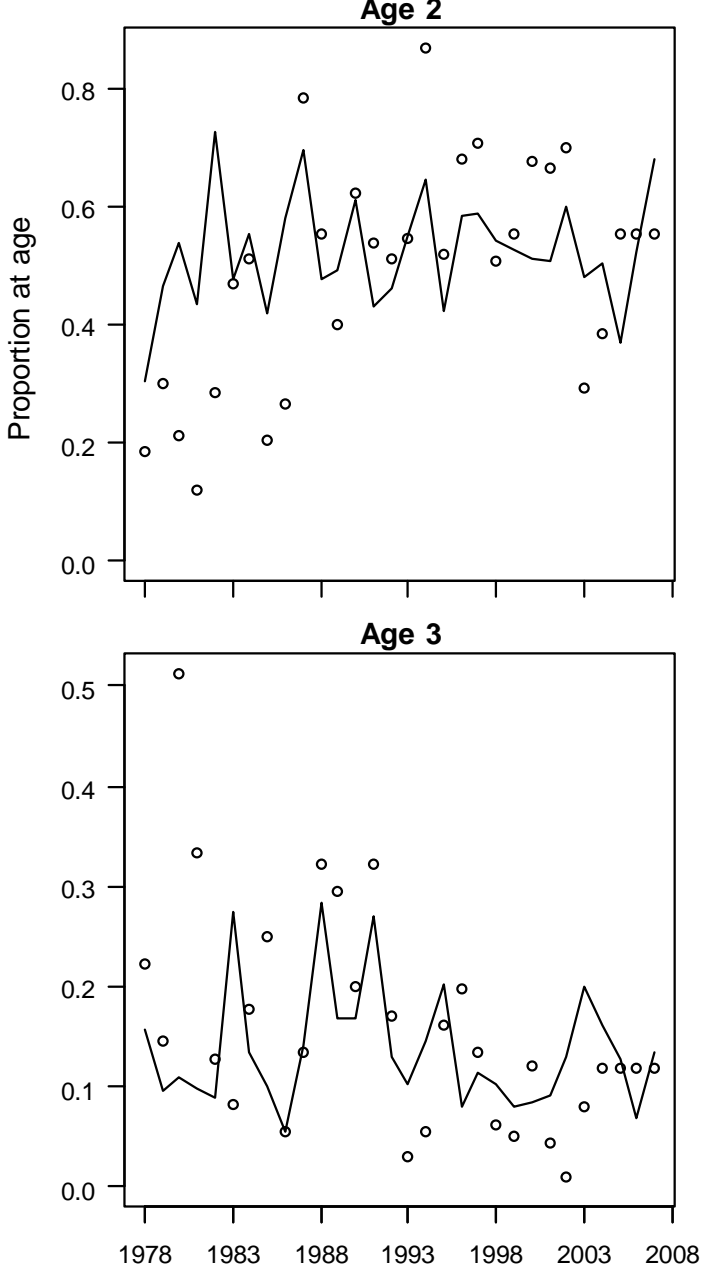

Age 4

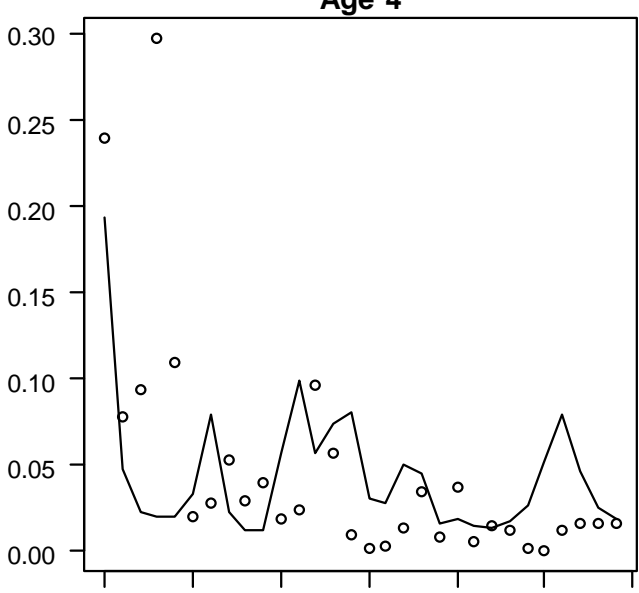

Age 5

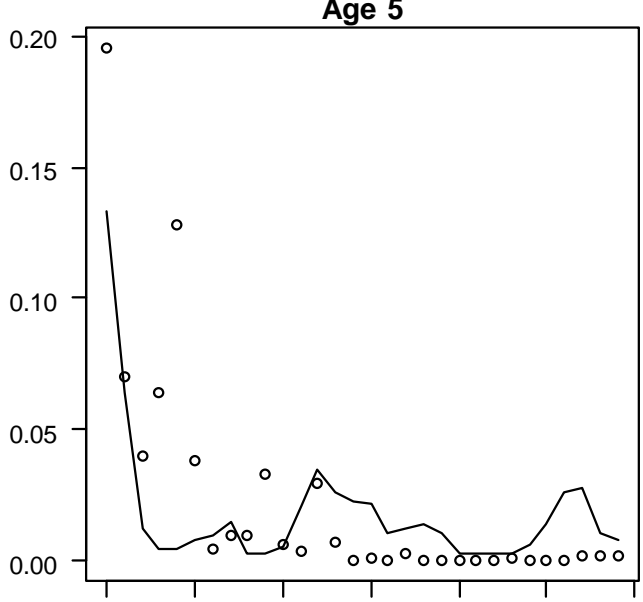

Age 6

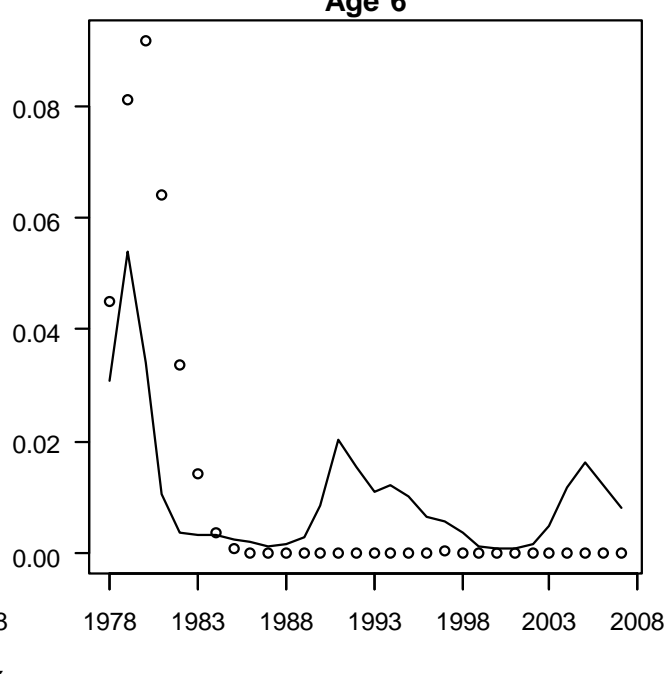

Figure S6: Silver hake observed (circles) and predicted (line) proportions-at-age of the spring trawl survey. 
Age 1

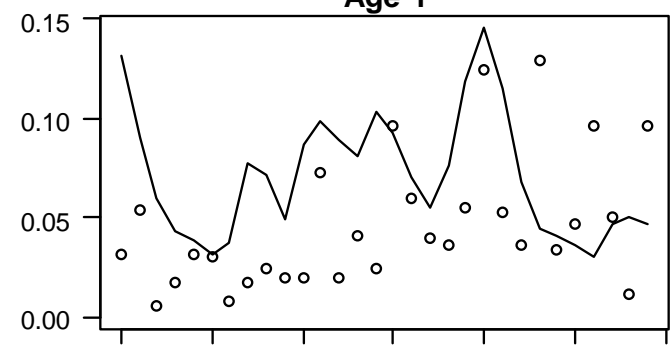

Age 2
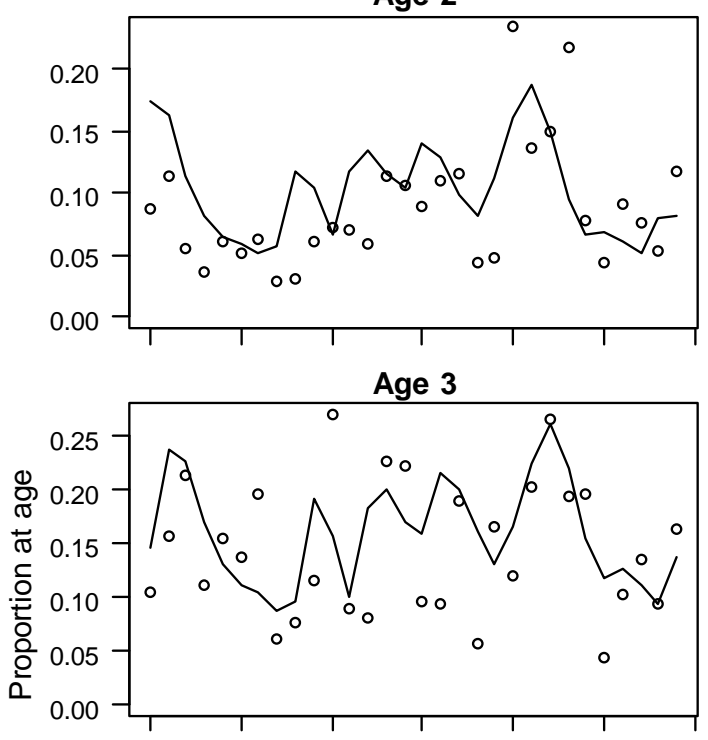

Age 4

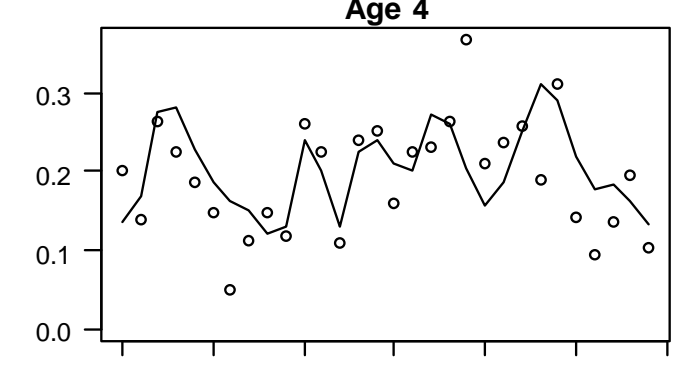

Age 5

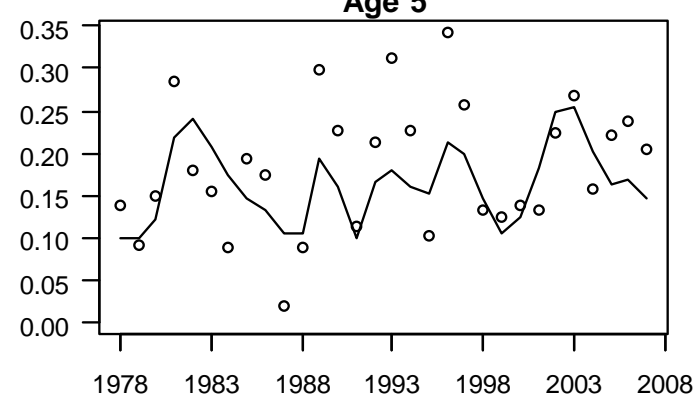

Age 6

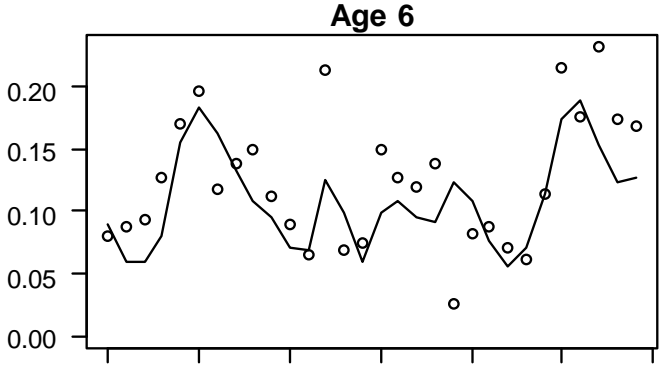

Age 7

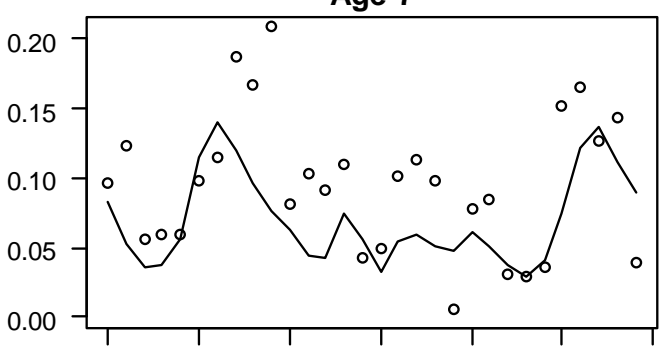

Age 8

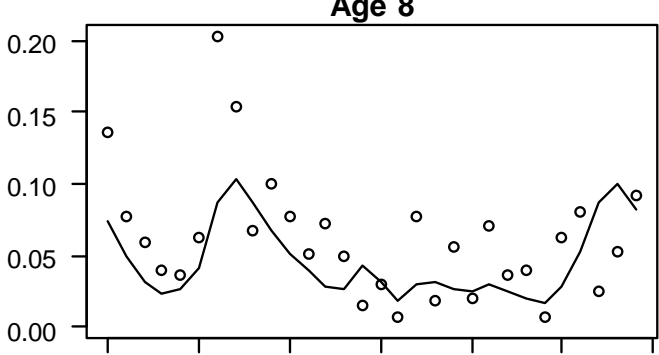

Age 9

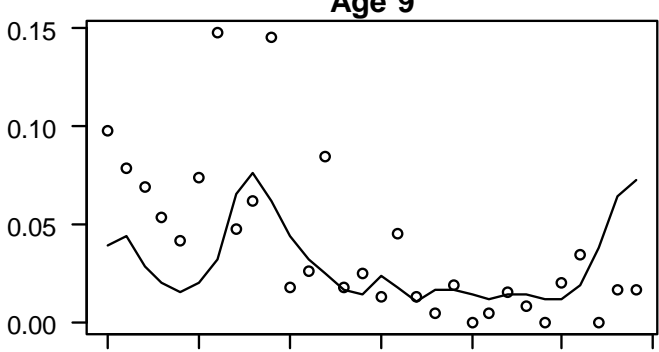

Age 10

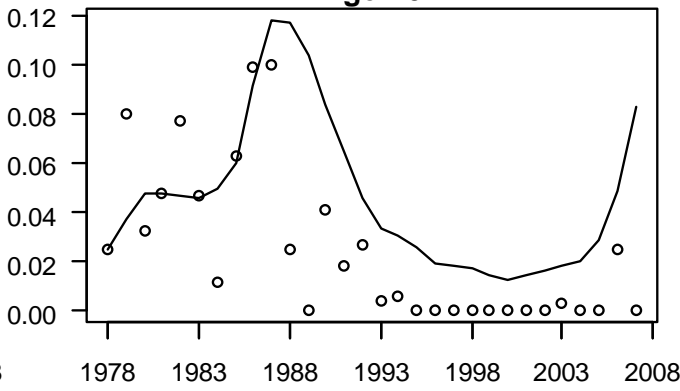

Year

Figure S7: Goosefish observed (circles) and predicted (line) proportions-at-age of the spring trawl survey. 


\section{MANUSCRIPT - III}

Intended for submission to Fisheries Research

\section{Multispecies management of the Georges Bank fish community}

Kiersten L. Curti and Jeremy S. Collie

Graduate School of Oceanography; University of Rhode Island; 215 South Ferry

Road; Narragansett, RI 02882 USA

\section{Christopher M. Legault}

National Marine Fisheries Service, Northeast Fisheries Science Center; 166 Water

Street; Woods Hole, MA 02543 USA 


\begin{abstract}
A key tenet to an ecosystem approach to fisheries is the explicit consideration of multiple, and potentially conflicting, objectives. Here we use stochastic forward projections to examine biomass trade-offs and the consequences of various fishing scenarios, while accounting for predation interactions among species. Forward projections are developed with a multispecies statistical catch-at-age model that incorporates nine fish species within the Georges Bank community. In particular, we explore the role of principal prey and intermediate predator-prey species. Stochastic projections indicated strong interactions among modeled species, though the interactions were not always direct. Examples of indirect interactions included the effect of goosefish on herring and similarly, the impact of goosefish on white hake. Consequently, population responses to fishing were a function of not only the rates of fishing, but also of these direct and indirect interactions among species. Further work is warranted to explore the sensitivity of projections to differing assumptions regarding recruitment and predator functional response. Yet, this framework represents a useful tool for investigating fisheries management scenarios within a multispecies framework.
\end{abstract}

\title{
KEYWORDS
}

stochastic forward projections, Georges Bank, multispecies statistical catch-at-age model 


\section{INTRODUCTION}

A key tenet to an ecosystem approach to fisheries is the explicit consideration of interactions among ecosystem components (Link 2010, Link et al. 2011). These interactions include the impacts of fishing and other stressors on ecosystem structure and function (Link et al. 2008a) as well as conflicting objectives among stakeholders (Link 2002). Biomass interactions can arise from predatory interactions between multiple fish species or competition among predator species and humans for forage fish species. Within marine fisheries, there are several examples of potential biomass trade-offs, including striped bass and menhaden in the mid-Atlantic (Uphoff 2003), marine mammals and groundfish off of the east coast of Canada (Fu et al. 2001), replacement of gadids and flatfish by "under-appreciated" species such as goosefish on the Northeast U.S. (NEUS) Continental Shelf (Link 2007), and competition between piscivores and the fisheries for prey species (Link and Sosebee 2008, Overholtz et al. 2008, Moustahfid et al. 2009a). Some studies have suggested that the single-species estimates of MSY cannot be simultaneously attained for each species within a system due to species interactions and energetic constraints (May et al. 1979, Link et al. 2008b, NEFSC 2008, Link 2010). This possible constraint exemplifies the need to explicitly address biomass trade-offs among species.

The current fish community structure on Georges Bank is profoundly different than it was half of a century ago; high levels of exploitation by both distant-water and domestic fleets resulted in marked changes in ecosystem structure (Fogarty and Murawski 1998, Link et al. 2002a, EcoAP 2009). The community is now largely dominated by both pelagic and elasmobranch species, in contrast to a primarily demersal 
community with high abundances of groundfish before the severe exploitation increase of the second half of the twentieth century (Link et al. 2008a, EcoAP2009). Multiple studies have indicated that the dominant piscivore has shifted from cod to spiny dogfish or goosefish (Link and Garrison 2002, Link 2007, Overholtz and Link 2007). In addition, pelagic fish species such as herring and mackerel are considered to be critical forage species within the ecosystem (Link et al. 2008a, Link et al. 2008b). While the species composition of the NEUS ecosystem has changed considerably, several food-web properties, such as the biomass of aggregate species groups, have remained relatively constant, indicating a highly connected, resilient system (Link et al. 2008a, Link et al. 2008b, Auster and Link 2009).

Within the NEUS ecosystem, a variety of approaches have been used to incorporate species interactions into population dynamic models to evaluate the predation losses experienced by prey species. Collectively, these studies have demonstrated that predation is a dominant source of mortality; predatory losses often exceed fishery landings and can regulate the dynamics of prey species (Tsou and Collie 2001, Overholtz and Link 2007, Tyrrell et al. 2008, Moustahfid et al. 2009b). Through the development of a multispecies statistical catch-at-age model (Chapters 1 and 2), we have further demonstrated the role of predation on Georges Bank. We have demonstrated that predation varies both temporally and ontogenetically, and that for the forage species, losses due to predation generally exceed those due to fishing. The present reauthorization of the Magnuson-Stevens Fisheries Conservation and Management Act (MSFCMA; Public Law 94-265) calls for overfished stocks to be rebuilt within ten years unless biology or environmental conditions dictate otherwise. Due to the strong influence of 
predation, the recovery of depleted stocks within the Georges Bank ecosystem may make biomass trade-offs, especially those involving forage fish populations, more pronounced.

While numerous multispecies and ecosystem models have been developed within fisheries research, the use of these models in fisheries management is still rare (Link 2010). However, it is noteworthy that several of the national fishery management councils are moving toward using these models to augment single-species methods. Within a multispecies or ecosystem framework, several tools have been developed for conducting forward projections, including Multispecies Forward Projection Model (MSFOR), Ecosim, and Management Strategy Evaluation (MSE) within Atlantis (Plagányi 2007). The MSFOR extends multispecies virtual population analysis (MSVPA) into a deterministic multispecies forecasting model (Sparholt 1994); however, some applications have extended the approach to incorporate stochasticity in recruitment (Gislason 1991). Ecosim was developed as a dynamic extension to Ecopath, and reformulates Ecopath's mass-balance equations into differential equations that include trophic interactions and harvest regimes (Walters et al. 1997). Atlantis employs MSE as the simulation framework, incorporating decision rules and resulting management actions (Fulton et al. 2011).

During the development of the multispecies statistical catch-at-age model, we characterized the interactions between Georges Bank fish species. In this manuscript, we use stochastic forward projections to explore the implications of various management scenarios and to examine the biomass trade-offs that arise from predation. Stochastic projections are of intermediate complexity between MSFOR and MSE within Atlantis. While this approach accounts for recruitment stochasticity as well as uncertainty in some 
of the food-selection parameters, it does not incorporate the full ecosystem, fishing fleets, or harvest control rules.

The focus of the forward projections is to explore the consequences of different fishing scenarios within the Georges Bank fish community while accounting for predation. In particular, we explore the role of principal prey and intermediate predatorprey species within the community (Figure 1). The impact of species interactions on top predator species could not be elucidated because these species were not food or growth limited within the multispecies formulation. Furthermore, in order to understand the impact of fisheries in an ecosystem context, the role of small pelagics must be understood (Link et al. 2008b). To this end, projections were used to explore two general management scenarios:

1. The response of prey populations when predator species are driven to low abundance levels with fishing, and

2. The response of prey populations if predator species currently at low levels of abundance recover.

Georges Bank is a complex, highly connected ecosystem (Link 1999, Link et al. 2008b). If the ecosystem were adequately represented by a simple trophic chain, one would expect prey populations to simply increase to higher equilibrium abundances due to a release in predation pressure if predators were driven to low abundance levels. Conversely, if predator species currently at low abundance levels were to recover, we would expect that prey populations could not be fished as heavily due to increased losses due to predation. However, since the Georges Bank community is a complex food web, 
we expect that community responses to fishing will not always be straightforward or direct.

\section{METHODS}

Forward projections were conducted with the multispecies statistical catch-at-age model developed in the first two chapters. With the exception of the calculation of spawning stock biomass (SSB) and recruitment, model formulations remained the same as those described for the full 9-species model.

Projections incorporated uncertainty in both species-preference coefficients as well as age-specific abundance in the first year. To characterize this uncertainty, Markov Chain Monte Carlo (MCMC) simulations were conducted for the 9-species multispecies model. Since spiny dogfish and winter skate abundances were considered to be known values in the multispecies model, MCMC simulations were conducted with the final single-species runs to estimate the posterior distributions for predicted age-specific abundances of the elasmobranch species. One-million simulations were conducted for each single-species elasmobranch model, and 396,000 were conducted for the multispecies model. For each MCMC analysis, the results from every $100^{\text {th }}$ simulation were saved and the first 10,000 simulations were discarded to account for the burn-in process (Figure S1 - Figure S10).

Recent five-year averages of weight-at-age were used to represent future agespecific weights in the projections. Likewise, consumption estimates from the most recent ten-year bin were used in the projection runs. Estimates of fishery selectivity were obtained from the final 9-species run. 
Estimates of age-specific maturity were obtained from multiple sources. For species that have been recently assessed with age-structured models (cod, herring, mackerel, white hake and pollock), age-specific maturity estimates were obtained from the most recent age-structured assessments. For goosefish and winter skate, maturity ogives were constructed from published maturation rates (goosefish: Richards et al. 2008; winter skate: Frisk et al. 2010). Published maturation rates were sex-specific for goosefish; therefore, separate sex-specific maturity ogives were first constructed and then averaged to obtain one sex-invariant estimate of the proportion mature-at-age. Previous spiny dogfish single-species assessments assumed a jackknife maturity at $80 \mathrm{~cm}$ for females. A jackknife maturity at $80 \mathrm{~cm}$ was assumed for all spiny dogfish individuals in this application. For silver hake, a maturity ogive was obtained from recent work examining the current knowledge of U.S. hake stocks (Helser and Alade 2012).

For many of the modeled species, predicted stock and recruitment estimates did not follow traditional stock-recruitment relationships, such as the Beverton and Holt or Ricker formulations (Figure 2). As a consequence, generalizations of the hockey stick model including a bent-hyperbola (Mesnil and Rochet 2010) and quadratic hockey stick (Barrowman and Myers 2000) were fit to the stock-recruitment data series. For cod, herring and mackerel, the estimated spawning stock at which recruitment became constant $\left(\mathrm{S}^{*}\right)$ fell within the range of spawning stock values predicted in the multispecies model. For these three species, $\mathrm{S}^{*}$ was initially set to the value estimated by each species-specific hockey stick model. For the remaining species, the predicted $\mathrm{S}^{*}$ fell outside of the range of predicted spawning stock levels. In these cases, $\mathrm{S}^{*}$ was set to the lowest spawning stock level predicted in the multispecies model for the teleost species 
and in the single-species model for the elasmobranchs. Recruitment was sampled from an empirical cumulative distribution function based on predicted recruitment from the statistical-catch-at-age models. At spawning stock levels greater than or equal to $\mathrm{S}^{*}$, recruitment was set to the sampled value. At spawning stock levels below $\mathrm{S}^{*}$, sampled recruitment was prorated so that recruitment declined linearly to zero. Recruitment estimation using an empirical cumulative distribution function implies that historical stock productivity is representative of future stock productivity.

However, when these empirical hockey-stick stock-recruitment models were used in a preliminary base run without fishing, all nine species did not coexist. Silver hake collapsed in every iteration, while mackerel, herring and cod collapsed in some iterations. To achieve a base run in which all nine species coexisted in the absence of fishing, $\mathrm{S}^{*}$ was set to the minimum SSB predicted in the 9-species model for all species but silver hake and herring. For these two prey species, $\mathrm{S}^{*}$ had to be reduced to $30 \%$ of the minimum SSB in order for the species to persist throughout the simulation (Figure 2). This run was considered the unfished base run for comparison of subsequent projection scenarios.

Several projections were conducted to explore specific biomass trade-offs within the two general scenarios discussed above. Each projection was run for 100 years and for each projection scenario, 300 iterations were conducted. For each iteration, recruitment was randomly selected from the empirical cumulative distribution function and a MCMC chain was selected to provide estimates of initial abundances and species-preference coefficients. 
As a status-quo scenario, each species was fished at the rate of fishing predicted in the last year of the 9-species model (Table 1). To establish a base fishing scenario, each species was fished at approximately the fishing mortality rate estimated to provide the single-species maximum sustainable yield (MSY) or a proxy of MSY, obtained from recent stock assessments. For silver hake and winter skate, F-based biological reference points were not available. Since these two species are not considered to be overfished, the fishing mortality rate predicted in the last year of the 9-species model was used to approximate the biological reference point. The initial goal was to establish a base fishing run using estimates of single-species fishing mortality-based reference points, with the fishing mortality rates in this base fishing run subsequently used as the basis for future projections. However, in initial projections with this scenario, goosefish collapsed when fished at its single-species $\mathrm{F}_{\mathrm{MSY}}$. Accordingly, goosefish fishing mortality was reduced to one-half of $\mathrm{F}_{\mathrm{MSY}}$ for the base fishing run (Table 1).

To further examine trade-offs, modeled fish species were grouped into three functional groups: top predators, intermediate predators and prey species (Figure 1). Top predators included spiny dogfish, winter skate, and pollock. Intermediate predators represented species that were both predators and prey and included goosefish, cod and white hake. Prey species represented those species that were primarily prey to piscivores and included herring, mackerel and silver hake. While silver hake was both a predator and prey in this model formulation, it was classified as a prey species due to the high predation mortality rates estimated in the 9-species model (Chapter 2).

To examine species' responses to various fishing scenarios, the base fishing and unfished projections were used to establish benchmarks related to SSB and commercial 
catch. The benchmark indicating a severely depleted stock was defined as $10 \%$ of the unfished equilibrium level, and will subsequently be referred to as $\mathrm{SSB}_{10 \%}$. This benchmark is consistent with that used in recent work investigating the status and trends of marine fisheries (Worm et al. 2009). A species was classified as severely depleted if the median SSB, averaged over the last five years of the projection, fell below this benchmark. Preliminary analyses explored using the median SSB in the final year of the projection as the metric instead of averaging over the last five years. The final status of the species was robust to the metric used.

Likewise, $25 \%$ of the unfished equilibrium spawning biomass, $\mathrm{SSB}_{25 \%}$, was considered a limit reference point. This benchmark is defined as the minimum stock size threshold within National Standard 1 of the MSFCMA; stocks are considered overfished if spawning biomass falls below this benchmark. A set of target reference points was developed using the base fishing scenario. Since the fishing mortality rates used in this projection were assumed to approximate $\mathrm{F}_{\mathrm{MSY}}$, it follows that the corresponding equilibrium SSB and catch from the base fishing run represent $\mathrm{SSB}_{\mathrm{MSY}}$ and MSY.

To investigate the impact of driving predator populations to low abundance levels, we fished down the food web (Table 1). In a first set of projections, we heavily fished the top predator species at 3-times their base fishing rates, investigating the impact on lower trophic levels. In a second set of projections, we fished both top and intermediate predator functional groups at three times their base fishing rates to determine the impact on the principal prey species.

The results of the 9-species model developed in Chapter 2 (hereafter referred to as the "key run") suggested that goosefish was the dominant predator of cod, mackerel and 
silver hake, whereas cod was the dominant predator of white hake and herring. Accordingly, the abundance of these intermediate predator species would have the greatest impact on prey species dynamics. To investigate the impact of recovered predator species, we therefore ran a set of projections in which the top predators were fished at 3-times their base rate of fishing, intermediate predators were not fished at all, and prey fishing rates were incrementally increased (Table 1). Our rationale was that minimizing the abundance of top predators would result in the greatest abundances of intermediate predators, thereby having the maximum possible impact on prey species. We sought to determine the level of fishing at which prey species could be sustainably fished, given that their principal predators were at or near the highest levels of abundance possible. A sustainable level of fishing was defined as a fishing mortality rate that did not cause the spawning stock biomass of a particular population to fall below the $\mathrm{SSB}_{25 \%}$ benchmark. Due to the importance of goosefish as predators to both intermediate predator and prey species groups, we conducted an additional set of projections in which goosefish were heavily fished at three-times their base rate, top predators were not fished, and fishing on remaining intermediate predator and prey species was sequentially increased (Table 1). The objective of this set of projections was to examine the potential role of goosefish in structuring community dynamics.

\section{RESULTS}

In the absence of fishing, top and intermediate predators generally increased to an equilibrium level of biomass (Figure 3). The exception was goosefish, whose biomass slightly decreased to a lower equilibrium biomass level. Winter skate biomass increased 
by over an order of magnitude even though winter skate fishing mortality in the last year of the 9-species key run was only 0.17 . This high sensitivity to even small changes in fishing mortality was due to a large difference between maturity and fishery selectivity ogives. Age of 50\% maturity was obtained from Frisk et al. (2010) and set at age-11. However, in the 9-species key run, full recruitment to the fishery was estimated at age-4. As a consequence, increases in $\mathrm{F}$ increased the removal of immature individuals from the population, thereby intensifying the impacts of fishing. In the base run, the three prey species achieved equilibrium at a spawning stock biomass lower than that estimated in the final year of the 9-species key run.

As in the 9-species key run, the dominant predator species for cod, silver hake and mackerel was goosefish, and that of herring was still cod (Figure 4). However, in contrast to the 9-species key run cannibalism replaced cod as the dominant source of predation on white hake as white hake recovered from fishing. Due to marked increases in the biomass of elasmobranchs, these species became more prominent predators, especially for silver hake, but they still did not represent dominant predators at the community level.

In this unfished base run, SSB levels at the end of the projection remained greater than the species-specific $\mathrm{SSB}_{10}$ \% benchmarks for all nine species (Figure 5). Final SSB estimates were also greater than the target reference points for both top and intermediate predator species, but lower than $\mathrm{SSB}_{\mathrm{MSY}}$ for the principal prey species. It is noteworthy that for all of the teleost species, $\mathrm{SSB}_{\mathrm{MSY}}$ was greater than $\mathrm{SSB}_{25 \%}$, and $\mathrm{SSB}_{10 \%}$, though the difference in magnitude between the various reference points varied among species. However, for the elasmobranch species, $\mathrm{SSB}_{\mathrm{MSY}}$ was lower than $\mathrm{SSB}_{25} \%$ for spiny 
dogfish and lower than both $\mathrm{SSB}_{25} \%$ and $\mathrm{SSB}_{10 \%}$ for winter skate. For these species, $\mathrm{SSB}_{\mathrm{MSY}}$ was lower than one or both of the benchmarks related to virgin biomass due to the large difference in equilibrium biomass between the unfished and base fishing projections, especially for winter skate.

The difference between initial and equilibrium biomasses in the unfished base run for many of the predator species was due to the recovery of these populations from fishing (Figure 3). For goosefish, there was a balance between more favorable conditions from a single-species perspective due to the absence of fishing, and added predation losses due to the increased biomass of spiny dogfish, it's only predator. Both cod and white hake biomasses were sufficiently low in the last year of the 9-species key run that when fishing was terminated they achieved a greater equilibrium biomass even though the biomass of some of their predators increased. Furthermore, for cod the decline in goosefish biomass, cod's principal predator, further reduced the total mortality experienced. For the prey species, the difference between initial and equilibrium biomass levels was a consequence of greater predation losses from recovered predator populations.

When fishing was either maintained at the status quo or introduced at speciesspecific base fishing rates, the biomasses of the top predators declined to stable equilibria with declines in proportion to the change in the rate of fishing (Figure 5, Figure S11). In both projections, winter skate biomass fell below all benchmarks due to its high vulnerability to fishing. Spiny dogfish and pollock biomass remained above all benchmarks in the status-quo scenario, but fell below limit or target reference points when subjected to their base fishing rates. 
For the intermediate predators, declines in predation between the projections with and without fishing were not able to compensate for notable increases in fishing mortality, resulting in decreased equilibrium biomass levels. This decrease in cod and white hake equilibrium biomass was sufficient to drive SSB below the MSY reference point. Goosefish equilibrium biomass only declined slightly due to the low fishing mortality rate in the status-quo scenario. However, between the status-quo and base fishing scenarios, changes in equilibrium biomass varied and were a function of both predator abundance and the magnitude of change in fishing mortality. Goosefish biomass declined and catch increased due to a further increase in fishing mortality (Figure 5, Figure 6, Table 1). Similarly, white hake biomass increased and catch decreased due to a decrease in fishing mortality. However, while cod fishing mortality declined slightly, both its biomass and catch increased due to decreased predation pressure by goosefish. Even with reduced biomass in the base fishing scenario, goosefish remained the dominant predator of cod (Figure S13).

Due to declines in the equilibrium biomass of all predator species between the unfished and status-quo scenarios, the biomass of all primary prey species increased (Figure 5). For mackerel and herring, this increase was sufficient for SSB to rise slightly above that associated with MSY, even though herring catch exceeded MSY (Figure 6). Like the intermediate predator group, changes in prey biomass between the status quo and base fishing projections varied among species. For both mackerel and herring, equilibrium biomass slightly declined. In the case of mackerel, this decline was due to an increase in fishing mortality, while the decline in herring was due to increased consumption by cod and silver hake resulting from increased biomass levels (Table 1, 
Figure S12, Figure S13). Increased silver hake biomass and catches were due to decreased predation pressure; fishing mortality did not change between the status quo and base fishing scenarios.

As fishing was increased on the top predator functional group to rates two- and three-times those of the base fishing scenario, the biomass and catch of top predators precipitously declined to levels below both the target and severely depleted ( $\left.\mathrm{SSB}_{10 \%}\right)$ benchmarks (Figure 7, Figure 8). Among the intermediate predators, goosefish biomass increased, while cod decreased slightly and white hake remained approximately constant. Increased goosefish biomass was due to decreased predation by spiny dogfish, while the small decrease in cod biomass was due to increased predation by goosefish (Figure S13, Figure S14). White hake biomass did not notably change because the biomasses of its predators, conspecifics and cod, also did not vary considerably between scenarios. Mackerel and silver hake biomasses remained approximately the same because the three top predators were not responsible for the majority of their predation losses. Consequently, the total biomass consumed of these species did not change markedly; decreased consumption by the top predator species was compensated by an increase in consumption by goosefish. In contrast, the elasmobranch species, while still not dominant predators, were responsible for a greater proportion of the biomass consumed of herring than silver hake in the base fishing projection (Figure S13). Accordingly, when top predators were heavily fished, herring biomass increased to above $\mathrm{SSB}_{\mathrm{MSY}}$ due to decreased consumption by both the elasmobranch species and cod (Figure 7). Across all species, trends in commercial catch generally followed trends in SSB as the top predators were fished down (Figure 8). 
With the top predators severely depleted, impacts of increased fishing of the intermediate predator group varied considerably among species. As fishing increased to two and three-times the base levels, goosefish exhibited precipitous declines in both SSB and total catch to levels below both target and $\mathrm{SSB}_{10 \%}$ reference points (Figure 7, Figure 8). In contrast, cod and white hake biomasses both fell below $\operatorname{SSB}_{\mathrm{MSY}}$ as catches increased, though the magnitude of these changes was less pronounced than that of goosefish. For these two gadid species, SSB remained above the $\mathrm{SSB}_{25 \%}$ overfishing benchmark. For cod, the impacts of added fishing losses were tempered by an exponential decline in predation pressure by goosefish (Figure 9). Fishing losses for white hake were similarly mediated by a general decline in both cannibalism and predation by cod.

As the biomass of goosefish declined, both silver hake biomass and commercial catch increased to levels exceeding the MSY-based reference points (Figure 7, Figure 8). Total consumption of silver hake decreased slightly, but most notably its dominant source of predation shifted from goosefish to cannibalism (Figure 9). With these changes in silver hake and goosefish, mackerel biomass initially remained constant (T3 vs IT2 projections) due to a balance between decreased goosefish consumption and increased silver hake predation. However, as silver hake SSB continued to increase, mackerel biomass and catch both fell below the MSY reference points due to increased predation pressure (Figure 7, Figure 8). Like mackerel, herring exhibited similar biomass trends due to declining goosefish and cod consumption as well as increased silver hake predation, though its biomass and catch both remained above MSY-based reference points in all projections. 
To examine how heavily the principal prey species could be fished when their dominant predators were near their maximum abundance levels, top predators were effectively eliminated from the community by fishing and intermediate predators were not fished. As a result, goosefish SSB increased substantially, though changes in cod and white hake were less pronounced (Figure 10). White hake abundance also increased, but cod SSB actually decreased slightly below $\mathrm{SSB}_{\mathrm{MSY}}$ due to increased goosefish predation. Trends in the dominant predators remained unchanged from the base fishing scenario. As fishing on the principal prey species was increased, prey biomass declined but not nearly at rates comparable to the rate of increase in fishing mortality (Figure 10). The increase in losses due to fishing was partly balanced by a decline in the biomass consumed of these prey species. At fishing levels 30-times the base rates (fishing mortality rates of 4.8, 6.3 and 7.2 for mackerel, herring and silver hake, respectively), only mackerel SSB fell below the $\mathrm{SSB}_{25}$, benchmark and none of the prey species were considered severely depleted. These fishing mortality rates likely are not biologically realistic, which may be in part due to assumptions regarding recruitment, discussed below. Herring did not become severely depleted until goosefish was heavily fished along with the top predators (G3P), which resulted in a three-fold increase in cod SSB. In this scenario, cod became the dominant predator within the community (Figure S15). Additionally, white hake SSB decreased due to increased consumption by cod and silver hake SSB increased due to decreased goosefish consumption.

When the abundance of goosefish was minimized through fishing, cod could experience fishing rates at approximately four-times the base rate of fishing and still exhibit a stable SSB greater than the overfishing benchmark (Figure 11). However, when 
goosefish was heavily fished and cod abundance was at its maximum (G3), herring became severely depleted due to increased cod predation. At three-times its base rate of fishing (S3), the SSB of silver hake remained greater than SSB $_{\text {MSY. Yet with a moderate }}$ fishing rate at two-times the base rate for cod and three-times the base rate for silver hake, the SSB of herring and mackerel still could not be reduced below $\mathrm{SSB}_{25 \%}$, even at fishing mortality rates five-times their base rates (P5).

\section{DISCUSSION}

Through the use of a multispecies statistical catch-at-age model, we examined the impact of several fishing scenarios on the dynamics of the Georges Bank fish community. Stochastic projections indicated strong interactions between modeled species, though the interactions were not always direct. One example of an indirect interaction was the impact of goosefish on herring. As goosefish biomass decreased, herring biomass also decreased due to increased predation by cod. As a result, overfishing goosefish permitted a community dominated by cod, but at the expense of herring. Another similar indirect interaction was evident between goosefish and white hake. As goosefish biomass decreased, white hake biomass similarly decreased due to increased predation by cod. Therefore, as a consequence of the effects of predation, population responses to fishing were a function of not only the rate of fishing, but also of both direct and indirect interactions among species.

Within intermediate predator and prey groups, varying trends among projections demonstrated the interplay between fishing and predator impacts on prey populations. For instance, the increase in both cod spawning stock biomass and commercial catch 
between the status quo and base fishing scenarios demonstrated the influence of predators, in this case goosefish, on prey dynamics because cod fishing mortality effectively remained constant between the two scenarios. Furthermore, when intermediate predators were heavily fished after top predators were driven to low abundance levels, the impacts of fishing on cod and white hake were tempered by changes in the predator community, particularly goosefish.

The community response when these intermediate predators were fished down also demonstrates the high degree of connectivity and indirect linkages within the system. As fishing on intermediate predator species increased, the magnitude of predation losses experienced by principal prey species did not vary substantially. Instead, the decline in intermediate predator abundance caused the species responsible for most of the predation to vary. As the biomass of goosefish and cod declined, the dominant predator of both mackerel and silver hake shifted from goosefish to silver hake, and that of herring shifted from cod to silver hake. Both mackerel and herring biomass declined as predation by silver hake increased; however, this decrease in SSB was more pronounced for mackerel. The more notable decline in mackerel over herring was likely due to a greater preference by silver hake for mackerel over herring (Chapter 2).

Multiple studies have demonstrated that the NEUS Continental Shelf is a highly connected, complex ecosystem (Link 1999, Garrison and Link 2000a). Network models of the system have indicated a high degree of connectance as well as mixed trophic impacts and indirect effects (Link et al. 2008b). Due to the generalist nature of many predators within the community, there are many diffuse interactions among species (Garrison and Link 2000c, Smith and Link 2010). These weak interactions contribute to 
the stability and resilience of the system (Garrison and Link 2000c, Link et al. 2008b, Auster and Link 2009). The results of the projections developed in this chapter provide further support that compensation occurs within trophic guilds or aggregate biomass groups due to the high degree of connectivity within the system.

The results of this work also emphasized the roles of particular species as suggested by the 9-species key run (Chapter 2). Over both the last 30 years as well as in forward projections, goosefish represented the dominant predator within the system unless it was reduced to a low abundance level through fishing. Accordingly, these projections support work on the trophic ecology and abundance of goosefish suggesting that goosefish is functionally replacing cod as the dominant piscivore in the northwest Atlantic (Link 2007). Furthermore, even when the abundance of goosefish was at a minimum, neither elasmobranch species represented a major predator of the modeled gadid species. These findings lend additional support to work indicating minimal interactions between many gadid and elasmobranch species (Link et al. 2002b, Link 2007).

In this analysis, modeled species were classified into three functional groups: top predators, intermediate predators and prey, and principal prey species. While these species classifications helped to simplify the examination of fishing effects on community dynamics, the division between functional groups and subsequent response to fishing was not clear cut due to the complexity of the Georges Bank food web. While goosefish was classified as an intermediate predator because of predation by spiny dogfish, it represented a top predator in terms of the magnitude of consumption of modeled fish. This high degree of piscivory in goosefish is consistent with previous studies (NEFSC 2010, Smith and Link 2010). Likewise, silver hake was designated as a 
principal prey species due to its high predation mortality estimated by the 9 -species key run, but silver hake is important as both predator and prey within the NEUS ecosystem (Garrison and Link 2000a, b, Link and Garrison 2002). This overlap among functional groups further demonstrates the complexity and indirect trophic links of the Georges Bank ecosystem.

The projections developed in this analysis required assumptions about the relationship between spawning stock biomass and recruitment for each species. In our first attempt at a base run, all nine species did not coexist in the absence of fishing. Reducing the specified spawning stock biomass level at which recruitment began to decline $\left(\mathrm{S}^{*}\right)$ permitted all nine species to coexist. However, this adjustment also caused some species to become overly robust to the impacts of fishing. A key example is the predicted response of the principal prey species to fishing. As fishing increased, prey SSB declined below $\mathrm{SSB}_{\mathrm{MSY}}$; however, it was nearly impossible to fish the populations to levels below $\mathrm{SSB}_{25 \%}$. Herring only became severely depleted when goosefish was heavily fished, due to severe predation pressure by cod. Clearly, neither of the above outcomes is realistic; all species do coexist within the community, albeit at different levels of abundance, and fishing does exert a strong impact on population dynamics. Consequently, this example illustrates the sensitivity of projection results to the assumed relationship between stock and recruitment. Furthermore, assumptions about the relationship between spawning stock biomass and recruitment are particularly important in projections that drive populations to low levels of abundance.

Part of the sensitivity encountered during the development of a base run may have also been a consequence of assumptions regarding predator functional response. In this 
model, we assumed a Type-II functional response in which the rate of change in predator consumption rates declines monotonically with increasing prey abundance. In contrast, a Type-III functional response permits prey switching and tempers the impacts of predation on prey species at low abundances because predators select a disproportionately larger proportion of the most abundant prey (Murdoch 1969). Due to the opportunistic feeding patterns of many of the modeled predator species, a Type-III functional response would have also been appropriate and may have potentially enhanced population stability and coexistence in the initial base run. The inability for species coexistence was also an issue in previous multispecies modeling efforts on Georges Bank. In particular, Collie and Delong (1999) found that a Type-III functional response was necessary in a multispecies biomass-dynamics model in order to have all species coexist in the absence of fishing.

As intermediate predator species were fished to low abundance levels, both silver hake SSB and commercial catch increased to levels greater than the MSY-based reference points. The increase in both metrics demonstrates how reference points for prey species vary with fluctuations in predator abundance. Estimated target benchmarks were a function of predator biomass in the base fishing scenario. On the other hand, $\mathrm{SSB}_{10 \%}$ and $\mathrm{SSB}_{25} \%$ were based on equilibrium SSB levels in the unfished scenario. For the principal prey species, equilibrium biomass in the unfished scenario was low compared to scenarios with fishing due to severe predation pressure imposed by unfished predator species. Previous studies have demonstrated the sensitivity of biological reference points to variation in life-history parameters, especially natural mortality (Collie and Gislason 2001). 
Collectively, the projections conducted here demonstrated that the most important drivers of population dynamics varied among species. For the top predator species as well as goosefish, fishing was the most important driver of species dynamics. In contrast, for cod, mackerel, silver hake and herring, both predation and recruitment appeared to be important drivers. In the base scenarios, predation pressure on these species was primarily due to goosefish and cod. The importance of recruitment was evident by the lack of species coexistence when $\mathrm{S}^{*}$ was set to values estimated by the hockey stick models. Furthermore, in the case of herring, the large magnitude of the $95^{\text {th }}$ percentiles of SSB also reflected the large interannual variation in recruitment. For the two hake species, population dynamics were partly self-regulated through cannibalism. Compared to other modeled species, these two species appeared to be relatively robust to the impacts of fishing and predation. Impacts of changes in either predator abundance or the imposed rate of fishing were tempered by a change in the degree of cannibalism.

In this chapter, we explored various fishing scenarios using stochastic forward projections. This projection framework incorporated uncertainty in food-selection parameters as well as stochasticity in recruitment. Further work is warranted to explore the sensitivity of projections to differing assumptions regarding recruitment and predator functional response. Yet, the use of forward projections demonstrated trade-offs in species abundance and community compositions that arose from different fishing patterns. As such, this framework represents a useful tool for investigating fisheries management scenarios within a multispecies framework. 


\section{REFERENCES}

Auster, P.J., and Link, J.S. 2009. Compensation and recovery of feeding guilds in a northwest Atlantic shelf fish community. Mar. Ecol. Prog. Ser. 382: 163-172.

Barrowman, N.J., and Myers, R.A. 2000. Still more spawner-recruitment curves: the hockey stick and its generalizations. Can. J. Fish. Aquat. Sci. 57(4): 665-676.

Collie, J.S., and Delong, A.K. 1999. Multispecies interactions in the Georges Bank fish community. In Ecosystem approaches for fisheries management. Alaska Sea Grant College Program, AK-SG-99-01, Fairbanks, Alaska. pp. 187-210.

Collie, J.S., and Gislason, H. 2001. Biological reference points for fish stocks in a multispecies context. Can. J. Fish. Aquat. Sci. 58(11): 2167-2176.

EcoAP (Northeast Fisheries Science Center Ecosystem Assessment Program). 2009. Ecosystem Status Report for the Northeast U.S. Continental Shelf Large Marine Ecosystem. Northeast Fish. Sci. Cent. Ref. Doc. 09-11, NOAA - National Marine Fisheries Service, Woods Hole, MA.

Fogarty, M.J., and Murawski, S.A. 1998. Large-scale disturbance and the structure of marine system: Fishery impacts on Georges Bank. Ecol. Appl. 8(1): S6-S22.

Frisk, M.G., Martell, S.J.D., Miller, T.J., and Sosebee, K. 2010. Exploring the population dynamics of winter skate (Leucoraja ocellata) in the Georges Bank region using a statistical catch-at-age model incorporating length, migration, and recruitment process errors. Can. J. Fish. Aquat. Sci. 67(5): 774-792.

Fu, C.H., Mohn, R., and Fanning, L.P. 2001. Why the Atlantic cod (Gadus morhua) stock off eastern Nova Scotia has not recovered. Can. J. Fish. Aquat. Sci. 58(8): 16131623.

Fulton, E.A., Link, J.S., Kaplan, I.C., Savina-Rolland, M., Johnson, P., Ainsworth, C., Horne, P., Gorton, R., Gamble, R.J., Smith, A.D.M., and Smith, D.C. 2011. Lessons in modelling and management of marine ecosystems: the Atlantis experience. Fish and Fisheries 12(2): 171-188.

Garrison, L.P., and Link, J.S. 2000a. Dietary guild structure of the fish community in the Northeast United States continental shelf ecosystem. Mar. Ecol. Prog. Ser. 202: 231-240. 
Garrison, L.P., and Link, J.S. 2000b. Diets of five hake species in the northeast United States continental shelf ecosystem. Marine Ecology-Progress Series 204: 243-255.

Garrison, L.P., and Link, J.S. 2000c. Fishing effects on spatial distribution and trophic guild structure of the fish community in the Georges Bank region. ICES J. Mar. Sci. 57(3): 723-730.

Gislason, H. 1991. The influence of variations in recruitment on multispecies yield predictions in the North Sea. ICES Marine Science Symposium, Multispecies Models Relevant to Management of Living Resources 193: 50-59.

Helser, T.E., and Alade, L. 2012. A retrospective of the hake stocks off the Atlantic and Pacific coasts of the United States: Uncertainties and challenges facing assessment and management in a complex environment. Fish. Res. 114(0): 2-18.

Link, J. 1999. (Re)Constructing feed webs and managing fisheries. In Ecosystem Approaches for Fisheries Management. Alaska Sea Grant College Program, AKSG-99-01, Fairbanks, Alaska. pp. 571-588.

Link, J., O'Reilly, J., Fogarty, M., Dow, D., Vitaliano, J., Legault, C., Overholtz, W., Green, J., Palka, D., Guida, V., Brodziak, J., Methratta, E., and Stockhausen, W.T. 2008a. Energy flow on Georges Bank revisited: the Energy Modeling and Analysis eXercise (EMAX) in historical context. J. Northwest Atl. Fish. Sci. 39: 83-101.

Link, J., Overholtz, W., O'Reilly, J., Green, J., Dow, D., Palka, D., Legault, C., Vitaliano, J., Guida, V., Fogarty, M., Brodziak, J., Methratta, L., Stockhausen, W., Col, L., and Griswold, C. 2008b. The Northeast US continental shelf Energy Modeling and Analysis exercise (EMAX): Ecological network model development and basic ecosystem metrics. Journal of Marine Systems 74(1-2): 453-474.

Link, J.S. 2002. What does ecosystem-based fisheries management mean? Fisheries 27(4): 18-21.

Link, J.S. 2007. Underappreciated species in ecology: "ugly fish" in the northwest Atlantic Ocean. Ecol. Appl. 17(7): 2037-2060.

Link, J.S. 2010. Ecosystem-Based Fisheries Management: Confronting Tradeoffs. Cambridge University Press, Cambridge. 
Link, J.S., Brodziak, J.K.T., Edwards, S.F., Overholtz, W.J., Mountain, D., Jossi, J.W., Smith, T.D., and Fogarty, M.J. 2002a. Marine ecosystem assessment in a fisheries management context. Can. J. Fish. Aquat. Sci. 59(9): 1429-1440.

Link, J.S., Bundy, A., Overholtz, W.J., Shackell, N., Manderson, J., Duplisea, D., Hare, J., Koen-Alonso, M., and Friedland, K.D. 2011. Ecosystem-based fisheries management in the Northwest Atlantic. Fish and Fisheries 12(2): 152-170.

Link, J.S., and Garrison, L.P. 2002. Changes in piscivory associated with fishing induced changes to the finfish community on Georges Bank. Fish. Res. 55(1-3): 71-86.

Link, J.S., Garrison, L.P., and Almeida, F.P. 2002b. Ecological interactions between elasmobranchs and groundfish species on the northeastern US continental shelf. I. Evaluating predation. N. Am. J. Fish. Manag. 22(2): 550-562.

Link, J.S., and Sosebee, K. 2008. Estimates and implications of skate consumption in the northeast US Continental Shelf ecosystem. N. Am. J. Fish. Manag. 28(3): 649662.

May, R.M., Beddington, J.R., Clark, C.W., Holt, S.J., and Laws, R.M. 1979. Management of multispecies fisheries. Science 205(4403): 267-277.

Mesnil, B., and Rochet, M.-J. 2010. A continuous hockey stick stock-recruit model for estimating MSY reference points. ICES J. Mar. Sci. 67(8): 1780-1784.

Moustahfid, H., Link, J.S., Overholtz, W.J., and Tyrrell, M.C. 2009a. The advantage of explicitly incorporating predation mortality into age-structured stock assessment models: an application for Atlantic mackerel. ICES J. Mar. Sci. 66(3): 445-454.

Moustahfid, H., Tyrrell, M.C., and Link, J.S. 2009b. Accounting explicitly for predation mortality in surplus production models: an application to longfin inshore squid. $\mathrm{N}$. Am. J. Fish. Manag. 29(6): 1555-1566.

Murdoch, W.M. 1969. Switching in general predators: experiments on predator specificity and stability of prey populations. Ecol. Monogr. 39(4): 335-354.

NEFSC (Northeast Fisheries Science Center). 2008. Assessment of 19 northeast groundfish stocks through 2007: Report of the 3rd Groundfish Assessment Review Meeting (GARM III), Northeast Fisheries Science Center, Woods Hole, 
Massachusetts, August 4-8, 2008. Northeast Fish. Sci. Cent. Ref. Doc. 08-15, NOAA - National Marine Fisheries Service, Woods Hole, MA.

NEFSC (Northeast Fisheries Science Center). 2010. 50th Northeast Regional Stock Assessment Workshop (50th SAW) Assessment Report. Northeast Fish. Sci. Cent. Ref. Doc. 10-17, NOAA - National Marine Fisheries Service, Woods Hole, MA.

Overholtz, W.J., Jacobson, L.D., and Link, J.S. 2008. An ecosystem approach for assessment advice and biological reference points for the Gulf of Maine-Georges Bank Atlantic herring complex. N. Am. J. Fish. Manag. 28(1): 247-257.

Overholtz, W.J., and Link, J.S. 2007. Consumption impacts by marine mammals, fish, and seabirds on the Gulf of Maine-Georges Bank Atlantic herring (Clupea harengus) complex during the years 1977-2002. ICES J. Mar. Sci. 64(1): 83-96.

Plagányi, É.E. 2007. Models for an ecosystem approach to fisheries. FAO Fish. Tech. Pap. 477, FAO, Rome.

Richards, R.A., Nitschke, P.C., and Sosebee, K.A. 2008. Population biology of monkfish Lophius americanus. ICES J. Mar. Sci. 65(7): 1291-1305.

Smith, B.E., and Link, J.S. 2010. The trophic dynamics of 50 finfish and 2 squid species on the Northeast US Continental Shelf. NOAA Tech. Memo. NMFS-NE-216.

Sparholt, H. 1994. Fish species interactions in the Baltic Sea. Dana 10: 131-162.

Tsou, T.S., and Collie, J.S. 2001. Predation-mediated recruitment in the Georges Bank fish community. ICES J. Mar. Sci. 58(5): 994-1001.

Tyrrell, M.C., Link, J.S., Moustahfid, H., and Overholtz, W.J. 2008. Evaluating the effect of predation mortality on forage species population dynamics in the Northeast US continental shelf ecosystem using multispecies virtual population analysis. ICES J. Mar. Sci. 65(9): 1689-1700.

Uphoff, J.H. 2003. Predator-prey analysis of striped bass and Atlantic menhaden in upper Chesapeake Bay. Fish. Manag. Ecol. 10(5): 313-322. 
Walters, C., Christensen, V., and Pauly, D. 1997. Structuring dynamic models of exploited ecosystems from trophic mass-balance assessments. Rev. Fish Biol. Fish. 7(2): 139-172.

Worm, B., Hilborn, R., Baum, J.K., Branch, T.A., Collie, J.S., Costello, C., Fogarty, M.J., Fulton, E.A., Hutchings, J.A., Jennings, S., Jensen, O.P., Lotze, H.K., Mace, P.M., McClanahan, T.R., Minto, C., Palumbi, S.R., Parma, A.M., Ricard, D., Rosenberg, A.A., Watson, R., and Zeller, D. 2009. Rebuilding Global Fisheries. Science 325(5940): 578-585. 
Table 1: Species-specific fishing mortality rates assumed in each projection scenario.

\begin{tabular}{cllllll} 
Species & $\mathbf{F}_{\text {quo }}$ & $\mathbf{F}_{\text {base }}$ & $\mathbf{F}_{\mathbf{T} 2}$ & $\mathbf{F}_{\mathbf{T 3}}$ & $\mathbf{F}_{\text {IT2 }}$ & $\mathbf{F}_{\text {IT3 }}$ \\
\hline \hline Spiny Dogfish & 0.121 & 0.207 & 0.414 & 0.621 & 0.621 & 0.621 \\
Winter skate & 0.166 & 0.166 & 0.332 & 0.498 & 0.498 & 0.498 \\
Goosefish & 0.068 & 0.185 & 0.185 & 0.185 & 0.37 & 0.555 \\
Cod & 0.266 & 0.25 & 0.25 & 0.25 & 0.5 & 0.75 \\
Mackerel & 0.060 & 0.16 & 0.16 & 0.16 & 0.16 & 0.16 \\
Pollock & 0.092 & 0.22 & 0.44 & 0.66 & 0.66 & 0.66 \\
White hake & 0.241 & 0.125 & 0.125 & 0.125 & 0.25 & 0.375 \\
Silver hake & 0.241 & 0.24 & 0.24 & 0.24 & 0.24 & 0.24 \\
Herring & 0.364 & 0.21 & 0.21 & 0.21 & 0.21 & 0.21
\end{tabular}

\begin{tabular}{clllll} 
Species & $\mathbf{F}_{\mathbf{P 1}}$ & $\mathbf{F}_{\mathbf{P 1 0}}$ & $\mathbf{F}_{\mathbf{P 1 5}}$ & $\mathbf{F}_{\mathbf{P 3 0}}$ & $\mathbf{F}_{\mathbf{G 3 P}}$ \\
\hline \hline Spiny Dogfish & 0.621 & 0.621 & 0.621 & 0.621 & 0.621 \\
Winter skate & 0.498 & 0.498 & 0.498 & 0.498 & 0.498 \\
Goosefish & 0 & 0 & 0 & 0 & 0.555 \\
Cod & 0 & 0 & 0 & 0 & 0 \\
Mackerel & 0.16 & 1.6 & 2.4 & 4.8 & 4.8 \\
Pollock & 0.66 & 0.66 & 0.66 & 0.66 & 0.66 \\
White hake & 0 & 0 & 0 & 0 & 0 \\
Silver hake & 0.24 & 2.4 & 3.6 & 7.2 & 7.2 \\
Herring & 0.21 & 2.1 & 3.15 & 6.3 & 6.3
\end{tabular}

\begin{tabular}{clllll} 
Species & $\mathbf{F}_{\mathbf{G} 3}$ & $\mathbf{F}_{\mathbf{C} 2}$ & $\mathbf{F}_{\mathbf{C} 4}$ & $\mathbf{F}_{\mathbf{S} 3}$ & $\mathbf{F}_{\mathbf{P 5}}$ \\
\hline \hline Spiny Dogfish & 0 & 0 & 0 & 0 & 0 \\
Winter skate & 0 & 0 & 0 & 0 & 0 \\
Goosefish & 0.555 & 0.555 & 0.555 & 0.555 & 0.555 \\
Cod & 0 & 0.5 & 1 & 0.5 & 0.5 \\
Mackerel & 0 & 0 & 0 & 0 & 0.8 \\
Pollock & 0 & 0 & 0 & 0 & 0 \\
White hake & 0 & 0 & 0 & 0 & 0 \\
Silver hake & 0 & 0 & 0 & 0.72 & 0.72 \\
Herring & 0 & 0 & 0 & 0 & 1.05
\end{tabular}




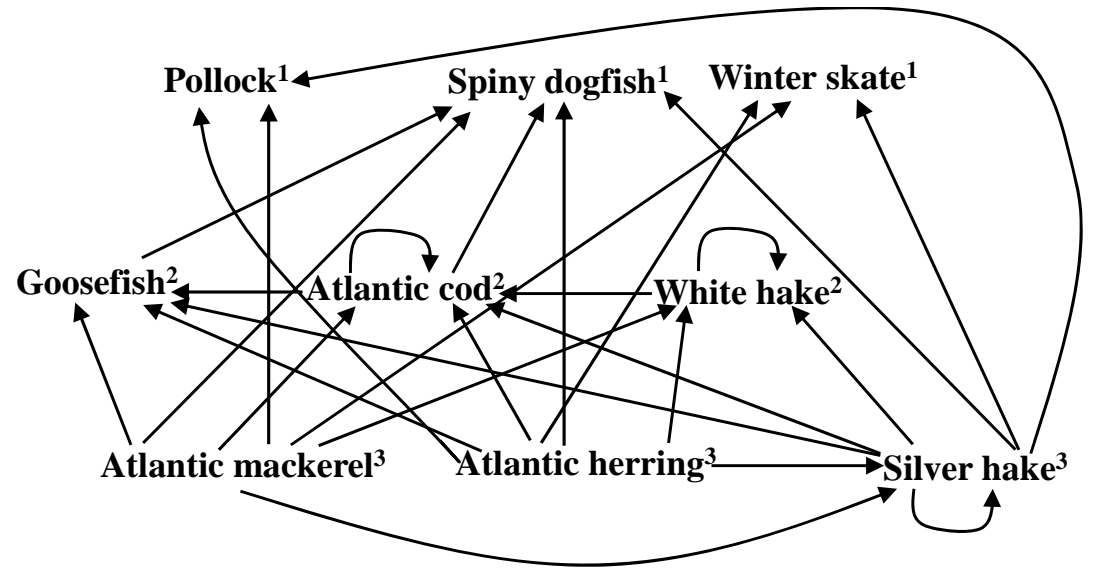

Figure 1: Predation interactions between the nine modeled Georges Bank fish species. Each species is grouped into one of three functional groups: 1) top predators, 2) intermediate predators, 3 ) principle prey species. The arrows point from prey to predator species. 

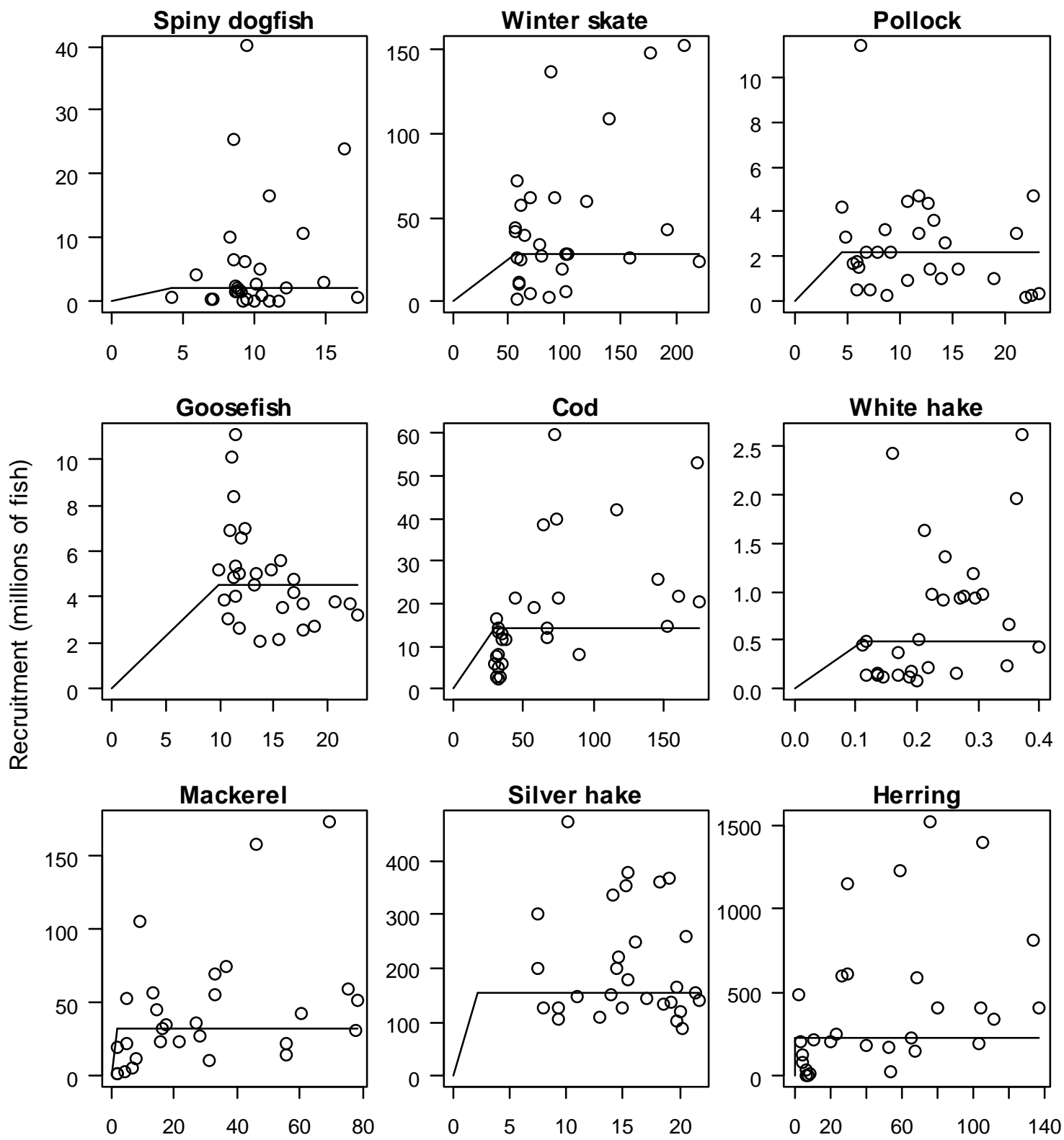

Spawning stock biomass $\left(10^{\wedge} 3 \mathrm{mt}\right)$

Figure 2: Predicted spawning stock biomass and recruitment estimates from the 9-species model (circles) and the fitted hockey-stick stock-recruitment models used in the forward projections (lines). The horizontal line represents the median recruitment. 

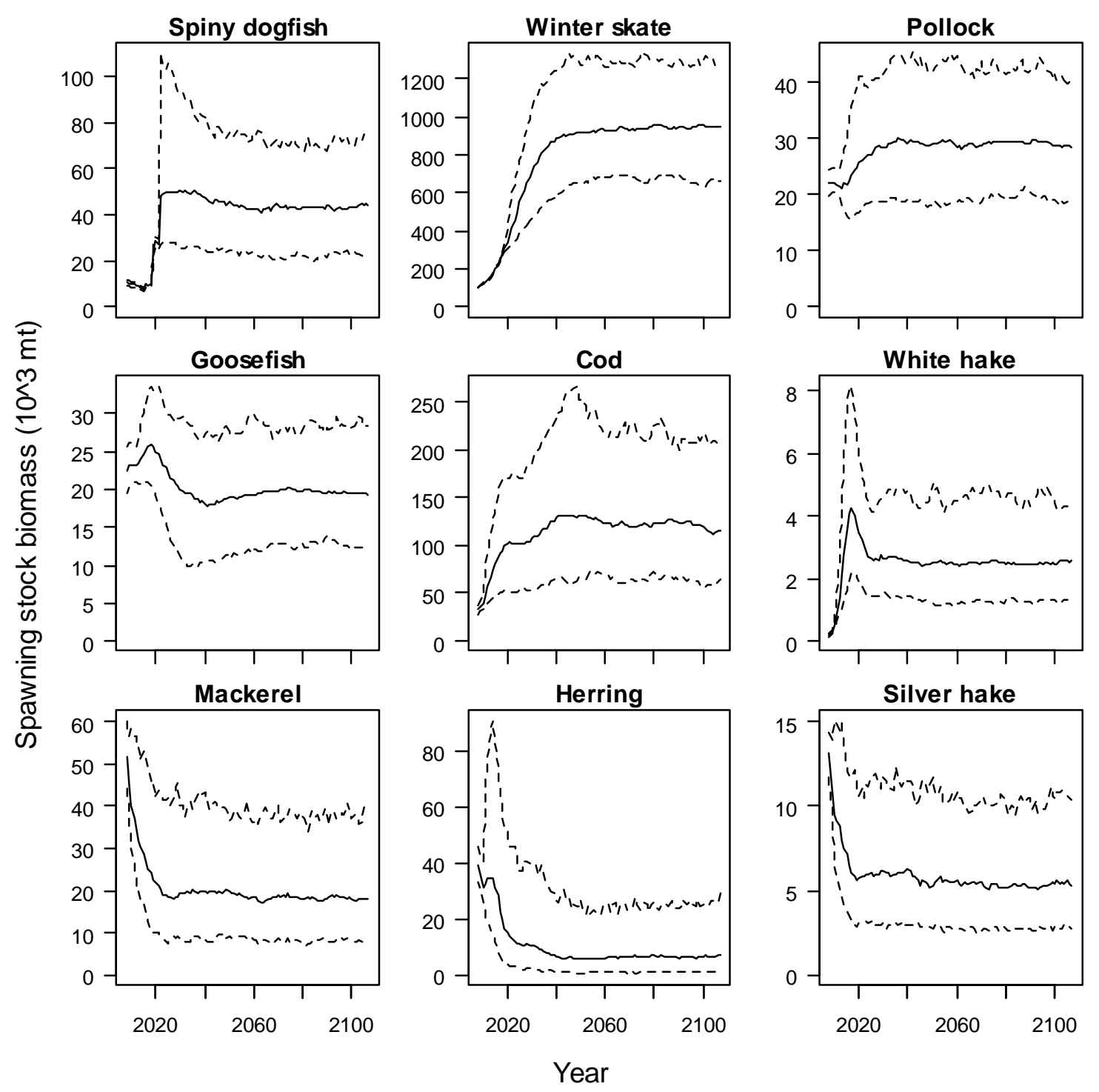

Figure 3: $95^{\text {th }}$ percentiles (dashed lines) and median (solid line) total annual spawning stock biomass $\left(10^{3} \mathrm{mt}\right)$ in the unfished base projection. 

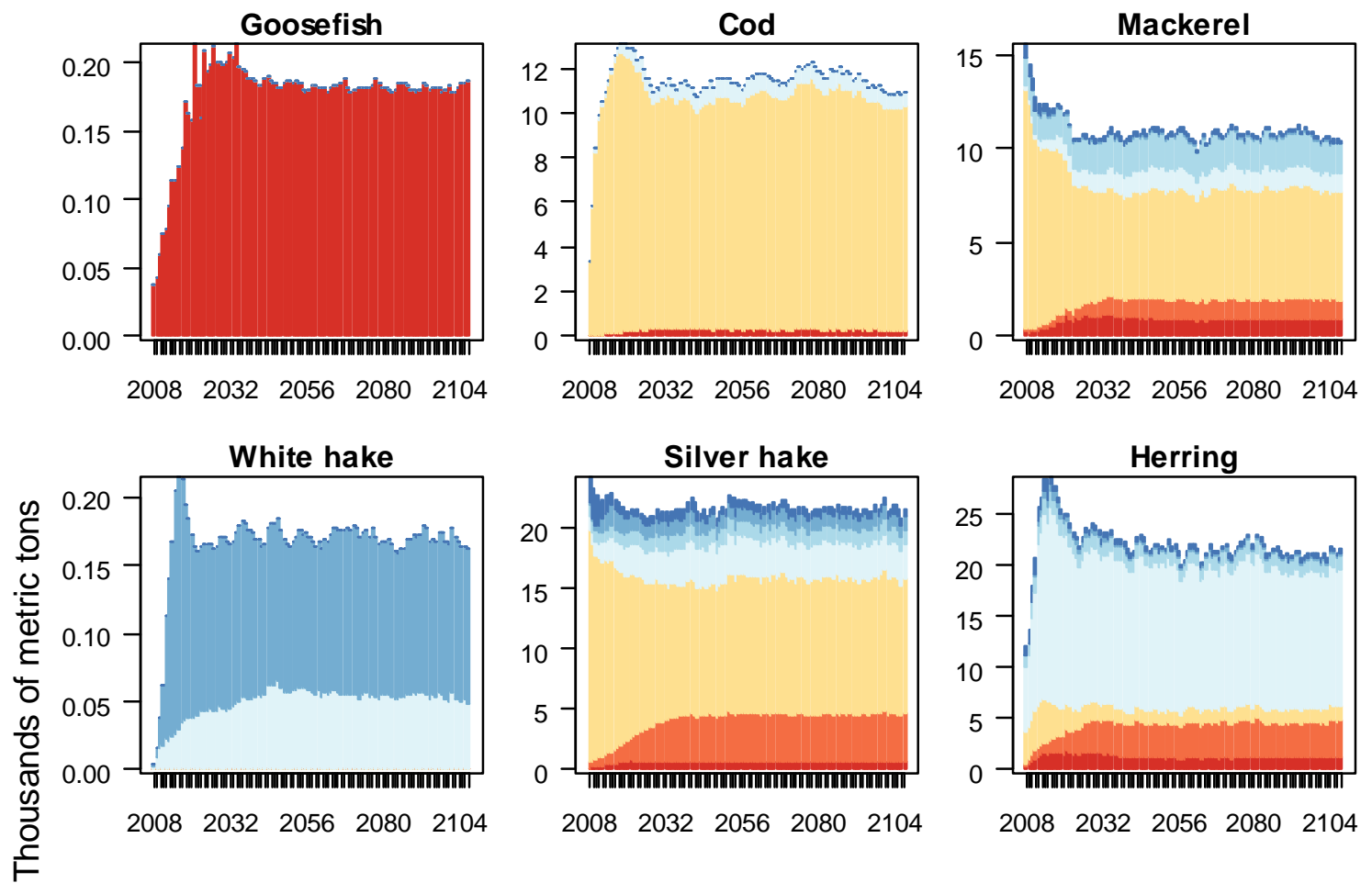

\footnotetext{
Predator species

- Spiny dogfish

- Winter skate

Goosefish

Cod

- Pollock

- White hake

- Silver hake
}

Year

Figure 4: Average annual predator-specific consumption (thousands of metric tons) of each prey species in the unfished base projection. 

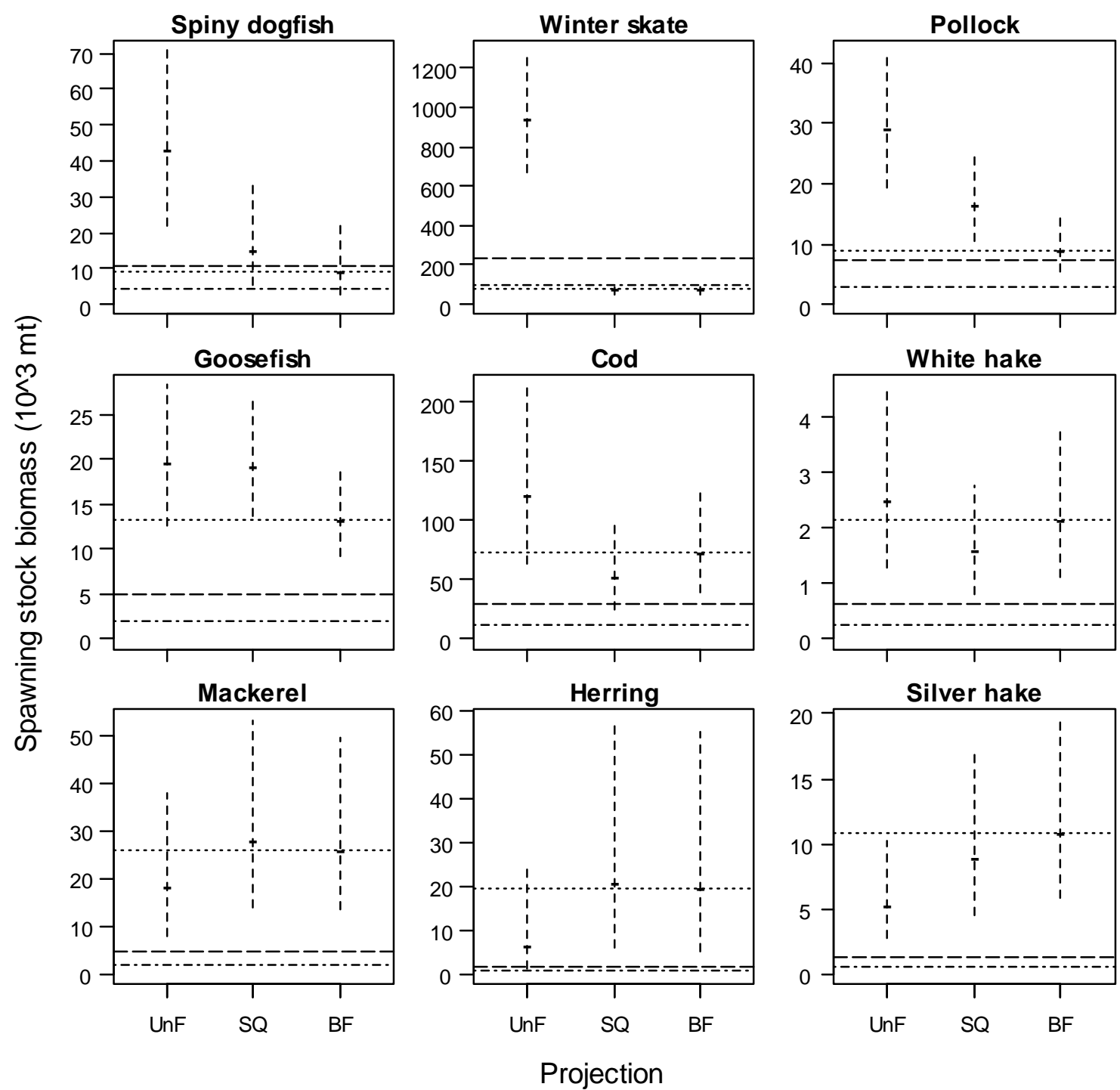

Figure 5: Comparison of the average median and $95^{\text {th }}$ percentiles (vertical dashed lines) of total spawning stock biomass in the unfished base projection (UnF), status quo (SQ) and base fishing projection (BaseF). For each species, the horizontal dotted line represents $\mathrm{SSB}_{\mathrm{MSY}}$, the dashed line represents $\mathrm{SSB}_{25} \%$ and the dot-dash line represents $\mathrm{SSB}_{10 \%}$. 

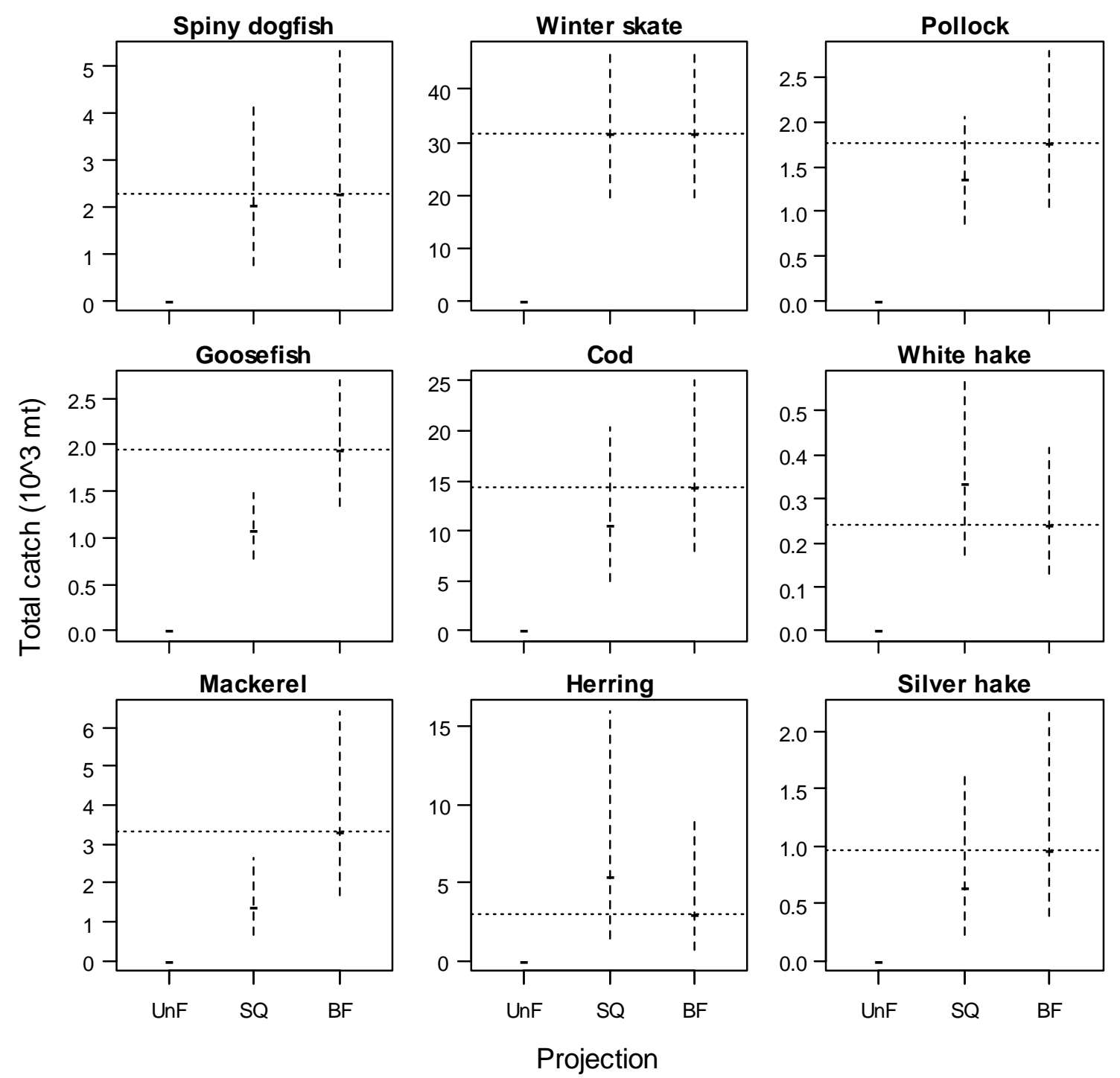

Figure 6: Comparison of the average median and $95^{\text {th }}$ percentiles (vertical dashed lines) of total commercial catch in the unfished base projection (UnF), status quo (SQ) and base fishing projection (BaseF). For each species, the horizontal dotted line represents MSY. 

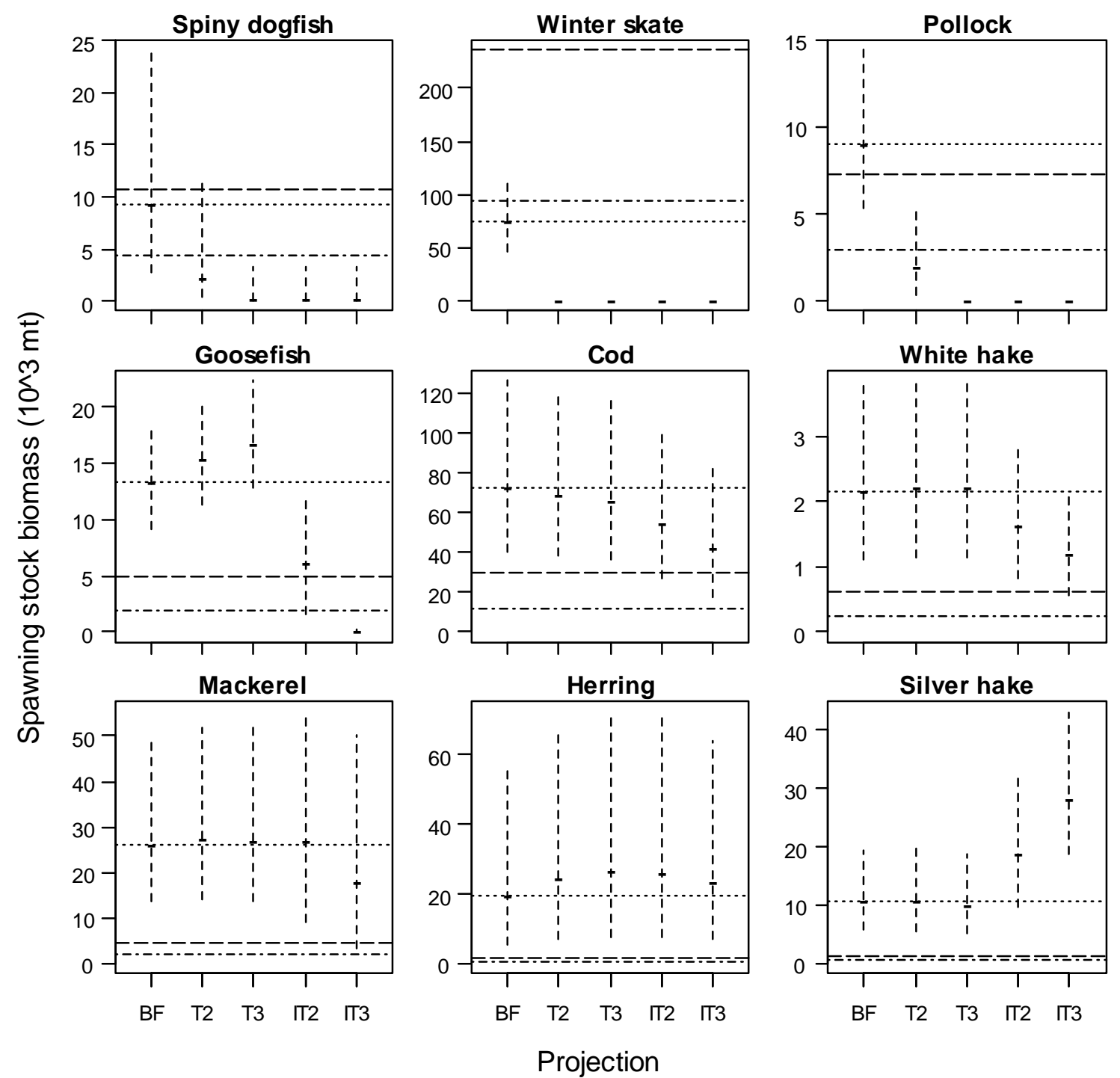

Figure 7: Comparison of the average median and $95^{\text {th }}$ percentiles (vertical dashed lines) of total spawning stock biomass as fishing mortality on the top predators is increased two (T2) and three (T3) times the fishing mortality rates in the base fishing projection (BF) while the remaining species were fished at the base fishing rates. Fishing mortality on the top predators was then maintained at three-times the BF, while fishing mortality on the intermediate predators was increased two (IT2) and three (IT3) times the base fishing mortality rates. Projection scenarios are further detailed in Table 1. The benchmarks are as detailed in Figure 5. 

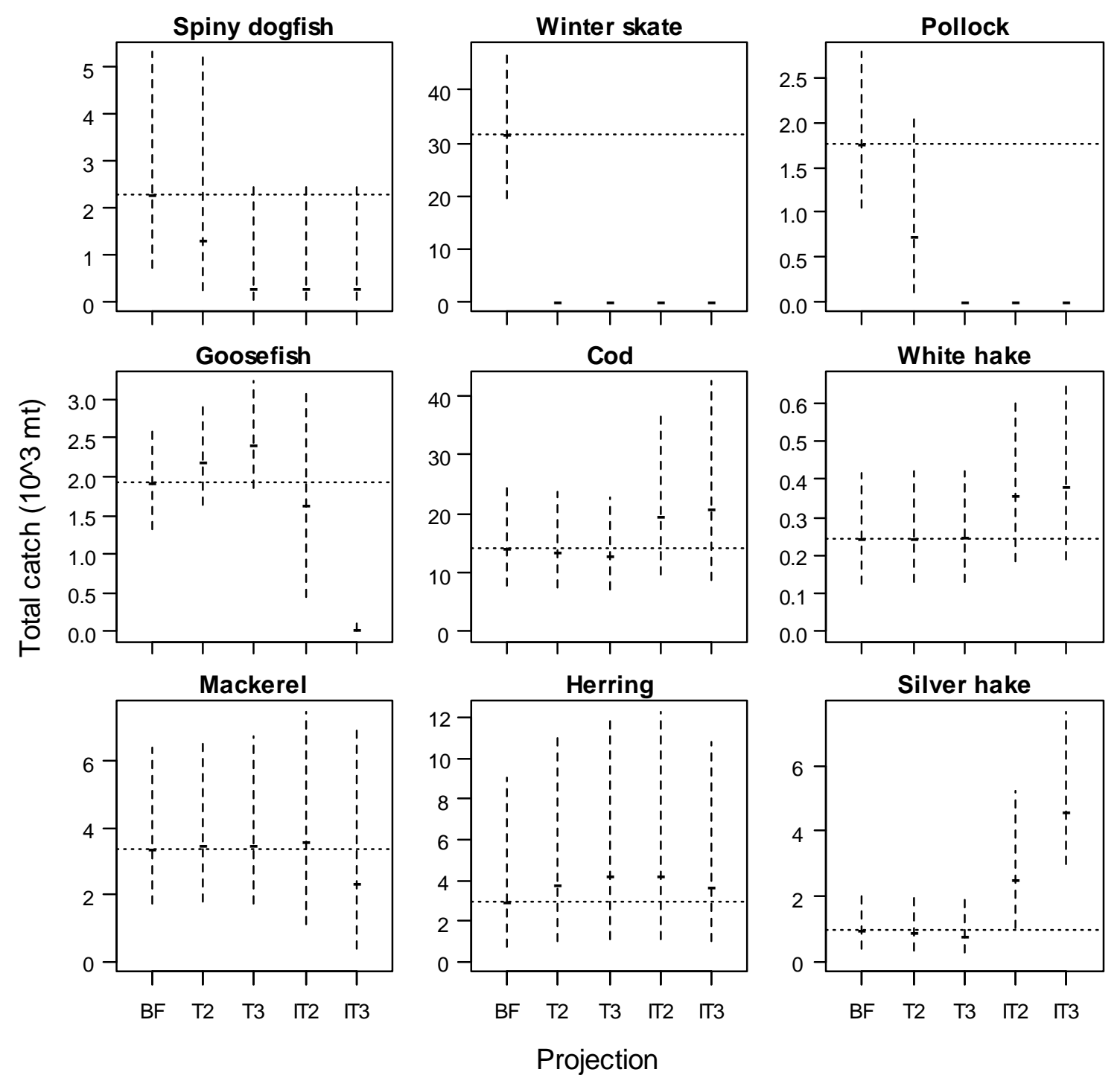

Figure 8: Comparison of the average median and $95^{\text {th }}$ percentiles (vertical dashed lines) of total commercial catch as fishing mortality was varied among top and intermediate predator species. For each species, the horizontal dotted line represents MSY. Projection scenarios are as described in Figure 7 and Table 1. 

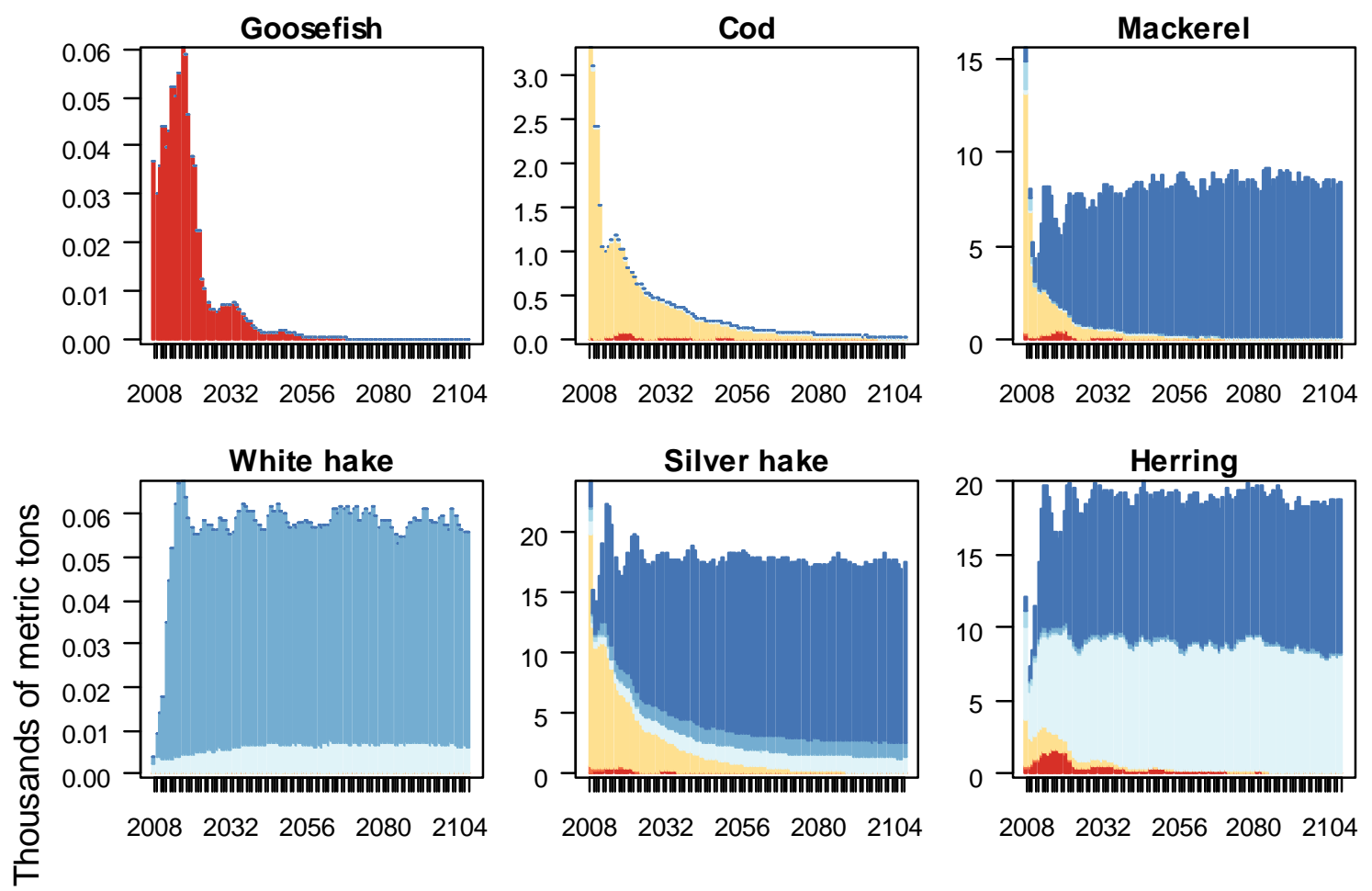

\footnotetext{
Predator species

- Spiny dogfish

- Winter skate

- Goosefish

Cod

- Pollock

- White hake

- Silver hake
}

\section{Year}

Figure 9: Average annual predator-specific consumption (thousands of metric tons) of each prey species in when both top and intermediate predators were fished at three-times their base rates of fishing. 

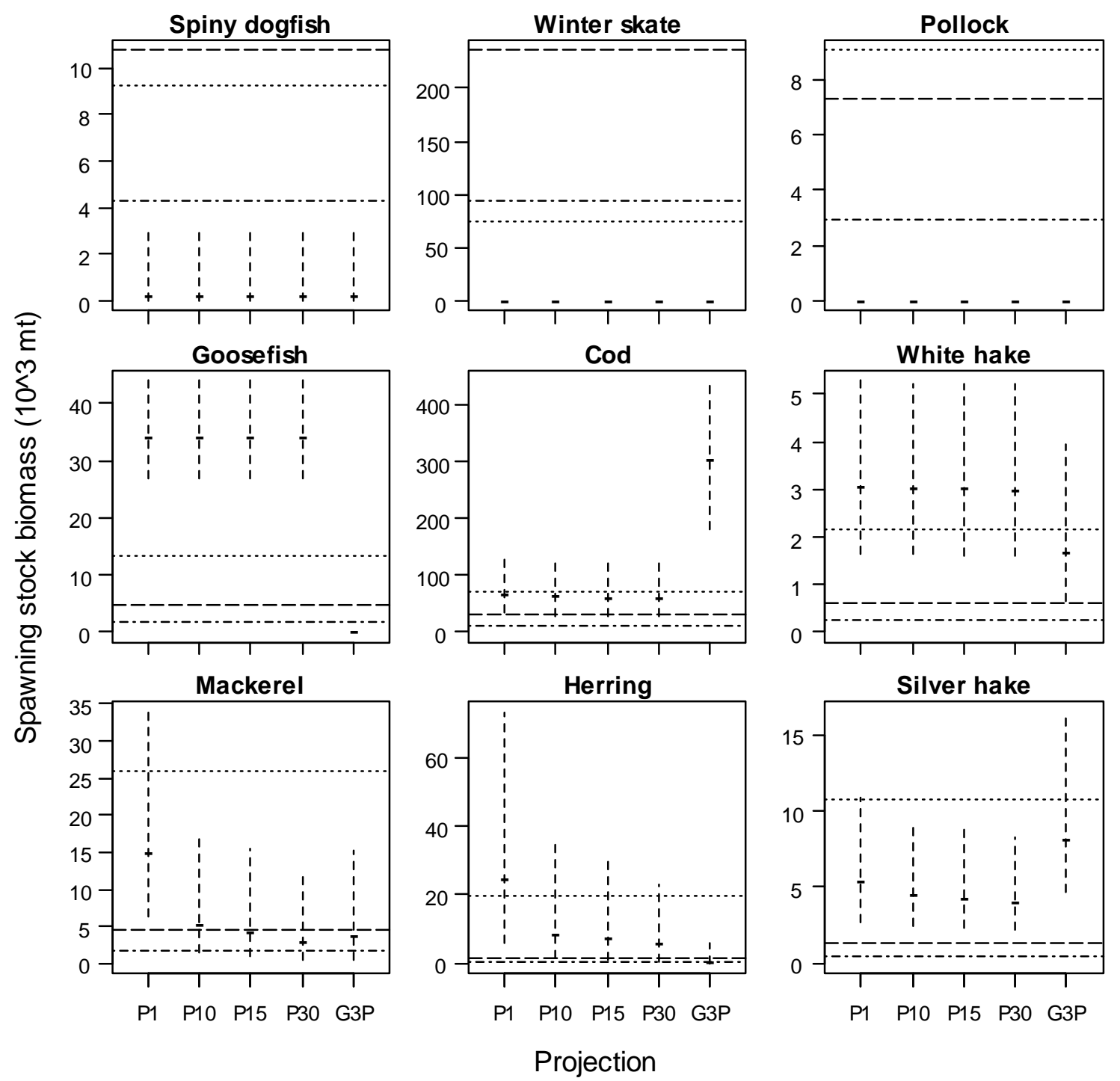

Figure 10: Comparison of the average median and $95^{\text {th }}$ percentiles (vertical dashed lines) of total spawning stock biomass as the fishing mortality on the prey species was increased from the base rate (P1) to ten (P10), fifteen (P15) and thirty (P30) times the base rate of fishing, while the top predators were heavily fished but intermediate predators were not fished. In the last projection (G3P), prey species were still fished at 30-times their base fishing rates, but goosefish was heavily fished as well. Projection scenarios are further detailed in Table 1. The benchmarks are as detailed in Figure 5. 

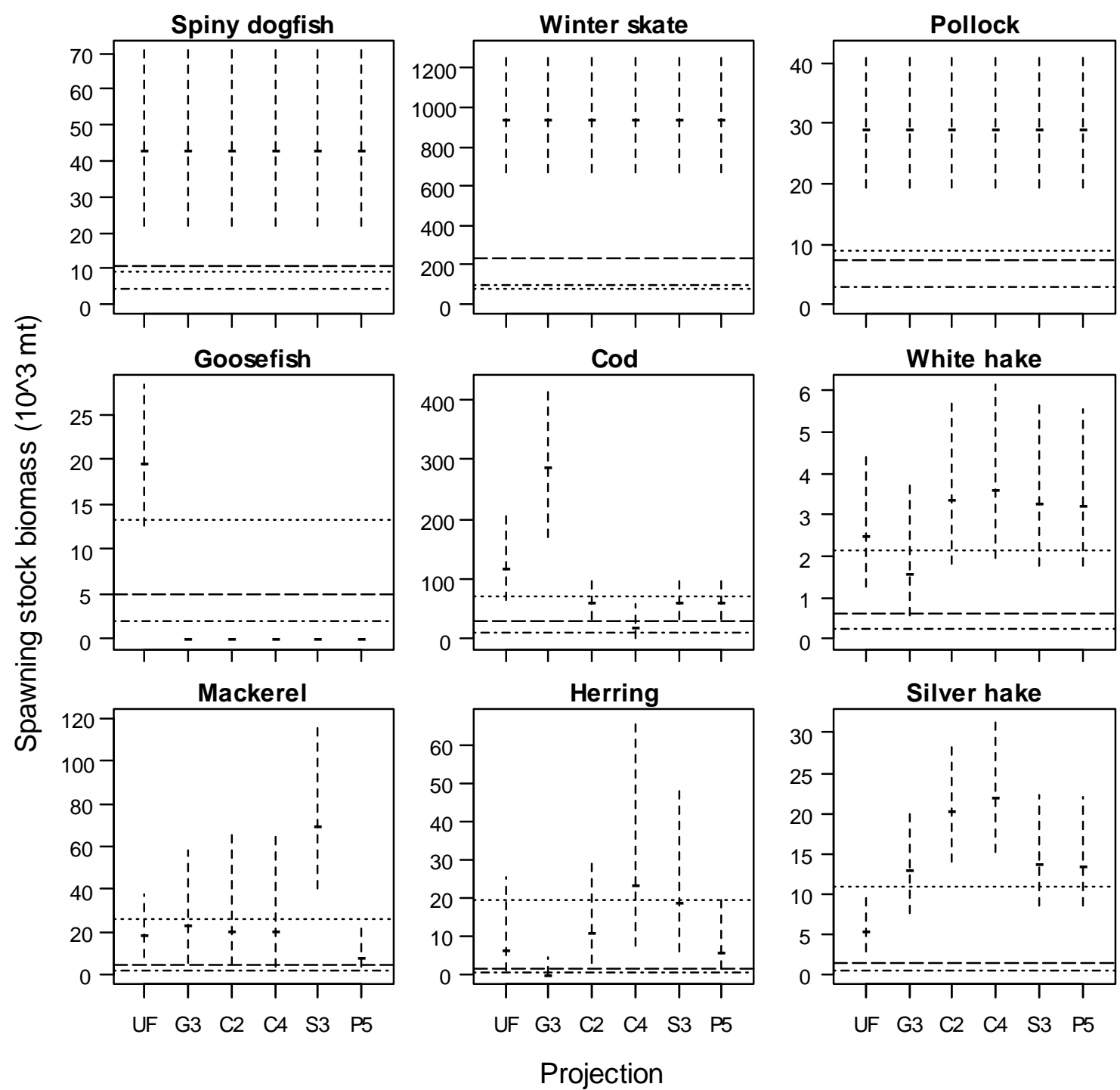

Figure 11: Comparison of the average median and $95^{\text {th }}$ percentiles (vertical dashed lines) of total spawning stock biomass as fishing was sequentially increased on goosefish (G3), cod (C2-C4), silver hake (S3) and finally the principal prey species (P5). Projection scenarios are detailed in Table 1. The benchmarks are as detailed in Figure 5. 


\section{SUPPLEMENTAL MATERIAL}

Age 0

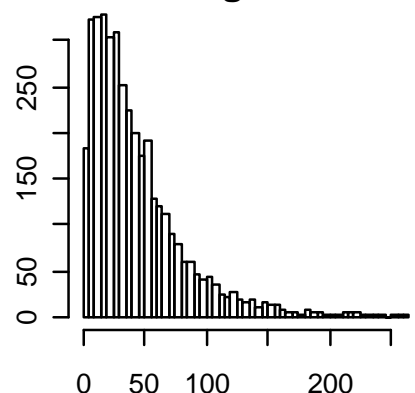

Age 3

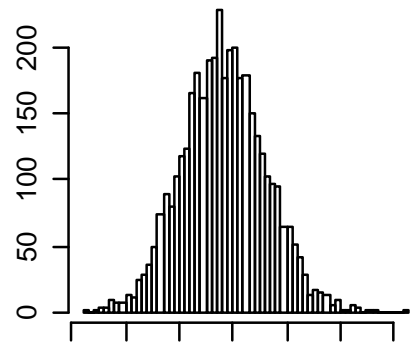

ปे
$\frac{0}{\Phi}$
$\frac{0}{0}$
$\frac{d}{4}$
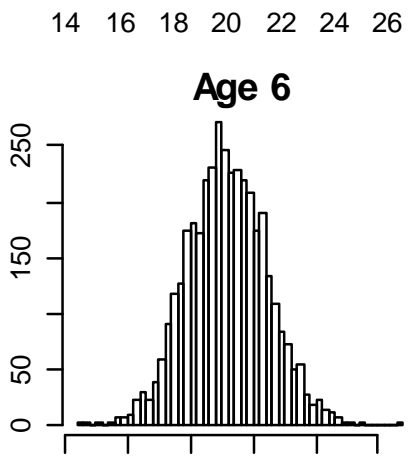

$\begin{array}{llllll}1.5 & 2.0 & 2.5 & 3.0 & 3.5 & 4.0\end{array}$

Age 9

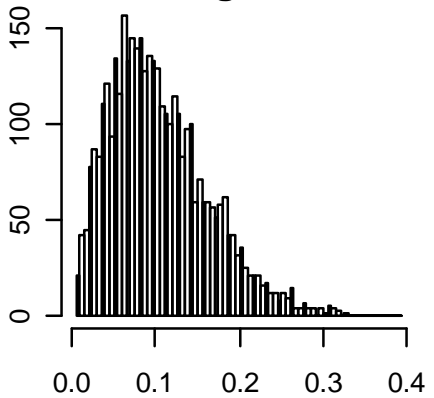

Age 1

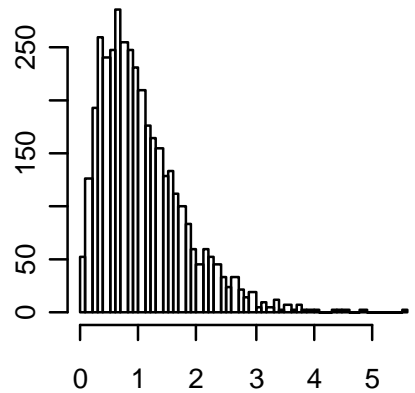

Age 4
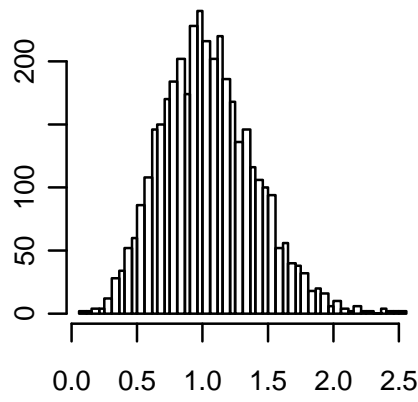

Age 7

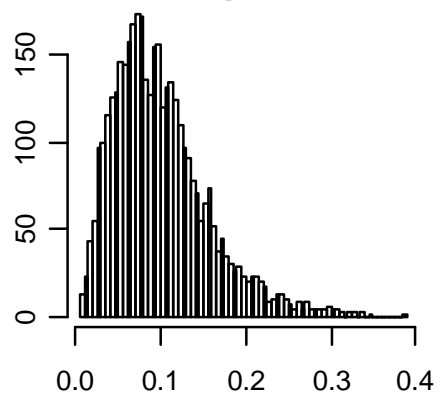

Age 10

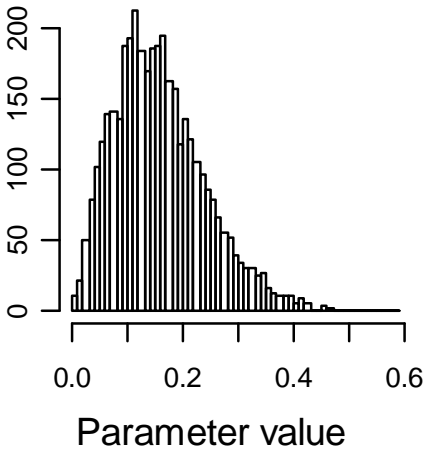

Age 2

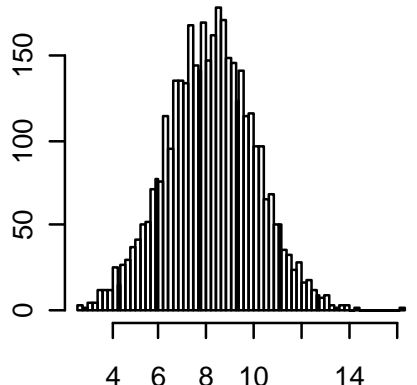

Age 5

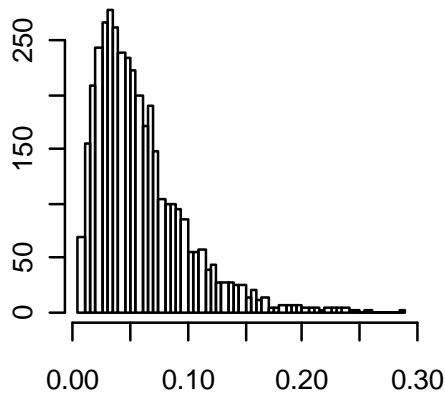

Age 8

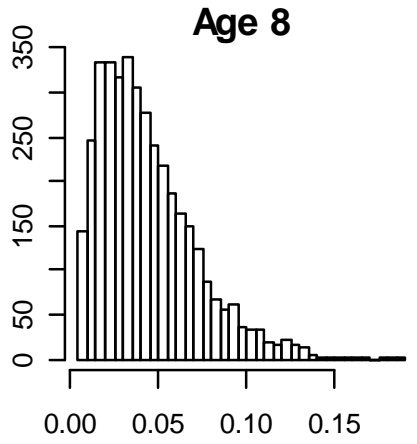

Age 11

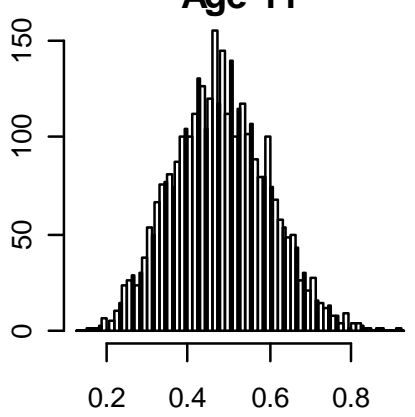

Figure S1: Estimated posterior distributions of predicted spiny dogfish abundance-at-age (millions of fish) in the last year of the 9-species model. 
Age 12

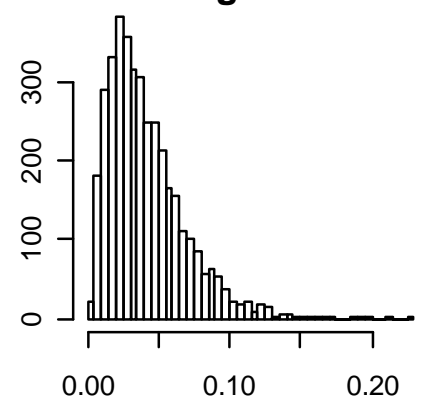

Age 15

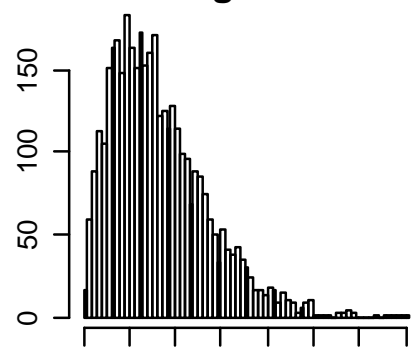

ठे
d
$\frac{0}{0}$
$\frac{d}{4}$
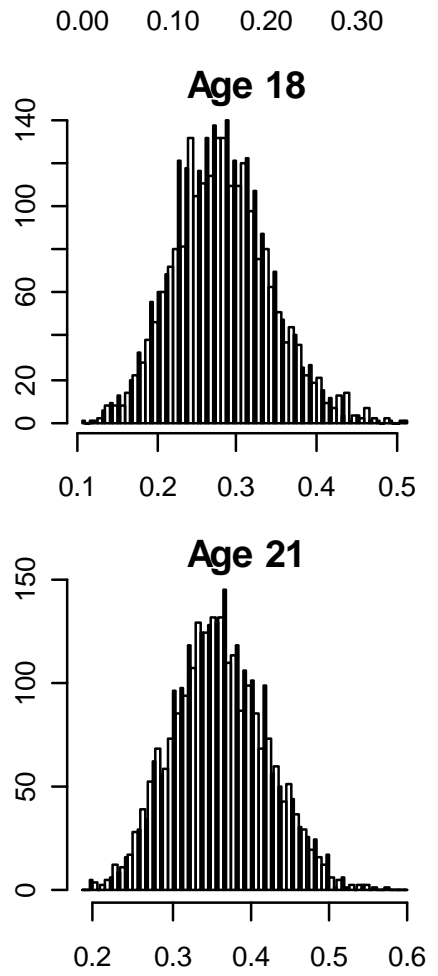

Age 13

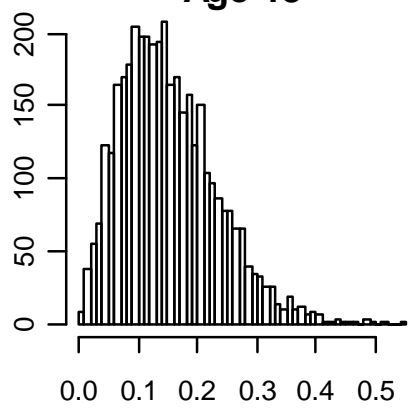

Age 16
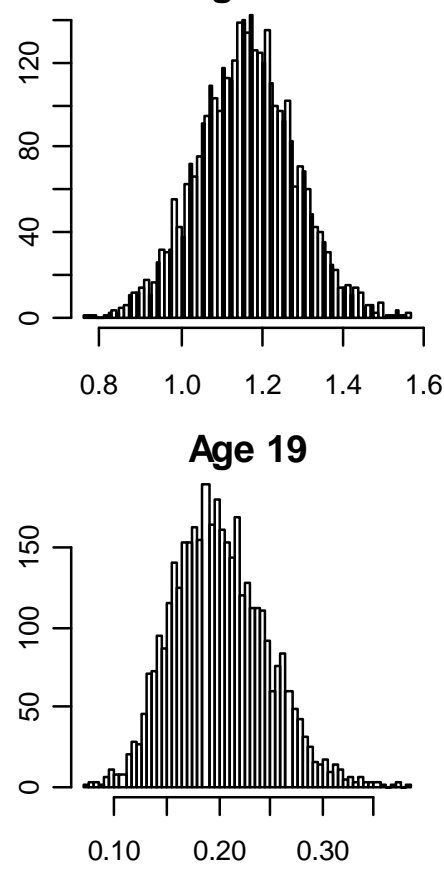

Age 22

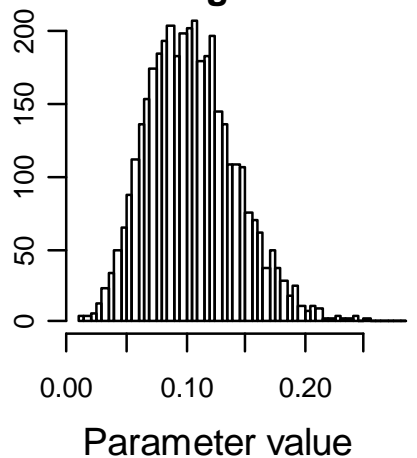

Age 14

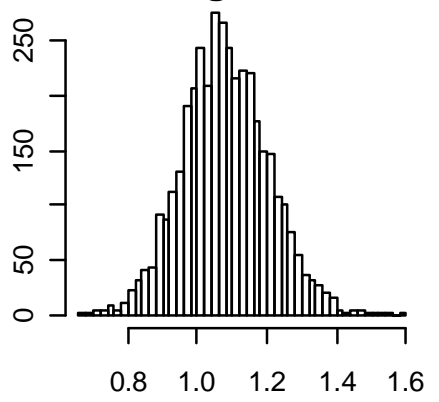

Age 17

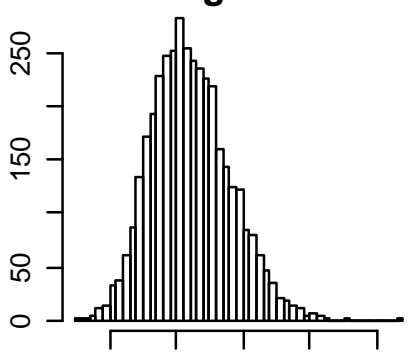

$\begin{array}{lllll}0.1 & 0.2 & 0.3 & 0.4 & 0.5\end{array}$

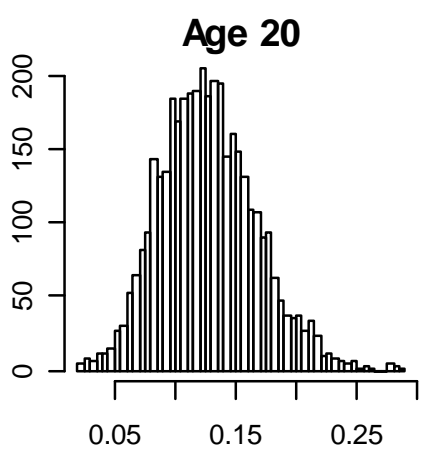

Age 23

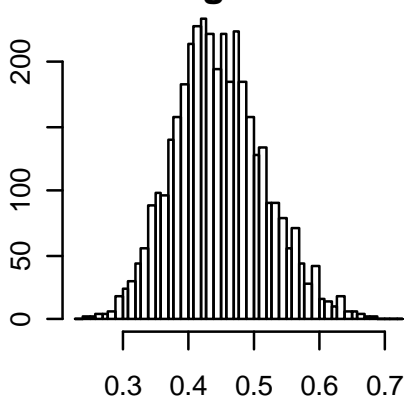

Figure S1, contd.: Estimated posterior distributions of predicted spiny dogfish abundance-at-age (millions of fish) in the last year of the 9-species model. 

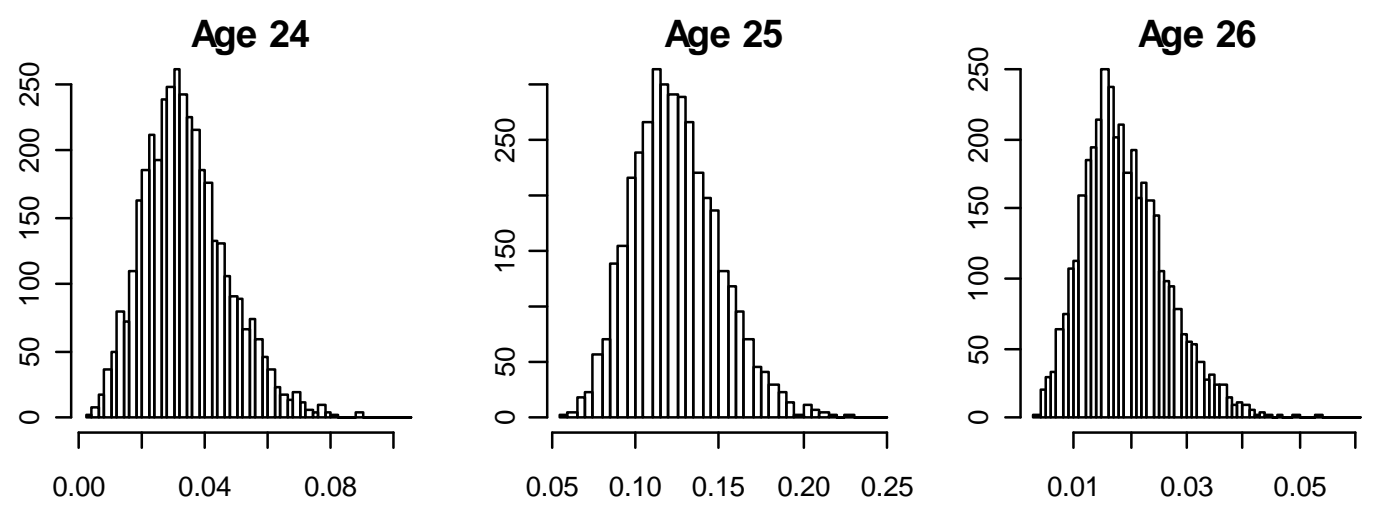

Age 27

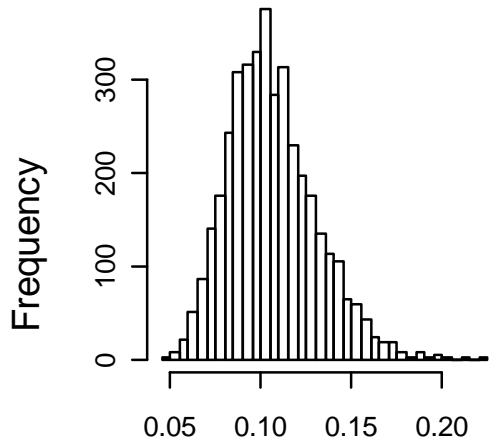

Age 28
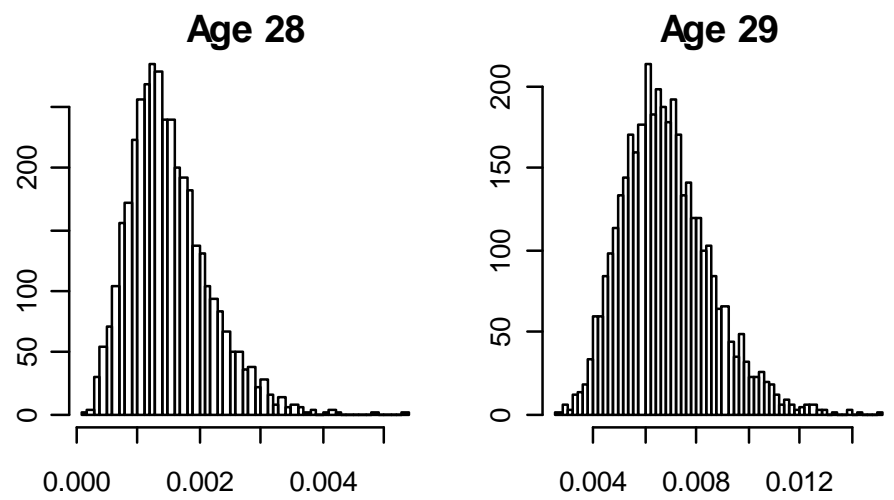

Age 30

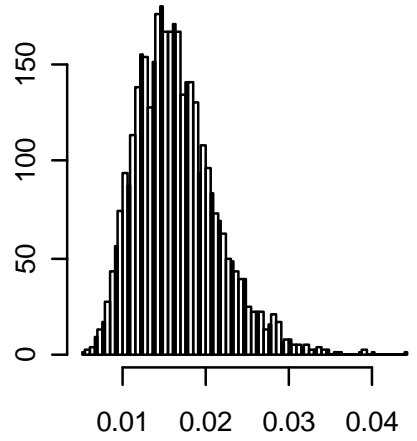

Parameter value

Figure S1, contd.: Estimated posterior distributions of predicted spiny dogfish abundance-at-age (millions of fish) in the last year of the 9-species model. 

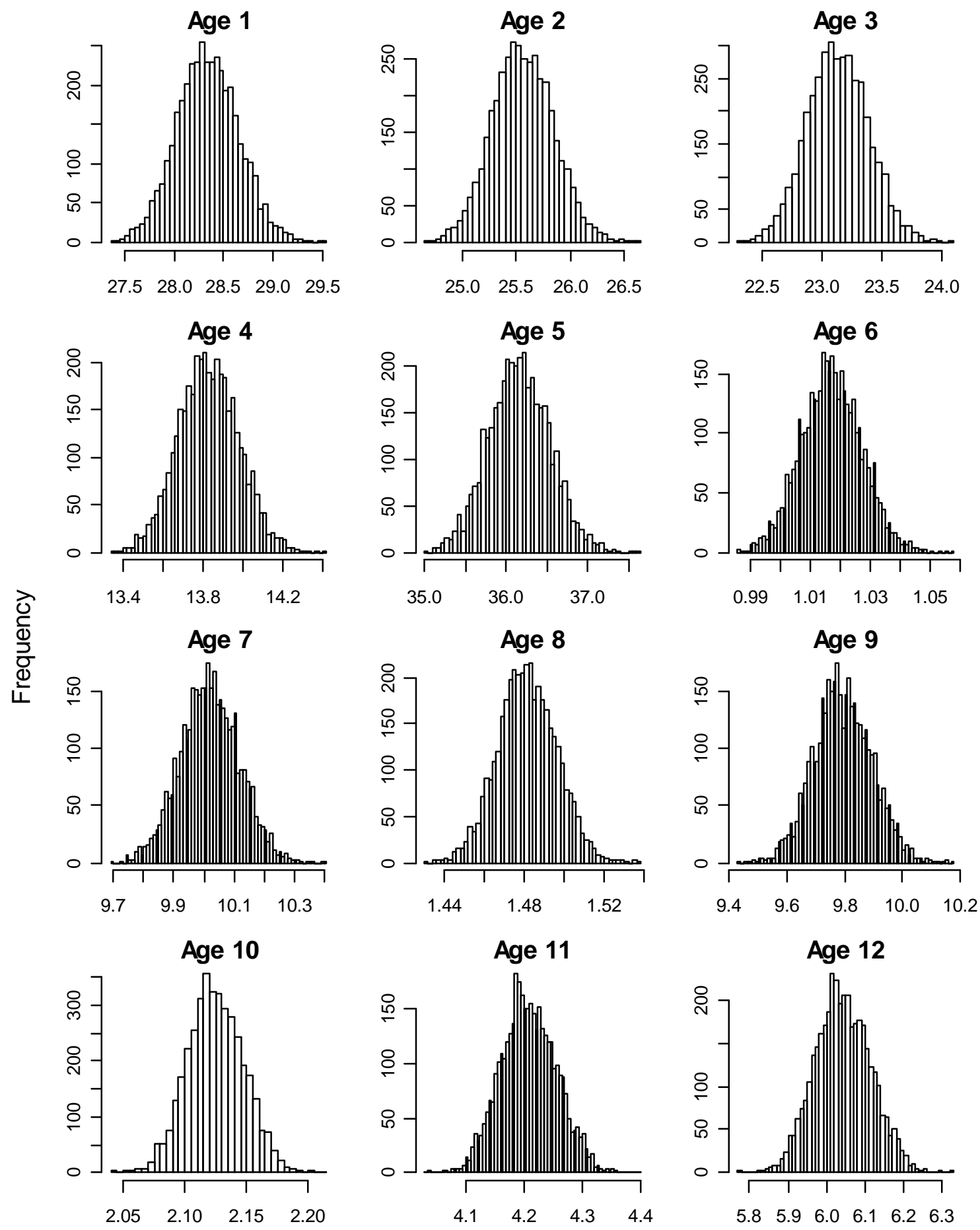

Parameter value

Figure S2: Estimated posterior distributions of predicted winter skate abundance-at-age (millions of fish) in the last year of the 9-species model. 

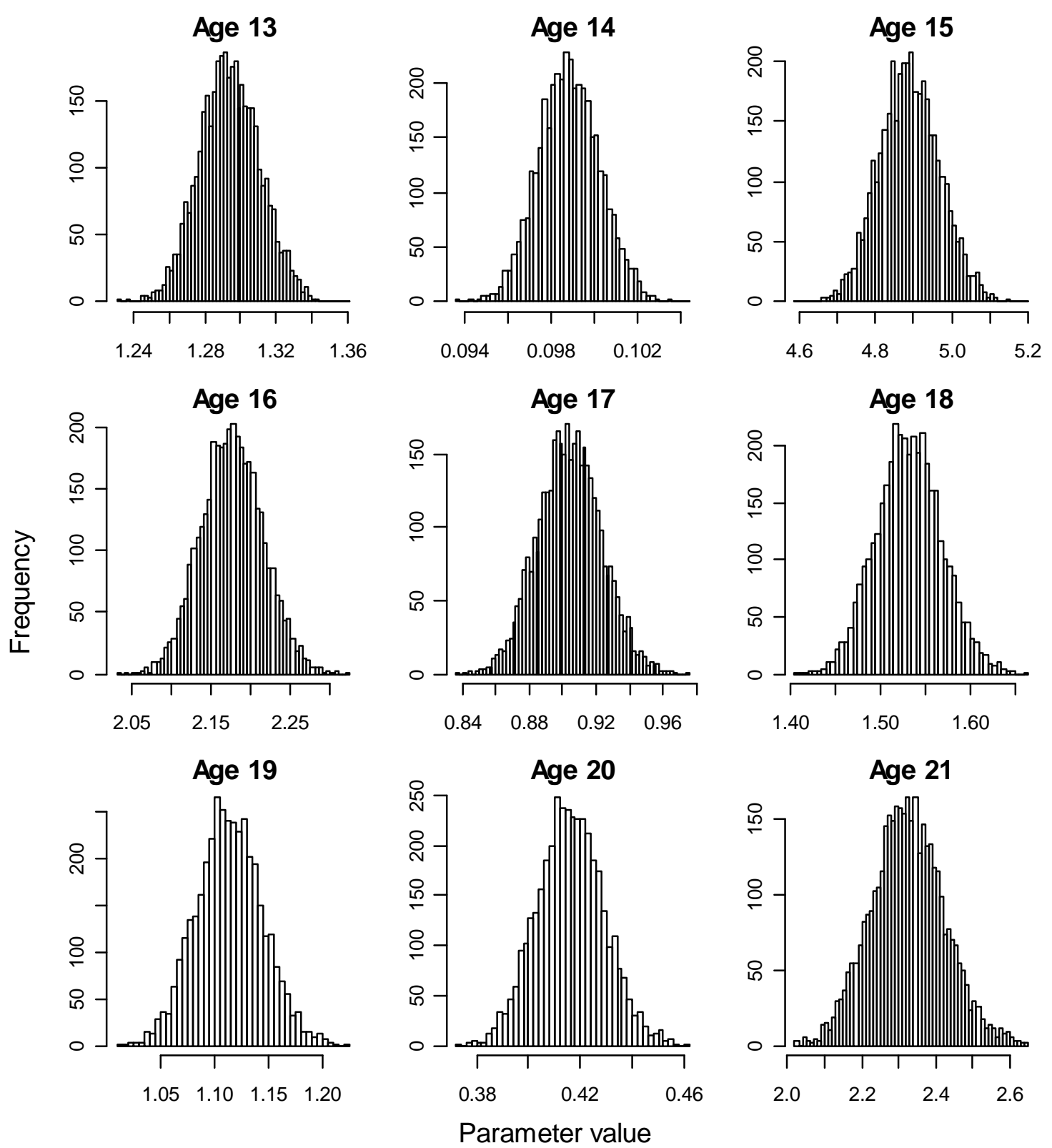

Figure S2 contd.: Estimated posterior distributions of predicted winter skate abundanceat-age (millions of fish) in the last year of the 9-species model. 

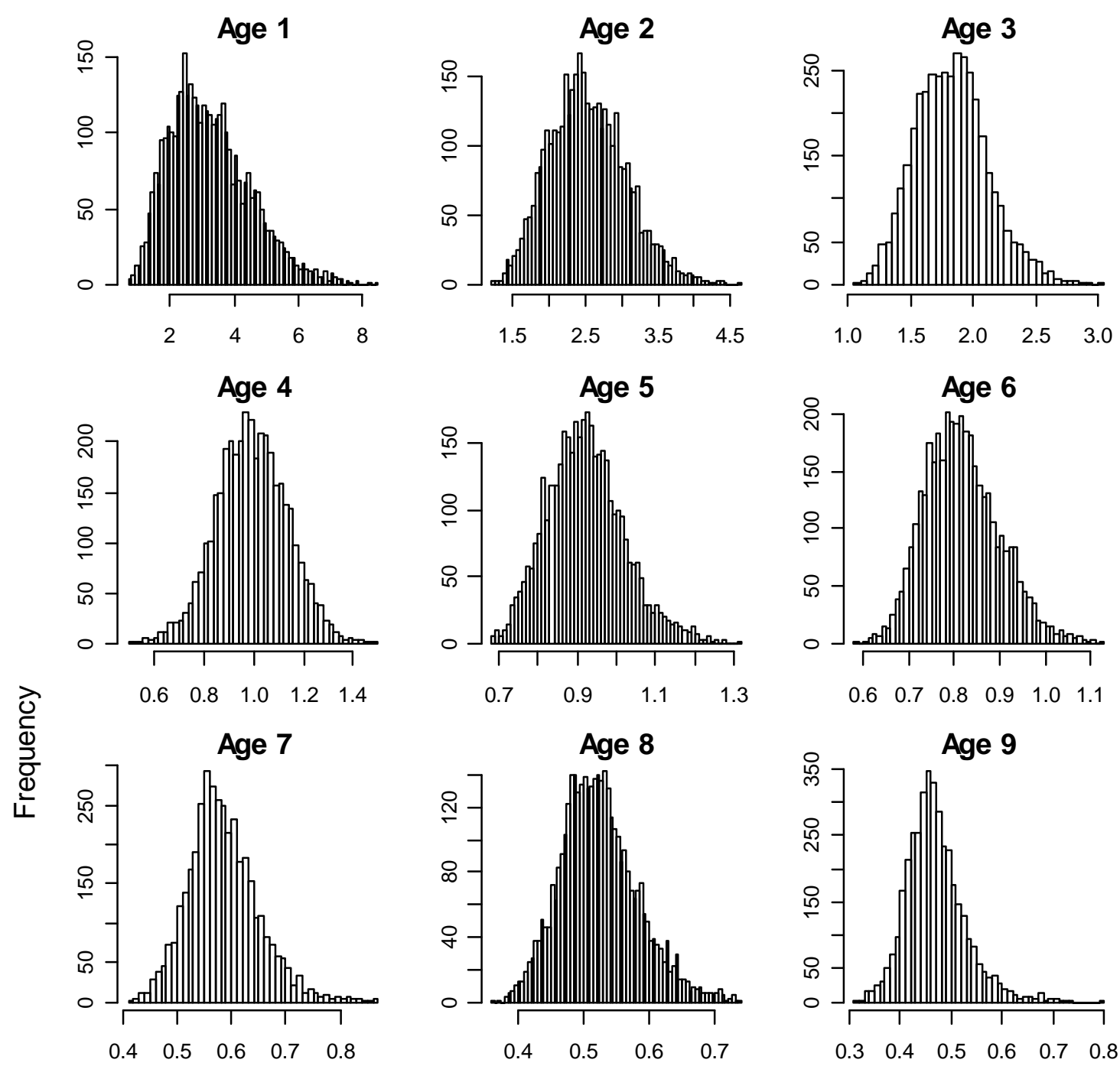

Age 10

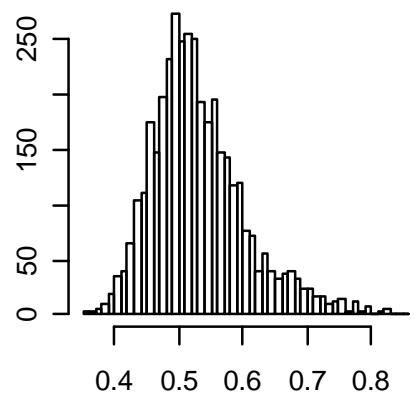

Parameter value

Figure S3: Estimated posterior distributions of predicted goosefish abundance-at-age (millions of fish) in the last year of the 9-species model. 
Age 1

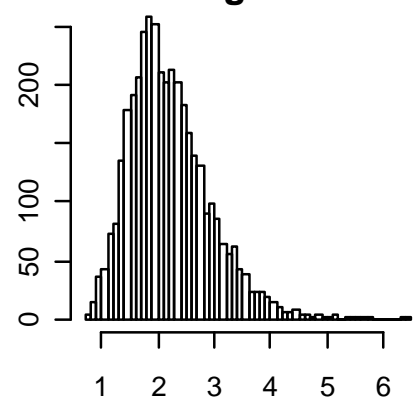

Age 4
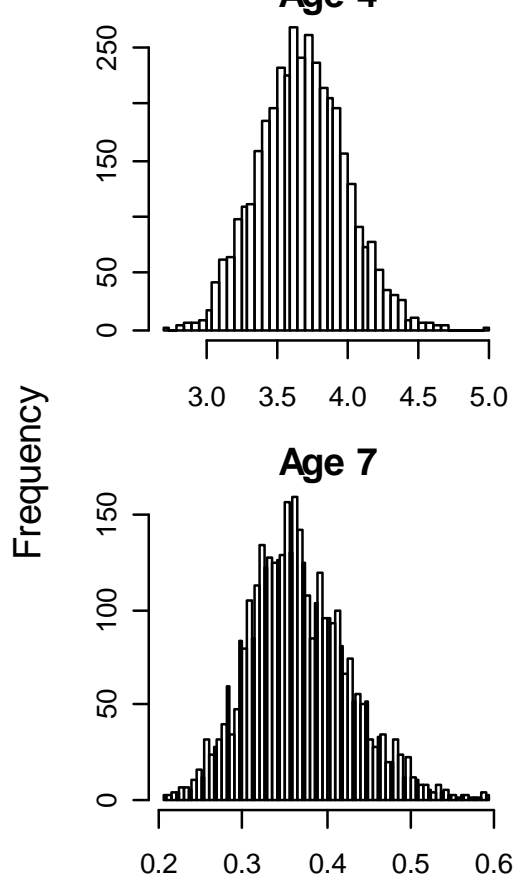

Age 10

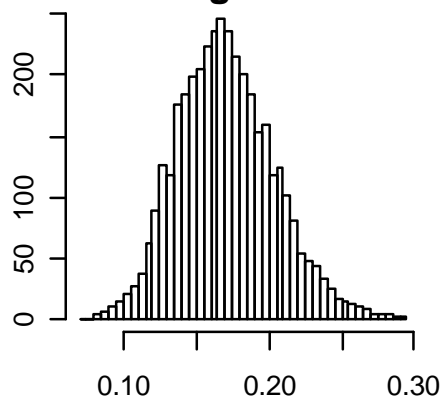

Age 2

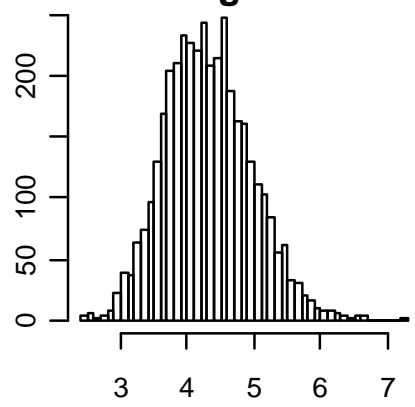

Age 5

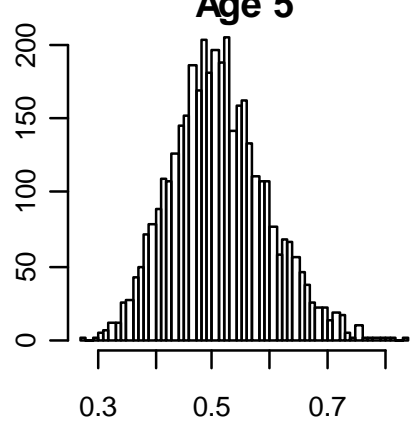

Age 8
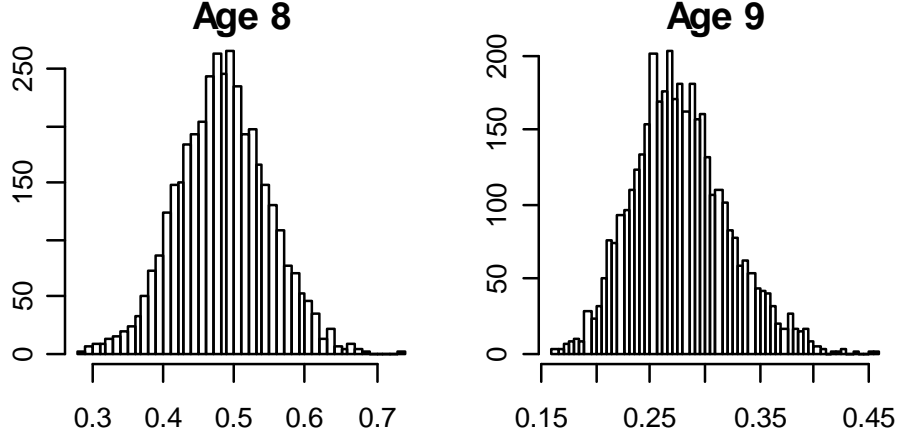

\section{Parameter value}

Figure S4: Estimated posterior distributions of predicted cod abundance-at-age (millions of fish) in the last year of the 9-species model. 

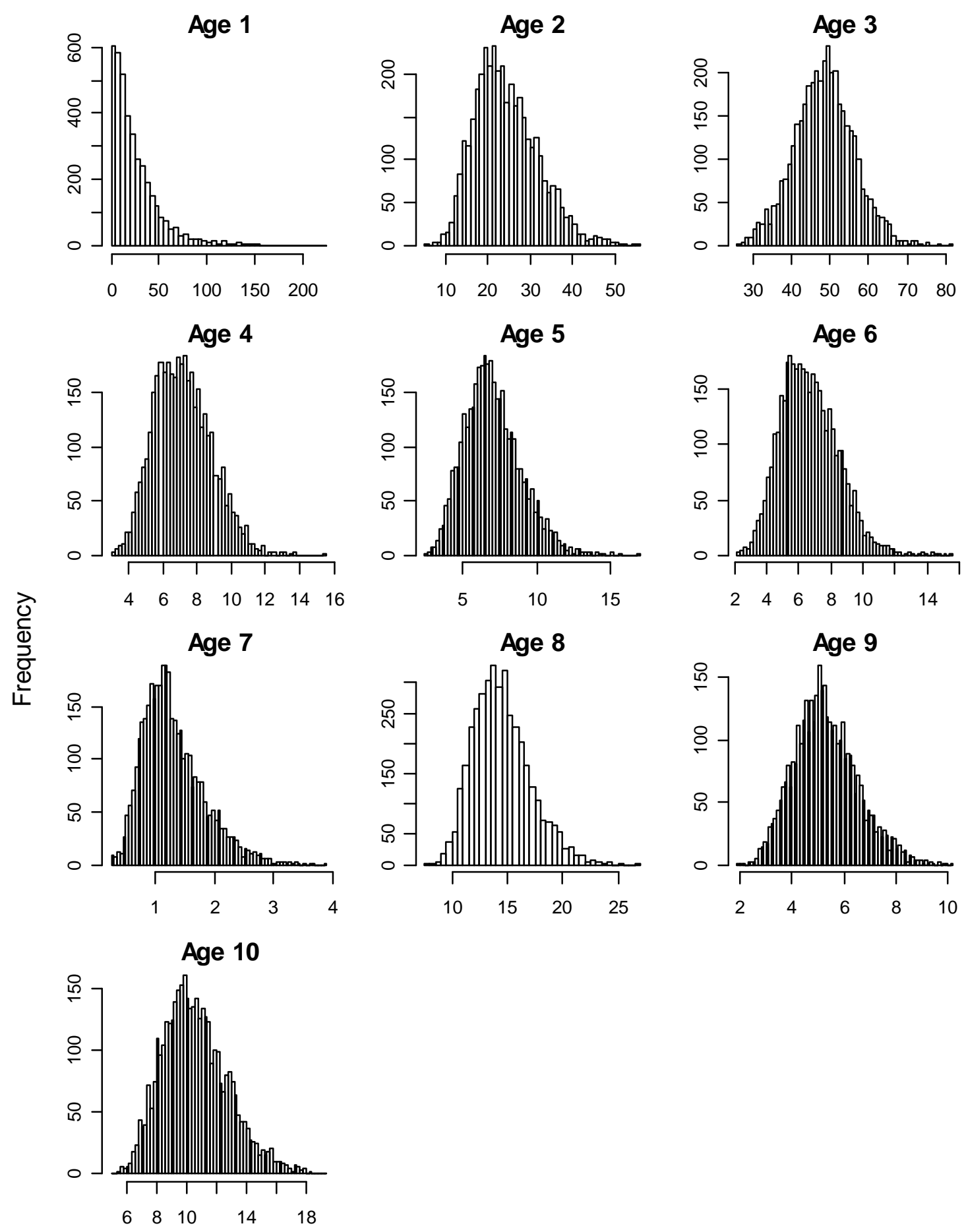

Parameter value

Figure S5: Estimated posterior distributions of predicted mackerel abundance-at-age (millions of fish) in the last year of the 9-species model. 


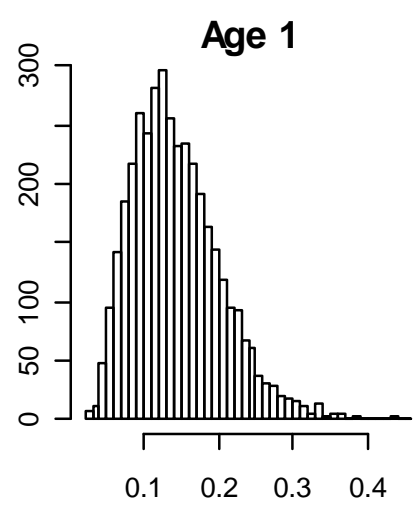

Age 2
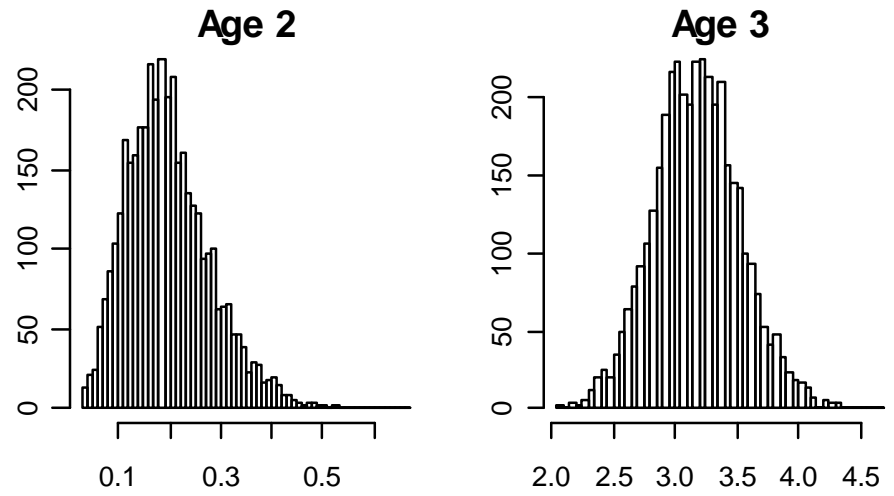

Age 4

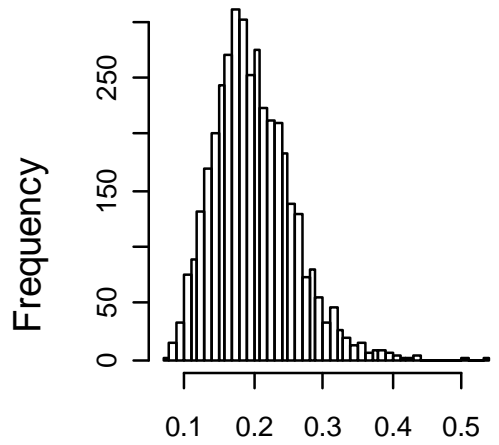

Age 5

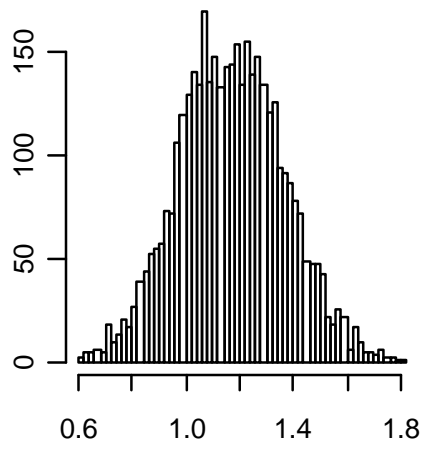

Age 6
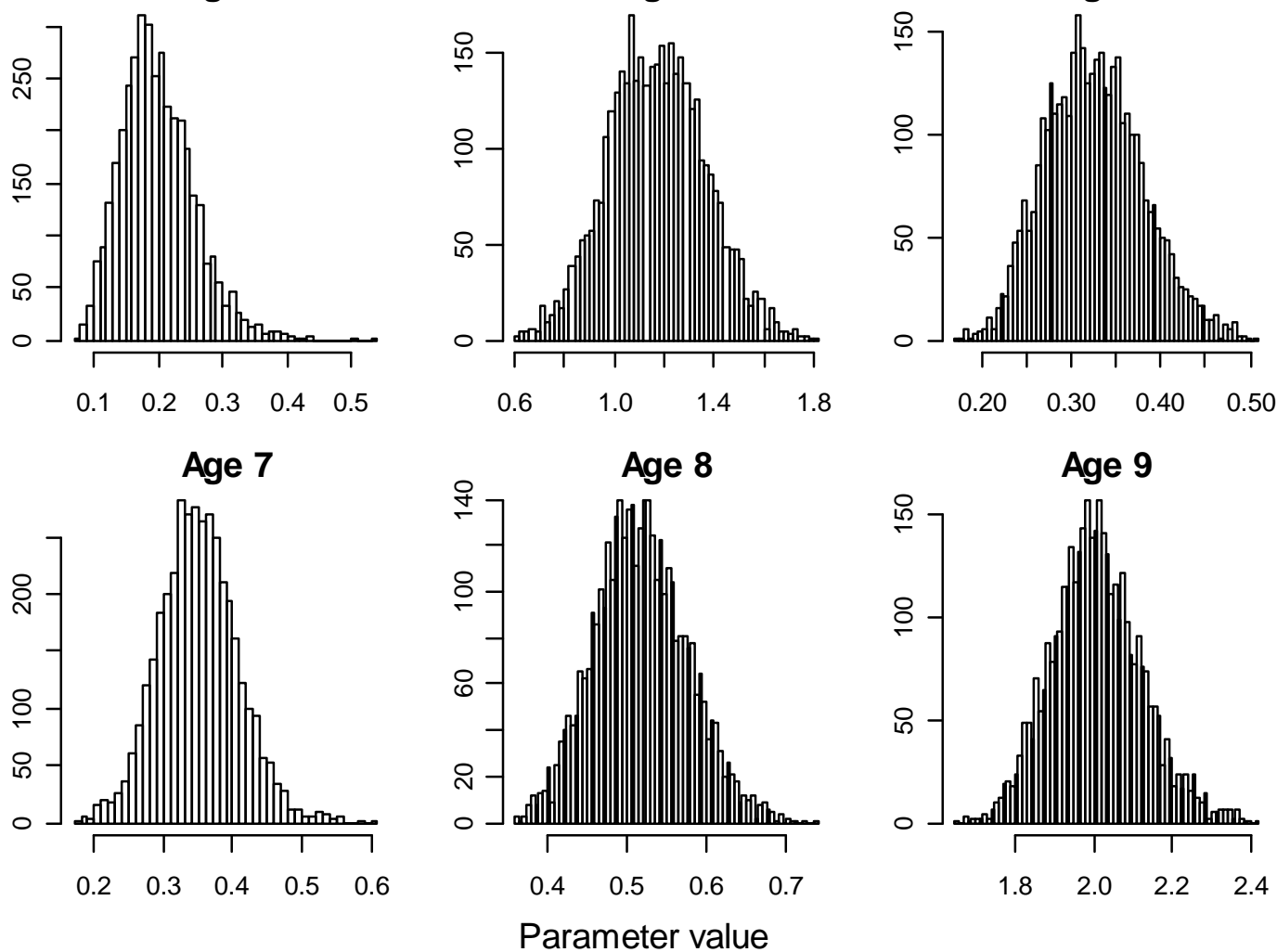

Figure S6: Estimated posterior distributions of predicted pollock abundance-at-age (millions of fish) in the last year of the 9-species model. 

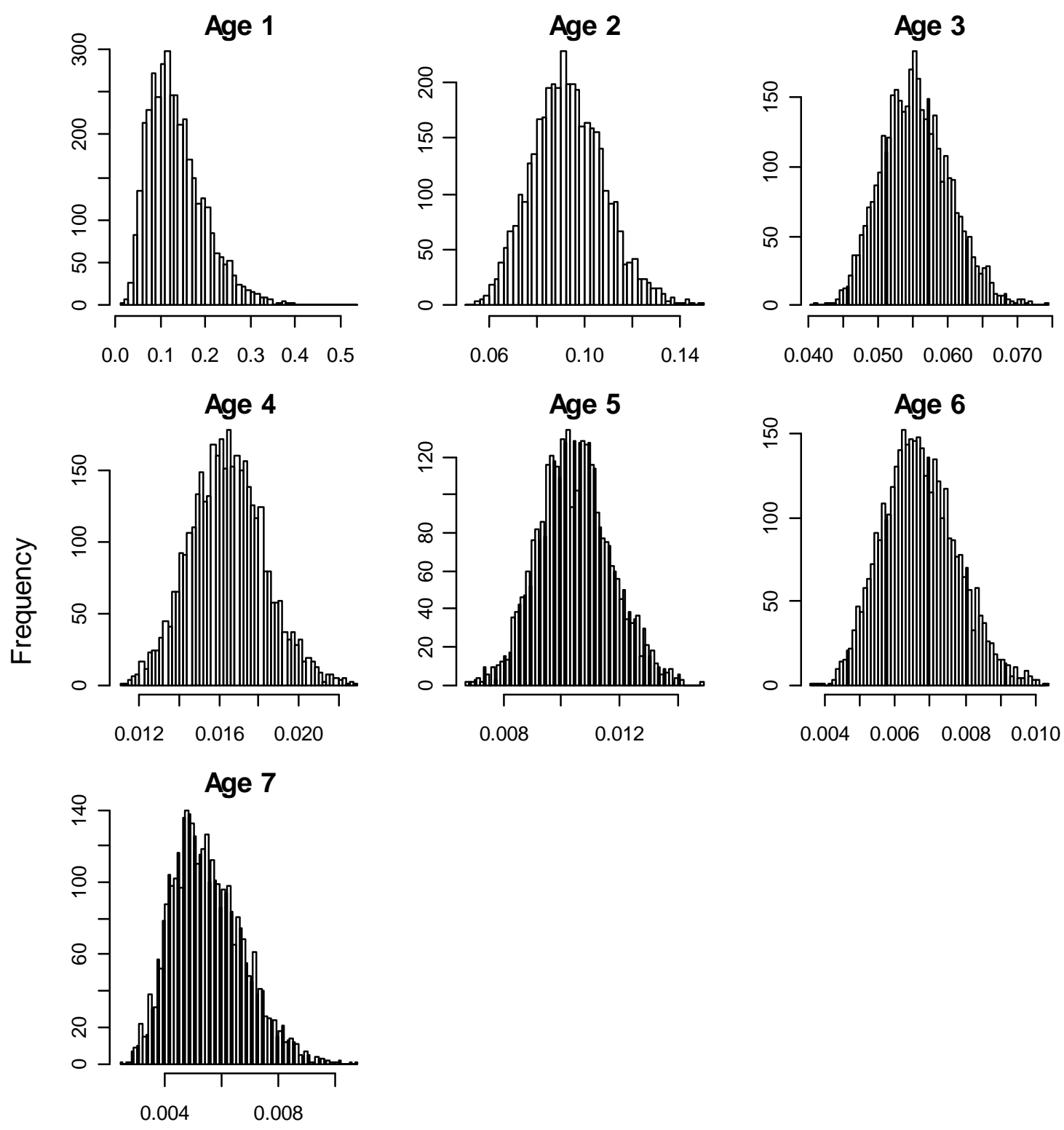

\section{Parameter value}

Figure S7: Estimated posterior distributions of predicted white hake abundance-at-age (millions of fish) in the last year of the 9-species model. 

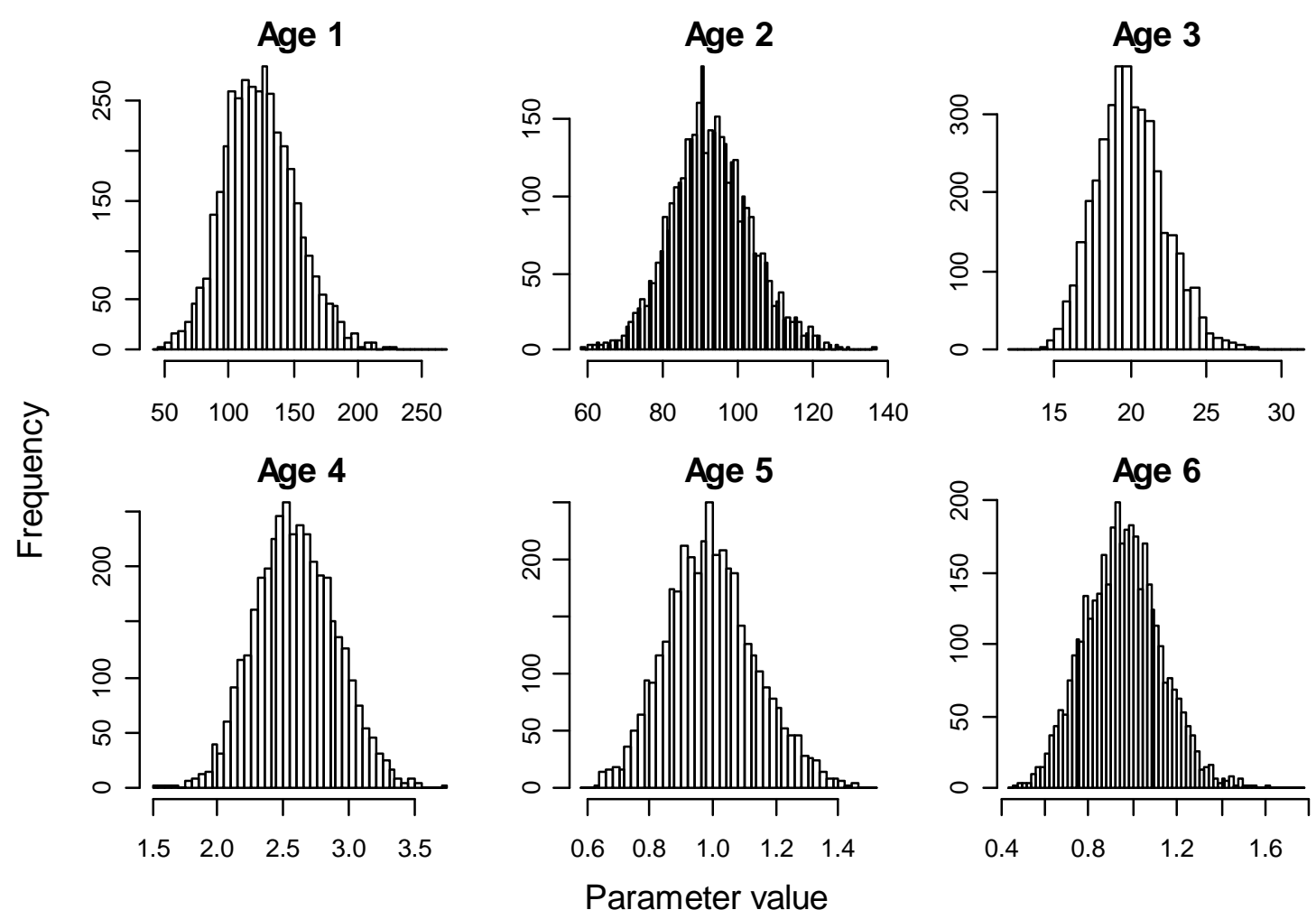

Figure S8: Estimated posterior distributions of predicted silver hake abundance-at-age (millions of fish) in the last year of the 9-species model. 

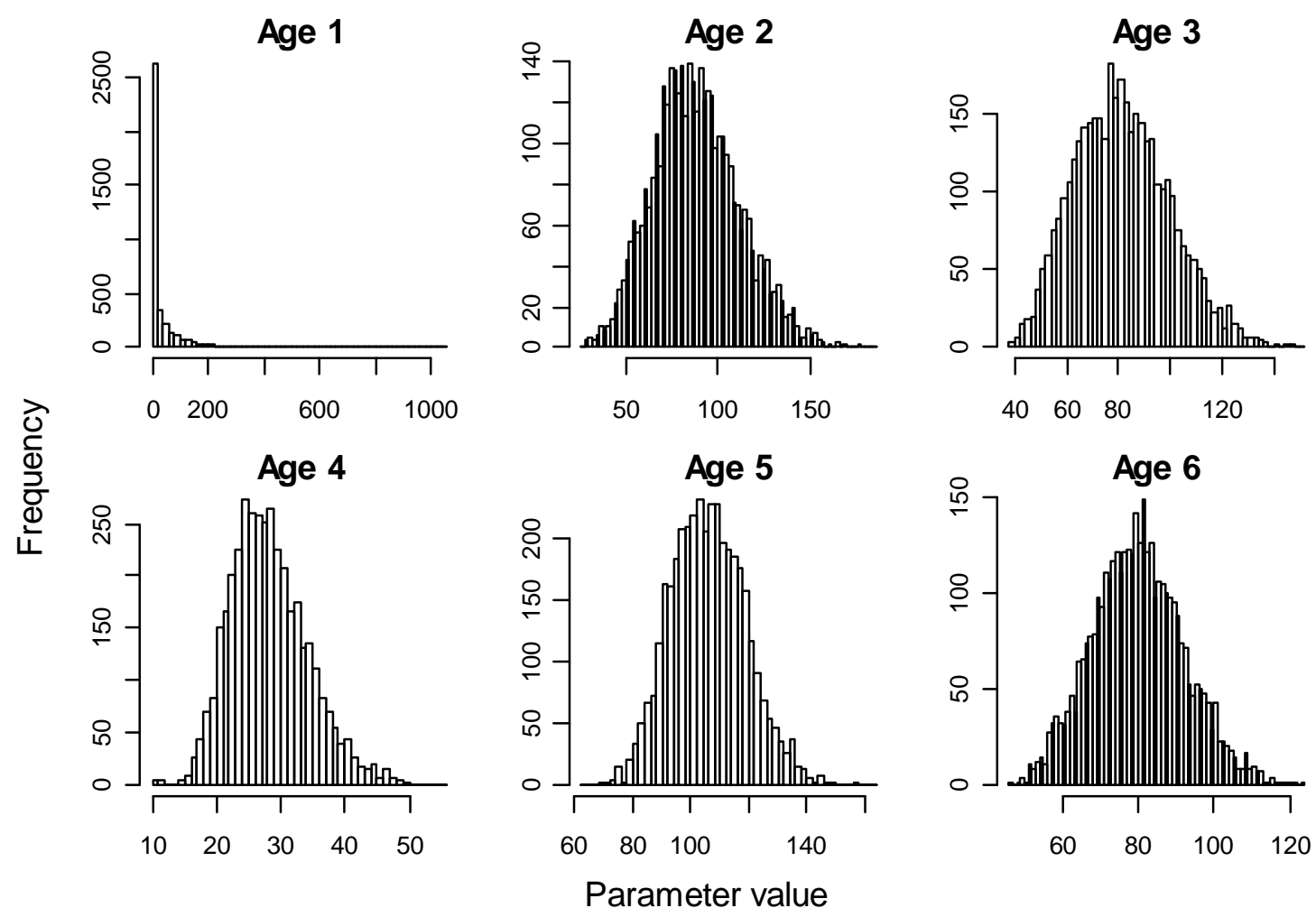

Figure S9: Estimated posterior distributions of predicted herring abundance-at-age (millions of fish) in the last year of the 9-species model. 

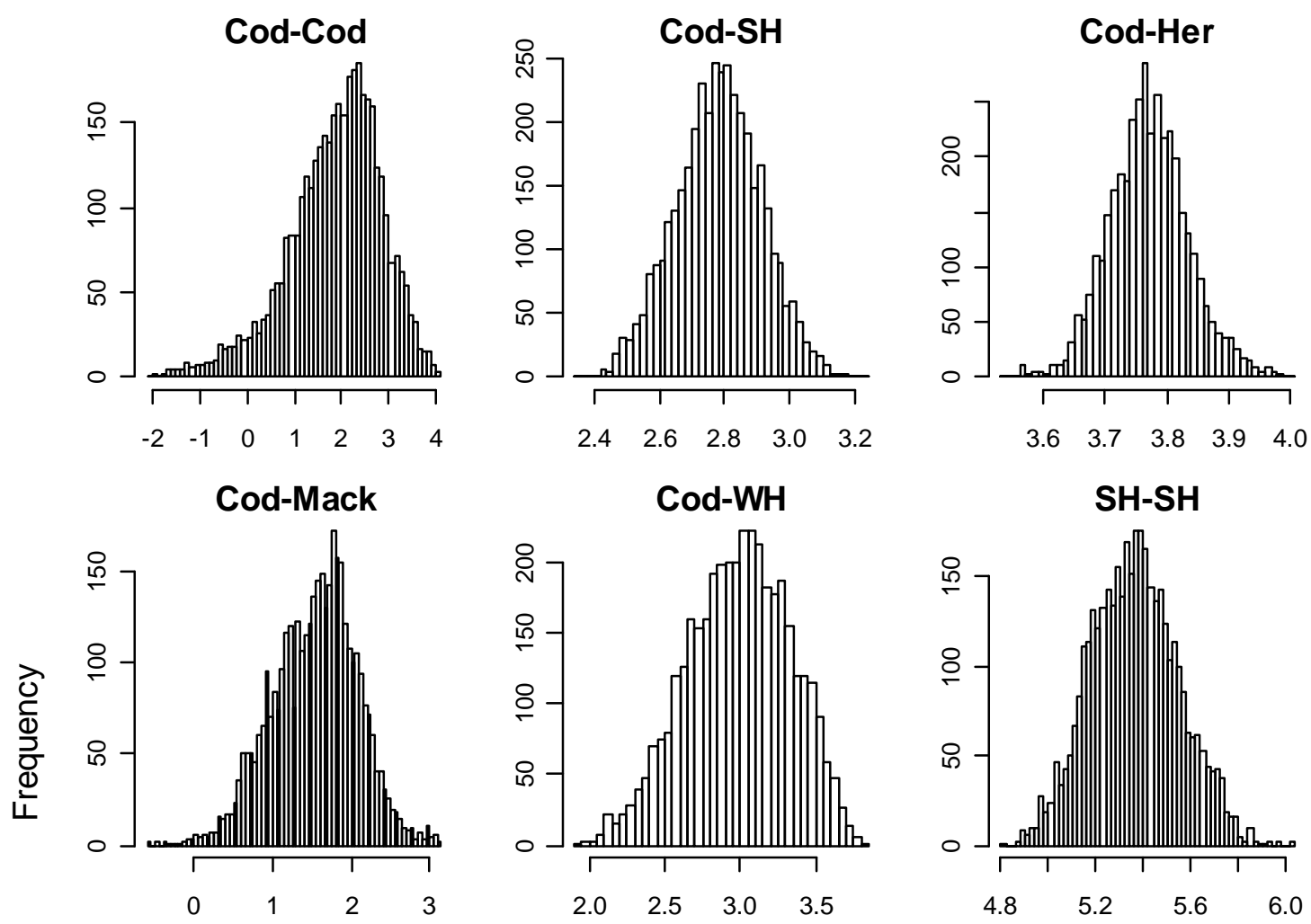

\section{Cod-WH}

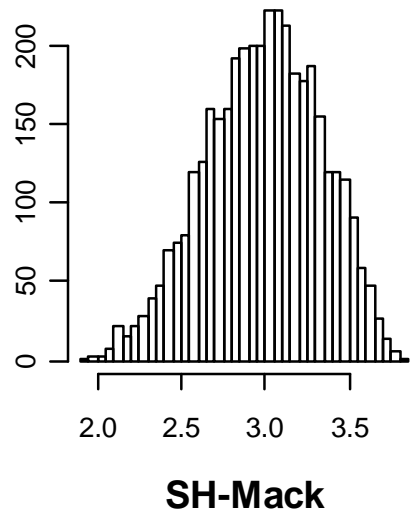

SH-SH
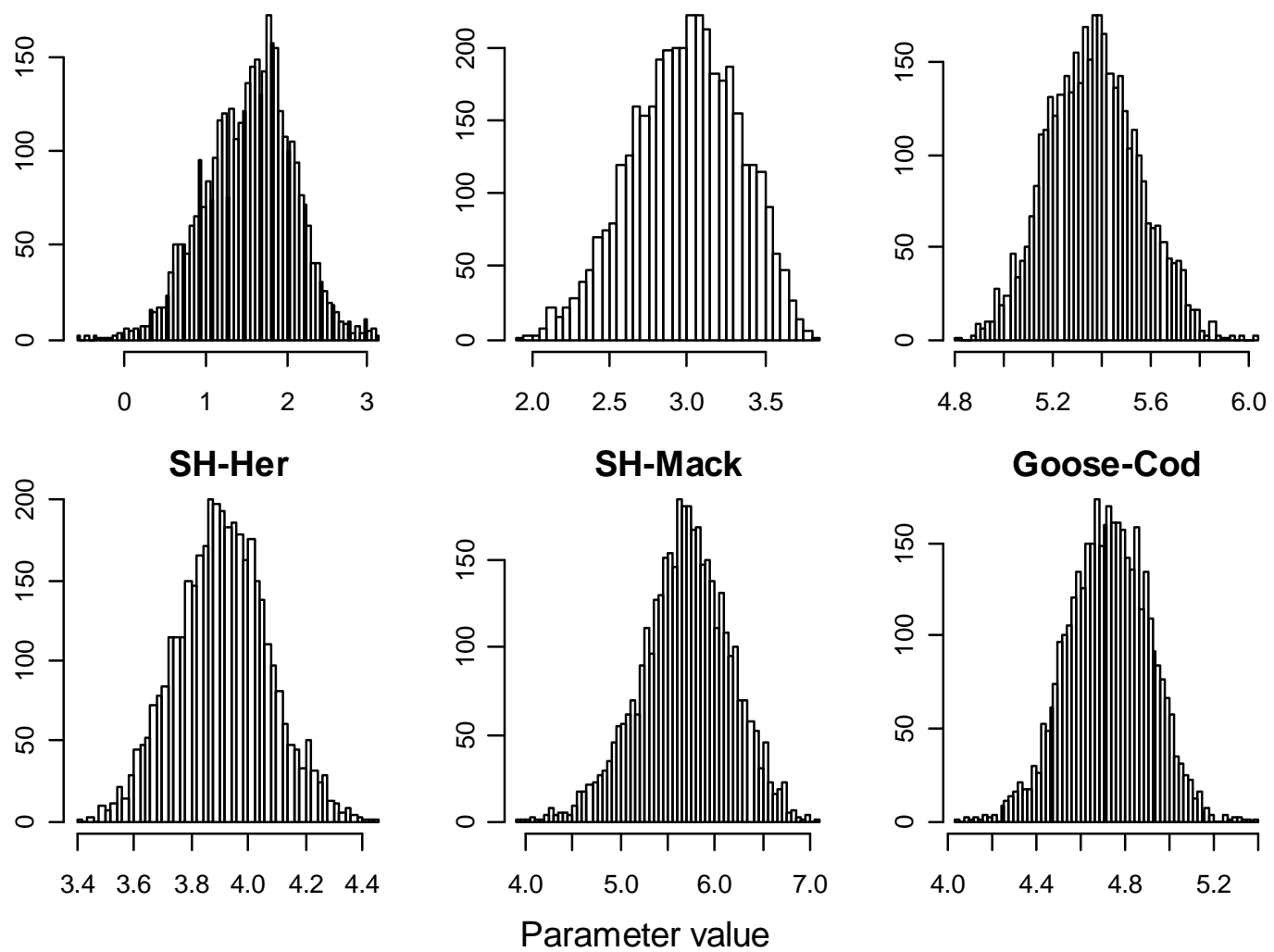

Figure S10: Estimated posterior distributions of predicted species-preference coefficients (log preference) from the 9-species model. Species abbreviations are as follows: spiny dogfish (SDog), winter skate (WSk), goosefish (Goose), mackerel (Mack), pollock (Pol), white hake (WH), silver hake (SH) and herring (Her). 

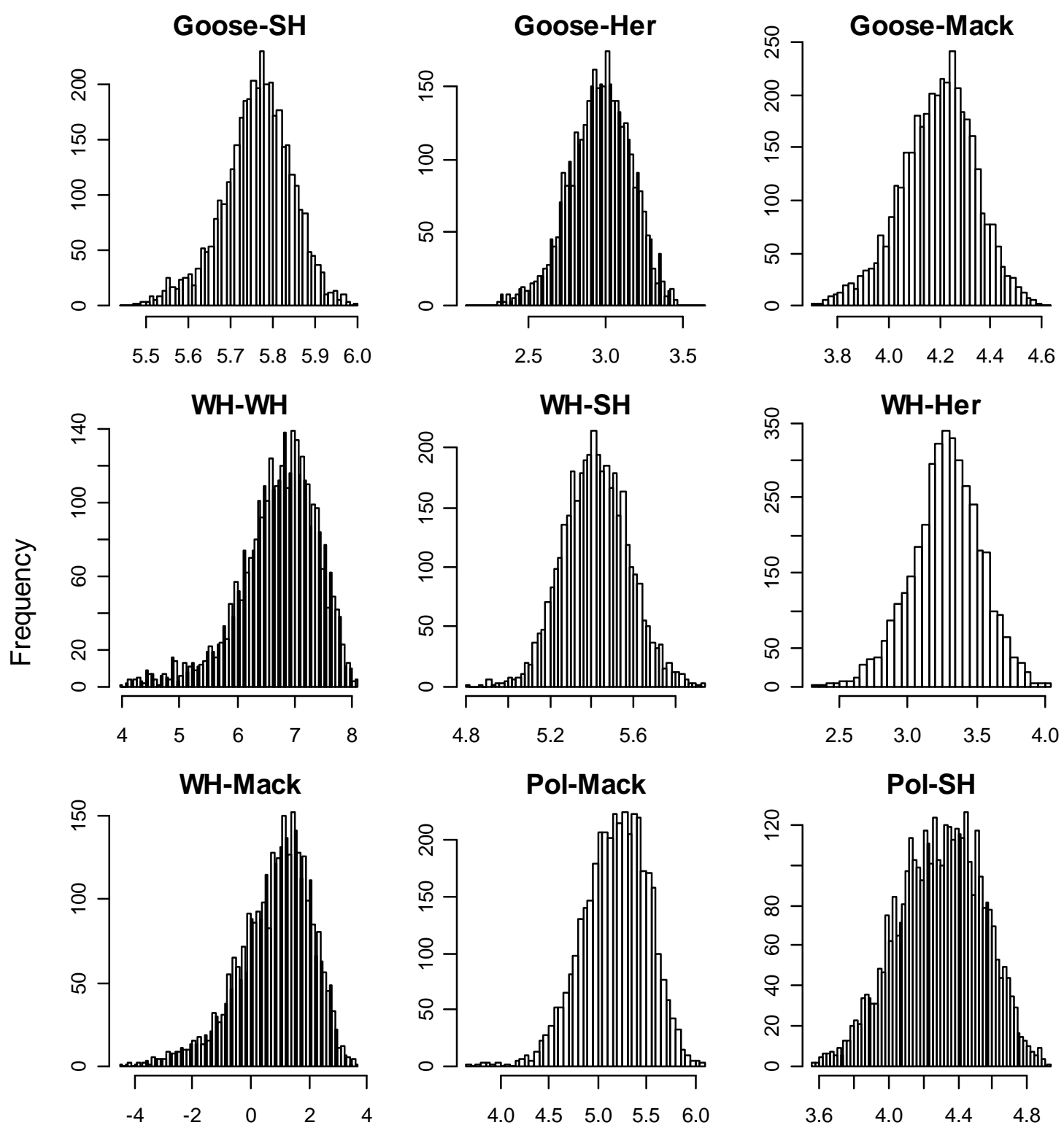

Pol-Mack
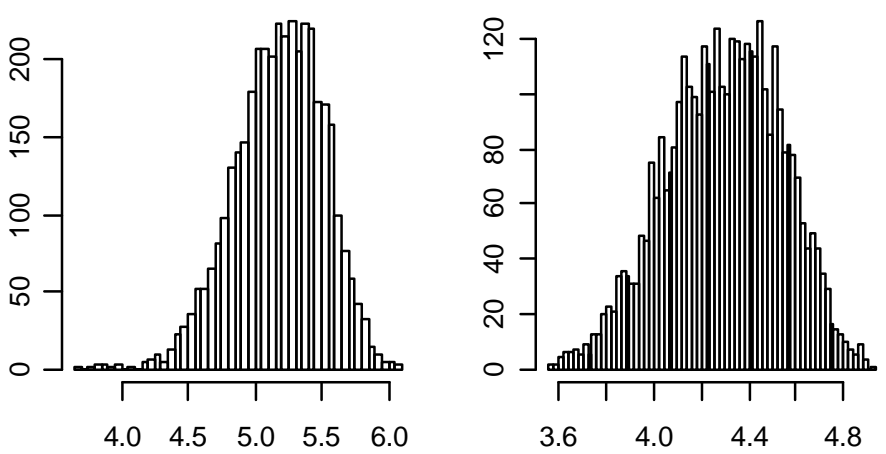

Parameter value

Figure S10, contd.: Estimated posterior distributions of predicted species-preference coefficients (log preference) from the 9-species model. Species abbreviations are as follows: spiny dogfish (SDog), winter skate (WSk), goosefish (Goose), mackerel (Mack), pollock (Pol), white hake (WH), silver hake (SH) and herring (Her). 

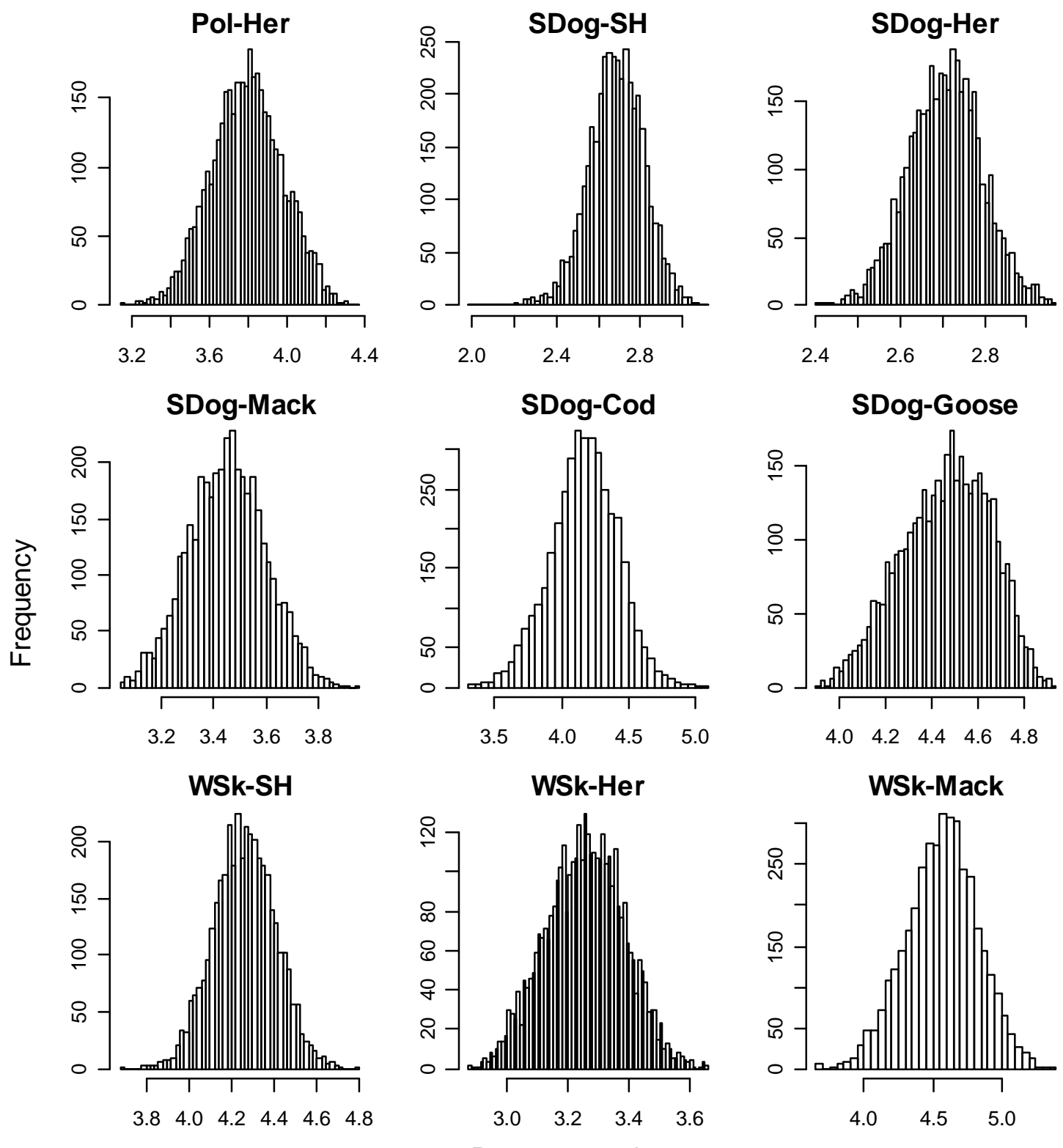

Parameter value

Figure S10, contd.: Estimated posterior distributions of predicted species-preference coefficients (log preference) from the 9-species model. Species abbreviations are as follows: spiny dogfish (SDog), winter skate (WSk), goosefish (Goose), mackerel (Mack), pollock (Pol), white hake (WH), silver hake (SH) and herring (Her). 

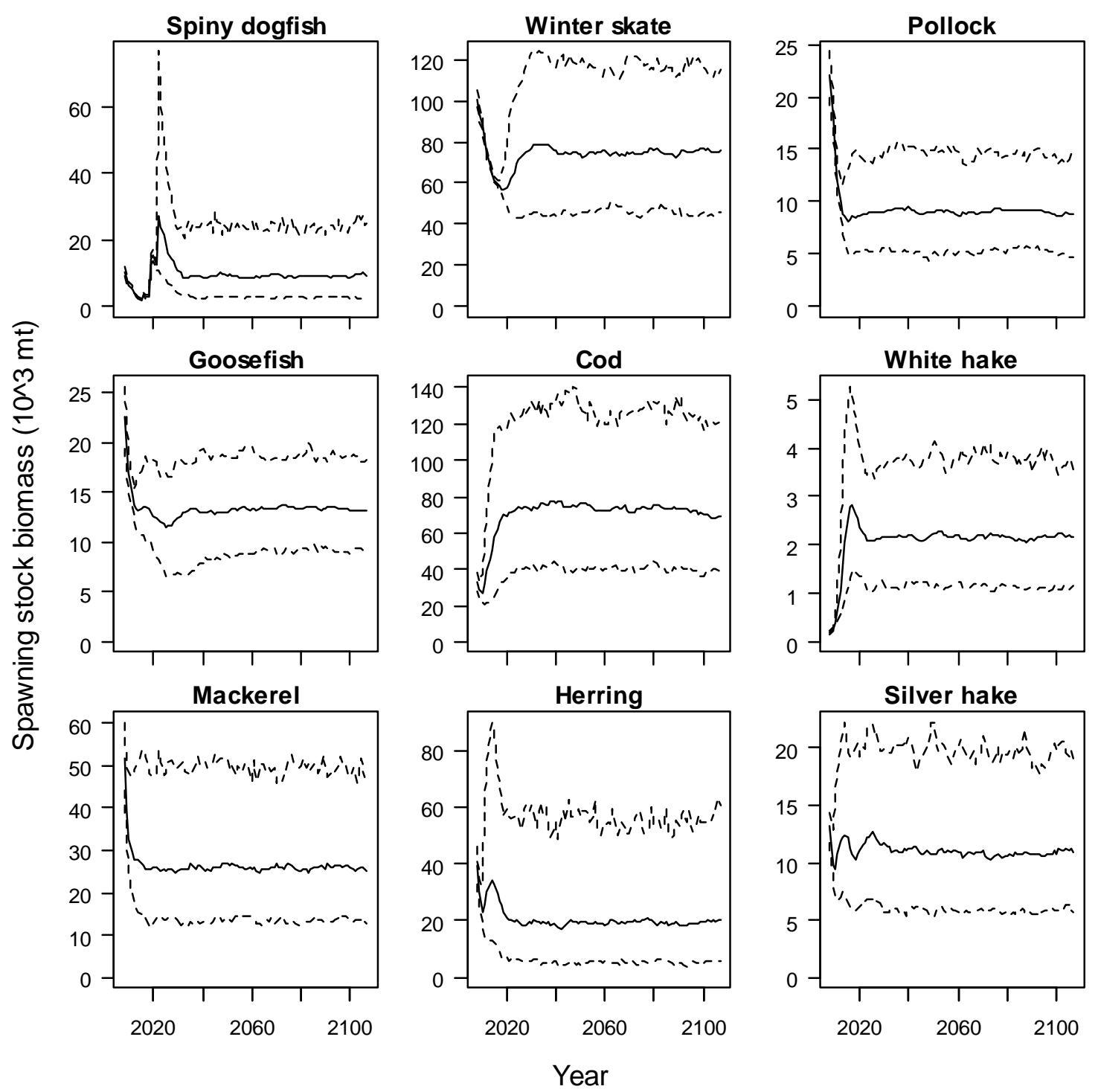

Figure S11: $95^{\text {th }}$ percentiles (dashed lines) and median (solid line) total annual spawning stock biomass $\left(10^{3} \mathrm{mt}\right)$ in the base fishing projection. 

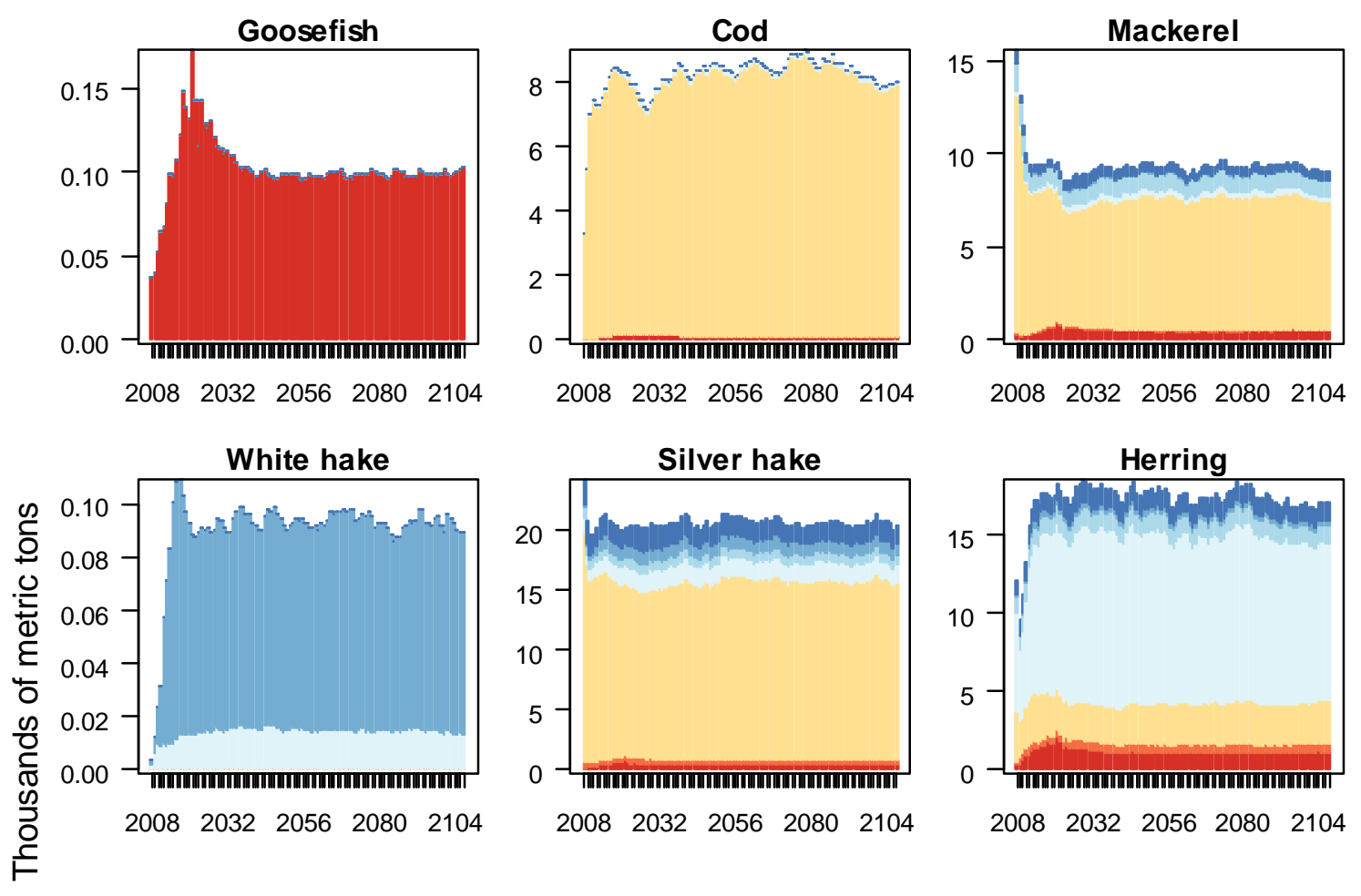

$$
\begin{aligned}
& \text { Predator species } \\
& \text { - Spiny dogfish } \\
& \text { Winter skate } \\
& \text { Goosefish } \\
& \text { Cod } \\
& \text { Pollock } \\
& \text { White hake } \\
& \text { Silver hake }
\end{aligned}
$$

\section{Year}

Figure S12: Average annual predator-specific consumption (thousands of metric tons) of each prey species in the status quo fishing projection. 

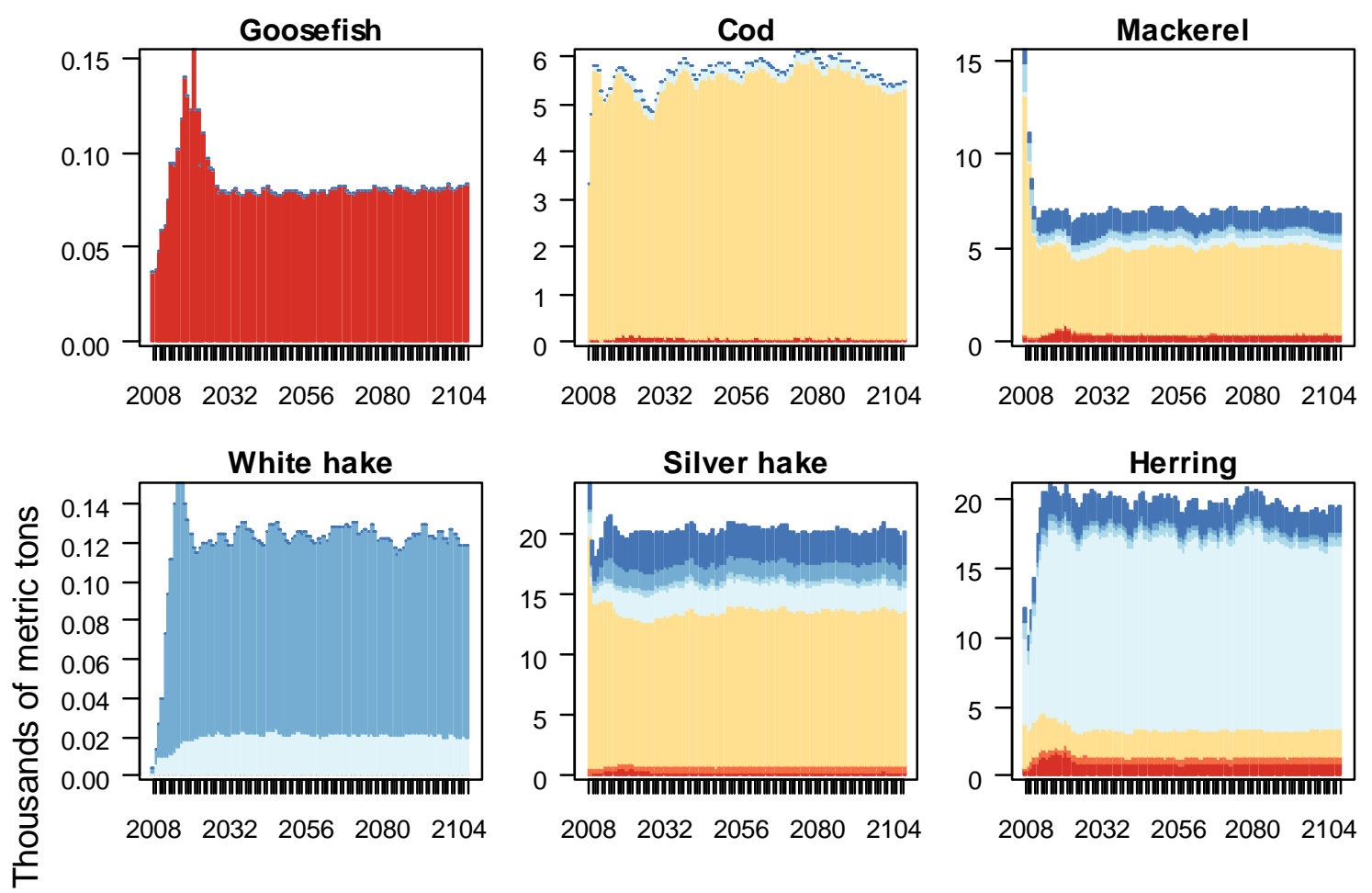

\footnotetext{
Predator species

- Spiny dogfish

- Winter skate

- Goosefish

Cod

- Pollock

- White hake

- Silver hake
}

\section{Year}

Figure S13: Average annual predator-specific consumption (thousands of metric tons) of each prey species in the base fishing projection. 

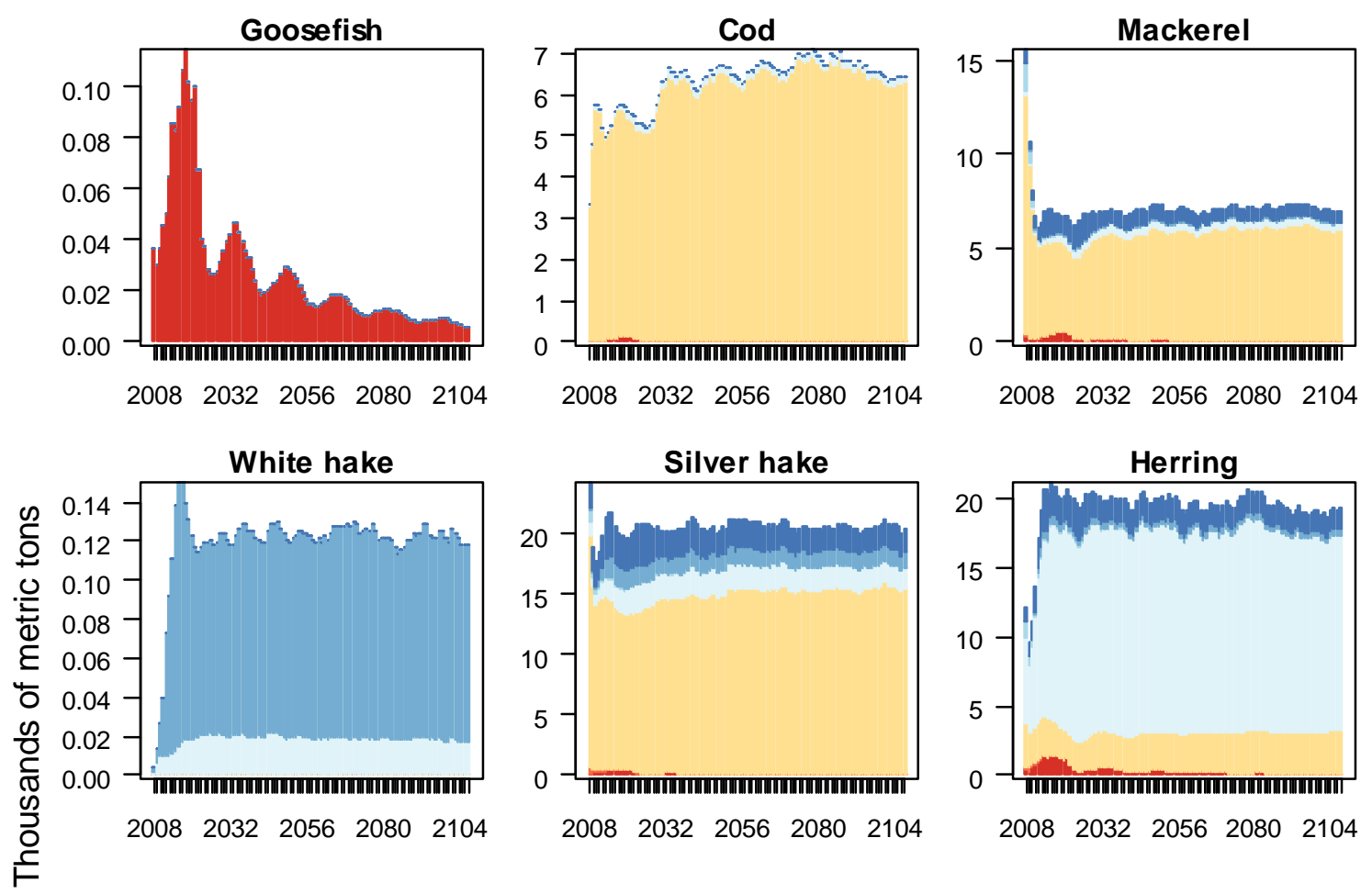

\footnotetext{
Predator species

- Spiny dogfish

- Winter skate

Goosefish

Cod

- Pollock

- White hake

- Silver hake
}

\section{Year}

Figure S14: Average annual predator-specific consumption (thousands of metric tons) of each prey species when the top predators are fished at three-times their base fishing rates, with the remaining species fished at their base rates. 

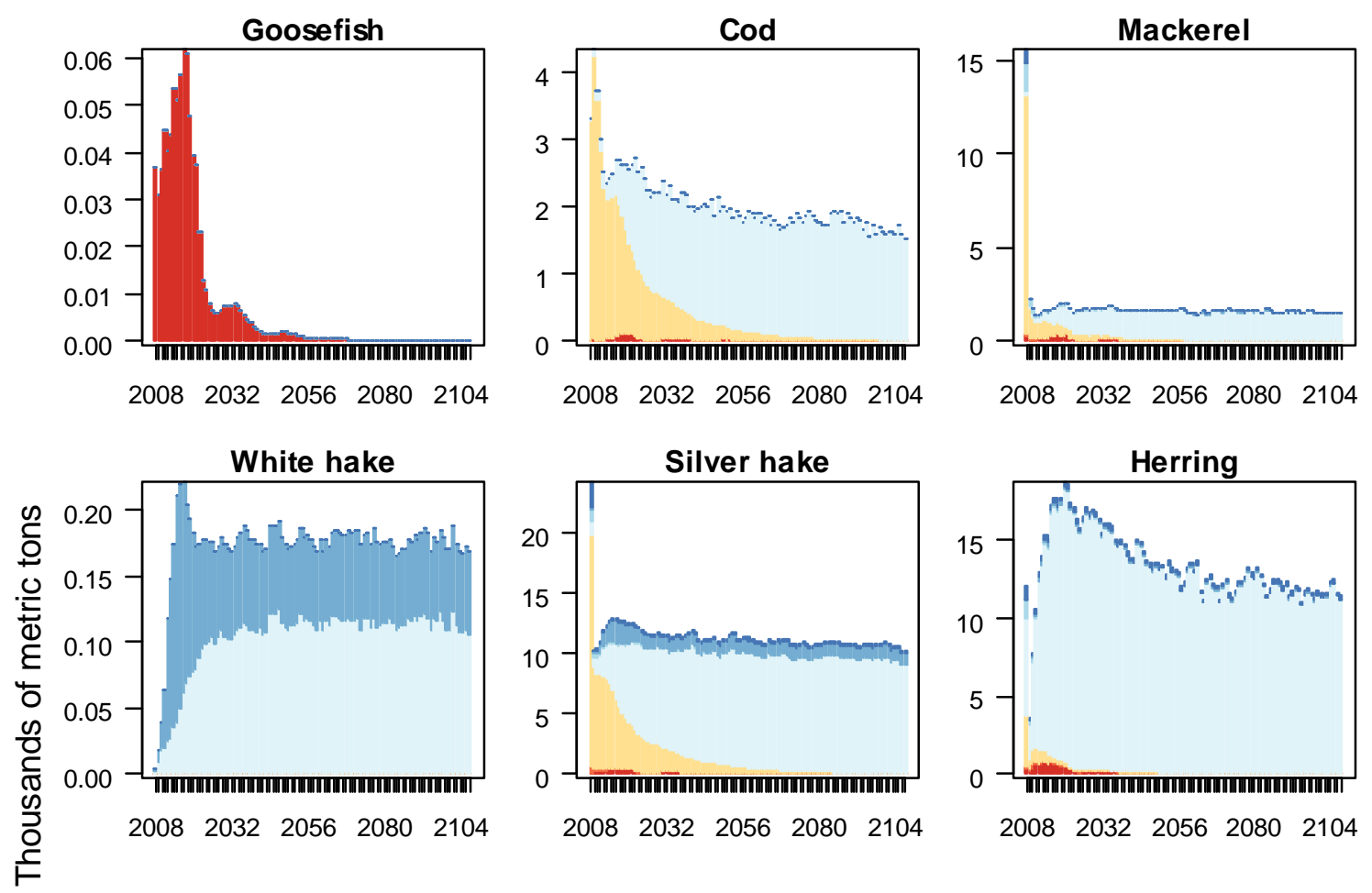

\footnotetext{
Predator species

- Spiny dogfish

- Winter skate

- Goosefish

Cod

- Pollock

- White hake

- Silver hake
}

\section{Year}

Figure S15: Average annual predator-specific consumption (thousands of metric tons) of each prey species when the top predators and goosefish are fished at three-times their base fishing rates, remaining intermediate predator species were unfished, and prey species were fished at 30-times their base fishing rates. 


\section{CONCLUSIONS}

Over the last half of a century, Georges Bank, a historically important fishing ground off the U.S. east coast, has experienced marked changes in ecosystem structure. As one of four subsystems comprising the Northeast U.S. Continental Shelf (NEUS), it is thought to currently be experiencing ecosystem overfishing and the sequential depletion of resources. Previous studies of the Georges Bank and NEUS fish communities have demonstrated that the predation losses experienced by prey species are substantial, are often greater than fishery landings, and vary notably over both time and prey age. As a consequence, it is recognized that predation exerts a strong influence on the dynamics of prey species in these ecosystems. This recognition enhances the need to quantify the losses due to predation when developing stock assessments for principal prey species.

Previous studies have investigated predation interactions on Georges Bank with a variety of multispecies and ecosystem approaches, including multispecies surplusproduction models, mass-balance models and multispecies virtual population analysis (MSVPA). Multispecies statistical catch-at-age models (MSCAA) differ from many of these approaches due to the statistical estimation of model parameters. Parameter estimation with statistical methods accounts for observation errors in the input time series of catches and predator diets, permitting the quantification of uncertainty in resulting parameter estimates. As a result, statistical catch-at-age models are one of the preferred methods for stock assessments because model uncertainty can inform management decisions. Furthermore, with the estimation of both age-specific initial abundances and annual recruitment as estimated parameters, the MSCAA model developed in this study does not rely on equilibrium assumptions or an assumed relationship between spawning 
stock biomass and recruitment. Fishing mortality rates in all years are also estimated with the model, in contrast to MSVPA where fishing mortality rates in the terminal year are generally set to fixed values.

The primary objective of this study was to develop a multispecies statistical catchat-age model of the Georges Bank fish community. The driving motivation was that development of an age-structured multispecies model that statistically estimated model parameters would provide a more complete picture of community dynamics than previous age-structured multispecies models (MSVPA) due to the incorporation of stochastic variability, recognition that input data contain observation error, and quantification of uncertainty. It is this level of statistical rigor that is generally expected of population dynamic models used to inform fisheries management. Therefore, in order for multispecies approaches to be used in future fisheries management, these additional modeling tools must be developed that begin to achieve the required level of statistical rigor. The Monte Carlo simulation analysis conducted in this study further enhanced confidence in model performance. Evaluation of model performance with simulated data is a necessary component of the development of any model. This analysis demonstrated that model parameters and derived indices could be estimated with confidence from input data with error levels similar to those obtained from the model fit to the observed data.

Like previous modeling efforts, the statistical multispecies model developed here demonstrated the strong impact of predation of Georges Bank fish community dynamics. For the principal prey species, herring and silver hake, the losses due to predation exceeded commercial landings. Yet while this principal finding is consistent with previous models, some species-specific predation mortality rates and trends in dominant 
predators differed from previous studies. In this model, goosefish was the most dominant predator species, in contrast to previous studies indicating that spiny dogfish, cod, and silver hake were the most dominant. In fact, predicted spiny dogfish and winter skate diets both indicated a small total consumption of modeled fish species, with consumption estimates less than that of cod, silver hake, and particularly goosefish. Throughout the time series, cod was the second most dominant predator, which contrasts with previous work indicating that the role of cod as a dominant piscivore in the northwest Atlantic has decreased over time as its abundance has declined. Furthermore, estimates of mackerel predation mortality rates varied among studies, as well as temporal trends in herring predation.

Collectively, these differences could arise from assumptions regarding the geographic range included in the model, the time step at which the model was implemented (e.g. annual versus quarterly), the species set included in the model or varying model formulations. For example, estimated species-preference coefficients incorporated all differences in food selection that were not attributable to size, including behavior and distributional differences between species. Additionally, several of the species included in this model are distributed over a greater range than just Georges Bank and undergo seasonal migrations. As a consequence, model development for just Georges Bank likely resulted in different estimated species-preference coefficients than would result from a model of the entire NEUS. Further work is warranted to investigate the consequences of these varying assumptions on the overall picture of community dynamics on the NEUS and Georges Bank. Resulting trends in predation also demonstrated that predation mortality rates exhibit strong temporal and ontogenetic 
variation. Accordingly, the consequence of structural uncertainty and the use of singlespecies approaches that assume constant rates of natural mortality in systems strongly impacted by predation also merits further investigation.

A benefit of multispecies statistical catch-at-age models is that parameter uncertainty can be incorporated into forward projections to investigate the consequences of potential management scenarios. The projections developed in this study indicated strong predation interactions among species, though the interactions were not always direct. Furthermore, projections demonstrated that the most important drivers of population dynamics varied among species between fishing, predation and recruitment.

With all modeling efforts, there is a tradeoff between increased biological realism and increased uncertainty in parameter estimation. However, even though the model developed here exhibited some sensitivity to dataset weights in the likelihood function as well as initial parameter estimates, food-selection parameters and species-specific predation mortality rates within a complex ecosystem such as Georges Bank were estimable. Accordingly, this work indicates that multispecies models can be fit statistically to time series of catch, abundance and diet data to quantify species interactions. As a consequence, multispecies, statistical catch-at-age models are useful tools for furthering ecosystem-based fisheries management. 